\author{
Universidade de São Paulo \\ Instituto de Física
}

\title{
Fotossensibilização de Vesículas Lipídicas Gigantes
}

\section{Tatiane de Paula Sudbrack}

Orientadora: Profa. Dra. Rosangela Itri

Dissertação de mestrado apresentada ao Instituto de Física para a obtenção do título de Mestre em Ciências

Comissão Examinadora:

Profa. Dra. Rosangela Itri (IFUSP)

Profa. Dra. Maria Tereza Moura Lamy (IFUSP)

Prof. Dr. Mauricio da Silva Baptista (IQUSP) 


\section{FICHA CATALOGRÁFICA}

Preparada pelo Serviço de Biblioteca e Informação do Instituto de Física da Universidade de São Paulo

Sudbrack, Tatiane de Paula

Fotossensibilização de Vesiculas Lipidicas Gigantes. São Paulo, 2011.

Dissertação (Mestrado) - Universidade de São Paulo. Instituto de Física. Depto. Física Aplicada.

Orientador: Profa. Dra. Rosangela Itri Área de Concentração: Biofísica.

Unitermos: 1.Biofísica; 2. Vesículas gigantes;

3. Peroxidação lipídica; 4. Cardiolipina;

5. Colesterol.

USP/IF/SBI-004/2012 
"Vamos começar...colocando um ponto final...pelo menos já é um sinal...de que tudo na vida tem fim/É tudo novo de novo... Vamos nos jogar onde já caímos...Tudo novo de novo...Vamos mergulhar do alto onde subimos"

(Paulinho Moska) 
Dedico esta dissertação, com muito amor, às pessoas que mais me apoiaram ao longo desses dois longos e intensos anos: pai \& mãe, Tassi e LM. Obrigada por estarem ao meu lado e me ampararem quando eu mais precisei! 


\section{Agradecimentos}

Aos meus pais, pelo apoio e incentivo ao longo de todos esses anos. Eu amo muito vocês.

À minha irmã Tassí, pelas Grigas construtivas, pelas risadas e conversas descontraídas.

$\mathcal{A} o \mathcal{L} \mathcal{M}$, por estar ao meu lado no momento em que eu mais precisei e continuar me apoiando e acreditando em mim. Sua presença foi fundamental nesses dois anos. Obrigada pelos chás/cafés, pela ajuda com o Matlab (facílitou muito a minha vida), pelas tardes no lab, e mais n-coisas!

$\mathcal{A}$ Profa ${ }^{a} r^{a}$ Rosangela Itrí, pelos 5 anos de orientação que se completarão ao final dessa dissertação e também por acreditar no meu potencial e me incentivar para que eu nunca desistisse. Além de todas as oportunidades oferecidas.

$\dot{\mathcal{A}} \mathcal{P}$ rofa $\mathcal{D r}^{a}$ Karin $\mathcal{A}$. Riske, por todos os ensinamentos e discussões construtivas, sem as quais esse trabalho jamais seria possivel.

À Ju, minha psicóloga, sem palavras.

Ao Tadeu, por ter sido um grande companheiro ao longo dessa estrada, que apesar de ter sido bifurcada, foi de grande valia. Você me ensinou muita coisa, muito do que eu sou hoje eu devo a você.

Aos amigos, Crís e Bruno, pelas tardes de estudo, pelos cafés/chás, ou simplesmente por terem sido um ombro amigo ao longo dessa jornada. $\mathcal{E}$ ao Tiago da Crís também, pela amizade!

À amiga Adriana Fratini, com a qual aprendi o significado da palavra força, e a qual esteve presente em grandes momentos da minha vida. Ao Jean e a Ragna também.

À Fabiana Verza, por ter me ouvido naquele sábado de zo1o e ao Bruno e Turbina também que me receberam tão bem. 
Ao pessoal do lab., Thais Schmidt, Helena, Andreza, Omar, Miguel, Paula, Leandro, Elisa. Em especial as duas primeiras que praticamente estiveram desde o começo da jornada. $\mathcal{E}$ também pelos Congressos divertidos! $\mathcal{A}$ presença de vocês foi fundamental!

Ao pessoal que começou a Graduação comigo, César, Denise, Ana, $\mathcal{L} u$, Mari Tanaka, Mari Marins, sem vocês eu também não teria chegado até aqui.

Aos amigos Felis \& Érica, Felipe pelos sábados divertidos que passamos juntos, com muita feijoada, mousse maravilhoso, Magic e Rock Band! A nossa banda é um sucesso!

À Aline Durães, pelas conversas de corredor!

$\grave{A} \mathcal{N}$ athy, que saiu do grupo faz um tempinho, mas com a qual eu tive bons momentos e me ajudou muito.

Ao pessoal que foi ou é do $\mathcal{L} \mathcal{A} \mathcal{L}$ : Korogui, Lelas, Vik.

Ao Profo $\mathcal{D r}$. Paulo Pascholati, por ter me permitido ser sua monitora. Através dessa oportunidade eu pude aprender muito.

$\grave{A}$ Profa $^{a} \mathcal{D r}^{a}$ Ana Regina Blak, por me ensinar que nesse instituto existem pessoas que se importam com a gente.

Ao Átilla \& Melina, pelos sábados no Crusp e coísas do gênero!

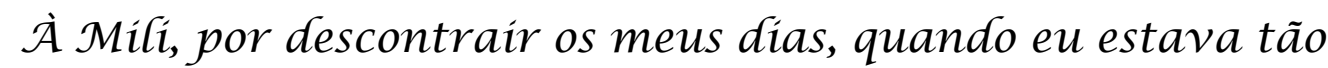
atarefada.

Às secretárias da $\mathcal{F} \mathcal{A} \mathcal{P}$, Lía e $\mathcal{E l l e n}$ e à ex-secretáría do $\mathcal{L} \mathcal{A} \mathcal{L}$, Ju.

Ao Kaká e ao $\mathcal{E} d u$ da eletrônica do $\mathcal{L} \mathcal{A} \mathcal{L}$, por uma ajuda e outra ao longo do percurso.

Ao cunhadinho, pelas tardes de War/Scotland Yard/Banco Imobiliário, $\mathcal{K F C}$ etc etc... 
À Elisa do grupo de Poluição, uma pessoa tão boa e disponivel, pela companhia nas aulas de yoga.

À minha família de Curitía, Daya, vó Dina, Gí, Fran, Tía Tânia, Tio Carlão, Tia Carmen e Ju.

À minha família de Santa María, Tía Lorí, Dani + Tobias, Téo + $\mathcal{N} a n d a$, Pedrinho, Tío Alceu e vó Vílma.

Aos Pitchs e Nininha, pela companhía.

Aos Paulos + João, pela amizade.

Aos professores das matérias da Pós-Graduação, Salinas, Passos e Frenkel.

Ao Éber e a Marina da CPG, por sempre quebrarem um galho pra gente!

À Profa Dr $^{a}$ Teresa Lamy e ao pessoal do lab. de Biofísica: Evandro, Rafael, Thais, Tiago, Cíntia, por terem cedido o espaço de seu laboratório para que as amostras fossem preparadas e por uma eventual ajuda no lab.

À algumas pessoas que passaram pela minha vida, mas já não são mais tão presentes assim, mas das quaís eu sinto saudades da amizade: Carol Minetto, Bruninha, Pati, Camila e Talitinha. Foram vocês que me incentivaram a entrar nessa "Coucura"!

À profa Joysé, por ter feito eu enxergar a Física com outros olhos.

Ao profo $\mathcal{A}$ (exandre, por ensinar a Fisica de uma forma tão bonita.

Aos apoios financeiros da $\mathcal{F} \mathcal{A P E S P}$ e da $C \mathcal{N} \mathcal{P} q$, que foram fundamentaís para a realização dessa pesquisa. 


\section{Resumo}

A Terapia Fotodinâmica é um tratamento promissor no cura de várias doenças oftalmológicas e dermatológicas, assim como tumores. Este tratamento utiliza a combinação de luz e um composto fotossensível na presença de oxigênio. Neste trabalho objetivamos entender mecanismos de fotossensibilização em membranas. Para isso, estudamos os efeitos de irradiação em Vesículas Unilamelares Gigantes (GUVs) compostas de POPC e Cardiolipina (CL) e POPC e Colesterol (Col), contendo uma molécula fotoativa (diC ${ }_{12}$-porf) ancorada à superfície dessas membranas. GUVs compostas por POPC e POPC:Col na presença da molécula fotoativa reagem ao estímulo da luz exibindo um aumento de área seguido de flutuações. $O$ mesmo foi observado para membranas de POPC contendo menos que 50mol\% de CL. Já para composições contendo $50 \mathrm{~mol} \%$ de $\mathrm{CL}$, a membrana passa a formar domínios lipídicos podendo ou não ser destruída durante a irradiação. Estes domínios podem ser suprimidos com a adição de EDTA (agente quelante de íons divalentes) na solução. Ao adicionarmos $\mathrm{CaCl}_{2}$ ao meio externo das GUVs contendo EDTA, percebemos que o efeito dos domínios e destruição da membrana reaparece. Tal fato evidencia que íons $\mathrm{Ca}^{++}$presentes em solução devem complexar com as cargas da $\mathrm{CL}$, levando à formação de domínios lipídicos. Ao quantificar o aumento de área sofrido pelas membranas percebemos que a presença de CL na membrana de POPC inibe o aumento de área para concentrações acima de $40 \mathrm{~mol} \%$ de CL. Já a presença de Col na membrana parece não contribuir significativamente para o aumento de área, embora o mesmo sofra oxidação. Além disso, evidenciou-se que na presença de $\mathrm{CL} / \mathrm{Col}$ o tempo de fotoclareamento de $\mathrm{diC}_{12}$-porf é muito maior do que na ausência destes. Estes resultados evidenciam que a inclusão de CL na membrana oferece um número maior de sítios de reação para o oxigênio singlete reduzindo a foto-degradação da molécula fotoativa. Já a inclusão de Col aumenta o tempo de vida da molécula fotoativa provavelmente devido ao fato da dupla ligação do Col estar mais próxima ao centro produtor de oxigênio singlete do que a dupla ligação do POPC. 


\begin{abstract}
Photodynamic Therapy is a promising treatment for the cure of many diseases, like tumors. This treatment uses a combination of light and a photosensitive molecule in the presence of oxygen. In this way, our objective is to understand photosensibilization mechanisms on membranes. For this purpose, we studied the effects of irradiation in Giant Unilamelar Vesicles (GUVs) composed of POPC and Cardiolipin (CL) and POPC and Cholesterol (Chol) in the presence of a photosensitive molecule ( $\mathrm{diC}_{12}$-porf). When the GUVs composed of POPC or POPC and Cholesterol (Chol) in the presence of the photosensitive molecule were irradiated, increase in surface area followed by fluctuations was observed. For GUVs composed of low concentrations of $\mathrm{CL}$, the membrane photo-response was similar to that observed for pure POPC. For GUVs composed of $50 \mathrm{~mol} \% \mathrm{CL}$ different responses to light irradiation were observed. Some lipid domains appear for GUVs in water under irradiation and the GUV might be destroyed. When the irradiation was done in the presence of EDTA (chelant agent), the formation of the domains was prevented. Further addition of $\mathrm{CaCl}_{2}$ to this solution induced the formation of domains again leading eventually to membrane disruption. These results suggest that divalent cations have effect on the binding to CL negative polar heads, favoring lipid domain formation. We quantified the area increase obtained for the GUVs. For GUVs composed of $\mathrm{CL}$ we observed that until $40 \mathrm{~mol} \%$ of $\mathrm{CL}$, the maximum expansion reached by the membrane area was similar to that obtained for pure POPC. For $50 \mathrm{~mol} \%$ of $\mathrm{CL}$ the increase of area is smaller than that found for GUVs composed only by POPC. For GUVs composed of Chol the behavior of the area is similar to that found for POPC. This means that the increase of area is mainly related to POPC peroxidation, although Chol hydroperoxide must be concomitantly formed too. Further, we observed that the $\mathrm{diC}_{12}$-porf photobleaching characteristic time for GUVs composed of $\mathrm{CL} / \mathrm{Chol}$ is greater than that noted for GUVs composed of POPC. This means that when we introduce $\mathrm{CL}$ we are increasing the possibilities of reaction of the singlet oxygen and the photosensitive molecule is protected. The insertion of Chol in the membrane also protects the photosensitive molecule.
\end{abstract}




\section{Índice}

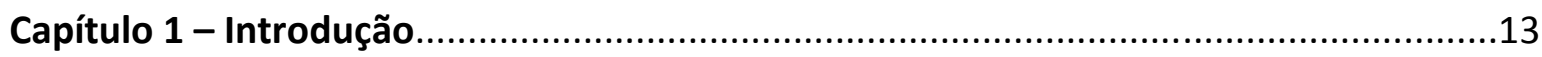

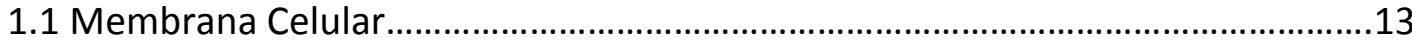

1.2 Lipídeos...........................................................................................................14

1.2.1 Classificação dos lipídeos de membrana...............................................14

1.2.2 Formas de auto-organização de lipídeos................................................18

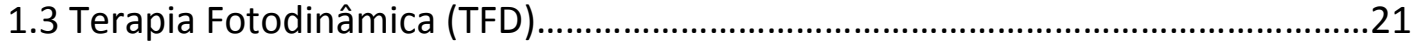

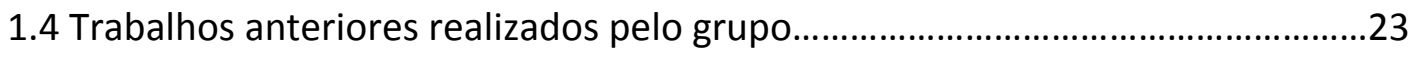

1.4.1 Photo-Induced Destruction of Giant Vesicles in Methylene Blue

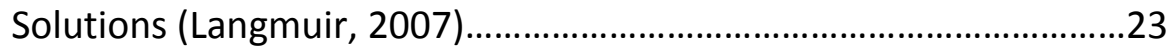

1.4.2 Giant Vesicles under Oxidative Stress Induced by a MembraneAnchored Photosensitizer (Biophysical Journal, 2009)......................27

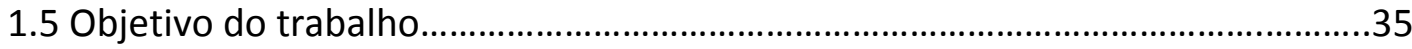

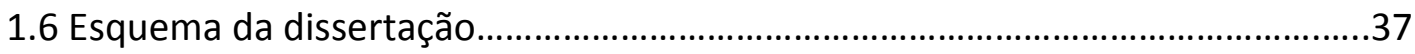

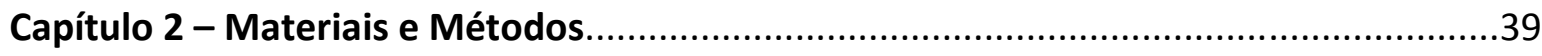

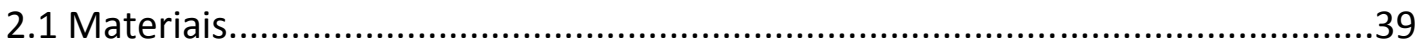

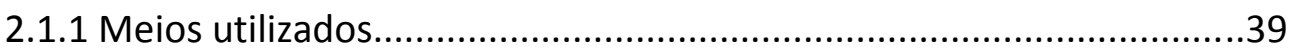

2.1.2 Lipídeos utilizados.......................................................................

2.1.3 Molécula fotoativa utilizada $\left(\right.$ diC $_{12}$-porf) ......................................40

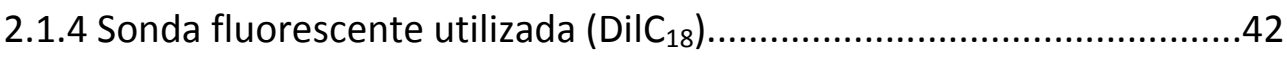

2.1.5 Composições de membrana utilizadas...........................................43

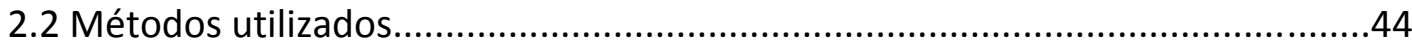

2.2.1 Técnica utilizada para o crescimento das GUVs..............................44

2.2.2 Microscopia Óptica (MO) .......................................................47

2.2.3 Medidas de aumento de área........................................................49

Capítulo 3 - Estudo do sistema POPC:CL na ausência da molécula fotoativa: Resultados e Discussão. .52 
Capítulo 4 - Foto-resposta de GUVs contendo a molécula fotoativa diC $_{12}$-porf: Análise Inicial e Discussão.

4.1 GUVs de POPC e POPC + 1 mol\% de dic 12 -porf...............................................67

4.2 Influência da intensidade de luz nos experimentos de irradiação com GUVs compostas de POPC + diC $_{12}$-porf

4.3 Estudos qualitativos das modificações morfológicas induzidas na membrana por foto-oxidação dos lipídeos..................................................................72

4.3.1 Sistemas de POPC + diC $_{12}$-porf em solução de açúcar........................72

4.3.2 Sistemas de POPC:CL + $\mathrm{diC}_{12}$-porf.............................................73

4.3.3 Sistemas de POPC:Col + diC 12 -porf em solução de açúcar...................79

4.4 Conclusões Parciais 80

Capítulo 5 - Foto-resposta de GUVs contendo a molécula fotoativa dic ${ }_{12}$-porf: Análises Quantitativas e Discussão 82

5.1 Medidas de aumento de área com campo AC para GUVs compostas de POPC + $\mathrm{diC}_{12}$-porf 82

5.2 Medidas de aumento de área com campo AC para GUVs compostas de POPC:Col +1 mol\% de dic 12 -porf.

5.3 Medidas de aumento de área com campo AC para GUVs compostas de POPC:CL +1 mol\% de diC ${ }_{12}$-porf

Capítulo 6 - Conclusões .104

Referências Bibliográficas. 106

Trabalho Publicados (Anexos) 111 


\section{Lista de Abreviaturas}

$\mathrm{CL}$ - cardiolipina

POPC - palmitoil oleoil fosfatidilcolina

DOPC - dioleoil fosfatidilcolina

DPPC - dipalmitoil fosfatidilcolina

min - minutos

Col - colesterol

AM - azul de metileno

MO - microscopia óptica

PE-porf - molécula fotoativa em trabalho anterior

$\mathrm{diC}_{12}$-porf - molécula fotoativa utilizada

nesta dissertação

cmc - concentração micelar crítica

tmc - temperatura micelar crítica

${ }^{1} \mathrm{O}_{2}$ - oxigênio singlete

SUVs - vesículas unilamelares pequenas

LUVs - vesículas unilamelares gigantes

GUVs - vesículas unilamelares gigantes

MLV - vesículas multilamelares

MLV - lipossomas multivesiculares
SOV - vesículas oligolamelares pequenas

LOV - vesículas oligolamelares grandes

GOV - vesículas oligolamelares gigantes

TFD - Terapia Fotodinâmica

$\lambda$-comprimento de onda

FS - fotossensibilizador

DMPE - dimiristoil fosfatidiletanolamina

$A_{\text {máx }}$ - aumento de área relativa máximo

EDTA - ácido etilenodiamino tetra-

acético

DilC $_{18}$ - marcador fluorescente $\left(1,1^{\prime}\right.$ dioctadecil - 3,3,3',3'- perclorato de tetrametilindocarbocianina)

FTO - óxido de estanho dopado com flúor

DOPG - dioleoil fosfatidilglicerol

POPG - palmitoil fosfatidilglicerol

eSM - esfingomielina de ovo

AC - corrente alternada

gli - glicose

sac - sacarose 


\section{Capítulo 1: Introdução}

\subsection{Membrana Celular}

A membrana celular tem como principal característica delimitar o interior da célula de seu exterior, permitindo a passagem seletiva de algumas moléculas do meio intracelular para o meio extracelular e vice-versa. Dessa forma, as membranas exercem um papel central na comunicação biológica. [1]

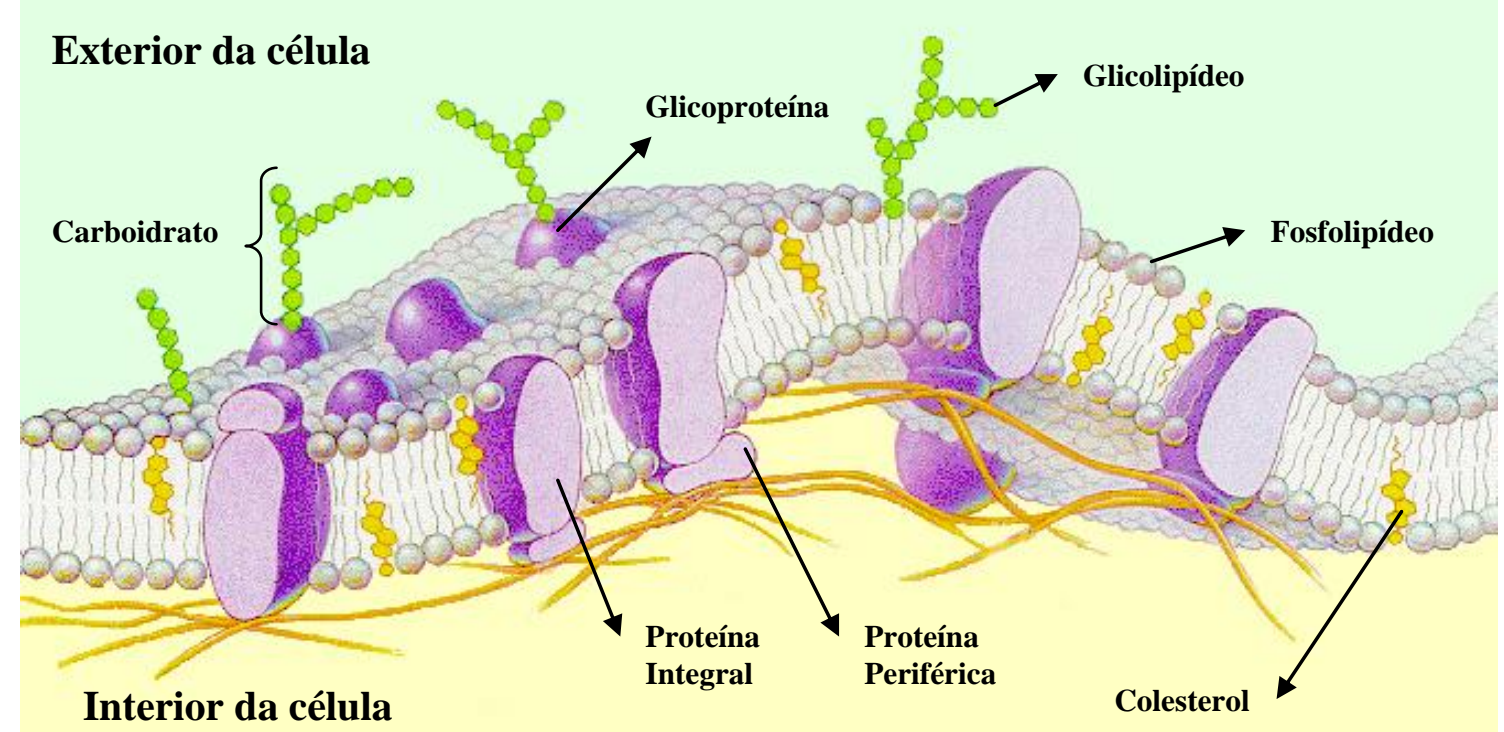

Figura 1.1: Esquema de uma membrana celular, extraída e modificada de [2].

O modelo mais aceito para descrever a organização da membrana celular está representado na figura 1.1, e é conhecido como modelo de "mosaico fluido". Neste modelo, a membrana celular é representada por uma bicamada lipídica (formada por uma associação de fosfolipídeos) e possui várias proteínas associadas (proteínas integrais, proteínas periféricas e glicoproteínas), assim como carboidratos, glicolipídeos e colesterol. A bicamada lipídica tem dupla função: é tanto um solvente para as proteínas da membrana quanto uma barreira de permeabilidade [1]. Os fosfolipídeos e colesterol serão melhor explicados na seção 1.2, pois serão objetos de estudo desse trabalho. 


\subsection{Lipídeos}

Os lipídeos são moléculas anfifílicas que, como representado na figura 1.2 , apresentam uma cabeça hidrofílica e uma cauda hidrofóbica. Assim, a cabeça polar dos lipídeos interage bem com solventes aquosos, enquanto as caudas apolares não têm afinidade por água e sim por solventes orgânicos, como por exemplo, o clorofórmio que é apolar.

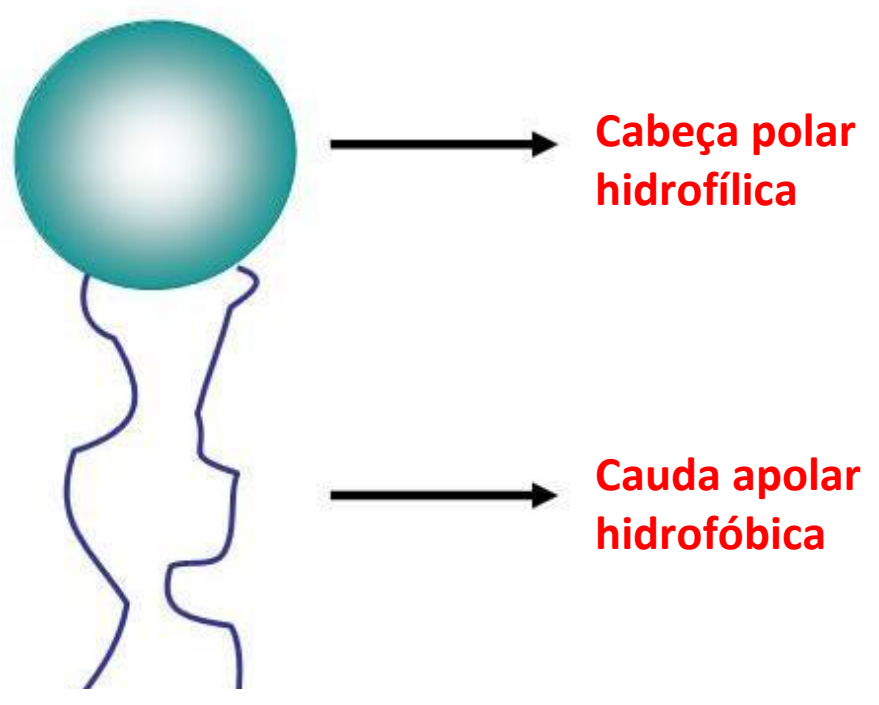

Figura 1.2: Esquema de um lipídeo: possui uma cabeça hidrofílica e uma cauda hidrofóbica, motivo pelo qual são conhecidos como moléculas anfifílicas. Imagem cedida gentilmente pela profa Karin A. Riske.

\subsubsection{Classificação dos lipídeos de membrana}

Existem três classes de lipídeos de membrana: fosfolipídeos, glicolipídeos e o colesterol. Os fosfolipídeos representam a principal classe de lipídeos de membrana, sendo constituídos de glicerol, duas cadeias de ácidos graxos e um álcool fosforilado, como representado na figura 1.3. [1] 


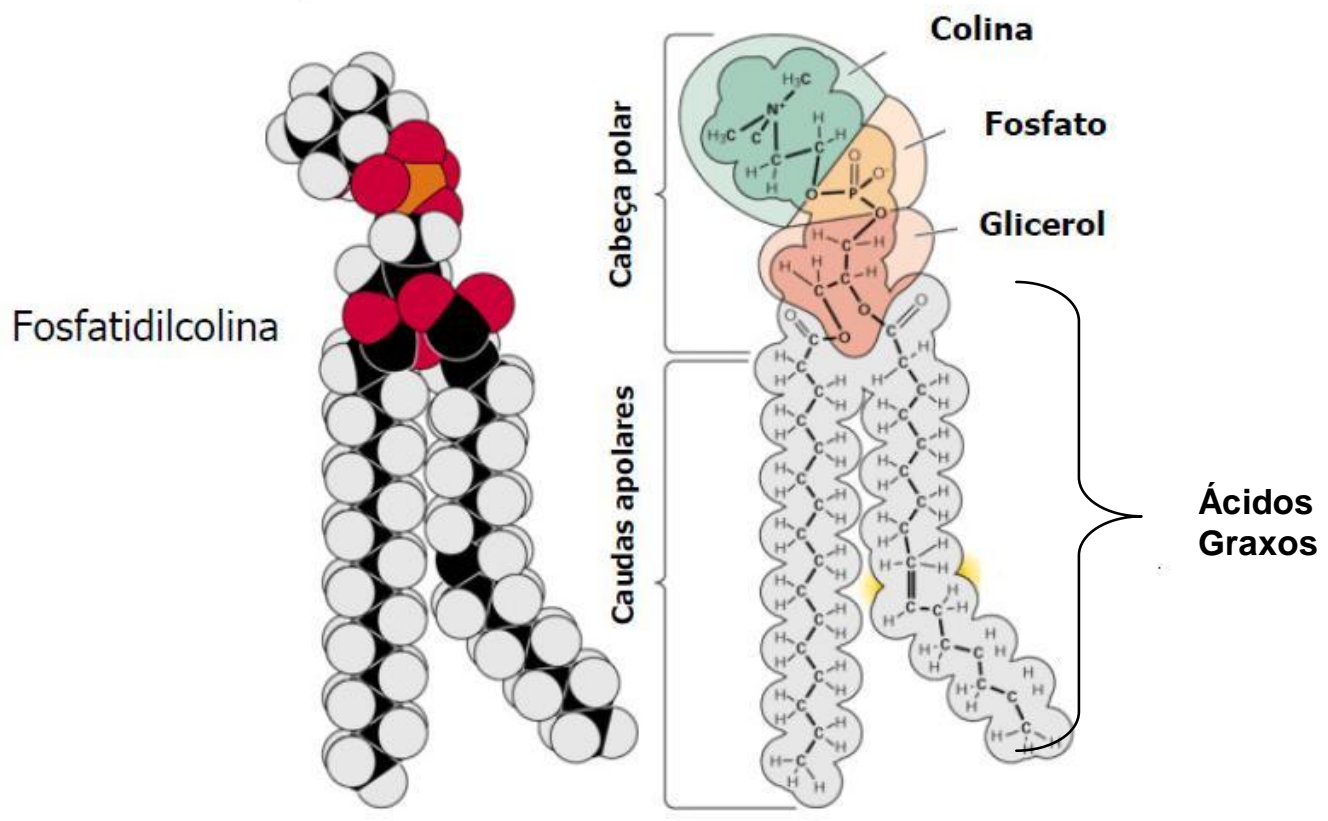

Figura 1.3: Esquema de um fosfolipídeo, fosfatidilcolina. Imagem extraída de [3].

Neste trabalho, estudaremos membranas compostas pelos seguintes fosfolipídeos: palmitoil oleoil fosfatidilcolina (POPC) e Cardiolipina (CL). As estruturas químicas desses lipídeos estão representadas nas figuras 1.4 e 1.5, respectivamente.

Utilizou-se a $\mathrm{CL}$, em especial, pois é um lipídeo encontrado na membrana interna da mitocôndria [4 e 5] e é um dos alvos de morte celular programada [6, 7 e 8]. A partir das imagens 1.4 e 1.5 é possível notar que a CL possui 2 grupos fosfato ionizáveis na cabeça polar e 4 caudas hidrofóbicas, diferentemente da estrutura do POPC.<smiles>CCCCCCCC/C=C\CCCCCCCC(=O)OC[C@@H](COP(=O)([O-])OCC[N+](C)(C)C)OC(=O)CCCCCCCCCCCC</smiles>

Figura 1.4: Estrutura química do POPC. Extraída de [9]. 


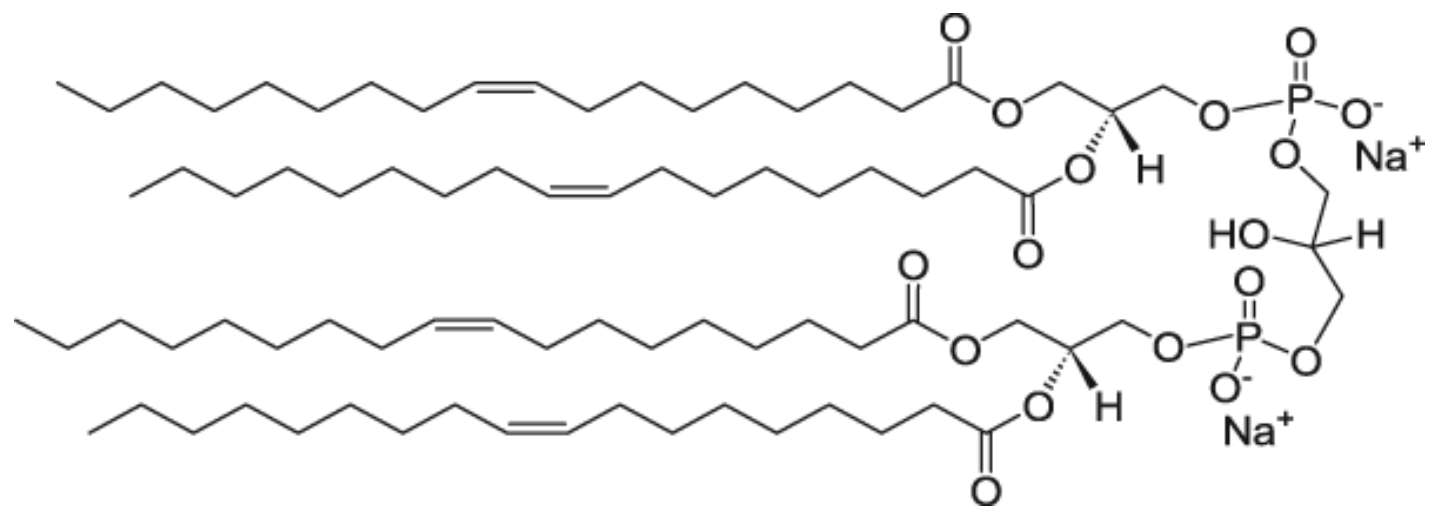

Figura 1.5: Estrutura química da Cardiolipina utilizada neste trabalho (ver Materiais e Métodos). Imagem extraída de [9].

As cadeias de ácidos graxos podem ser saturadas ou insaturadas, como representado na figura 1.6. Tais insaturações podem deixar as caudas mais flexíveis. Dependendo da temperatura, as cadeias de ácidos graxos podem se apresentar em um estado ordenado rígido (fase gel) como a imagem à direita da figura 1.7, ou num estado desordenado, fluido (fase líquido-cristalina), como a imagem à esquerda da figura 1.7. [1]

Saturado

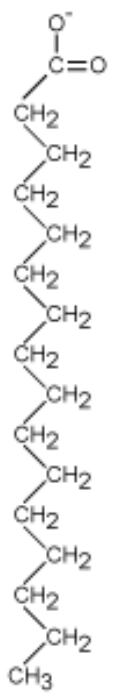

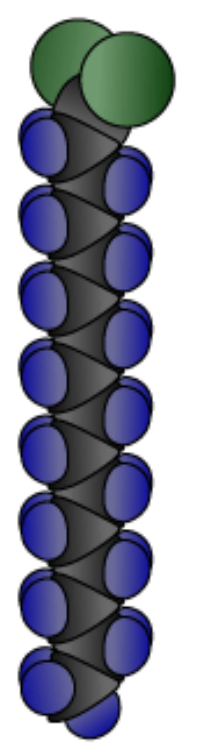

Insaturado

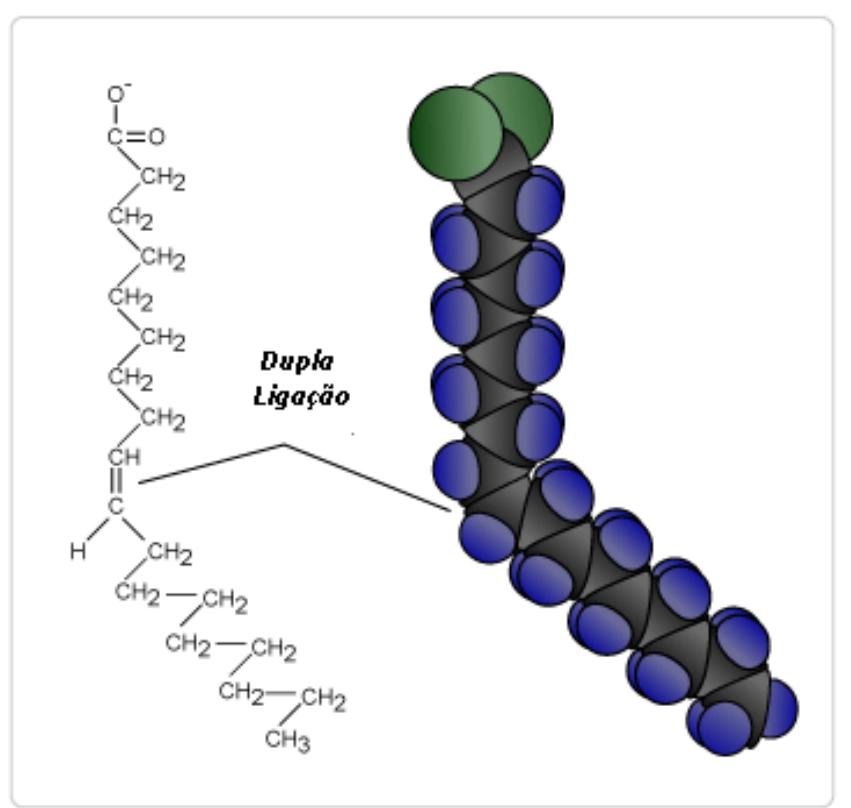

Figura 1.6: Na primeira imagem temos um ácido graxo saturado. Já a segunda imagem apresenta um ácido graxo insaturado. Imagem extraída de [10]. 

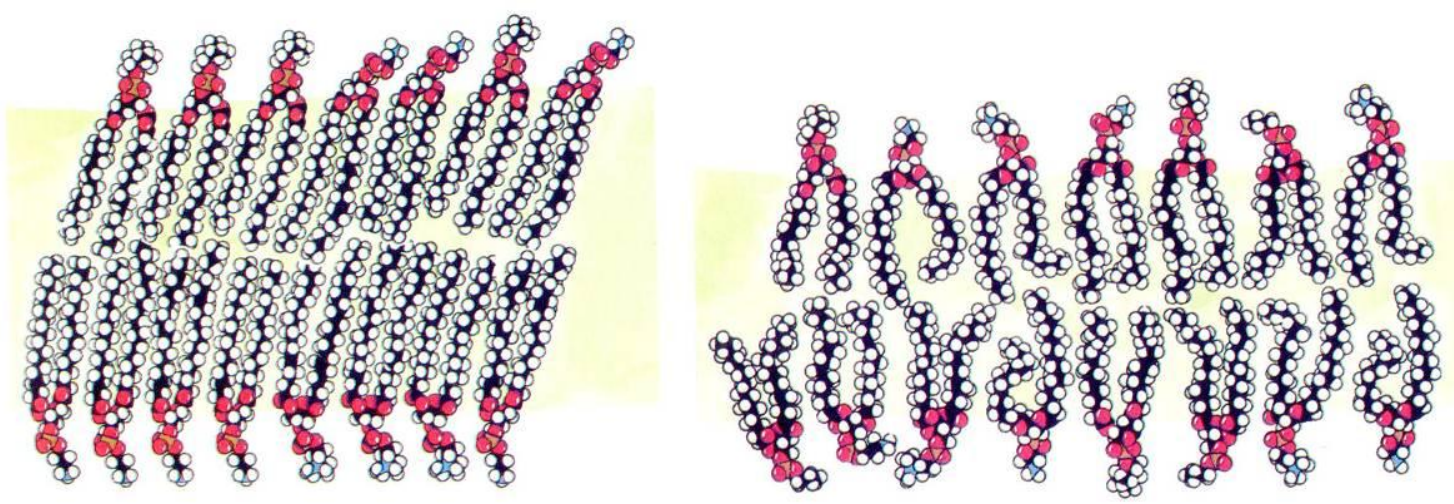

Figura 1.7: Esquematização da fase gel e da fase líquido-cristalina de lipídeos. Imagem de extraída de [11].

A transição de um estado para o outro ocorre quando a temperatura se eleva acima da temperatura $T_{m}$, conhecida como temperatura de transição de fase ou de fusão. Essa temperatura depende do comprimento das cadeias de ácidos graxos e de seu grau de insaturação. Por exemplo, para o POPC, lipídeo utilizado nesse trabalho, a temperatura de transição de fase é de $-2^{\circ} \mathrm{C}$ [9]. Já para a $\mathrm{CL}$, realizamos uma medida de calorimetria de varredura diferencial, DSC (dados não mostrados) e percebemos que a temperatura de transição de fase está abaixo de $5^{\circ} \mathrm{C}$.

Como citado no começo desta seção, outro lipídeo importante em membranas eucarióticas é o colesterol. As membranas citoplasmáticas de células eucariontes são geralmente ricas em colesterol, enquanto as membranas de suas organelas têm tipicamente quantidades muito menores desse lipídeo neutro [2]. Uma representação desse lipídeo encontra-se na figura 1.8.

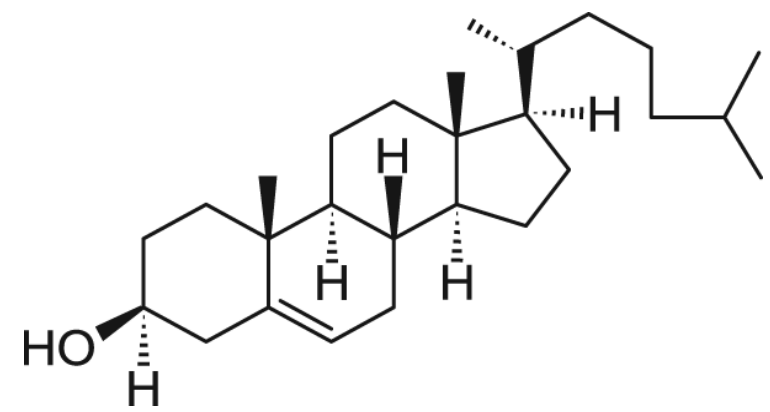

Figura 1.8: Estrutura química do colesterol. Imagem extraída de [9]. 
Nesta dissertação trabalharemos com membranas lipídicas compostas por POPC e CL. Além disso, avaliaremos também a influência do colesterol sobre as propriedades da membrana em algumas bicamadas lipídicas de POPC.

\section{$\underline{1.2 .2 ~ F o r m a s ~ d e ~ a u t o-o r g a n i z a c ̧ a ̃ o ~ d e ~ l i p i ́ d e o s ~}$}

Algumas formas de auto-organização nas quais as moléculas anfifílicas podem ser encontradas, quando na presença de um solvente aquoso, estão representadas na figura 1.9. As diferentes estruturas que as moléculas anfifílicas possuem, no caso distintas relações entre volume ocupado pela cabeça polar e as caudas hidrofóbicas, dão origem a diferentes tipos de empacotamento das moléculas resultando em distintas organizações geométricas.

Forma

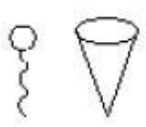

Cone invertido
Organização

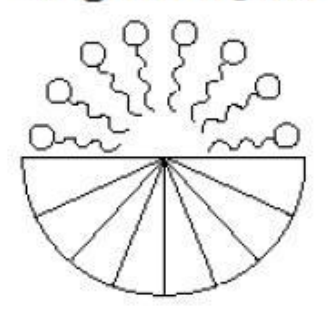

Micelas

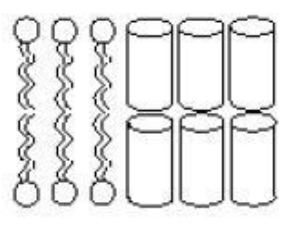

Bicamada

Figura 1.9: Possíveis formas geométricas de moléculas anfifílicas e possíveis tipos de organização. Na parte superior, a molécula possui apenas uma cauda hidrofóbica e sua forma é do tipo cone invertido. A melhor condição de empacotamento das mesmas gera estruturas globulares com curvatura positiva. Na parte inferior a molécula possui duas caudas hidrofóbicas e o melhor empacotamento é o de bicamadas planas. Imagem extraída de [12]. 


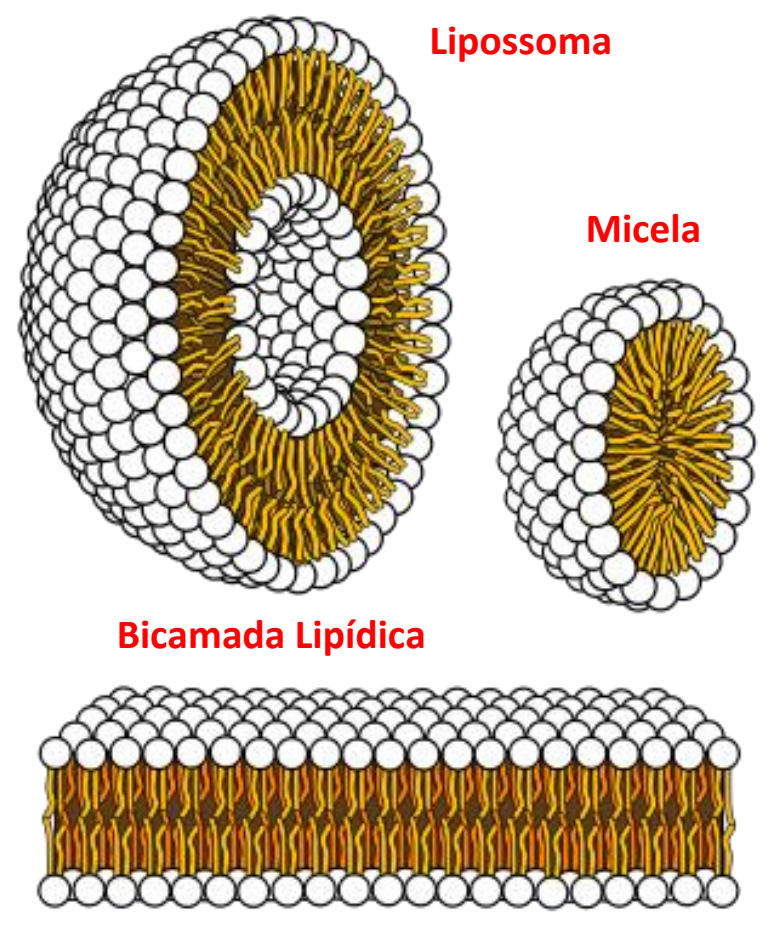

Figura 1.10: Possíveis formas de organização dos lipídeos. Lipossomas ou vesículas possuem forma globular contendo uma cavidade aquosa. Micelas encapsulam suas caudas evitando o contato do interior hidrofóbico com o meio externo polar aquoso. Geralmente, detergentes se organizam dessa forma. Por último está representada a bicamada lipídica. Imagem extraída de [13].

Em soluções aquosas as moléculas anfifílicas (como detergentes) formam micelas (figura 1.10). Tal arranjo molecular elimina contatos desfavoráveis entre a água e as cadeias hidrofóbicas das moléculas anfifílicas e ainda permite a solvatação das cabeças polares. As micelas se formam a partir de uma concentração micelar crítica $(\mathrm{cmc})$ e uma temperatura micelar crítica (tmc). Os valores da $\mathrm{cmc}$ e da tmc dependem das características da molécula anfifílica (como cabeça polar iônica ou não iônica zwiteriônica e tamanho da cauda hidrofóbica) e das condições da solução. [11]

Os lipossomas e bicamadas lipídicas (figura 1.10), diferentemente das micelas, são formados por moléculas anfifílicas que possuem duas caudas hidrocarbônicas. Lipossomas, também chamados de vesículas, geralmente são constituídos de uma ou mais bicamadas de fosfolipídeos concêntricas, que mimetizam a organização lipídica presente nas membranas biológicas. 
Vesículas lipídicas têm sido vastamente utilizadas para estudar aspectos físicoquímicos de vários processos biológicos. Uma esquematização dos tipos de utilização e classificação dos lipossomas encontram-se na figura 1.11.

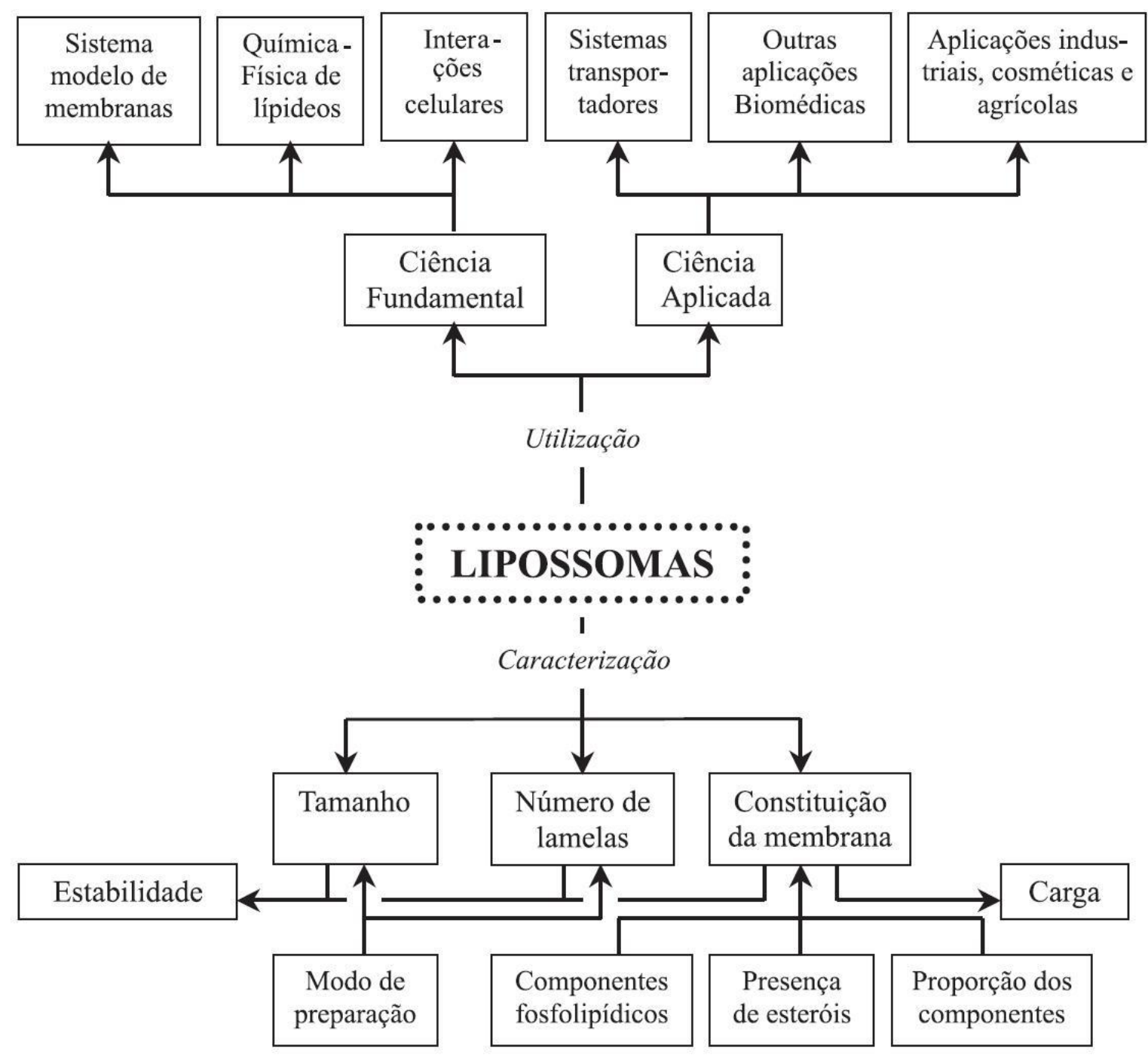

Figura 1.11: Esquematização dos tipos de utilização e classificação dos lipossomas. Imagem extraída de [14].

Na figura 1.12 descrevemos a classificação das vesículas, de acordo com o seu tamanho e número de lamelas. As vesículas unilamelares pequenas (SUVs) têm seu diâmetro entre 25 e 100nm, as vesículas unilamelares grandes (LUVs) têm seu diâmetro entre 100nm e $1 \mu \mathrm{m}$ e as vesículas unilamelares gigantes (GUVs) possuem seu diâmetro entre $10 \mu \mathrm{m}$ e $100 \mu \mathrm{m}$. 
As vesículas unilamelares gigantes são o foco deste trabalho e são interessantes, pois além de seu tamanho representar bem o tamanho de uma célula, são passíveis de observação por microscopia óptica.

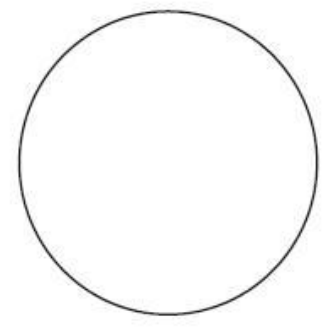

GUV

SUV

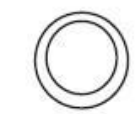

LOV
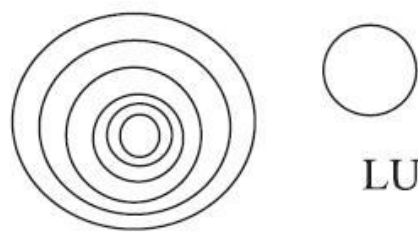

LUV

MLV

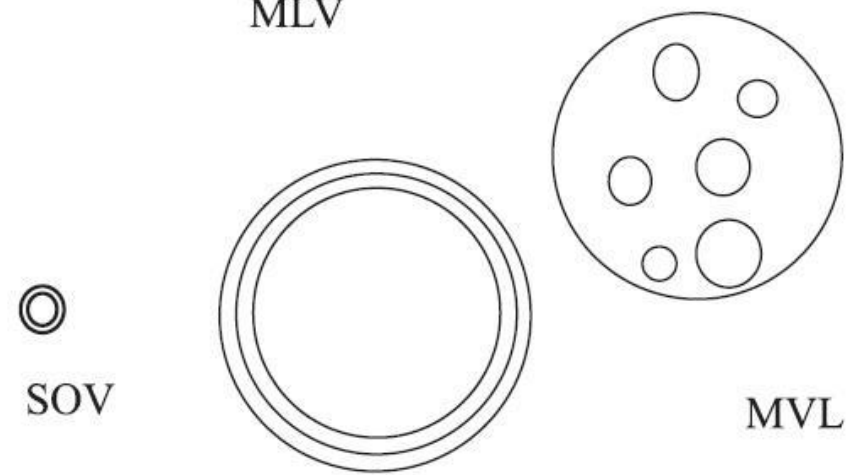

GOV

Figura 1.12: Representação esquemática dos vários tipos de lipossomas, mostrando a base da sua classificação em termos de tamanho, número de lamelas e sua posição relativa em: Vesículas multilamelares (MLV), vesículas unilamelares pequenas (SUV), vesículas unilamelares grandes (LUV), vesículas unilamelares gigantes (GUV), lipossomas multivesiculares (MLV), vesículas oligolamelares pequenas (SOV), vesículas oligolamelares grandes (LOV) e vesículas oligolamelares gigantes (GOV). Cada linha representa uma bicamada lipídica (lamela). Imagem extraída de [14]. As representações não estão em escala.

\subsection{Terapia Fotodinâmica (TFD)}

A Terapia Fotodinâmica é um tratamento promissor para várias patologias tais como câncer e doenças cardiovasculares, dermatológicas e oftálmicas. O procedimento clínico da TFD utiliza um composto fotossensibilizador (FS) e luz. A TFD é baseada nas reações foto-oxidativas, na qual um fotossensibilizador é ativado por luz visível na presença de oxigênio tecidual, gerando espécies reativas de oxigênio singlete $\left({ }^{1} \mathrm{O}_{2}\right)$ e 
radicais livres $\left({ }^{\circ} \mathrm{OH}, \mathrm{HO}_{2}{ }^{\circ}\right.$ e $\left.{ }^{\circ} \mathrm{O}_{2}{ }^{-}\right)$, que promovem a destruição irreversível dos tecidos tratados [15 e 16]. No diagrama de Jablonski, esquematizado na figura 1.13, estão representadas, de forma geral, as etapas fotoquímicas e fotofísicas envolvidas no processo de fotoativação de um composto após absorver radiação.

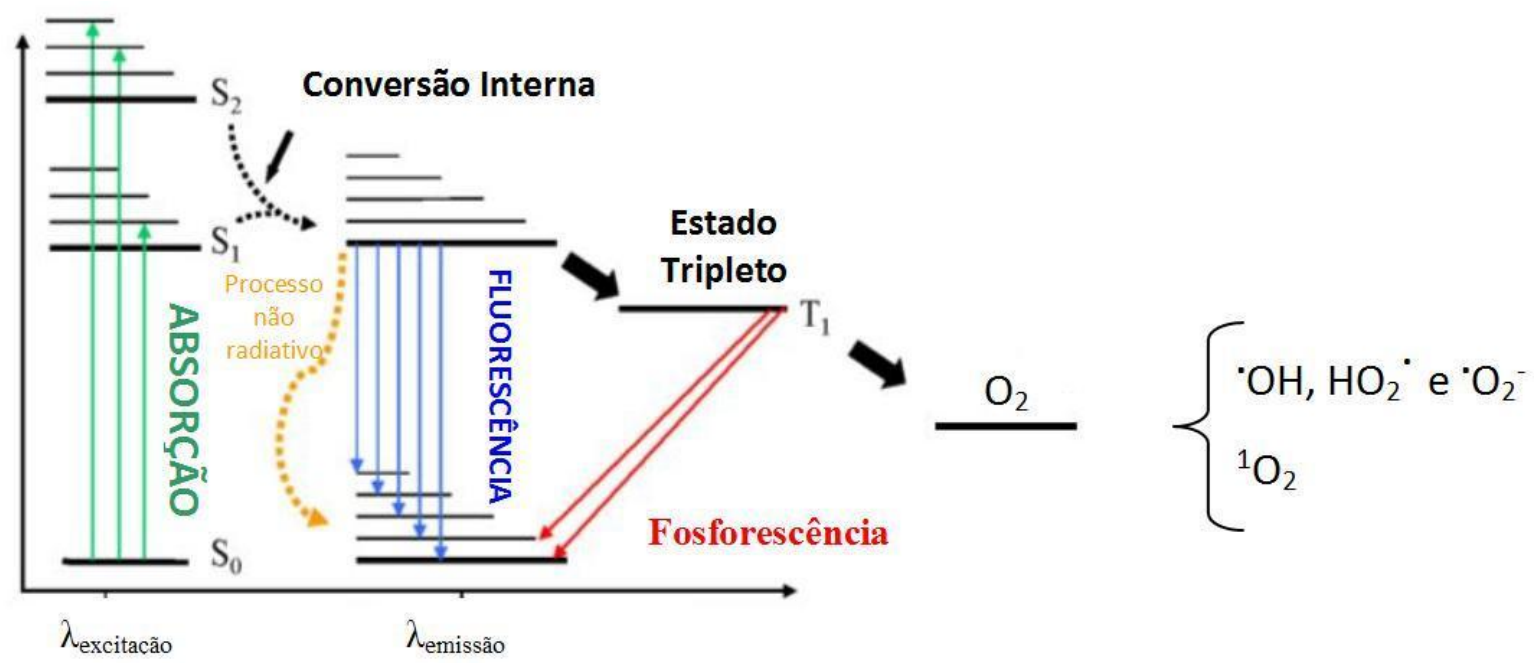

Figura 1.13: Diagrama de Jablonski para o processo de fotoativação.

Após a absorção de luz, o fotossensibilizador, inicialmente no estado fundamental $\left(S_{0}\right)$, é ativado para um estado excitado singlete de vida curta $\left(\mathrm{S}_{1}\right)$, podendo retornar ao estado $S_{0}$ por um processo radiativo, emitindo um fóton (fluorescência) ou por conversão interna com perda de energia na forma de calor (processo não radiativo), ou ainda, via cruzamento intersistema, decaindo para um estado triplete excitado de vida longa $\left(T_{1}\right)$ [17]. A partir deste estado, basicamente por dois mecanismos de reação (Reações do Tipo I e II), são geradas as espécies citotóxicas na presença de oxigênio. Reações do Tipo I podem produzir radicais livres e outras espécies reativas de oxigênio, como ânions superperóxidos, radicais hidroxila, peróxidos de hidrogênio, etc, que são resultantes da transferência de elétrons ou hidrogênios entre a molécula do fotossensibilizador no estado $T_{1}$ e moléculas biológicas. As reações do Tipo II envolvem a interação entre o oxigênio e o estado triplete do fotossensibilizador para mediar, via transferência de energia, a formação do oxigênio singlete $\left({ }^{1} \mathrm{O}_{2}\right)$, que se acredita ser uma das principais espécies citotóxicas na TFD. [18] 
Embora se conheçam bem os dois mecanismos de foto-reação de moléculas fotossensibilizadoras, os mecanismos de fotossensibilização em membranas biológicas são obscuros. Neste contexto, o grupo da profa Rosangela Itri iniciou uma linha de pesquisa, há alguns anos, centrada na investigação de possíveis mecanismos envolvidos em fotossensibilização de membranas modelo.

Em particular, dois trabalhos utilizando a observação por microscopia óptica (MO) de vesículas unilamelares gigantes foram desenvolvidos e publicados $[19,20]$, cujos resultados serão sumarizados na próxima seção. Ambos trabalhos envolveram a colaboração do prof. Mauricio S. Baptista do IQUSP, e do grupo do prof. Carlos M. Marques do Institute Charles Sadron, Strasbourg - França.

\subsection{Trabalhos anteriores realizados pelo grupo}

Anterior a esta dissertação, dois trabalhos já foram publicados pelo grupo, com o objetivo de investigar cenários de destruição da membrana lipídica $[19,20]$. Ambos trabalhos foram importantes para delimitar uma série de condições para a execução dessa dissertação.

\subsubsection{Photo-Induced Destruction of Giant Vesicles in Methylene Blue Solutions (Langmuir,} $\underline{2007)}$

No trabalho [19], utilizaram-se GUVs compostas de DOPC, um lipídeo que possui as duas caudas insaturadas. Estas vesículas eram diluídas em soluções de glicose acrescidas de diferentes concentrações de azul de metileno (AM - molécula fotoativa) e expostas à irradiação no comprimento de onda 546nm. Dependendo da concentração de AM as vesículas se rompiam e eram destruídas. Para concentrações menores que $10 \mu \mathrm{M}$ de AM nenhum efeito foi observado durante a irradiação, tal que as GUVs permaneciam inalteradas. Por outro lado, para concentrações igual ou acima de $25 \mu M$ de AM, após alguns minutos de irradiação todas as vesículas eram destruídas. 
Para explicar o efeito de foto-destruição ocorrido com as vesículas, foram propostas pelos autores duas hipóteses que estão representadas na figura 1.14. É bem conhecido que a foto-irradiação de AM leva à geração com boa eficiência de moléculas de oxigênio singlete, ${ }^{1} \mathrm{O}_{2}$, altamente reativas e que causam peroxidação lipídica.

A primeira hipótese formulada seria que o oxigênio singlete produzido in situ na solução aquosa atacaria uma das duplas ligações causando quebra desta (figura 1.14 superior). Já na segunda hipótese (figura 1.14 inferior) o oxigênio singlete atacaria as duas duplas ligações presentes no DOPC, formando ácidos nonanóicos e quebrando simetricamente as duas caudas do DOPC no carbono 9.

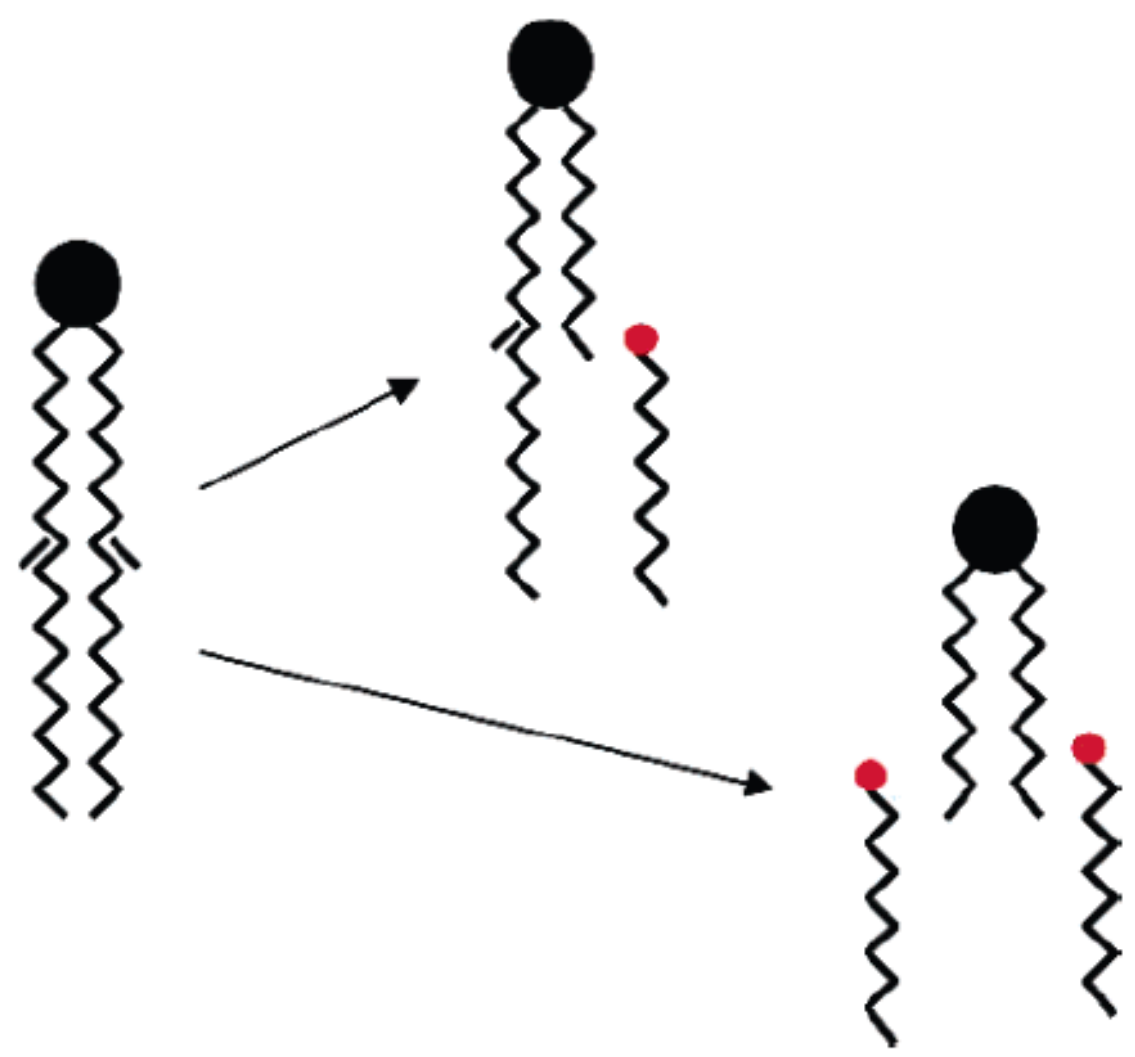

Figura 1.14: Esquema do efeito de foto-destruição de um fosfolipídeo. Quando o oxigênio singlete ataca a dupla ligação do lipídeo, o tamanho de sua cadeia hidrocarbônica é reduzido criando fragmentos que são ejetados para a solução. Imagem extraída de [19]. 
Assim, se somente uma das caudas fosse quebrada, o fosfolipídio tornar-se-ia assimétrico e uma cadeia com nove átomos de carbono, que no caso deveria ser um ácido nonanóico, seria liberada da membrana para a solução aquosa.

No caso do ataque do ${ }^{1} \mathrm{O}_{2}$ às duas insaturações das 2 cadeias do DOPC, o fosfolipídio se transformaria em uma molécula simétrica mais curta e duas moléculas de ácido nonanóico deveriam ser geradas. Sabe-se que moléculas anfifílicas de cadeia hidrofóbica curta, como ácidos graxos, são mais propícias a formarem micelas em solução aquosa (não observáveis por MO). Tal fato justificaria a formação de macroporos visíveis nas GUVs através de mecanismos de solubilização. Além disso, moléculas foto-oxidadas de DOPC de cadeia mais curta podem também ser extraídas da membrana lipídica num processo de co-micelização com ácidos nonanóicos gerados.

Para testar se a hipótese de que ácidos nonanóicos estavam sendo liberados para solução foi feito um experimento de tensão superficial, conforme será explicado a seguir.

A partir da figura 1.15, podemos observar que a tensão superficial de uma solução aquosa contendo lipossomas na presença ou na ausência de $A M$, ambas na ausência de irradiação, quase não é alterada ao longo do tempo. Já quando se irradia a solução de lipossoma na presença do AM, percebe-se que há uma diminuição da tensão superficial. Diferentemente dos fosfolipídeos, o acido nonanóico migra para a interface água-ar, independentemente do processo de preparação, diminuindo a tensão de superfície como está mostrado na figura 1.16.

Podemos notar, a partir das figuras 1.15 e 1.16, que para uma concentração de 2,5 $\mu \mathrm{M}$ de ácido nonanóico a diminuição da tensão superficial observada é muito parecida para o caso da solução de lipossomas irradiadas com AM ( $8 \mathrm{mN} / \mathrm{m})$. Apesar da boa concordância entre os resultados, os autores ressaltam que a comparação quantitativa entre resultados de tensão superficial de ácido nonanóico e de lipossomas foto-oxidados deve ser feita com cautela, devido ao fato de que diferentes moléculas anfifílicas podem ser geradas durante o processo de fotólise.

Assim, a partir desse experimento foi possível inferir que o resultado de fotooxidação do DOPC gera agentes tensoativos que reduzem a tensão de superfície da 
interface ar-água, não se sabendo exatamente quais são esses agentes, embora os resultados concordem bem com os experimentos de diminuição da tensão superficial do ácido nonanóico.

A partir deste trabalho, concluir-se que GUVs em solução de AM poderiam ser destruídas, dependendo da concentração de AM, via o ataque das duplas ligações do DOPC pelo oxigênio singlete criado em solução, durante a irradiação.

Vale lembrar que para estes experimentos realizados em GUVs na presença de AM não se sabia a eficiência do processo, pois o oxigênio singlete era produzido na solução de AM.

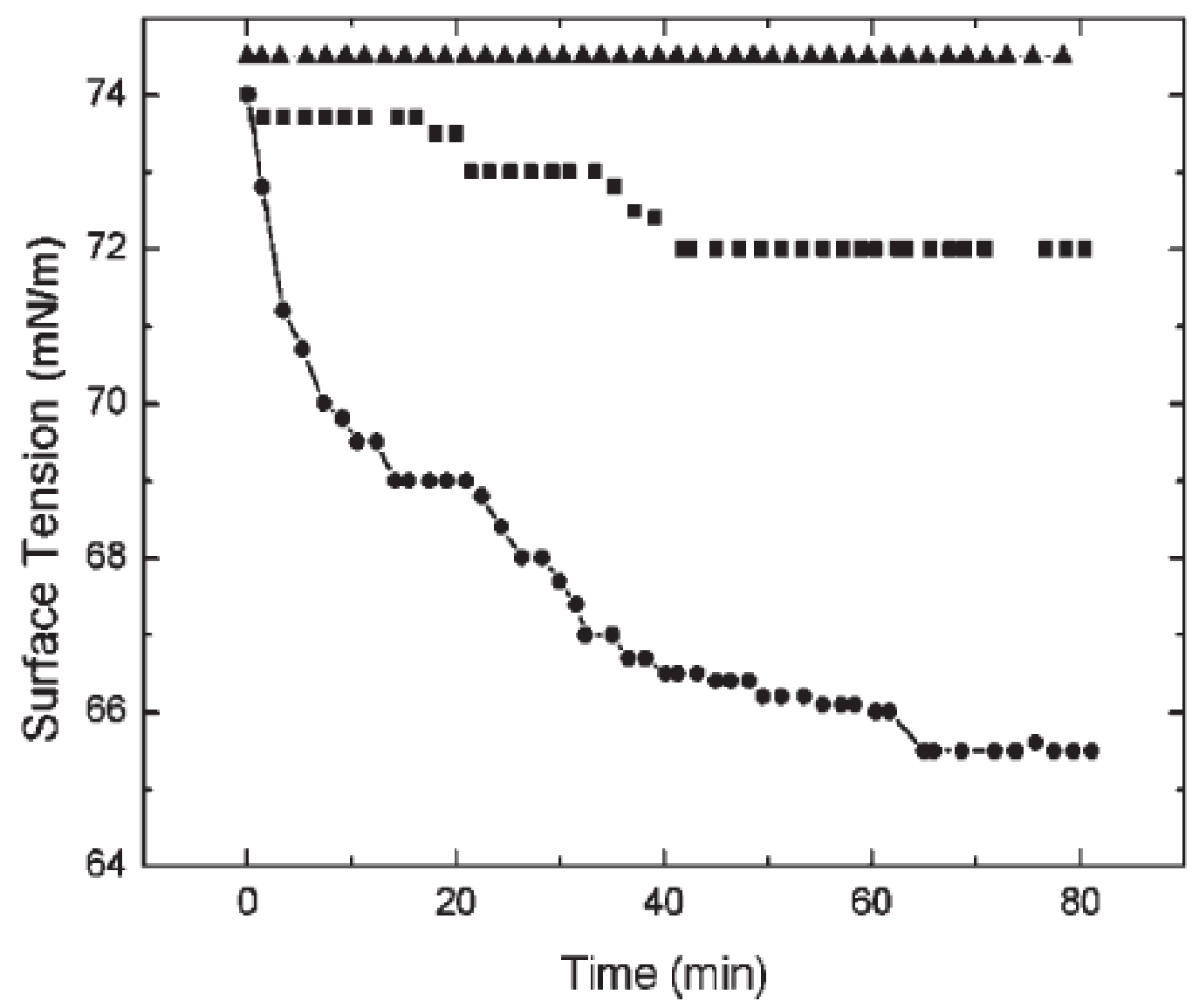

Figura 1.15: Tensão superficial de uma solução aquosa de lipossoma de DOPC em função do tempo. Os triângulos representam soluções sem azul de metileno. Os quadrados soluções na presença de AM, sem irradiação e os círculos representam soluções na presença de azul de metileno e irradiação. Imagem extraída de [19]. 


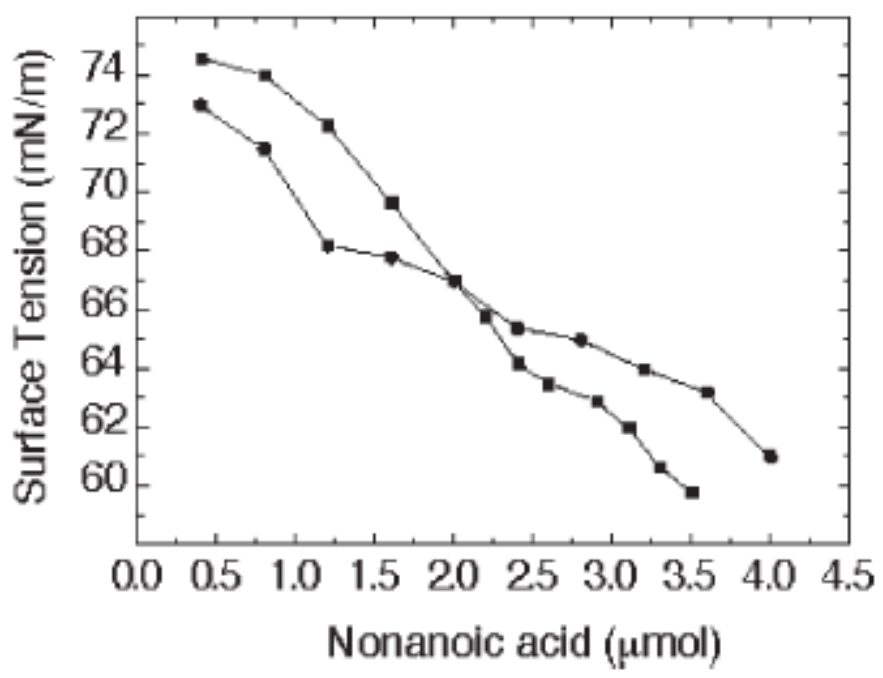

Figura 1.16: Tensão superficial de soluções de ácidos nonanóicos. Os quadrados representam deposições das moléculas anfifílicas na interface ar-água. Os círculos representam diluição direta na sub-fase. Imagem extraída de [19].

1.4.2 Giant Vesicles under Oxidative Stress Induced by a Membrane-Anchored Photosensitizer (Biophysical Journal, 2009)

Num outro trabalho [20], realizado por mim durante a Iniciação Científica, sob orientação da profa Rosangela Itri e em colaboração com a profa Karin A. Riske (Departamento de Biofísica - UNIFESP), para se estudar melhor a eficiência do processo, sintetizou-se uma nova molécula fotossensibilizadora (figura 1.17). Essa molécula consistia de uma porfirina ligada à cabeça polar de dois lipídeos DMPE (dimiristoil fosfatidiletanolamina), a qual denominamos PE-porf. Dessa forma, como a porfirina encontrava-se ligada a dois fosfolipídeos, a molécula fotoativa encontrava-se ancorada à membrana das vesículas unilamelares gigantes. A síntese foi realizada pelo Dr. Adjaci F. Uchoa do grupo do profo Mauricio S. Baptista (IQUSP).

Assim, nesse trabalho estudou-se o efeito de irradiação em membranas compostas por POPC (figura 1.4) e diferentes concentrações da molécula fotoativa de 0,5mol\% até 10mol\% de PE-porf. 


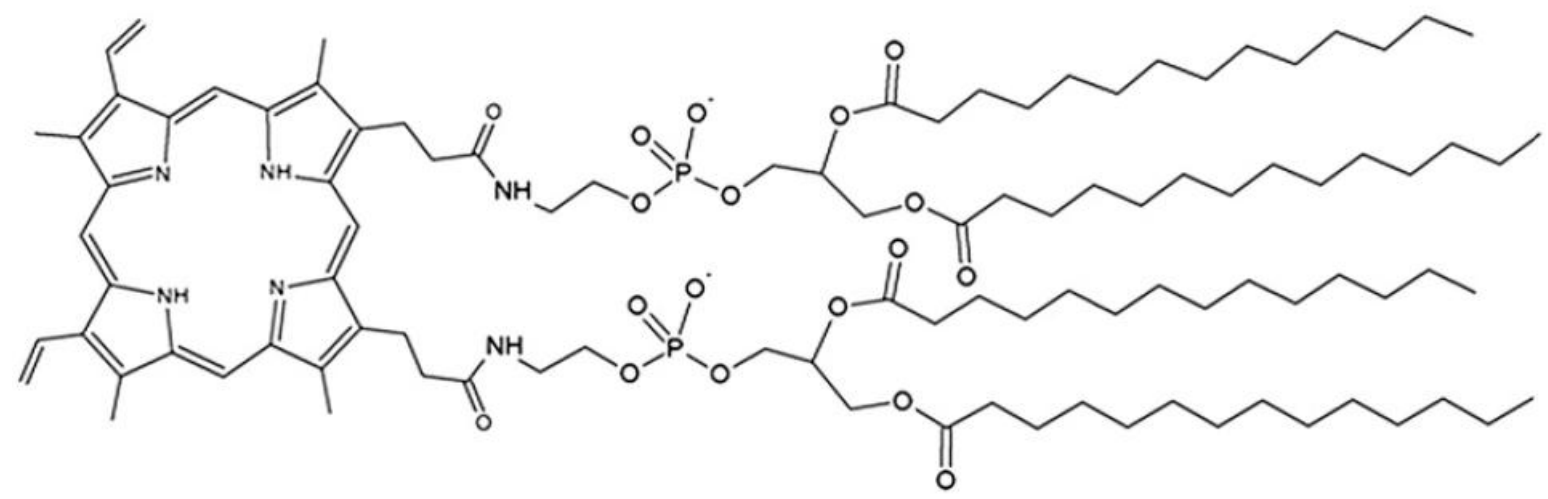

Figura 1.17: Estrutura química da PE-porf. Imagem extraída de [20].

A porfirina possui um pico de excitação de comprimento de onda $(\lambda)$ em torno de 400nm (espectros de emissão e excitação podem ser encontrados em [20]). Assim, para irradiarmos as GUVs sempre utilizávamos o filtro de excitação (acoplado ao microscópio) de mesmo comprimento de onda. Com a irradiação, a maioria das GUVs começava a flutuar, apresentando aumento de área e consequente formação de buds (pequenas vesículas ligadas a vesícula mãe por finos pescoços). Tal cenário está apresentado na figura 1.18.

Vale lembrar que em nenhum caso foi observada a destruição da membrana, pois observamos que a porfirina possui um tempo de fotoclareamento muito rápido [20]. A partir da figura 1.19 o experimento de fluorescência mostra que ao longo da irradiação temos um grande decaimento da intensidade de fluorescência.

Assim, para essa molécula, ao contrário do AM utilizado no trabalho [19], a molécula perde a capacidade de gerar ${ }^{1} \mathrm{O}_{2}$ com o tempo, pois existe foto-oxidação da própria molécula PE-porf, refletido pelo seu fotoclareamento rápido. Portanto, a reação de peroxidação não deve ser completa e devemos estar observando apenas o primeiro estágio de foto-oxidação da molécula de POPC [20]. 

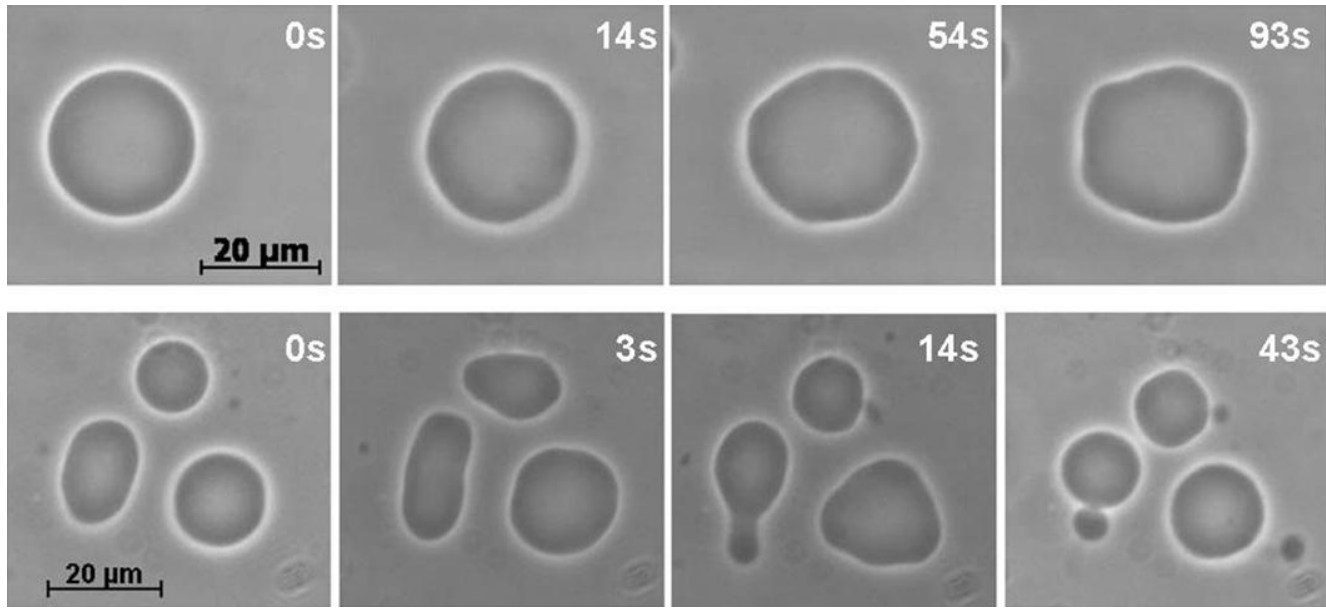

Figura 1.18: Efeito de irradiação para vesículas compostas de POPC $+5 \mathrm{~mol} \%$ de PE-porf. A primeira imagem é antes da irradiação e as demais após vários segundos de irradiação com $\lambda=400 \mathrm{~nm}$ [20].
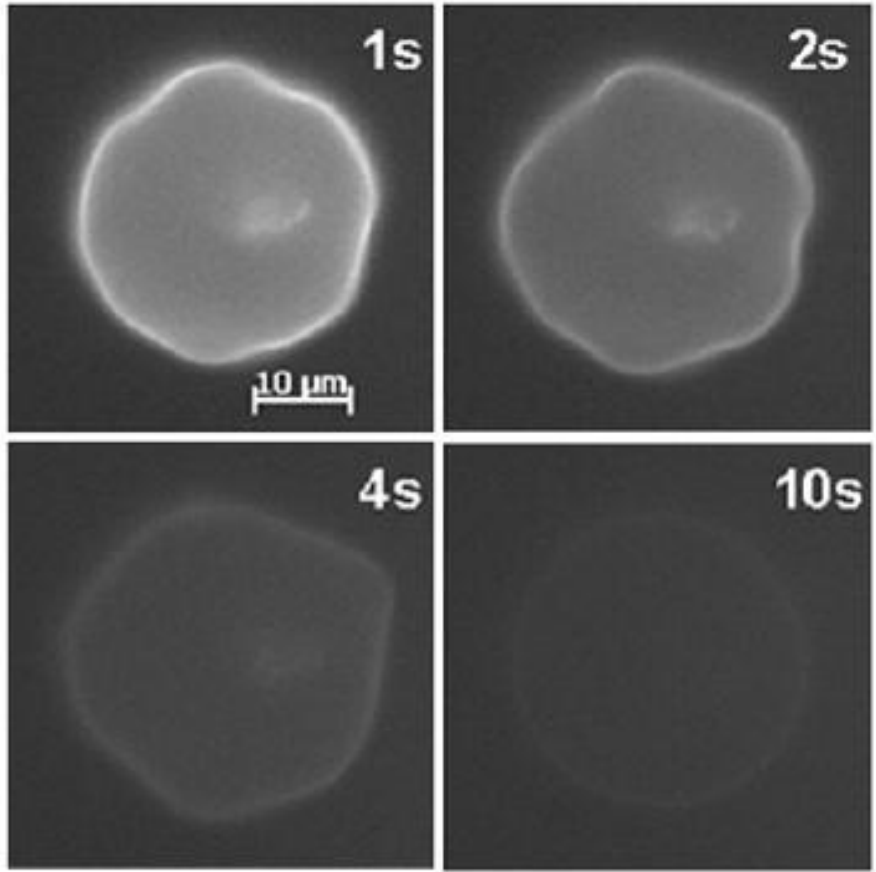

Figura 1.19: Imagem de fluorescência de uma vesícula de POPC + 3mol\% PE-porf. Após 10s é possível perceber o grande decaimento de intensidade de fluorescência [20].

Para se verificar se o efeito de aumento de área era devido à produção de oxigênio singlete a partir da irradiação da molécula fotoativa, fizemos um experimento com um supressor de oxigênio singlete, a azida sódica, mostrando que a foto-oxidação era de fato mediada pela formação de oxigênio singlete [20]. 
Para tentar entender o efeito de aumento de área da membrana, sem destruí-la com a irradiação, propusemos que o oxigênio singlete atacaria a dupla ligação do POPC, gerando um hidroperóxido lipídico (figura 1.20), cujo grupo -OOH mais hidrofílico migraria para a superfície da membrana impondo assim um aumento de área. Tal aumento de área observado pela incorporação de um hidroperóxido na membrana foi também previsto por simulação de dinâmica molecular [21].

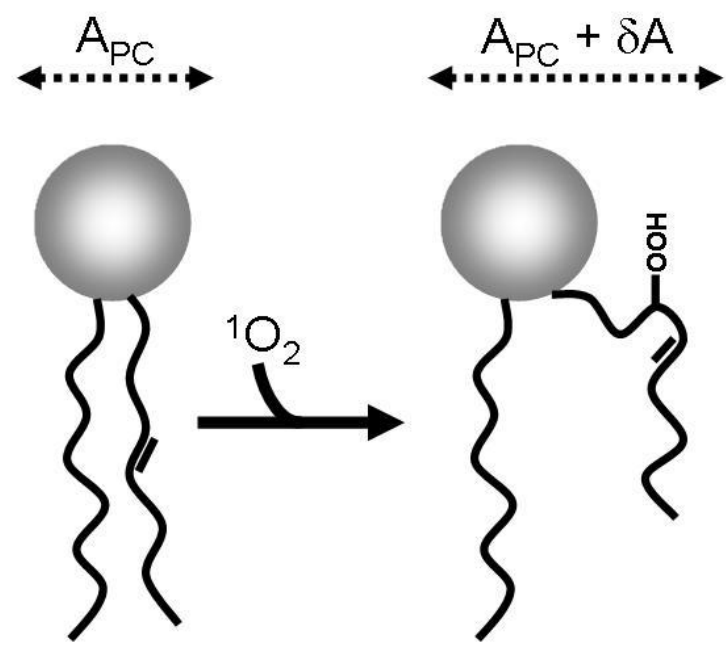

Figura 1.20: Proposta do que ocorre com o lipídeo durante a irradiação. Imagem extraída de [20].

Para analisarmos quantitativamente tal expansão de área, utilizamos o método de eletrodeformação colocando as GUVs na presença de um campo elétrico oscilante, conforme será explicado abaixo.

Um fato conhecido é que GUVs, contendo pequenas quantidades de sal em sua cavidade aquosa, na presença de um campo elétrico de corrente alternada, se deformam formando elipsóides prolatos ou oblatos dependendo da frequência aplicada e da relação entre a condutividade das soluções interna e externa [22 e 23]. No caso a vesícula se deforma expandindo todo seu excesso de área, sendo que as flutuações térmicas são suprimidas. Baseados neste experimento propusemos medir os semi-eixos de um elipsóide prolato (segunda imagem da figura 1.21) e analisar quantitativamente o aumento de área induzido por foto-oxidação da membrana. 
Na figura 1.21 mostramos a imagem de uma vesícula durante a irradiação na qual aplicamos campo elétrico AC. A partir da medida dos semi-eixos em função do tempo para cada vesícula, foi possível estimar o aumento de área para GUVs contendo POPC + PEporf, para diversas concentrações da molécula fotoativa.

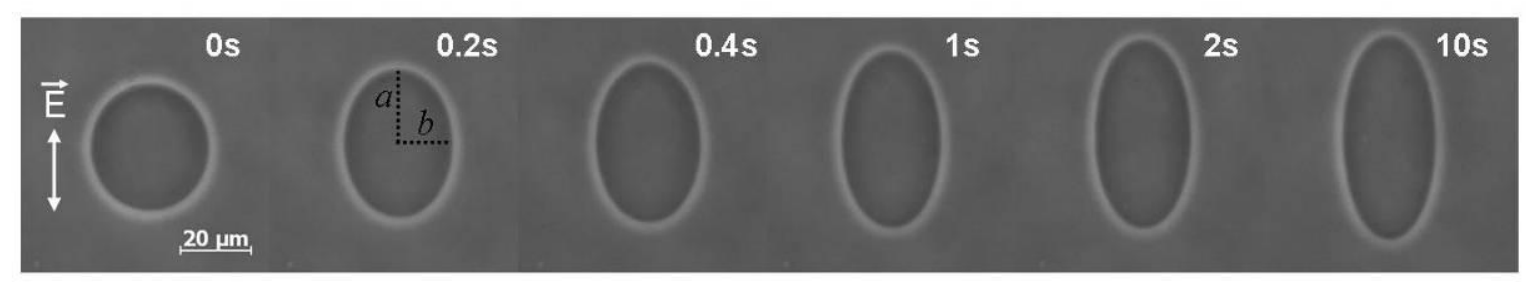

Figura 1.21: Vesícula de POPC + 1mol\% PE-porf: a primeira imagem é antes da irradiação e as demais após a irradiação. É possível observar que a vesícula se alinha ao campo, tornando-se prolata, pois maior é o seu aumento de área [20].

Após medir os semi-eixos $a$ e $b$ que estão representados na figura 1.21, é possível calcular a área reduzida de um elipsóide prolato, dada pela equação 1,

$$
A=\frac{1}{2}\left(\frac{a}{b}\right)^{\frac{1}{3}}\left[\left(\frac{b}{a}\right)+\left(\frac{\operatorname{arcsen} \varepsilon}{\varepsilon}\right)\right]
$$

onde $\varepsilon^{2}=1-\left(\frac{b^{2}}{a^{2}}\right)$.

Ressalta-se aqui que a área reduzida de um elipsóide prolato é definida como:

$$
A_{\text {reduzida }}=\frac{A_{\text {prolato }}}{A_{\text {esfera }\left.\right|_{R}}}=\frac{2 \pi b\left(b+a \frac{\operatorname{arcsen} \varepsilon}{\varepsilon}\right)}{4 \pi R^{2}}
$$

ou seja, corresponde à razão entre a área superficial de um elipsóide prolato e a área superficial de uma esfera equivalente de raio $\mathrm{R}$, tal que o volume da esfera e do elipsóide são iguais. Assim $R$ é dado por: 


$$
\frac{4}{3} \pi R^{3}=\frac{4}{3} \pi a b^{2}
$$

Portanto,

$$
R=Q b^{2} \stackrel{\frac{1}{3}}{3}
$$

Assumimos nesse modelo que o volume da vesícula permanece constante durante a irradiação.

A figura 1.22 apresenta resultados experimentais típicos (círculos) do aumento de área das GUVs em função do tempo de irradiação. A partir destes dados podemos notar que as vesículas aumentam de área em função do tempo, mas em poucos segundos ocorre uma saturação. É possível perceber também que quanto maior o valor da concentração da molécula fotoativa maior o aumento de área.

O conjunto de dados pode ser representado pela equação 2 ,

$$
\frac{\Delta A}{A_{0}}=\frac{\Delta A_{\text {máx }}}{A_{0}}\left(1-e^{-\frac{t}{\tau}}\right)_{(2)}
$$

onde $\Delta$ Amáx representa o aumento máximo de área obtido pela vesícula sem que ela forme "buds", $\tau$ está ligado ao tempo de fotoclareamento, ${ }^{A_{0}}$ é a área inicial da vesícula e t é o tempo de irradiação [20].

A figura 1.23 apresenta os valores médios dos parâmetros, $\Delta A_{\text {máx }} / A_{0}$ e $\tau$, obtidos através do ajuste da equação 2 aos dados experimentais (linhas sólidas na figura 1.22). 


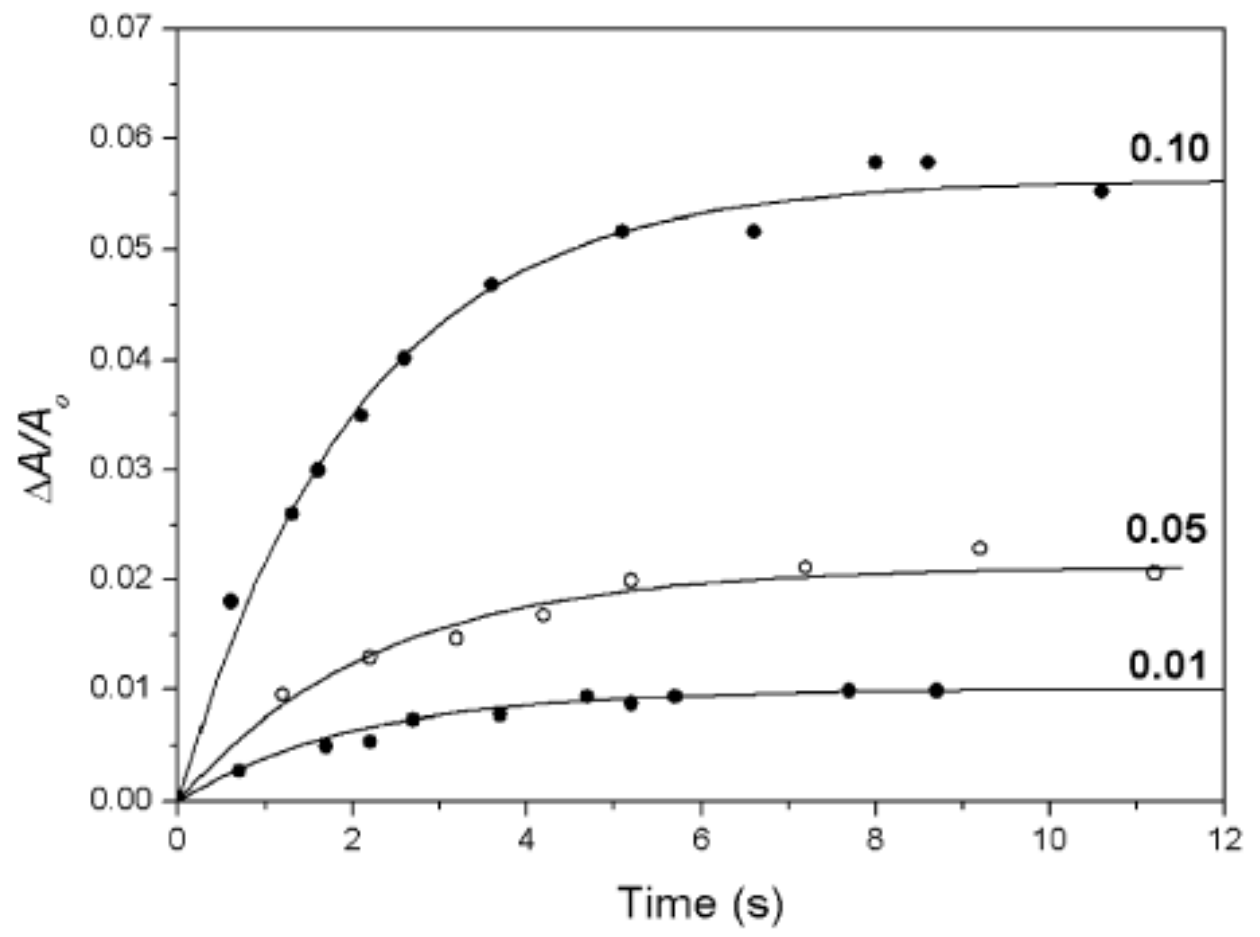

Figura 1.22: Aumento de área em função do tempo para 3 vesículas com concentrações diferentes de PEporf (descritas na figura). Imagem extraída de [20].

Dos gráficos da figura 1.23 é possível então observar que o aumento de área é linear com o aumento da concentração da molécula fotoativa, enquanto o parâmetro $\tau$ é constante. 


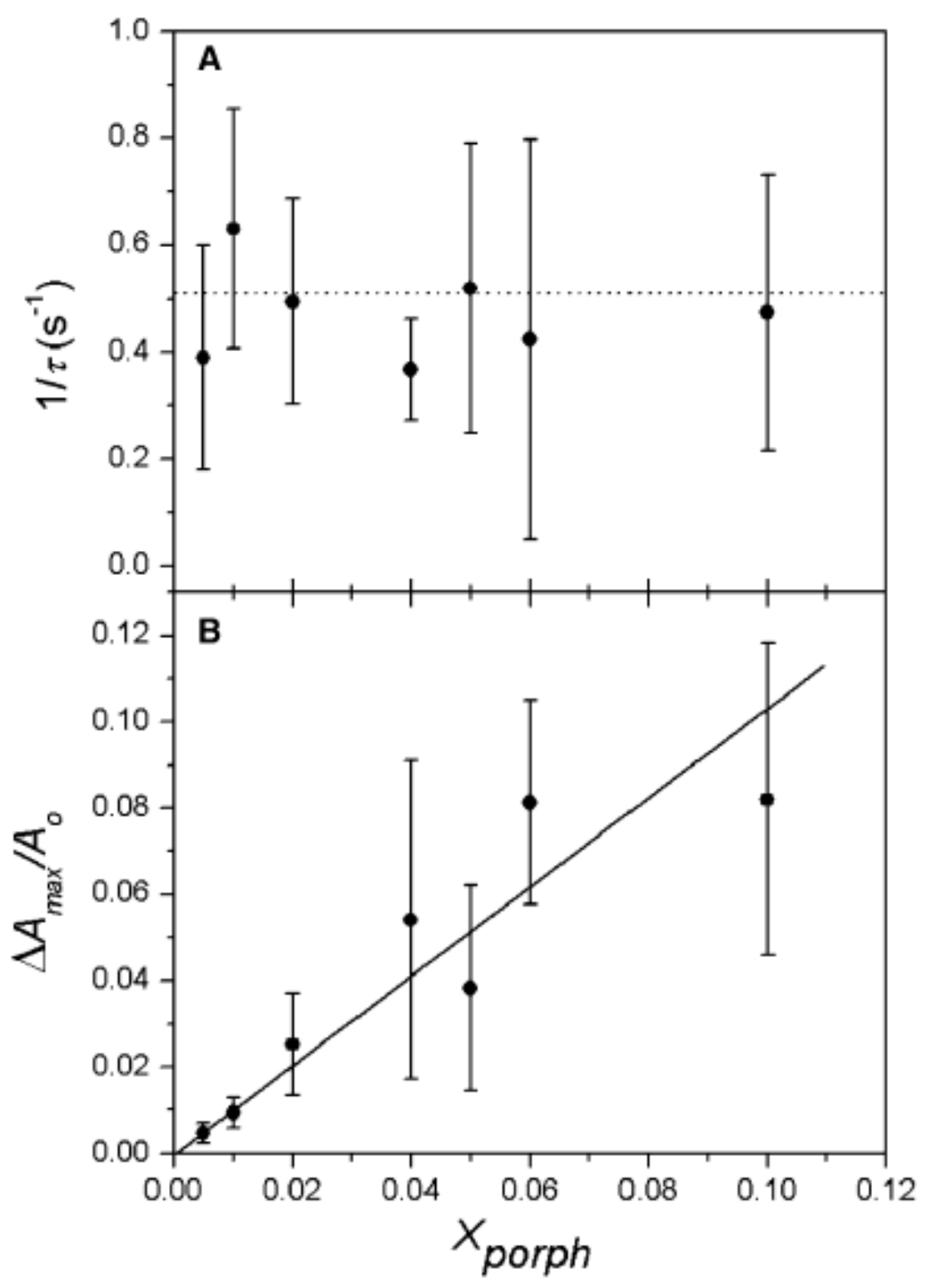

Figura 1.23: Média dos parâmetros obtidos, aumento de área e $\tau$ em função da concentração de PE-porf. Cada ponto representa a média de aproximadamente 10 vesículas. Imagem extraída de [20].

Após obter esses resultados, através de buscas realizadas na literatura, o grupo encontrou um trabalho de dinâmica molecular [21], no qual estimou-se o aumento de área causado pela formação de hidroperóxidos de lipídeos. Um aumento linear na área por lipídeo foi observado em simulações de bicamadas com até 50mol\% de lipídeos hidroperoxidados, os quais tinham o hidroperóxido no nono carbono de suas caudas. Uma extrapolação desse trabalho para até 100mol\% de lipídeos com hidroperóxidos mostram 
que a área por lipídeo pode aumentar de 65 para $75 \AA^{2}$. Este resultado foi corroborado recentemente pela aluna de doutorado Thais F. Schmidt através de isotermas de compressão de monocamadas de Langmuir.

Portanto, utilizando tal aumento por lipídeo hidroperoxidado, estimamos a quantidade de hidroperóxidos formados nos nossos experimentos. Para isso, primeiramente, calculou-se a taxa de produção de oxigênio singlete, para a qual obteve-se um valor de $900{ }^{1} \mathrm{O}_{2} / \mathrm{s}$ [20]. Após calcular essa taxa foi possível quantificar a eficiência do processo, ou seja, obteve-se que para cada 270 oxigênios singletes produzidos durante a reação foto-oxidativa somente 1 ataca as duplas ligações.

A partir desse valor obtido para a eficiência, foi possível inferir que o aumento de área sofrido pela vesícula era associado à peroxidação de 3-60\% dos lipídeos, para concentrações de PE-porf variando de 0,5mol\% até $10 \mathrm{~mol} \%$. Dessa forma, nesse trabalho tivemos um aumento de área da bicamada de até $8 \%$ para uma quantidade de $60 \%$ de lipídeos peroxidados, sem destruição da membrana lipídica. Para maiores detalhes ver trabalho completo no Anexo 1.

\subsection{Objetivo do trabalho}

O objetivo do presente trabalho é mimetizar uma membrana celular de forma bem simplificada, contendo somente lipídeos e tentar entender a morte celular foto-induzida, a partir do efeito de irradiação em vesículas gigantes com uma molécula fotossensível ancorada em sua superfície, como está esquematizado na figura 1.29.

Como mostrado na seção anterior o grupo já vem desenvolvendo há algum tempo experimentos com vesículas gigantes compostas somente por um tipo de lipídeo, POPC (uma insaturação) ou DOPC (duas insaturações).

Assim, o objetivo desta dissertação foi continuar os estudos já iniciados pelo grupo, estudando o efeito de irradiação em membranas mistas de POPC e CL ou POPC e Col, com uma molécula fotoativa ancorada em sua superfície, buscando entender o efeito da influência de CL/Col na membrana e na resposta à foto-oxidação. 


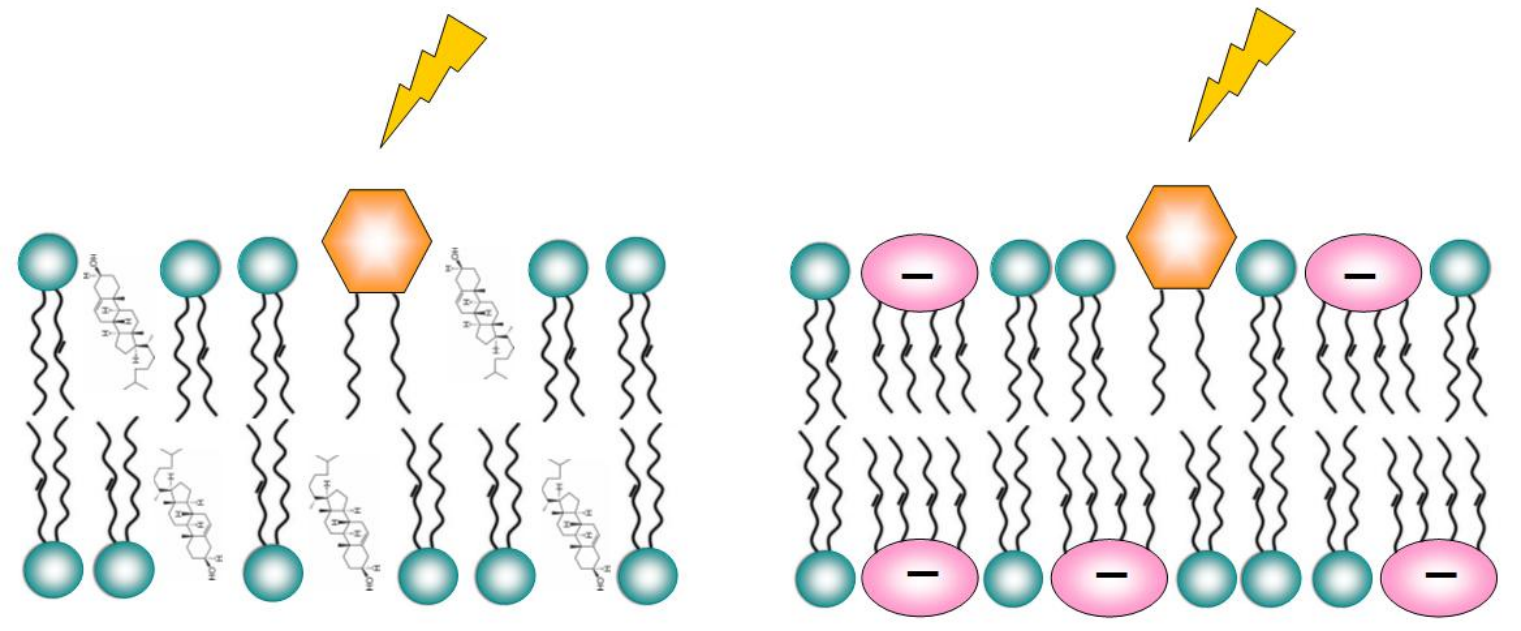

Figura 1.24: Esquema das bicamadas lipídicas, contendo a molécula fotoativa ancorada em sua superfície. A primeira bicamada representa a composição POPC:Col e a segunda representa POPC:CL.

Vale a pena ressaltar a experiência do nosso grupo era somente de trabalhar com lipídeos zwiteriônicos. Assim, no começo desse trabalho não tínhamos experiência na formação de GUVs contendo CL (2 cargas negativas e 4 caudas insaturadas) por eletroformação. Para iniciarmos esse trabalho buscamos na literatura formas de como a técnica de eletroformação seria aplicada para vesículas carregadas.

Existem poucos trabalhos na literatura sobre GUVs contendo $\mathrm{CL}$ em sua composição lipídica [24 - 31], sem um protocolo de eletroformação bem definido. Dessa forma, uma parte desta dissertação teve como objetivo realizar experimentos para a obtenção das melhores condições de eletroformação de GUVs contendo CL. 


\subsection{Esquema da dissertação}

\section{Capítulo 1:}

No capítulo 1 foi feita uma breve introdução sobre as motivações deste trabalho bem como os seus objetivos. A principal motivação deste trabalho é a investigação de mecanismos de fotossensibilização em membranas modelo.

Partindo desses pressupostos, foi feita uma breve introdução sobre a membrana celular, sobre lipídeos (macromoléculas que compõem a membrana celular) e suas formas de auto-organização, como por exemplo, um lipossoma (forma utilizada para mimetizar a membrana) e sobre terapia fotodinâmica e aplicações.

Além disso, foi feito um breve preâmbulo sobre os trabalhos anteriores realizados no grupo. Tais trabalhos também foram realizados de forma a tentar entender o efeito de irradiação em vesículas unilamelares gigantes (GUVs).

\section{Capítulo 2:}

No capítulo 2 serão apresentados os materiais utilizados para a realização deste trabalho e também as metodologias utilizadas para a realização dos experimentos.

\section{Capítulo 3:}

No capitulo 3 serão mostrados os resultados dos experimentos realizados com as membranas modelo, GUVs na ausência da molécula fotoativa. As GUVs utilizadas para este estudo eram formadas por diferentes composições de POPC e CL, nas quais variaramse algumas condições durante o crescimento. Entre algumas destas variações estão: a freqüência de crescimento, o tempo de crescimento e o meio de crescimento. 
Capítulo 4:

No começo deste capítulo falar-se-á brevemente sobre o efeito de fotoclareamento sofrido pela molécula fotoativa e também será mostrado que somente as GUVs que contém a molécula fotoativa alongam ao serem irradiadas na presença do campo.

Será feita uma análise da influência dos filtros para os experimento de aumento de área e também serão apresentados os resultados dos efeitos da irradiação nas GUVs que continham a molécula fotoativa ancorada em sua superfície. Primeiramente serão mostrados os resultados para POPC, depois para POPC:CL e POPC:Col.

Em particular, para a concentração de $50 \mathrm{~mol} \%$ de $\mathrm{CL}$, considerada uma concentração crítica, foram feitos estudos do efeito de irradiação em diversos meios como: $\mathrm{NaCl}$, Hepes, EDTA e $\mathrm{CaCl}_{2}$.

\section{Capítulo 5:}

Neste capítulo será mostrada a análise quantitativa dos efeitos da irradiação, ou seja, os resultados para os experimentos de aumento de área de GUVs na presença de um campo elétrico AC. Primeiramente serão mostrados os resultados de aumento de área para POPC e na seqüência para POPC:CL e POPC:Col.

\section{Capítulo 6:}

No capítulo 6 serão feitas as considerações finais do trabalho. 


\section{Capítulo 2: Materiais e Métodos}

\subsection{Materiais}

Para preparar as soluções lipídicas utilizamos clorofórmio da Casa Americana. A sacarose e a glicose utilizadas para preparar as GUVs também foram obtidas da Casa Americana. Tais soluções de sacarose e glicose sempre foram preparadas com água milliQ.

Como nesse trabalho utilizaram-se membranas contendo Cardiolipina (CL - Figura 1.5 do capítulo 1) foi de extrema importância o estudo do crescimento destas GUVs mistas crescidas em sacarose e glicose na presença de alguns sais para investigar a possível influência da carga da cabeça polar do lipídeo na formação da bicamada.

Dessa forma, nas próximas subseções serão descritos os meios aquosos em que as vesículas foram crescidas, os lipídeos utilizados, a molécula fotoativa utilizada e também o marcador fluorescente utilizado em alguns estudos.

\section{$\underline{\text { 2.1.1 Meios utilizados }}$}

Os meios utilizados foram soluções de sacarose e glicose preparadas em água milli$\mathrm{Q}(\mathrm{pH} \sim 6)$ na presença e na ausência dos seguintes aditivos: 0,5mM de $\mathrm{NaCl} ; 1 \mathrm{mM}$ Hepes; 0,1mM EDTA (ácido etilenodiamino tetra-acético - ver estrutura química na figura 2.1). Todos os sais foram obtidos da Sigma Aldrich.

Por fim, percebeu-se um efeito muito interessante, que será apresentado no capítulo 4, e resolveu-se estudar também vesículas de sacarose +0,1mM de EDTA diluídas em glicose + 0,1 $\mathrm{mM}$ EDTA + 0,5 $\mathrm{mM} \mathrm{CaCl}_{2}$ (obtido da Sigma Aldrich também). 


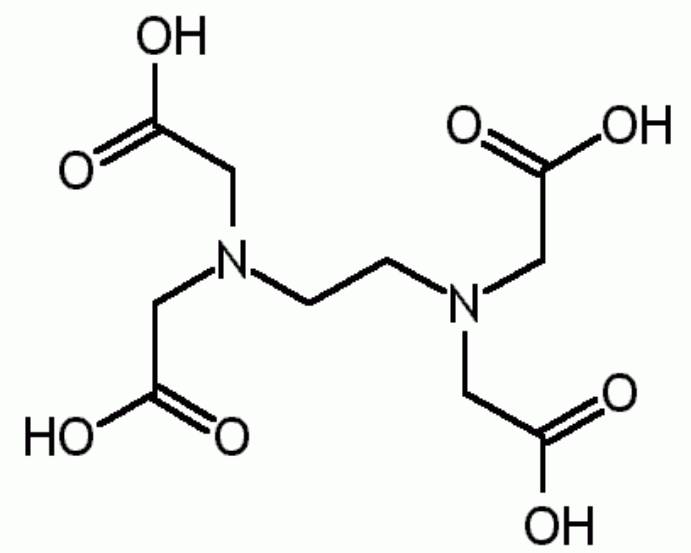

Figura 2.1: Estrutura química do EDTA. O EDTA age como quelante, formando complexos muito estáveis com íons metálicos [32]. Imagem extraída de [33].

\section{$\underline{\text { 2.1.2 Lipídeos utilizados }}$}

Os lipídeos utilizados nesse trabalho foram: Cardiolipina (1, 1'2,2' - tetraoleoil cardiolipina - sal de sódio - lote: 181CA-44); POPC (1 - palmitoil - 2 - oleoil - sn - glicero - 3 - fosfatidilcolina - lote: 160 - 181PC -184) e o colesterol (Col - lote: 57-88-5); todos considerados lipídeos de membrana. As estruturas químicas desses lipídeos estão representadas nas figuras 1.4, 1.5 e 1.8 do capítulo 1 , na mesma ordem em que foram descritos. Os dois primeiros lipídeos citados foram obtidos da Avanti Lipids, enquanto o colesterol foi obtido da Sigma Aldrich.

\subsubsection{Molécula fotoativa utilizada (diC $\underline{12}_{\text {-porf) }}$}

A molécula fotoativa utilizada ao longo do trabalho foi sintetizada pelo pósdoutorando Adjaci U. Fernandes (IQUSP) em colaboração com o profo Maurício S. Baptista (IQUSP) e consiste de um grupo porfirina ligado a duas cadeias dodecil, esquematizada na figura 2.2. Denominamos esta molécula fotoativa de $\mathrm{diC}_{12}$-porf ao longo do trabalho. 


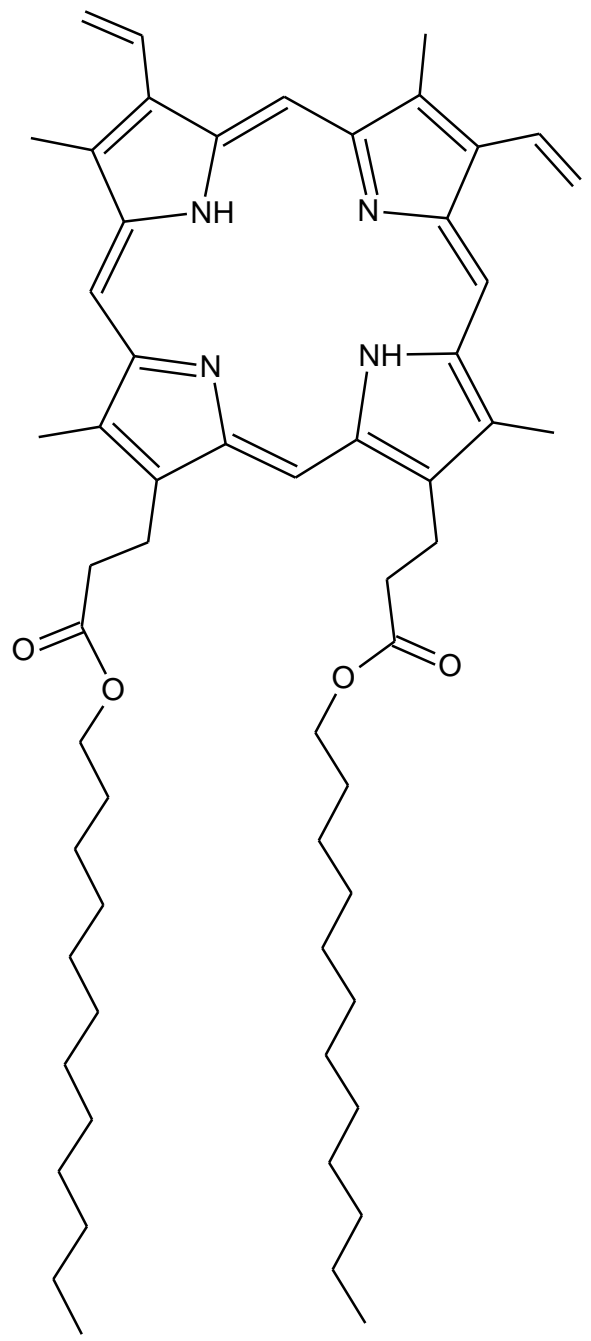

Figura 2.2: Estrutura química da molécula fotossensível diC $\mathrm{C}_{12}$-porf, sintetizada pelo Dr. Adjaci U. Fernandes.

O espectro de absorção da molécula diC ${ }_{12}$-porf pode ser apreciado na figura 2.3. A partir deste espectro é possível observar que a molécula possui um pico de absorção máximo em torno de $407 \mathrm{~nm}$, similar à molécula de protoporfirina IX. Portanto, a nova molécula sintetizada mantém as propriedades de absorção do fotossensibilizador porfirina.

Além disso, dic 12 -porf tem rendimento quântico de geração de oxigênio singlete igual a 0,7 [34], diferentemente da molécula PE-porf estudada em [20], que possuía rendimento quântico igual a 0,5. 


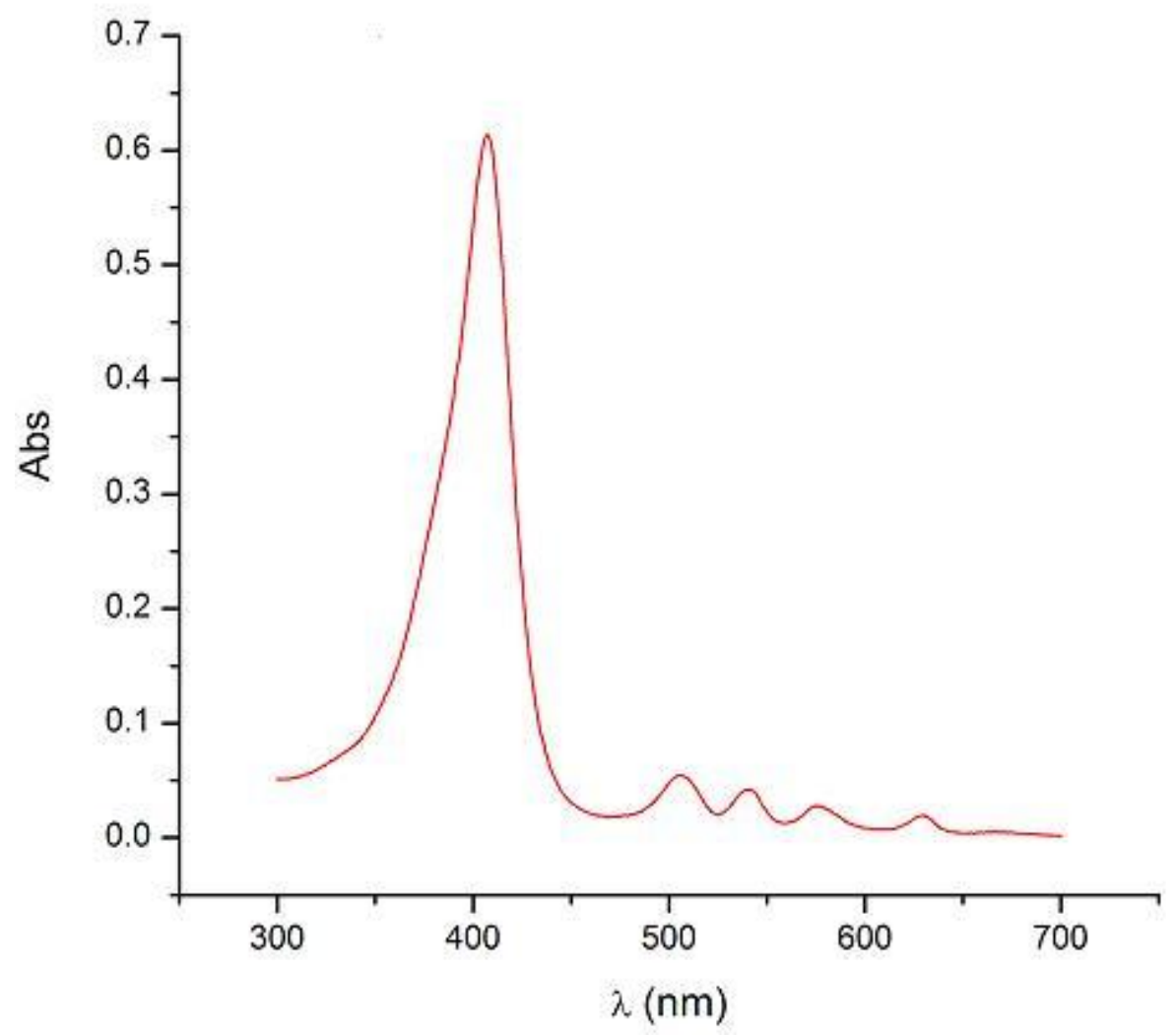

Figura 2.3: Espectro de absorção da molécula fotoativa diC $_{12}$-porf. Para obtermos esse espectro utilizamos uma cubeta de caminho óptico de $1 \mathrm{~cm}$ e uma concentração de $5 \mu \mathrm{M}$ de diC ${ }_{12}$-porf.

\subsubsection{Sonda fluorescente utilizada (DilC $\underline{18}_{1}$ )}

Em um dos estudos deste trabalho, com membranas mistas de POPC e $\mathrm{CL}$, na ausência da molécula fotoativa, foi utilizado um marcador fluorescente para tentar se investigar a presença de uma possível separação de fases e/ou formação de domínios, como será apresentado no capítulo 3.

O marcador fluorescente utilizado foi o DilC 18 (1,1'- dioctadecil - 3,3,3',3'perclorato de tetrametilindocarbocianina), o qual está representado na figura 2.4 e foi gentilmente cedido pela profa Karin A. Riske. Para excitar esse marcador utilizamos o filtro de comprimento de onda de $546 \mathrm{~nm}$ [32]. 


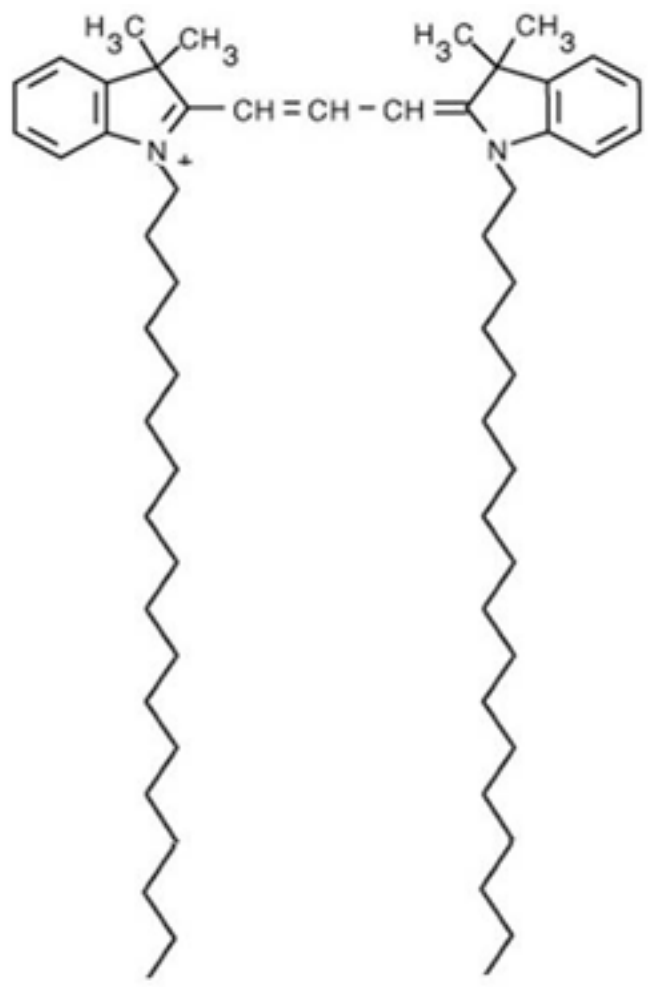

Figura 2.4: Estrutura química da sonda fluorescente DilC $C_{18}$. Imagem extraída de [35].

\subsubsection{Composições de membrana utilizadas}

Como citado em 2.1.2 utilizou-se 3 tipos de lipídeos para formar as membranas, além de se incorporar a molécula fotoativa na bicamada. Para preparar as GUVS utilizamos um estoque de $300 \mu$ l de uma solução lipídica, na qual a concentração total de lipídeos era de 2,5mM em clorofórmio. As variações das concentrações dos lipídeos utilizados estão representadas na figura 2.5 . 


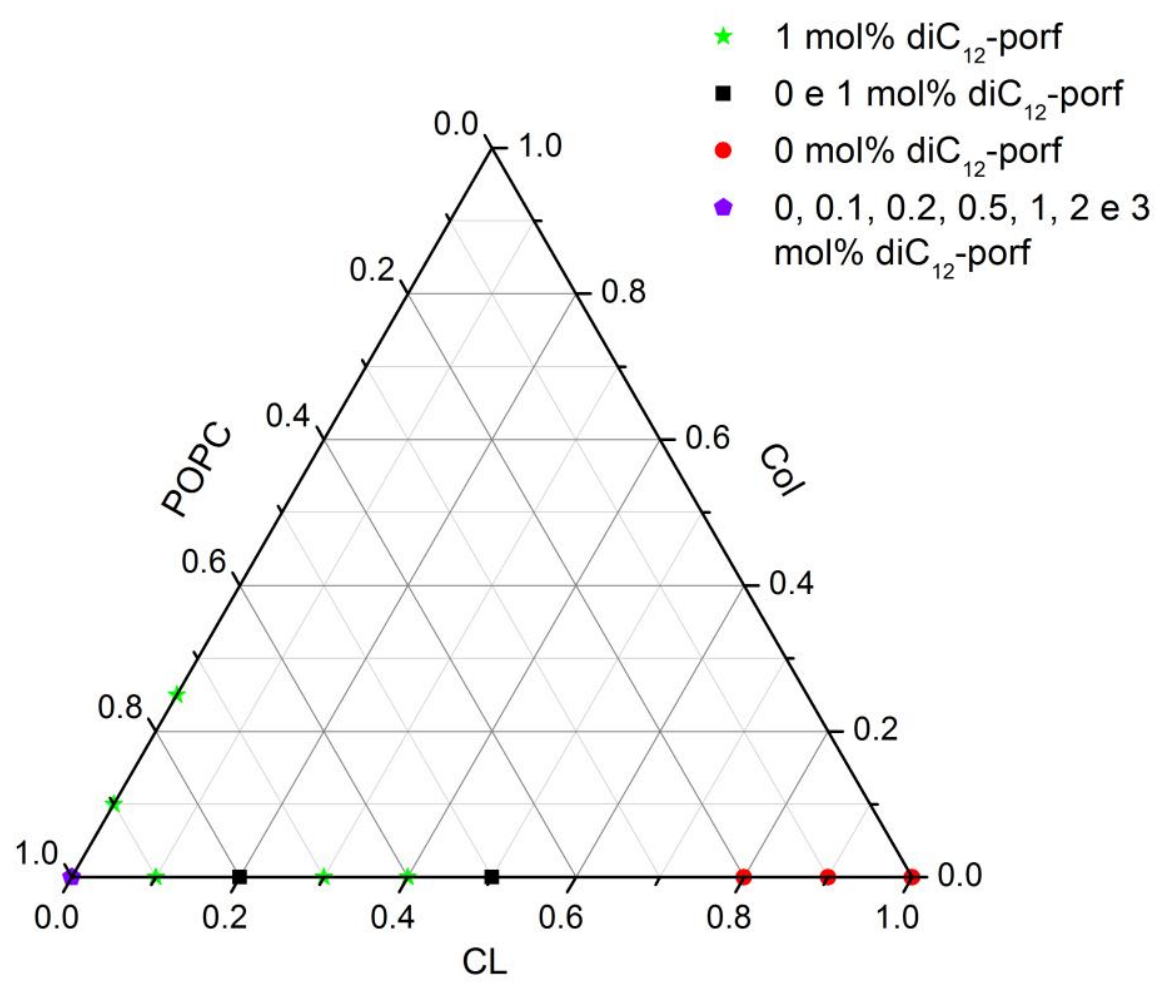

Figura 2.5: Composições lipídicas utilizadas para formar as GUVs. A partir do diagrama ternário pode-se observar que só estudamos composições binárias, chegando-se até $25 \mathrm{~mol} \%$ de Col e $100 \mathrm{~mol} \%$ de CL. Os símbolos em vermelho foram estudados somente na ausência da molécula fotoativa, enquanto os demais foram estudados na presença de $\mathrm{diC}_{12}$-porf, nas concentrações indicadas na legenda.

\subsection{Métodos utilizados}

\subsubsection{Técnica utilizada para o crescimento das GUVS}

A técnica utilizada para formar as Vesículas Unilamelares Gigantes (GUVs) foi a eletroformação [36]. Nesse método utilizam-se duas lâminas condutoras de vidro recobertas com FTO (óxido de estanho dopado com flúor). Essas lâminas só possuem um lado condutor, e sobre esse lado são espalhados aproximadamente $8 \mu l$ de uma solução lipídica de concentração total de lipídeos de 2,5mM (figura 2.6a).

Após espalhar a solução lipídica, o substrato é deixado no vácuo para que todo o clorofórmio seja evaporado. Logo após esse processo, um espaçador de teflon é colocado 
entre as lâminas, de forma que os filmes da solução lipídica fiquem voltados um para o outro. Estas lâminas podem ser seladas ou com uma graxa de silicone ou com presilhas de metal (figura 2.6b).

A seguir se preenche o espaço livre com uma solução de $0,2 \mathrm{M}$ de sacarose (figura 2.6c) e aplica-se uma tensão de aproximadamente $1 \mathrm{~V}$ e frequência de $10 \mathrm{~Hz}$ através de um gerador de ondas (figura 2.6d). Para o crescimento das vesículas utilizamos onda senoidal. Esse protocolo de crescimento foi previamente estabelecido no trabalho [20], o qual foi descrito na introdução - capítulo 1.

Na figura 2.7, obtida de [37] é possível ver um esquema de como as vesículas se formam pela técnica de eletroformação e, na figura 2.8 , tem-se uma foto das GUVs crescendo enquanto estão conectadas ao gerador de ondas.

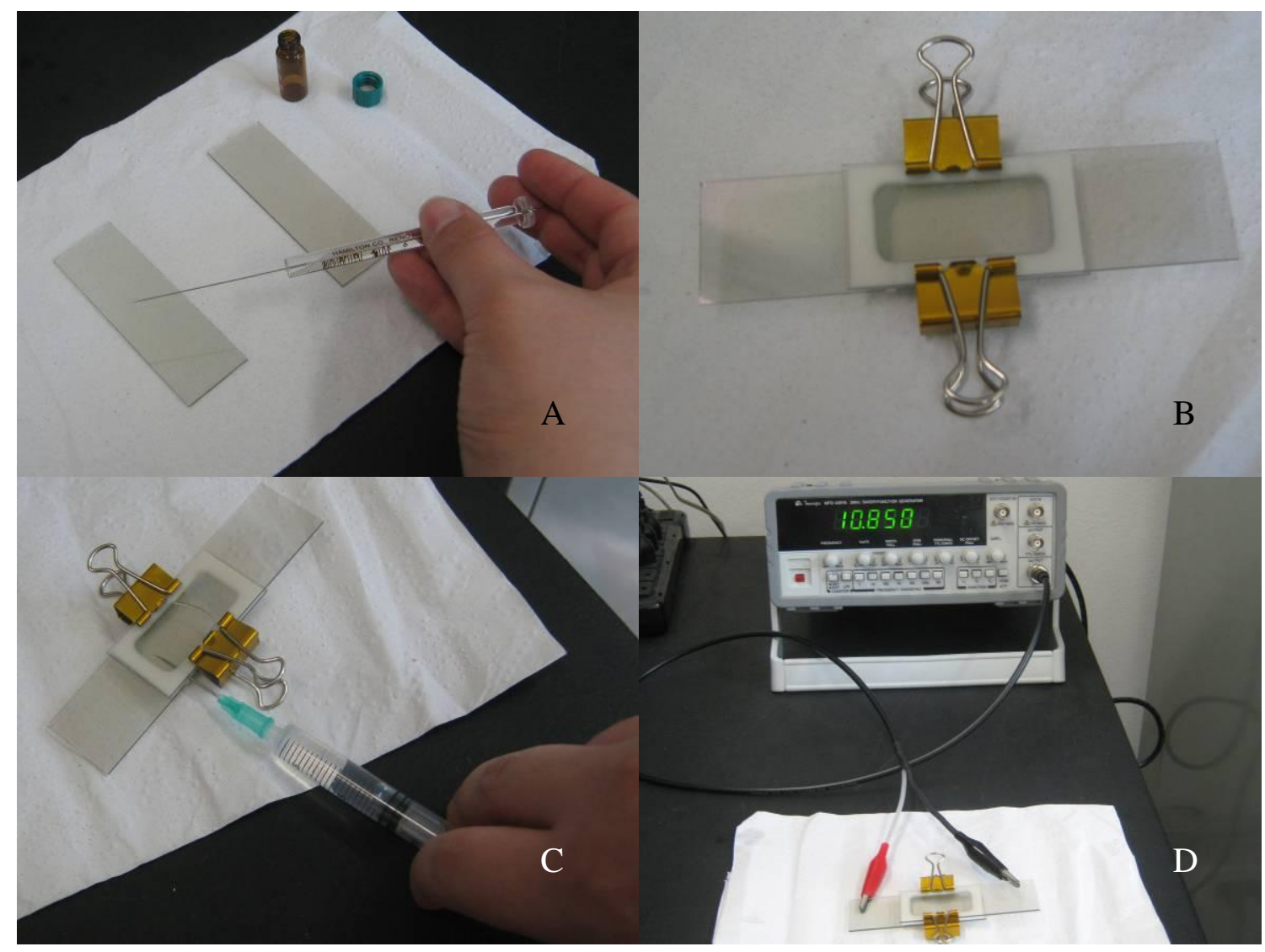

Figura 2.6: Procedimento experimental utilizado, técnica de eletroformação. (A) A solução lipídica está sendo espalhada sobre o lado condutor das duas lâminas recobertas por FTO. (B) Os lados condutores ficam com as faces voltadas para dentro e entre eles é colocado um espaçador de teflon. As lâminas são seladas 
com duas presilhas. (C) O espaço livre é preenchido com sacarose. (D) Conecta-se o gerador de ondas, com função de onda senoidal, amplitude de $1 \mathrm{~V}$ e frequência de $10 \mathrm{~Hz}$.
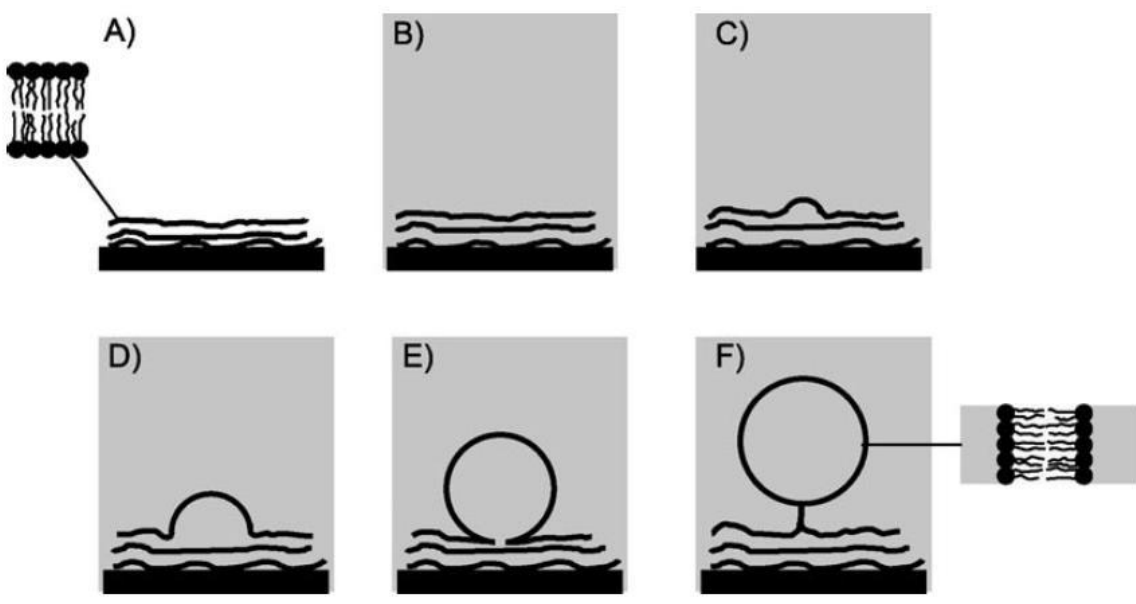

Figura 2.7: Representação esquemática de uma GUV sendo formada através da técnica de eletroformação, enquanto um campo elétrico é aplicado. Imagem extraída de [37].

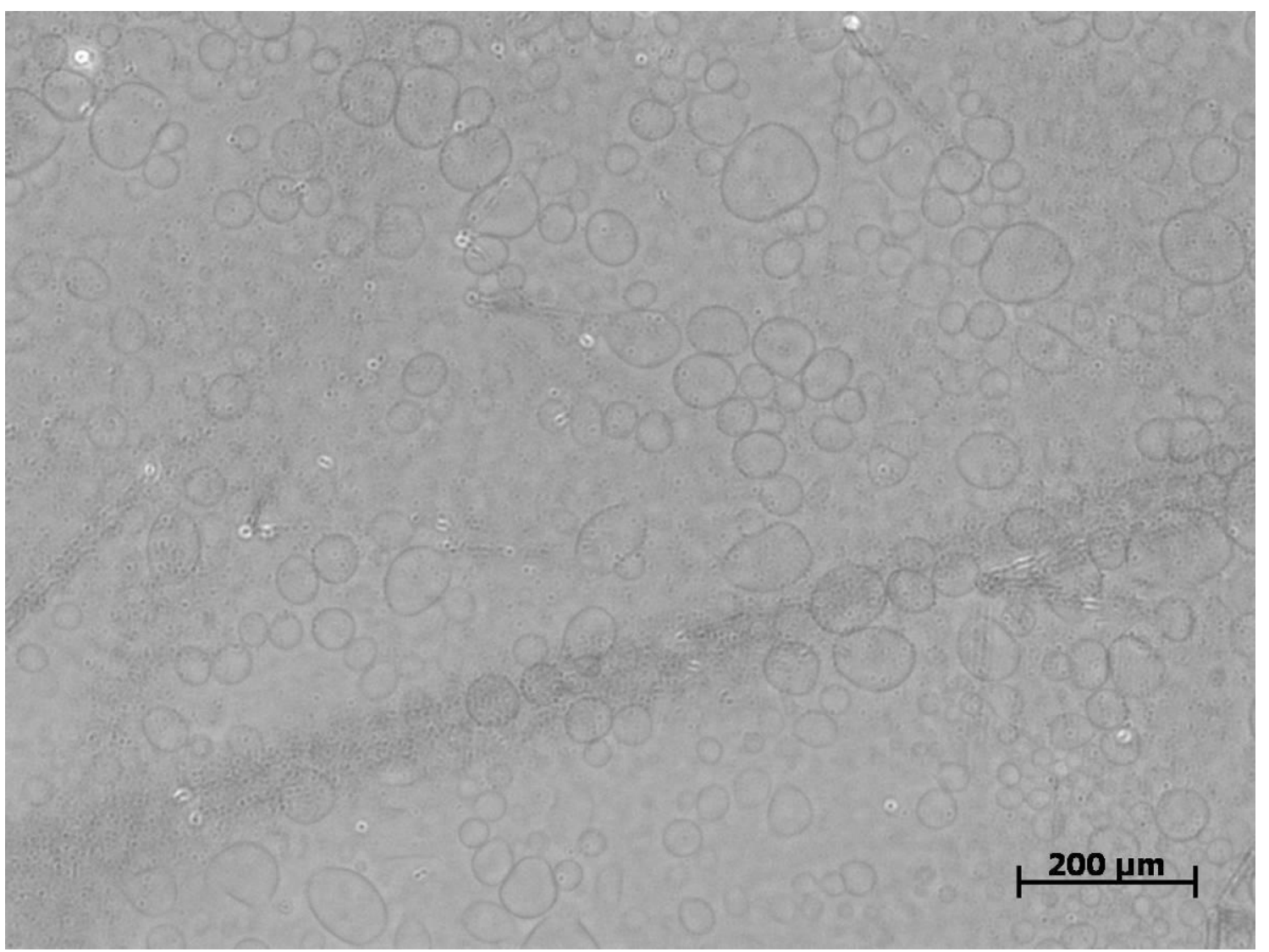

Figura 2.8: GUVs crescendo enquanto o campo elétrico é aplicado entre as lâminas condutoras, imagem obtida com a objetiva 10x. 
Para vesículas compostas somente por POPC ou POPC:Col o tempo que o campo elétrico é aplicado é de aproximadamente 2 horas, conforme protocolo previamente estabelecido em [20]. Já para vesículas compostas de CL, observamos que o tempo que o campo elétrico deveria ser aplicado variava em função da concentração da CL e do meio no qual a mesma se encontra. Percebemos que GUVs compostas majoritariamente por $\mathrm{CL}$ eram mais difíceis de crescer em 2 horas, apresentando vesículas pequenas e mal formadas, além da presença de macro domínios visíveis. Tais efeitos serão melhor explorados e descritos no Capítulo 3. Como resultado, estabelecemos um protocolo de aplicar o campo elétrico durante 1 hora para GUVs contendo menos de 50 mol\% de CL e meia hora para GUVs contendo 50 mol\% de CL e concentrações maiores (ver resultados no capítulo 3$)$.

Após aplicar o campo elétrico, as vesículas são retiradas da cela e diluídas aproximadamente 10 vezes em uma solução equimolar de glicose. Assim o volume interno das GUVS é preenchido somente com sacarose enquanto que o meio externo contém principalmente glicose. Isso permite criar uma assimetria de açúcares entre os meios externo e interno. Tal assimetria tem dupla finalidade: criar um contraste óptico, devido à diferença de índice de refração e permitir que as vesículas se localizem no chão da câmara de observação do microscópio óptico invertido, pois a sacarose é mais densa que glicose.

\subsubsection{Microscopia Óptica (MO)}

Para visualizarmos as GUVS, foi utilizado um microscópio óptico invertido Zeiss Observer D1 (figura 2.9), equipado com as seguintes objetivas Ph1 10x, Ph2 40x e Ph2 63x e as imagens foram gravadas com uma câmera Zeiss AxioCam MRm.

Acoplada ao microscópio existe uma lâmpada de mercúrio HXP-R 120W com filtros de excitação em 365, 400, 480 e 546nm. Como o comprimento de excitação da porfirina é em torno de 400nm (como pode ser observado no espectro de absorção da figura 2.3) utilizamos o filtro de mesmo valor para irradiar as GUVs. 
Além disso, o microscópio possui quatro modos de visualização (contraste de fase, transmissão, fluorescência e RICM). Dentre estes modos, neste trabalho foram utilizados somente o modo contraste de fase (figura 2.10A) e o modo de fluorescência (figura 2.10B).

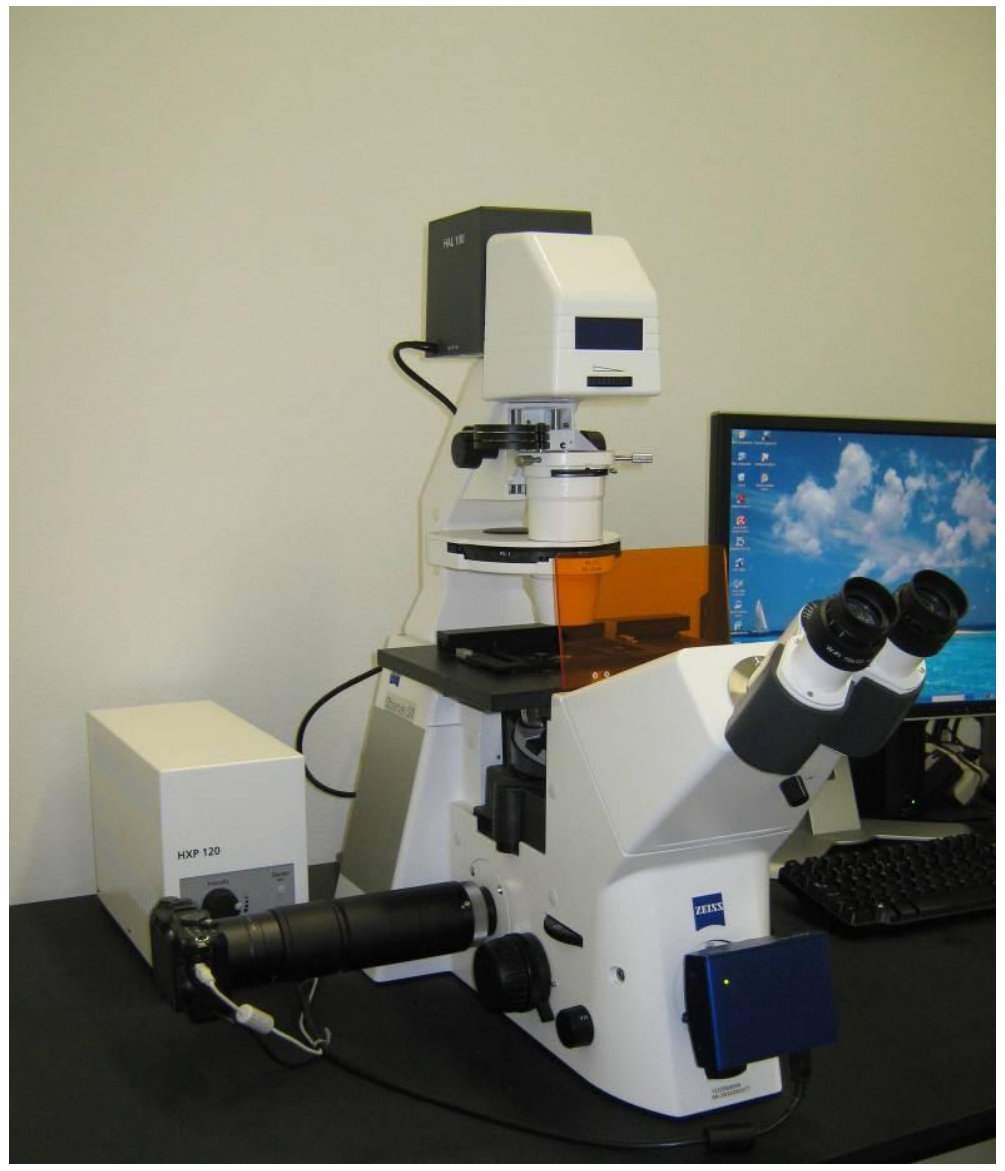

Figura 2.9: Microscópio invertido Zeiss Axiovert.
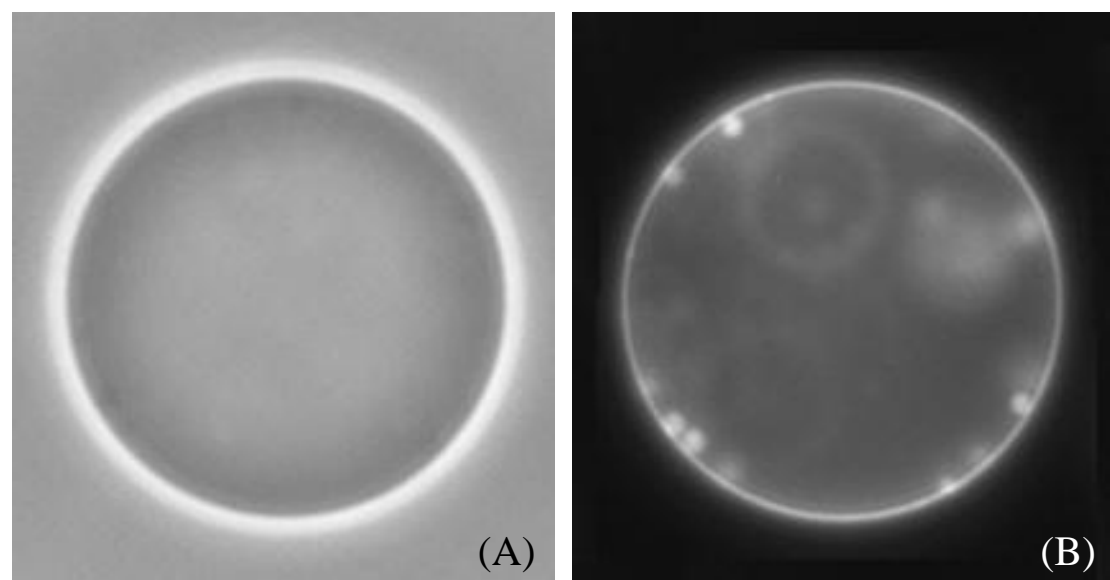
Figura 2.10: A primeira imagem é de uma vesícula no modo contraste de fase. Já a segunda vesícula se observa através do modo de fluorescência. Como será visto mais adiante, os pontos brilhantes nessa imagem representam domínios lipídicos.

Como é possível observar na figura 2.10, a partir da imagem de microscopia só é possível ter acesso ao equador da vesícula, como representado na figura ilustrativa 2.11.

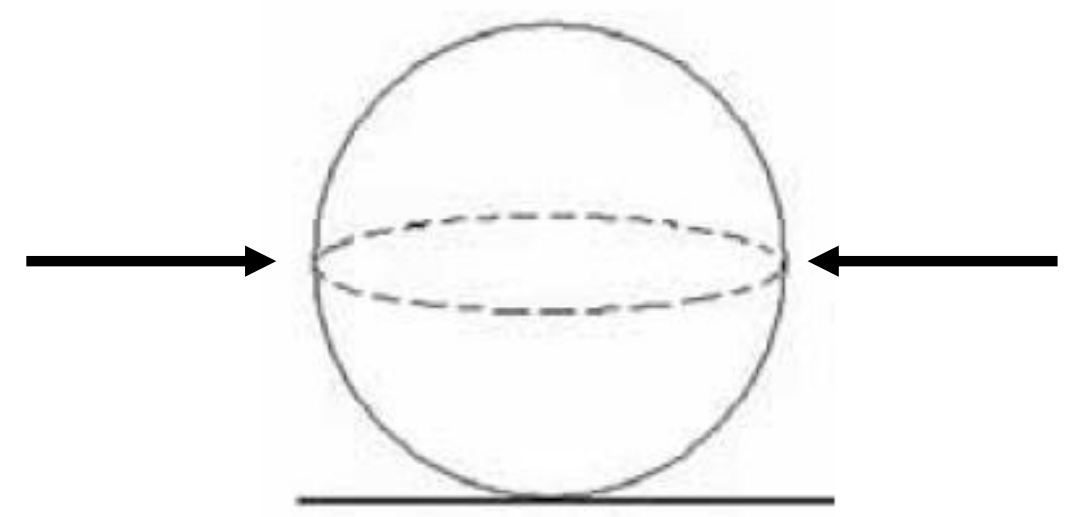

Figura 2.11: Representação de uma GUV e de seu equador.

\subsubsection{Medidas de aumento de área}

No presente trabalho, assim como no trabalho [20], as vesículas durante a irradiação passam a flutuar, acompanhadas por um aumento de área. Dessa forma, para quantificar tal aumento utilizou-se o mesmo método de análise, estabelecido em [20], através da aplicação de um campo elétrico senoidal de frequência alta (1MHz).

Para isso, utilizou-se uma cela de observação da Eppendorf que contêm dois eletrodos paralelos (distância $0,5 \mathrm{~mm}$ ) e entre os quais as GUVS ficavam depositadas (figura 2.12). Essa cela é conectada ao mesmo gerador de ondas que utilizamos para crescer as vesículas, enquanto irradiamos as GUVs e aplicamos o campo elétrico.

$\mathrm{Na}$ figura 2.13, está representada a cela de observação e como esta fica acoplada ao microscópio. 


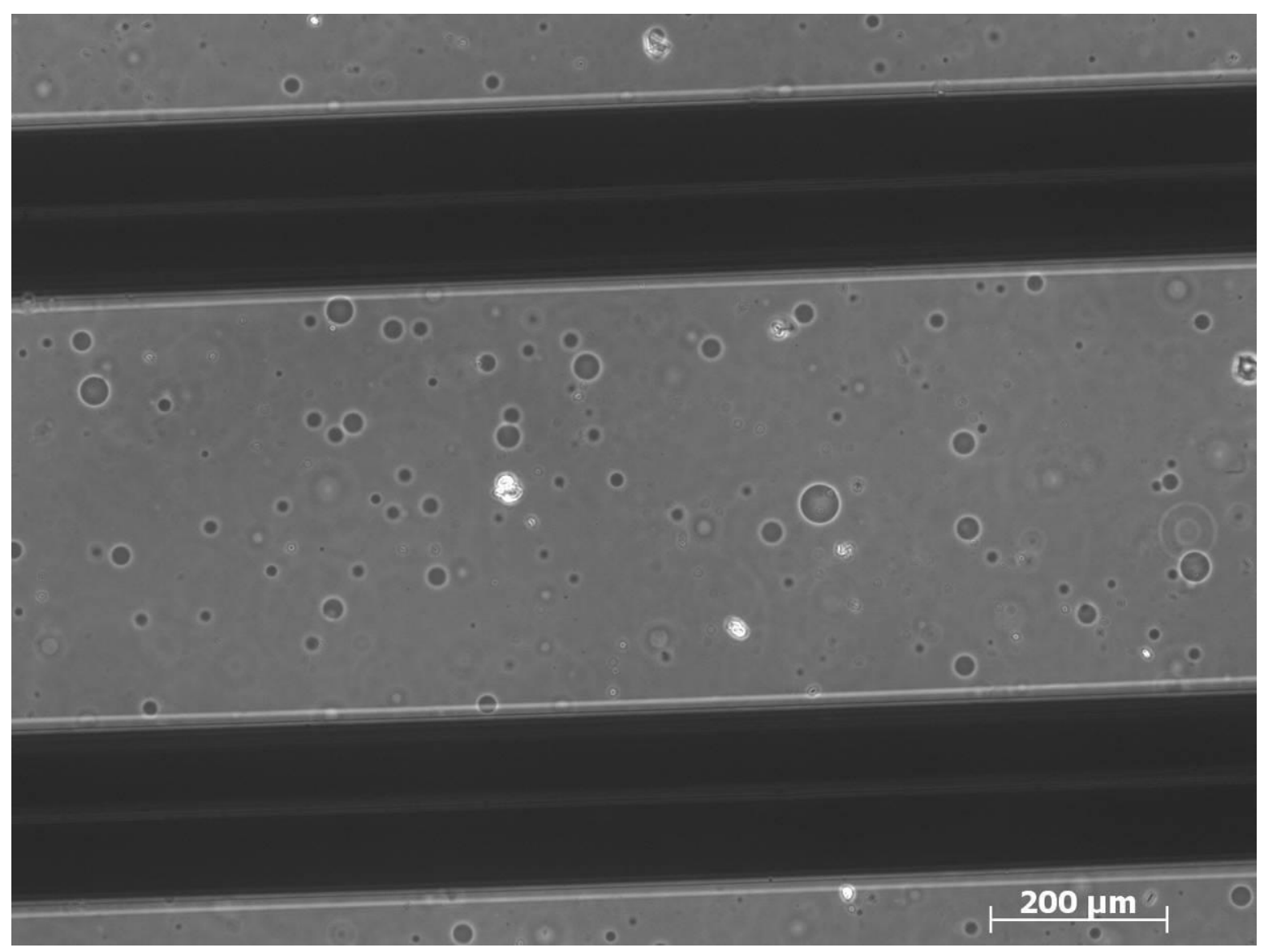

Figura 2.12: Vesículas depositadas entre os eletrodos da câmara de fusão da Eppendorf. Essa imagem foi obtida com a objetiva 10x.

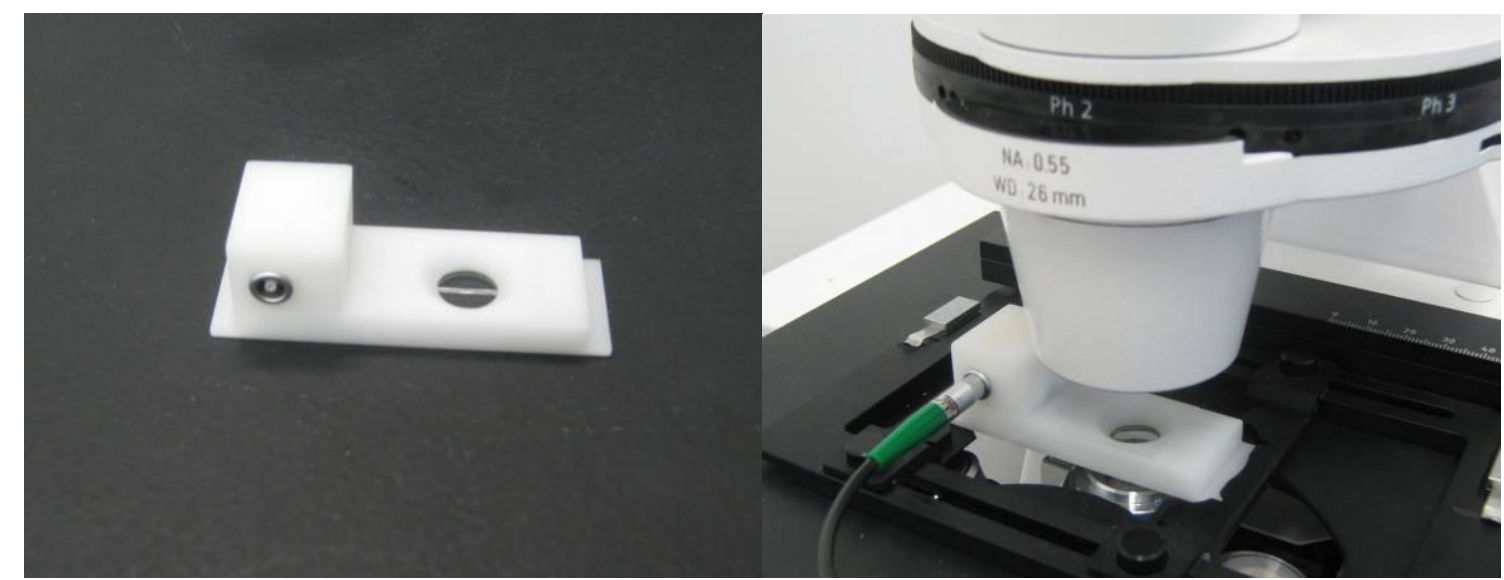

Figura 2.13: À direita a câmara de fusão utilizada para aplicar o campo elétrico nas vesículas e à esquerda a imagem de como essa câmara é acoplada ao microscópio.

Como apresentado no capítulo 1, para se conseguir objetos prolatos deve-se utilizar uma frequência de aproximadamente $1 \mathrm{MHz}$ e a condutividade interna da vesícula 
deve ser maior que a externa. Para garantir que isso ocorra, adiciona-se 0,5mM de $\mathrm{NaCl}$ na solução de sacarose, que fica encapsulada no interior da vesícula. Esse protocolo foi previamente estabelecido no trabalho [20], que foi apresentado no capítulo 1 e também se encontra no Anexo 1.

É importante ressaltar aqui que foi utilizada onda senoidal com alta frequência, com o campo elétrico em amplitude máxima do gerador (da ordem de 8V). Para frequências baixas ( $\mathrm{da}$ ordem de $\mathrm{kHz}$ ), as vesículas se moviam muito na cela de observação na presença do campo elétrico, dificultando a obtenção da imagem para posterior medida das dimensões da área da membrana. 


\section{Capítulo 3: Estudo do sistema POPC:CL na ausência da molécula fotoativa: Resultados e Discussão}

Primeiramente foram feitos alguns experimentos com as GUVs na ausência da molécula fotoativa, para podermos observar como a presença da CL influenciava na formação e morfologia da membrana. As proporções de lipídeo utilizadas foram POPC:CL (100:0); (80:20) ; (50:50) ; (20:80); (10:90) e (0:100), como está apresentado no diagrama de fases ternário da figura 2.5 do capítulo 2 .

Além de investigar as composições lipídicas da membrana, investigaram-se também como as condições da técnica de eletroformação influenciavam no crescimento das GUVs. Assim, para avaliar tais efeitos variaram-se algumas condições de crescimento.

Como comentado no capítulo 2, o tempo de crescimento pode influenciar na formação das vesículas compostas por CL. Dessa forma, cresceu-se GUVs com dois tempos de crescimento, 30 minutos e 1 hora.

Além disso, estudaram-se também membranas compostas somente por $\mathrm{CL}$, como será visto ao final deste capítulo. Tal estudo foi feito nas mesmas condições do parágrafo anterior, mas além de variar os tempos de crescimentos variou-se também a frequência de crescimento. As frequências utilizadas foram a habitual de $10 \mathrm{~Hz}$ e a frequência de $500 \mathrm{~Hz}$ como em [38]. Nesse trabalho, os autores utilizam um novo protocolo para a técnica de eletroformação, de forma a poderem crescer GUVs sob condições fisiológicas com alta força iônica. Assim, os íons oscilam rapidamente e não prejudicam a formação das GUVs.

Outro efeito observado nesse estudo com as vesículas compostas por CL foi a formação de algumas regiões com domínios visíveis na superfície das GUVs para determinadas concentrações desse lipídeo, como será mais bem discutido adiante neste capítulo. De acordo com a estrutura da CL (fig. 1.5 do capítulo 1), a mesma possui dois grupos fosfato oferecendo duas cargas negativas por CL na superfície da membrana. Para investigar se o aparecimento destes domínios é relacionado à presença de íons em 
solução aquosa, mesmo em concentrações pequenas, ou à segregação de lipídeos, estudou-se o crescimento das GUVs na ausência e presença do EDTA. É bem conhecido que o EDTA age como quelante, formando complexos muito estáveis com diversos íons metálicos presentes em solução [32, 39, 40].

- GUVs POPC:CL (100:0) em solução aquosa contendo sacarose e glicose, tempo de crescimento 2 horas

O primeiro passo foi investigar a formação de vesículas compostas somente por POPC. Como pode ser visto na figura 3.1, observamos GUVs com morfologia esférica, sem a presença de domínios, deformações ou flutuações significativas.

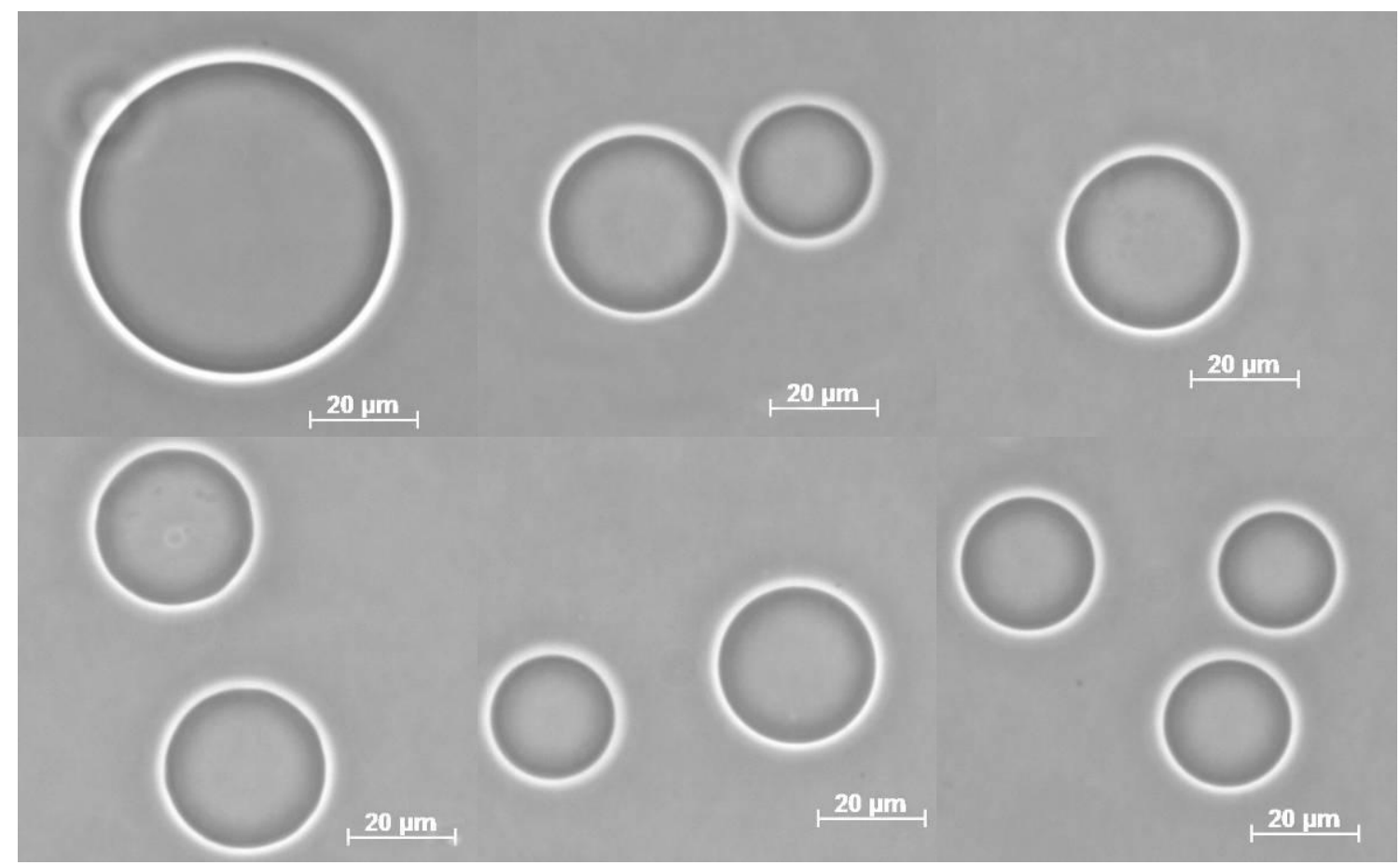

Figura 3.1: GUVs de POPC:CL (100:0) crescidas por 2 horas por eletroformação. Imagens obtidas por modo de contraste de fase, objetiva de 63x. 
- GUVs POPC:CL (80:20) em solução aquosa contendo sacarose e glicose, tempo de crescimento 1 hora

Para as GUVs contendo $20 \mathrm{~mol} \%$ de CL e com as condições de crescimento descritas acima, podemos observar pela figura 3.2 que estas apresentam morfologia normal, similares às GUVs formadas somente por POPC. Note que as GUVs parecem ter distribuição homogênea de lipídeos.

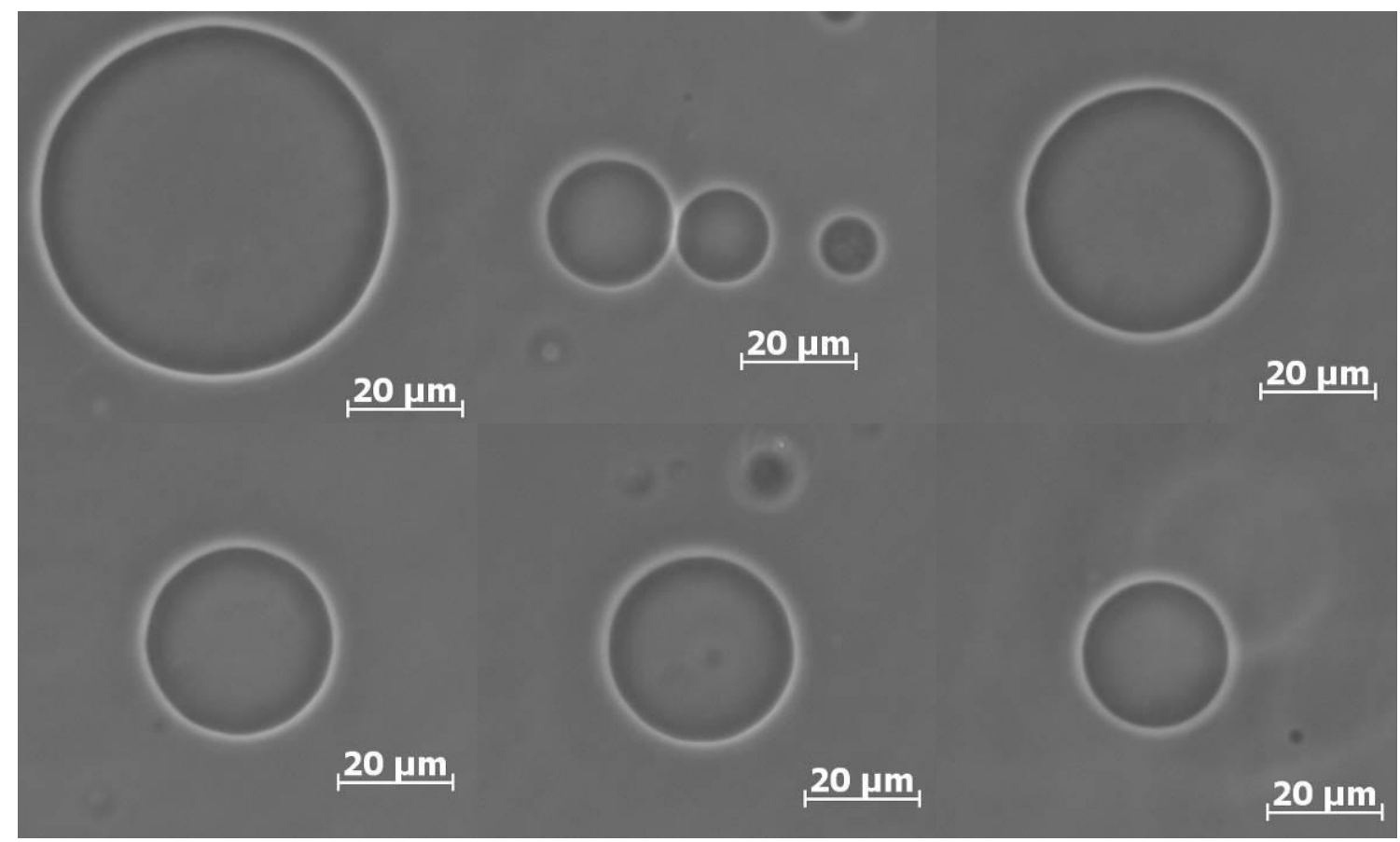

Figura 3.2: GUVs de POPC:CL (80:20) crescidas por 1 hora por eletroformação. Imagens obtidas por modo de contraste de fase, objetiva de $63 x$.

- GUVs de POPC:CL (50:50) em solução aquosa contendo sacarose e glicose, tempo de crescimento 1 hora

Após crescer GUVs de POPC:CL (80:20), aumentamos a concentração de CL para $50 \mathrm{~mol} \%$ de $\mathrm{CL}$ por um tempo de crescimento de 1 hora. Como é possível observar pela figura 3.3 algumas GUVs apresentaram morfologia normal (C e F) e algumas GUVs 
apresentaram domínios (pontos pretos/brilhantes - A, B e D). Observaram-se também algumas vesículas pequenas para essa composição de membrana.

Assim, com este resultado é possível perceber que para membranas contendo 50mol\% de CL em 50mol\% de POPC começa a ficar visível a presença de alguns domínios na membrana. Para investigar se a formação destes domínios poderia ser atribuída à complexação de íons da solução com grupos fosfato da $\mathrm{CL}$, as GUVs foram crescidas em solução contendo EDTA, conforme descrito a seguir.

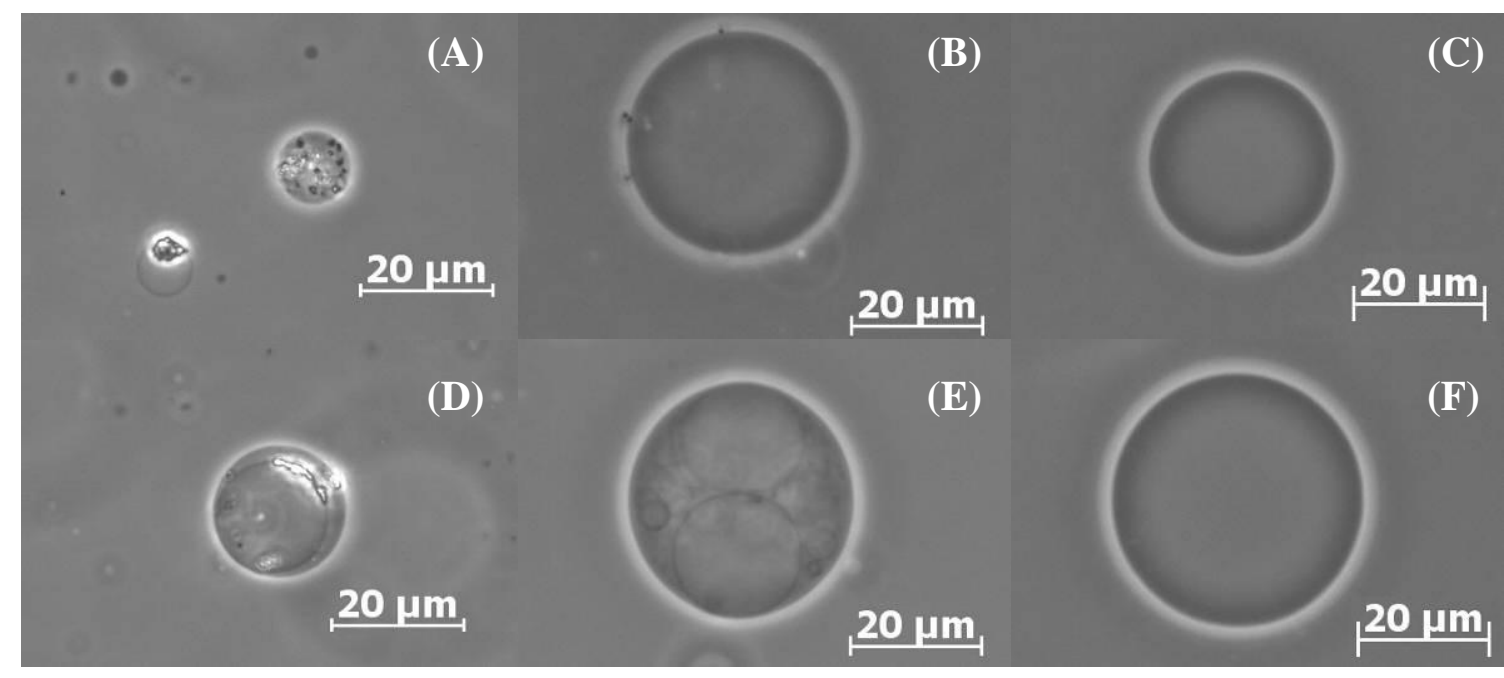

Figura 3.3: GUVs de POPC:CL (50:50) crescidas por 1 hora por eletroformação. Imagens obtidas por modo de contraste de fase, objetiva de 63x. Nestas imagens temos GUVs normais (C e F), GUVs com domínios brilhantes/pretos (A, B e D) e uma GUV normal, mas com várias vesículas internas (E).

- GUVs de POPC:CL (50:50) em solução aquosa contendo sacarose e glicose com adição de 0,1mM EDTA, tempo de crescimento 1 hora

Dados anteriores da literatura mostraram que impurezas constituídas por íons divalentes (em concentrações diminutas da ordem de ppm) presentes em solução aquosa interagem com lipídeos negativamente carregados em condições de baixa concentração lipídica. A concentração lipídica de dispersões de GUVs obtidas por eletroformação é em geral da ordem de 1-10 $\mu \mathrm{M}$, portanto baixas o suficiente para serem sensíveis a pequenas quantidades de íons divalentes presentes em solução [39]. 
Além disso, um trabalho anterior relata que a presença de impurezas em vesículas compostas por POPC e POPG (POPG, um lipídeo carregado) pode deixar a membrana mais frágil para que sejam feitos poros, através da técnica de eletroporação, na qual são aplicados pulsos elétricos na membrana [40].

Mais recentemente, foi demonstrado que a adição de sal aumenta a estabilidade de domínios em GUVs compostas por DOPG:eSM:Col (DOPG, um lipídeo carregado negativamente; eSM - esfingomielina de ovo), enquanto o EDTA tem efeito oposto [32]. Ainda segundo este trabalho, no qual o sal $\mathrm{CaCl}_{2}$ foi adicionado ao meio externo das GUVs, percebeu-se que íons cálcio têm efeito estabilizante de domínios.

Essa estabilidade de domínios foi caracterizada pela temperatura na qual ocorre a miscibilidade destes domínios, ou seja, a temperatura na qual os domínios se misturam ou de um outro ponto de vista desaparecem, visualmente por microscópio óptica. Assim, em [32] adicionou-se 0,1mM de EDTA na solução de GUVs e percebeu-se que a temperatura de miscibilidade diminui em torno de $6^{\circ} \mathrm{C}$. Já no caso onde se adiciona $0,5 \mathrm{mM}$ de $\mathrm{CaCl}_{2}$ a temperatura aumenta em torno de $5^{\circ} \mathrm{C}$ comparada com o caso onde a solução não possui nenhum aditivo. Dessa forma concluiu-se que íons divalentes presentes como impurezas na solução estabilizam domínios em vesículas carregadas, ou seja, a temperatura na qual esses domínios tendem a desaparecer aumenta.

Assim, em termos de $C L$, que é um lipídio negativamente carregado, a formação de domínios pode estar ligada de alguma forma à presença de cargas na superfície da membrana e à presença de íons na solução. Para investigar tal hipótese, estudamos a mesma composição lipídica do item anterior, mas crescemos as GUVs em solução de sacarose contendo 0,1 mM EDTA e as diluímos também em solução de glicose contendo 0,1 mM EDTA.

Notamos que as GUVs não possuem domínios (pontos pretos) na presença de EDTA, refletindo um compromisso entre quantidade de $C L$ na bicamada e o agente quelante na solução aquosa. A figura 3.4 mostra algumas imagens de GUVs compostas por POPC:CL (50:50) na presença de 0,1 mM de EDTA nas soluções interna e externa das GUVs. 


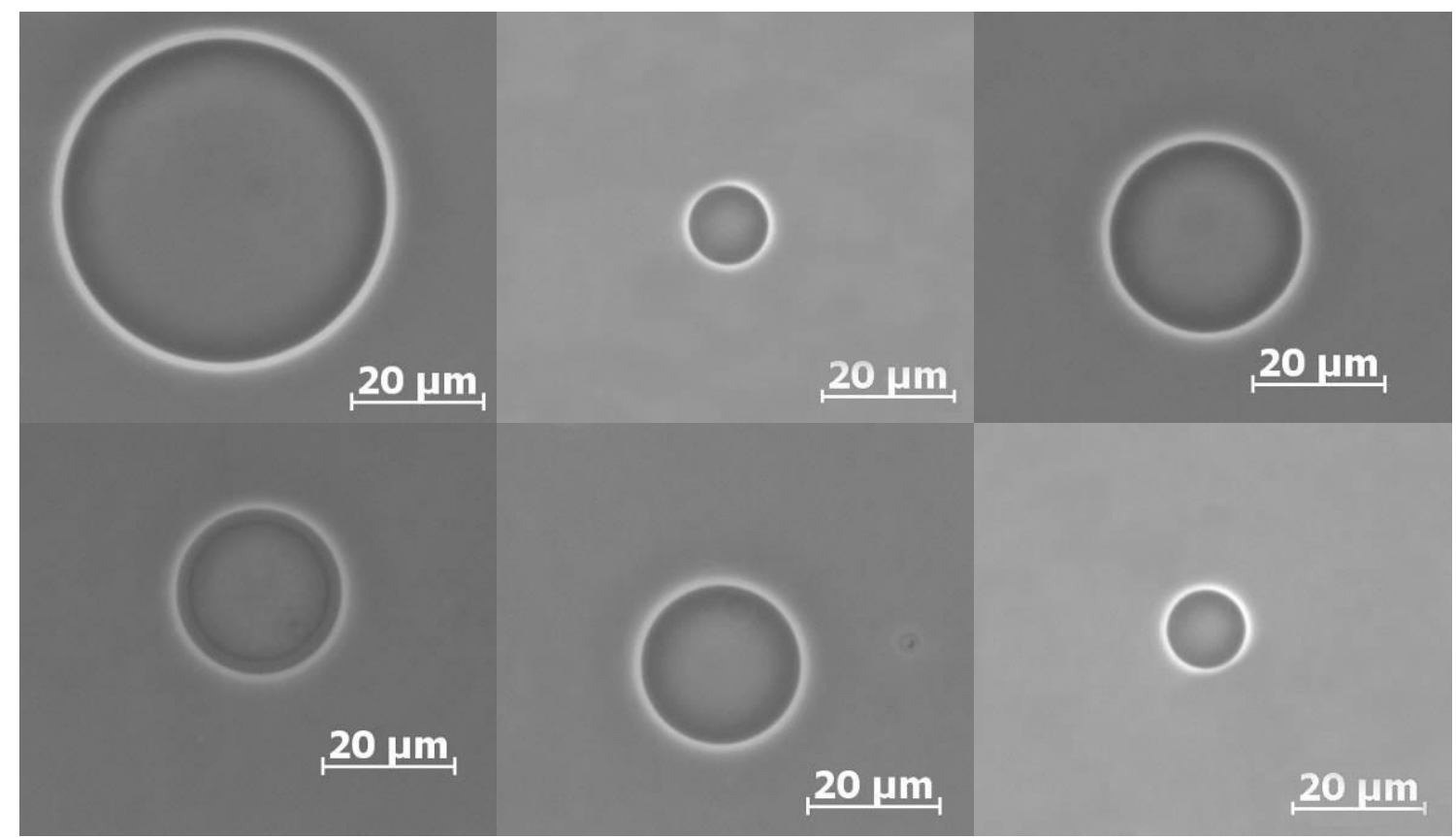

Figura 3.4: GUVs de POPC:CL (50:50) que cresceram por 1 hora por eletroformação com 0,1mM de EDTA, as imagens mostram GUVs com morfologia normal. Imagens obtidas por modo de contraste de fase, objetiva de $63 x$.

Para as GUVs crescidas em 30 minutos o efeito foi bem parecido para as crescidas em 1 hora, mas no caso das vesículas crescidas com EDTA nenhuma apresentou domínios. Assim, os resultados de GUVs em soluções na presença e ausência de EDTA mostraram que, na ausência da molécula fotossensibilizadora, as vesículas podem apresentar pequenos domínios lipídicos (macroscopicamente visíveis), muito provavelmente devido à complexação da CL com os íons divalentes presentes em solução. Tal complexação favorece a segregação de lipídeos. Este ponto será retomado no capítulo 4, na presença da molécula fotoativa.

- GUVs de POPC:CL (20:80) em solução aquosa contendo sacarose e glicose, tempo de crescimento 1 hora

Para GUVS com $80 \mathrm{~mol} \%$ de $\mathrm{CL}$ e tempo de crescimento de uma hora sem EDTA (figura 3.5), obtivemos algumas GUVs com morfologia típica (C e F), algumas com 
domínios pretos $(B, D$ e $E)$, algumas deformadas $(B, D$ e $E)$ e algumas multivesiculares $(A$, B, D e E). Muitas GUVs dessa população apresentavam dimensões pequenas, em comparação às normalmente observadas para sistemas compostos somente por POPC.

Para essa composição lipídica muitas vesículas são mal formadas. Estas aparentam segregação de lipídeos e/ou formação de muitas "pequenas" vesículas (ainda visíveis macroscopicamente) aglomeradas dentro de uma vesícula maior, gerando agregados vesiculares mal formados (figura 3.5B e 3.5E).

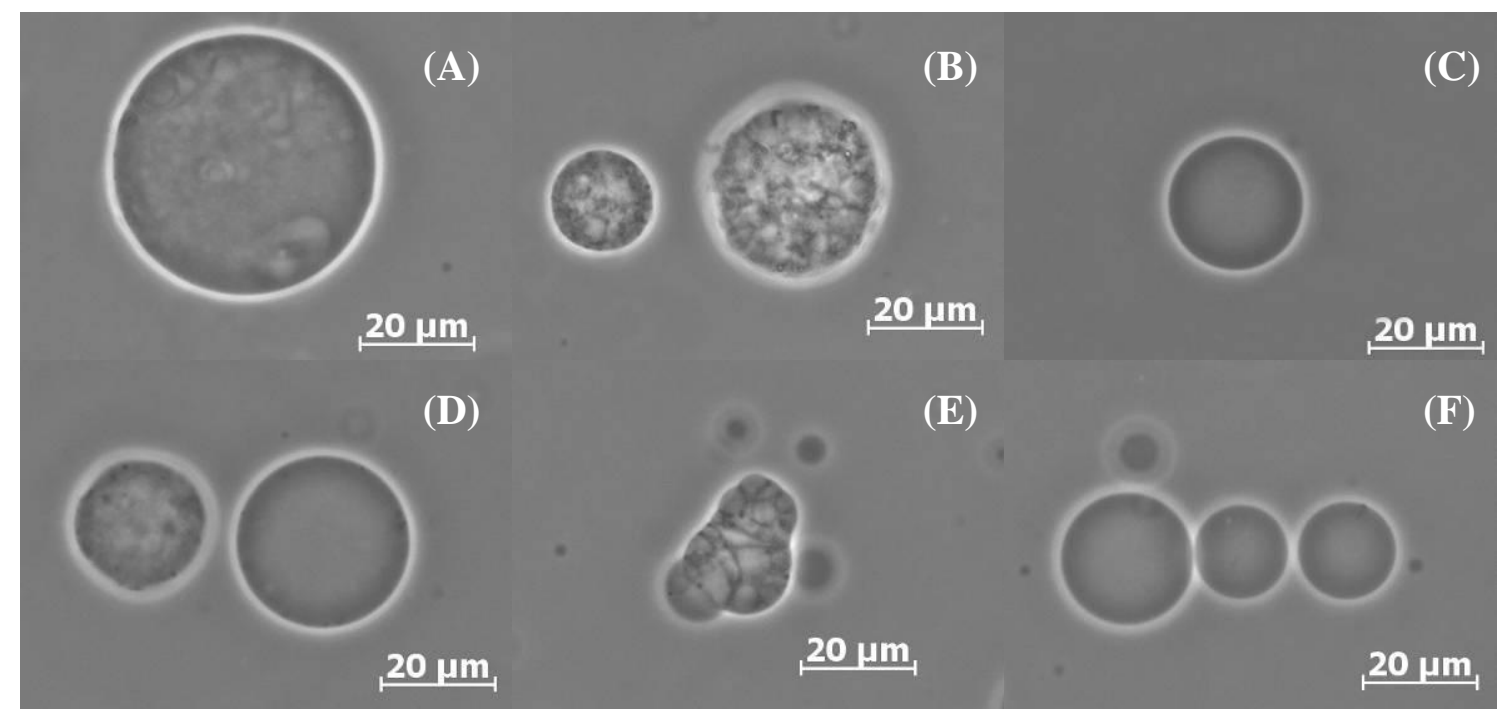

Figura 3.5: GUVs de POPC:CL (20:80) para o tempo de crescimento de uma hora por eletroformação, sem EDTA. Imagens obtidas por modo de contraste de fase, objetiva de 63x: em C e F temos GUVs normais. Em B, D e E é possível observar GUVs deformadas, que apresentam domínios pretos. Em A, B, D e E as GUVs apresentam várias vesículas internas.

A partir desse resultado é possível inferir que quanto maior a concentração de $\mathrm{CL}$ na membrana, temos uma frequência maior de GUVs mal formadas, sendo que o diâmetro da maior parte da população observada é menor em relação a GUVs compostas por POPC ou aquelas contendo pequenas concentrações de CL. Assim, é possível concluir que quanto maior a concentração de CL na bicamada lipídica mais difícil para formar as GUVs pela técnica de eletroformação. Além disso, independentemente da formação de domínios, os resultados mostraram que com o aumento de CL na composição lipídica da membrana, predominam GUVs de tamanho menor; este fato é corroborado também por 
[28]. Nesse trabalho, os autores também observaram que o tamanho das vesículas diminui na presença de $\mathrm{CL}$, em comparação com POPC puro e também que a população de GUVs compostas por CL diminui.

- GUVs de POPC:CL (20:80) em solução aquosa contendo sacarose e glicose com adição de 0,1mM EDTA, tempo de crescimento 1 hora

Para essa população de GUVs (figura 3.6), observamos que a maior parte das GUVs não apresentava domínios, mas algumas ainda apresentavam domínios pretos. Vale ressaltar que algumas GUVs que não apresentavam domínios, possuíam vesículas internas.

Observou-se também que a população de GUVs continuou sendo predominantemente de GUVs pequenas, provavelmente devido à dificuldade de se crescer GUVs com EDTA por eletroformação, por este ser um sal. Por este motivo, não se utilizou concentrações maiores de EDTA, devido à dificuldade em crescer GUVs nessa composição já com pouco sal dentro da cavidade aquosa do lipossoma.

O efeito para GUVs que cresceram por 30 minutos por eletroformação foi similar para as GUVs que cresceram por 1 hora. 


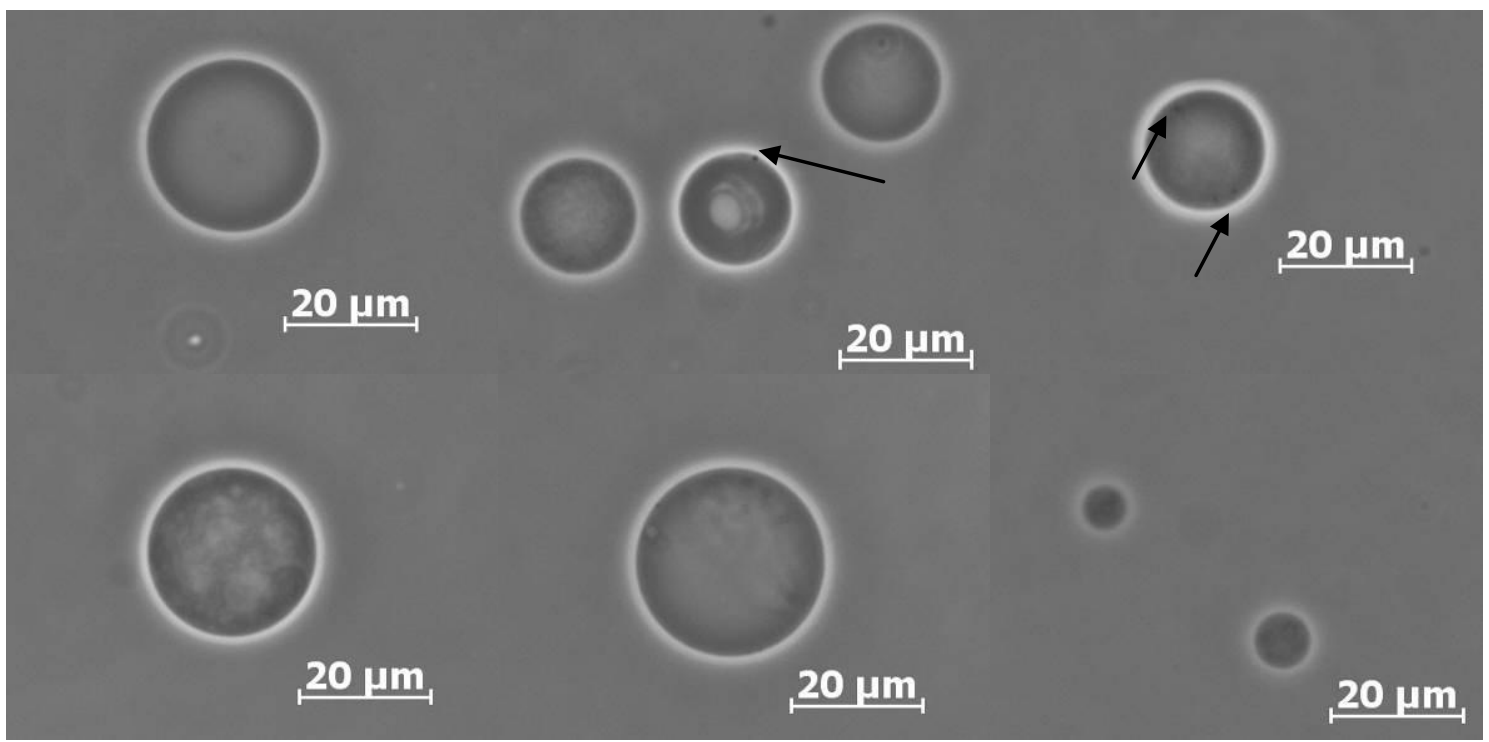

Figura 3.6: GUVs de POPC:CL (20:80) para o tempo de crescimento de uma hora por eletroformação, com EDTA na solução. Imagens obtidas por modo de contraste de fase, objetiva de 63x. Através destas imagens é possível observar que a maioria das GUVs tem morfologia normal. Na segunda, quarta e quinta imagem as GUVs possuem várias vesículas internas. As setas estão indicando GUVs que apresentam pequenos domínios.

- GUVs de POPC:CL (10:90) em solução aquosa contendo sacarose e glicose, tempo de crescimento 1 hora

Para essa configuração obteve-se algumas GUVs deformadas, com domínios brilhantes (claros) e/ou pretos (figura 3.7). As vesículas, quando não tinham os domínios, apresentavam em sua grande maioria vesículas internas e a maioria da população era de vesículas pequenas. 


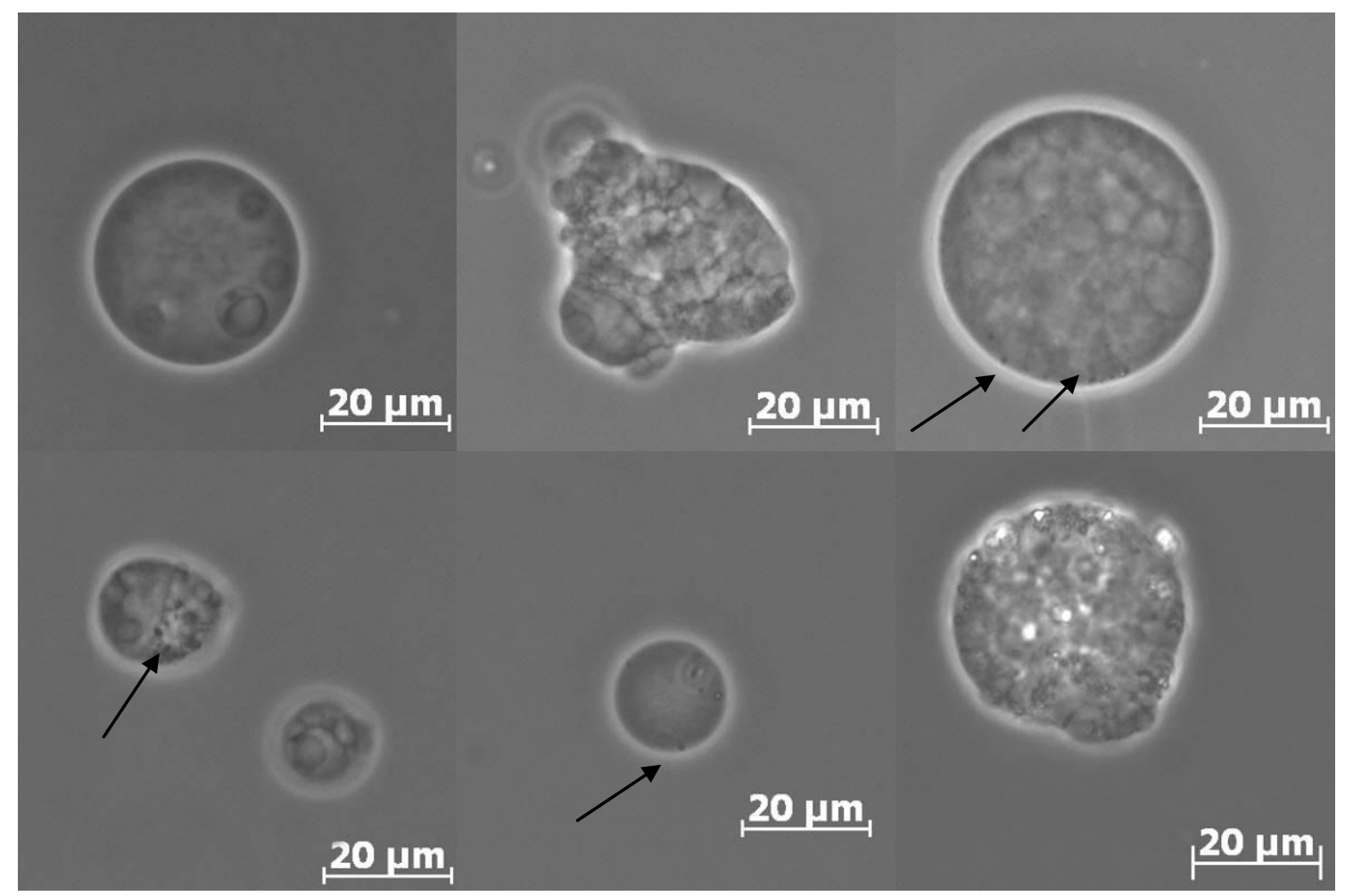

Figura 3.7: Sete vesículas de POPC:CL (10:90), com tempo de crescimento de 1 hora por eletroformação. As duas primeiras vesículas aparentemente não apresentam domínios, mas apresentam várias vesículas internas. As vesículas da terceira à quinta foto apresentam domínios pretos e algumas estão deformadas. A vesícula da última foto apresenta domínios brilhantes e está deformada. As setas estão apontando os domínios. Imagens obtidas em contraste de fase, objetiva de 63x.

- GUVs de POPC:CL (10:90) em solução aquosa contendo sacarose e glicose, tempo de crescimento 30 minutos

Ao crescer as GUVs com estes parâmetros, como podemos ver na figura 3.8, parte da população de GUVs não apresentou vesículas internas e outra parte tinha domínios pretos e/ou continham muitas vesículas internas.

A população predominante continuou sendo de vesículas pequenas. Podemos observar que para essa composição de membrana e condições de eletroformação, as vesículas eram menos deformadas, em comparação às GUVs da figura 3.7. 


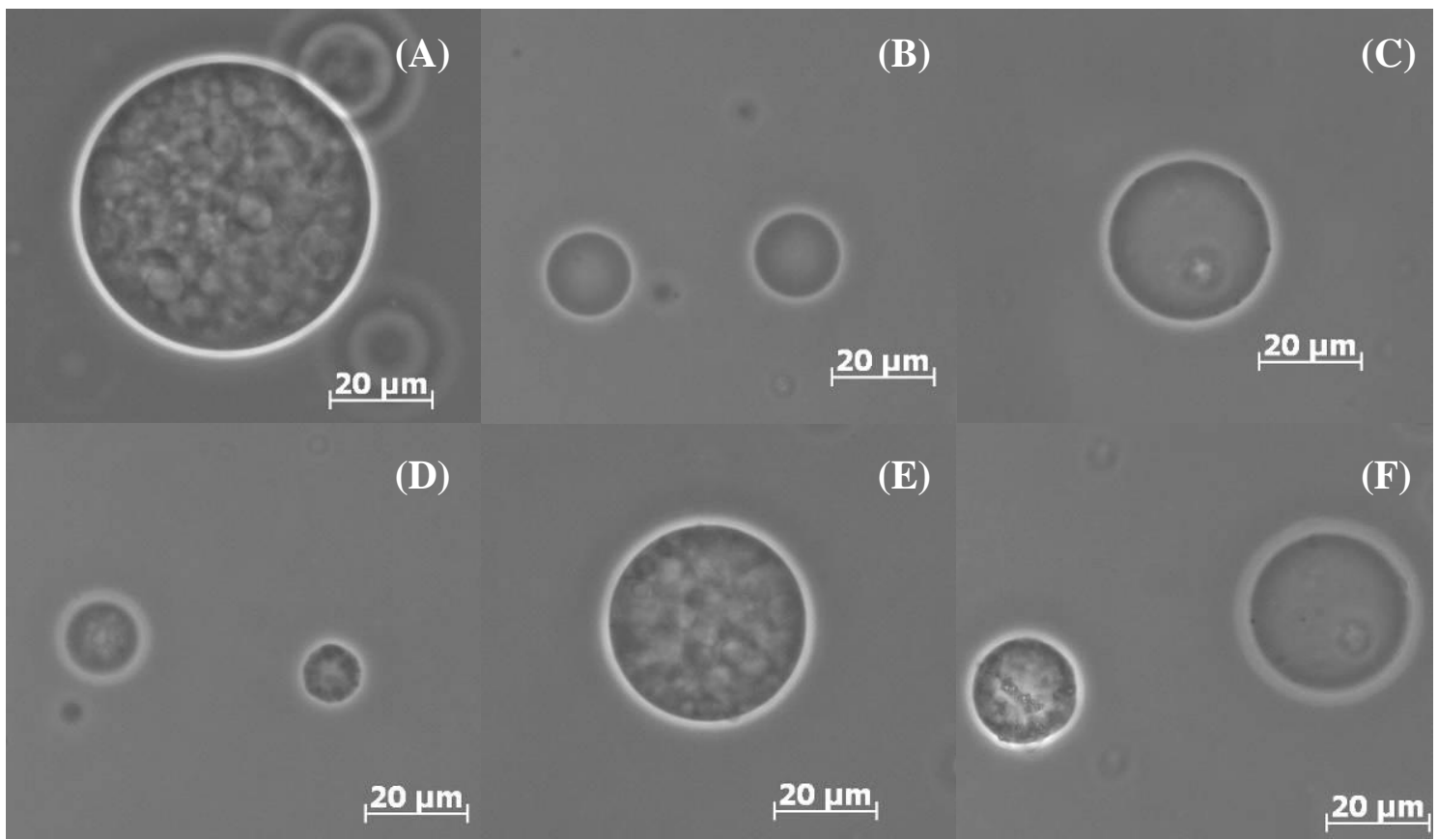

Figura 3.8: Vesículas de POPC:CL (10:90), com tempo de crescimento de 30 minutos por eletroformação. É possível observar que a maioria das vesículas são esféricas e não deformadas. As vesículas de $A$, E e $F$ apresentam muitas vesículas internas. As vesículas de B apresentam morfologia normal. Já as vesículas de $C$ apresentam domínios pretos. Imagens obtidas em contraste de fase, objetiva 63x. Uma ampliação da imagem C pode ser vista na figura 3.9.

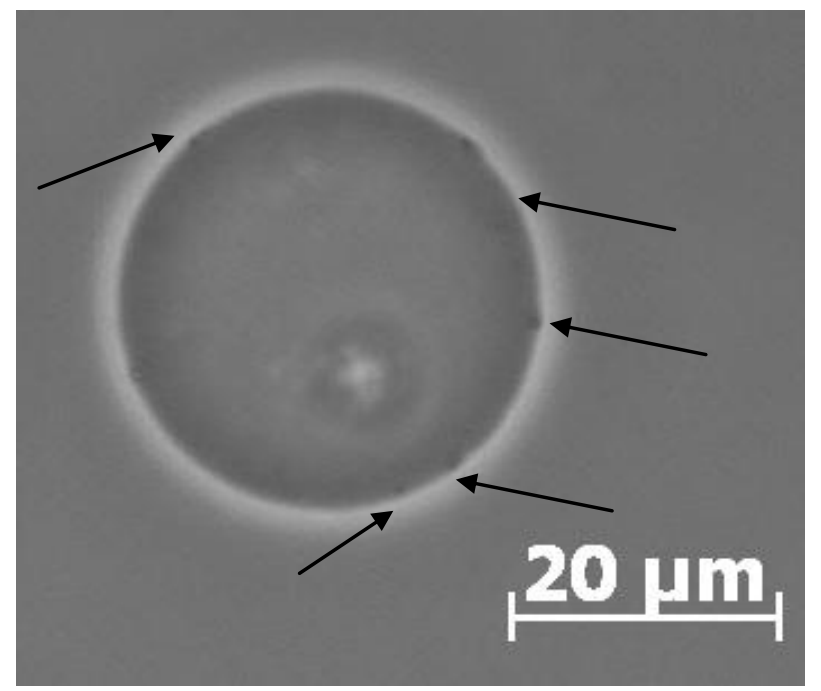

Figura 3.9: Imagem 3.8, ampliada para melhor visualização dos domínios (setas).

Portanto, parece haver um compromisso entre o tempo de crescimento e a formação de GUVs grandes e menos deformadas contendo majoritariamente $\mathrm{CL}$, pois para 
30 minutos de crescimento se formaram mais GUVs grandes do que para 1 hora de crescimento.

- GUVs de POPC:CL (0:100) em solução aquosa contendo sacarose e glicose, tempo de crescimento 1 hora e freqüência $10 \mathrm{~Hz}$

Para essas condições, a população de GUVs apresentou vesículas deformadas e pequenas; dentre estas a maioria possuía vesículas internas e domínios pretos, somente poucas GUVs não apresentavam multi-vesículas internas. Algumas imagens das GUVs nestas condições podem ser vistas da figura 3.10.

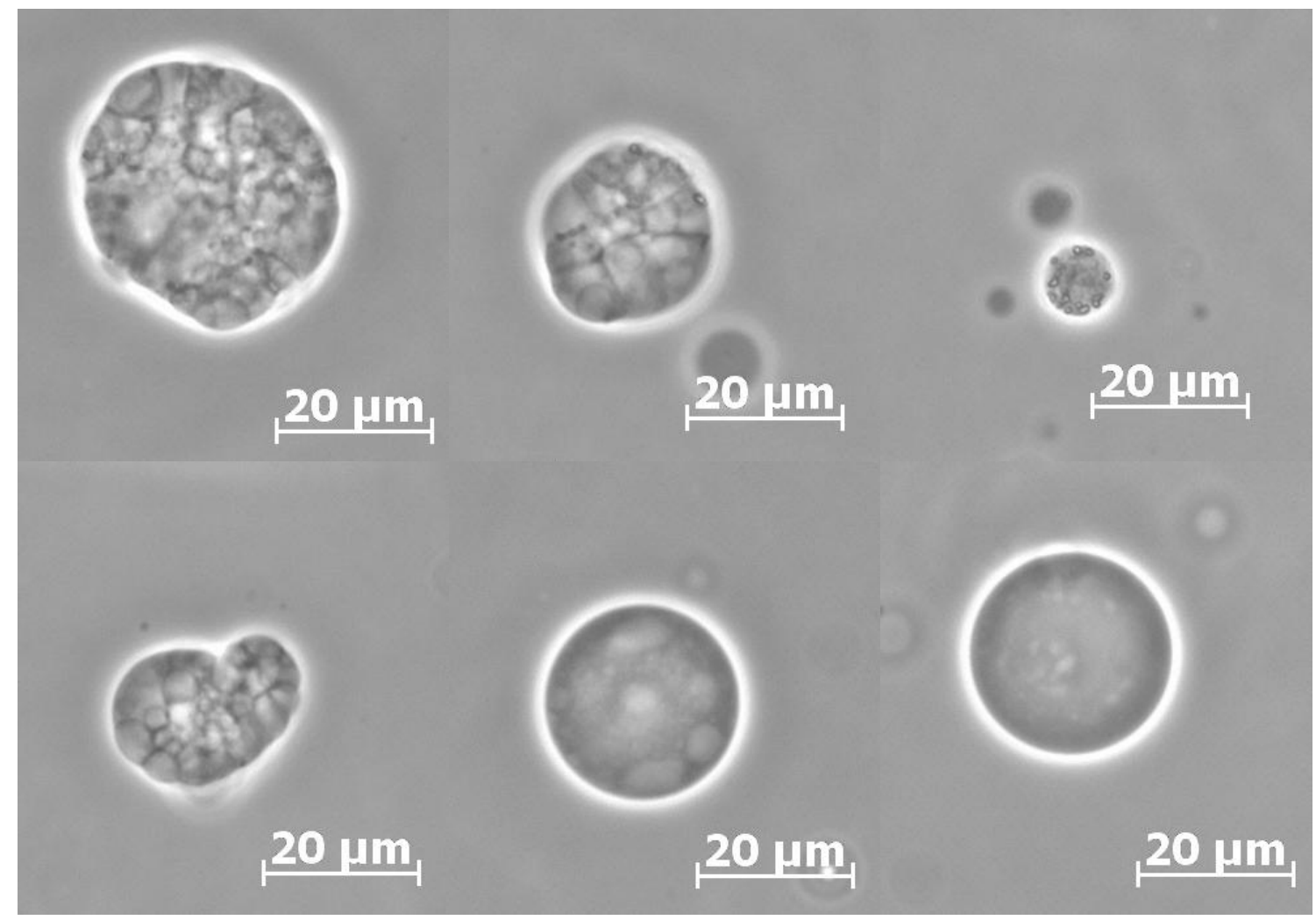

Figura 3.10: GUVs de POPC:CL (0:100) crescidas na presença de um campo elétrico senoidal com freqüência de $10 \mathrm{~Hz}$, no tempo de crescimento de 1 hora. Imagens obtidas em contraste de fase, objetiva 63x. Nas quatro primeiras imagens, as GUVs são deformadas e apresentam várias vesículas internas, bem como domínios pretos. Já nas duas ultimas imagens encontramos vesículas esféricas, mas que apresentam várias vesículas internas. 
Ainda com a frequência de $10 \mathrm{~Hz}$, estudamos as GUVs na presença e ausência de EDTA, para 1 hora e 30 minutos de crescimento e estas apresentaram efeitos similares aos das GUVs da figura 3.10.

Para a frequência de $500 \mathrm{~Hz}$, todas as configurações (tempo de crescimento: 1 hora com EDTA, 1 hora sem EDTA, 30 minutos com EDTA e 30 minutos sem EDTA) apresentaram as mesmas características, citadas anteriormente, vesículas pequenas e com domínios pretos. Mas, diferentemente das configurações com $10 \mathrm{~Hz}$, não foram observadas GUVs deformadas e nem tantas com vesículas internas. Assim, existe também um compromisso entre a frequência e uma melhor formação de vesículas para 100mol\% de $C L$.

Para a frequência de $500 \mathrm{~Hz}$, na qual conseguimos formar vesículas um pouco melhores do que com 10Hz, estudamos ainda POPC: $\mathrm{CL}(0: 100)$ acrescidas de $1 \mathrm{~mol} \%$ de DilC $_{18}$, marcador fluorescente. A estrutura química desse marcador se encontra na figura 2.4 do capitulo 2 .

Foi possível observar nos experimentos com o marcador fluorescente, que para GUVs com muitas vesículas internas, havia uma grande emissão de fluorescência de todas as partes das vesículas.

Entretanto, conforme a fluorescência ia diminuindo de intensidade, apenas os domínios (visualizados como pretos inicialmente por contraste de fase), se destacavam. Este experimento está apresentado na imagem 3.11.

Para as GUVs não vesiculadas, o fluoróforo só marcava os pontos pretos e a membrana da vesícula (figura 3.12). 


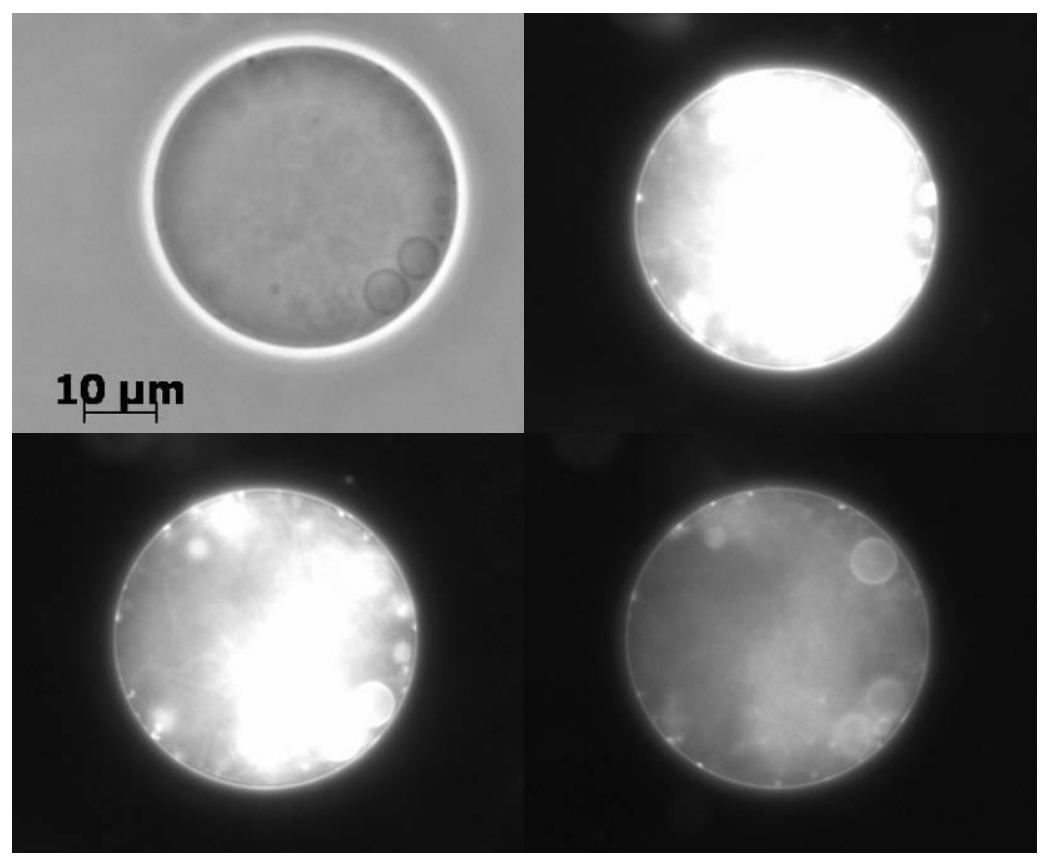

Figura 3.11: GUV de POPC:CL (0:100) + 1mol\% DilC ${ }_{18}$. A primeira observada em contraste de fase e as outras em modo de fluorescência, objetiva 63x. É possível observar um decréscimo de fluorescência na vesícula com o passar do tempo.

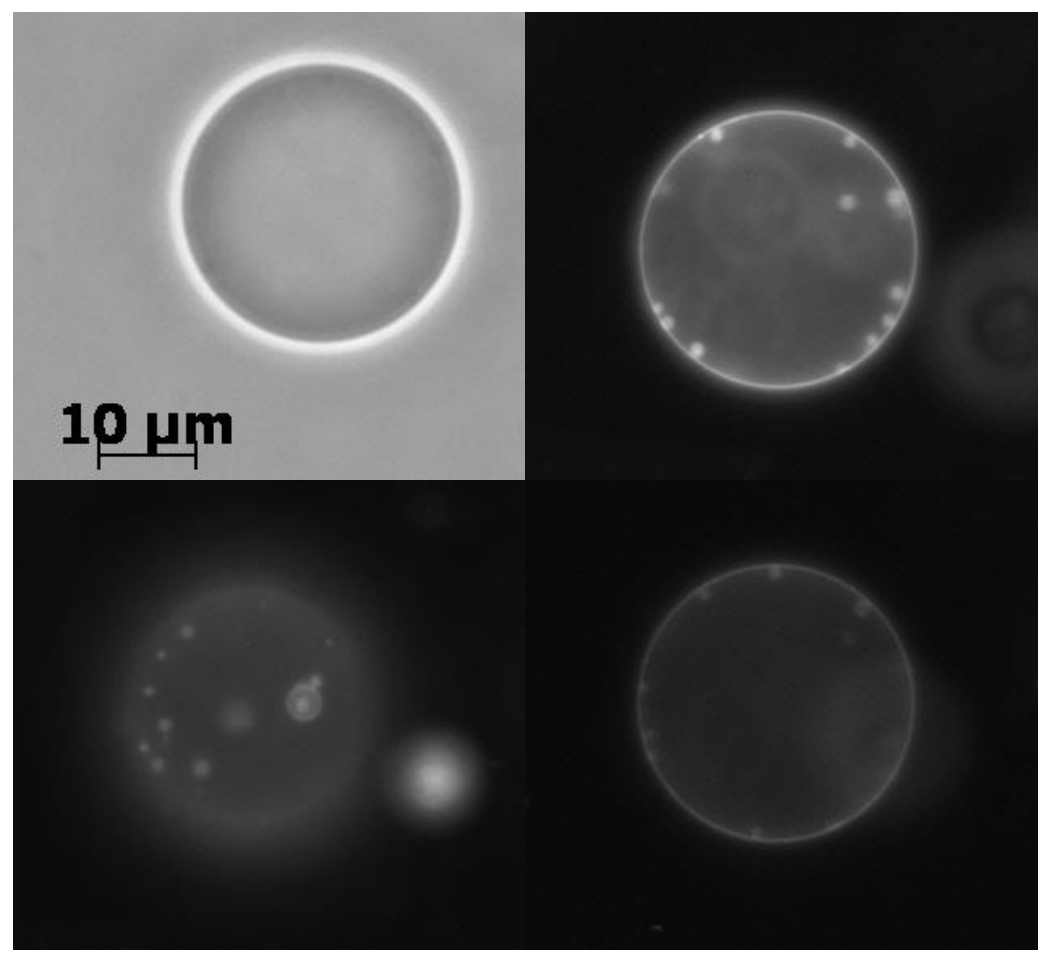

Figura 3.12: GUV de POPC: $\mathrm{CL}(0: 100)+1 \mathrm{~mol}^{2}$ Dil $_{18}$. A primeira imagem foi observada em contraste de fase e as outras em modo de fluorescência, objetiva 63x. 
Comparando os resultados obtidos para GUVs de POPC:CL (0: 100) e (10:90) com GUVs de (20:80) é possível perceber que quanto mais CL na membrana, mais difícil crescer GUVs com morfologia normal. Conforme diminuímos a concentração de $\mathrm{CL}$, crescem menos GUVs deformadas.

A realização deste trabalho foi muito importante para definirem-se as condições para se estudar o efeito da composição lipídica de membranas contendo cardiolipina. 0 efeito da adição de EDTA é crucial na eletroformação. O efeito da presença de cálcio na solução contendo as GUVs com alto teor de cardiolipina será visto no capítulo 4. Estabeleceu-se assim que a concentração limite na qual se investigaria os efeitos de fotossensibilização com GUVs contendo CL seria a concentração de 50 mol\% de CL. Acima desta composição, a concentração usada de EDTA não consegue reduzir satisfatoriamente o efeito da carga superficial da membrana, e também não é possível aumentar mais a concentração de EDTA dado que este prejudica a formação das GUVs por eletroformação por ser um sal. Estabeleceu-se também que se continuaria trabalhando com $10 \mathrm{~Hz}$ de frequência para as GUVs com 50 mol\% de CL, pois para esta concentração as vesículas se formavam bem: vesículas unilamelares com distribuição homogênea de lipídeos. 


\section{Capítulo 4: Foto-resposta de GUVs contendo a molécula fotoativa diC $_{12}$-porf: Análise Inicial e Discussão}

\subsection{GUVs de POPC e POPC + 1 mol\% dic 12 -porf}

Nessa seção, será apresentado o resultado de um experimento, onde foram preparadas separadamente dois tipos de GUVs: vesículas compostas somente por POPC, e vesículas compostas por POPC na presença de $1 \mathrm{~mol} \%$ da molécula fotoativa. Ambas amostras continham 0,5mM NaCl em sua solução interna. Este experimento foi utilizado para comprovarmos que somente GUVs contendo diC $_{12}$-porf exibiam aumento de área sob irradiação.

Para tanto misturou-se as duas amostras em um mesmo eppendorf e colocou-se a mistura na câmara de fusão, com a qual é possível aplicar um campo elétrico AC nas vesículas (como descrito no capítulo 2). Simultaneamente à aplicação do campo elétrico,

irradiamos as GUVs com $\lambda=400 \mathrm{~nm}$ e as observamos no microscópio pelos modos de contraste de fase e fluorescência, utilizando a própria fluorescência da diC $\mathrm{C}_{12}$-porf.

Como é possível observar nas imagens da figura 4.1, somente as GUVs que contém a molécula fotoativa aparecem nas imagens de fluorescência e, ao mesmo tempo que as irradiamos, é possível observar que somente estas se alongam na direção do campo elétrico. Portanto, este experimento demonstra que somente as GUVs que contém a molécula fotoativa respondem à luz, ou seja, aumentam de área alongando na direção do campo elétrico análogo ao observado no trabalho anterior [20]; enquanto que as GUVs que contém somente POPC permanecem inalteradas. 


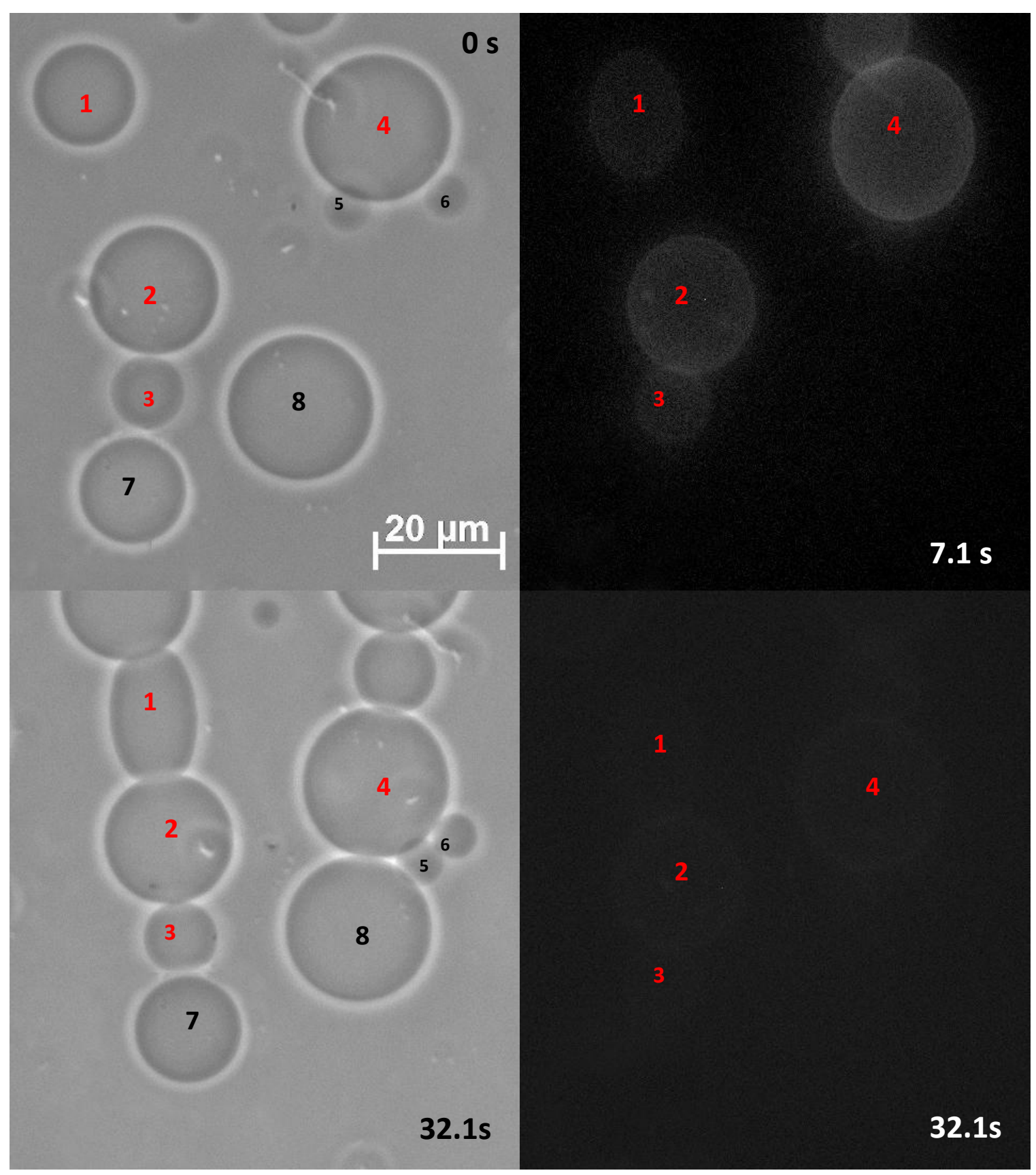

Figura 4.1: Na primeira imagem os números em preto mostram as GUVs que não tem fluorescência, ou seja, são compostas somente de POPC e os números em vermelho estão mostrando as GUVs que possuem molécula fotoativa e alongam com a irradiação na presença do campo elétrico. As imagens do lado esquerdo foram obtidas no modo contraste de fase e as imagens do lado direito foram obtidas no modo de fluorescência. Foram numeradas todas as GUVs para que o leitor possa acompanhar a evolução das GUVs com o tempo. A partir dessa imagem vemos que após aproximadamente 30s as vesículas já sofreram fotoclareamento. Estas imagens foram obtidas com a objetiva 40x. 
Além disso, nesse mesmo experimento foi possível observar que a molécula fotoativa sofre fotoclareamento com o tempo, de maneira análoga ao que ocorreu com a outra molécula, PE-porf, investigada em [20]. Podemos relacionar o fotoclareamento com a perda de capacidade da molécula fotoativa (à base de porfirina) em produzir oxigênio singlete. Tal fato pode ser observado através das imagens apresentadas na figura 4.1, onde é possível perceber um fotoclareamento rápido, sendo que a fluorescência é quase inexistente após cerca de 30 s de irradiação da diC ${ }_{12}$-porf.

\subsection{Influência da intensidade de luz nos experimentos de irradiação com} GUVs compostas de POPC + diC $_{12}$-porf

Como observamos na seção anterior 4.1 , as vesículas contendo diC $_{12}$-porf sofrem um aumento de área após serem irradiadas, como já havíamos observado com outra molécula fotoativa em [20]. Assim, de forma a verificar qual seria a melhor condição para quantificar tal aumento de área, estudamos a influência da intensidade de luz enquanto aplicávamos o campo elétrico. A lâmpada de mercúrio acoplada ao microscópio possui 4 filtros para intensidade total de luz de irradiação: 12,5\%, 25\%, 50\% e 100\%.

A figura 4.2 apresenta os dados do aumento de área em relação à área inicial em função do tempo, para GUVs compostas por POPC sob irradiação e na presença do campo elétrico, para os diferentes filtros de intensidade de luz e concentração fixa da molécula fotoativa de $1 \mathrm{~mol} \%$. Experimentos deste mesmo tipo foram descritos nos capítulos 1 e 2 . 


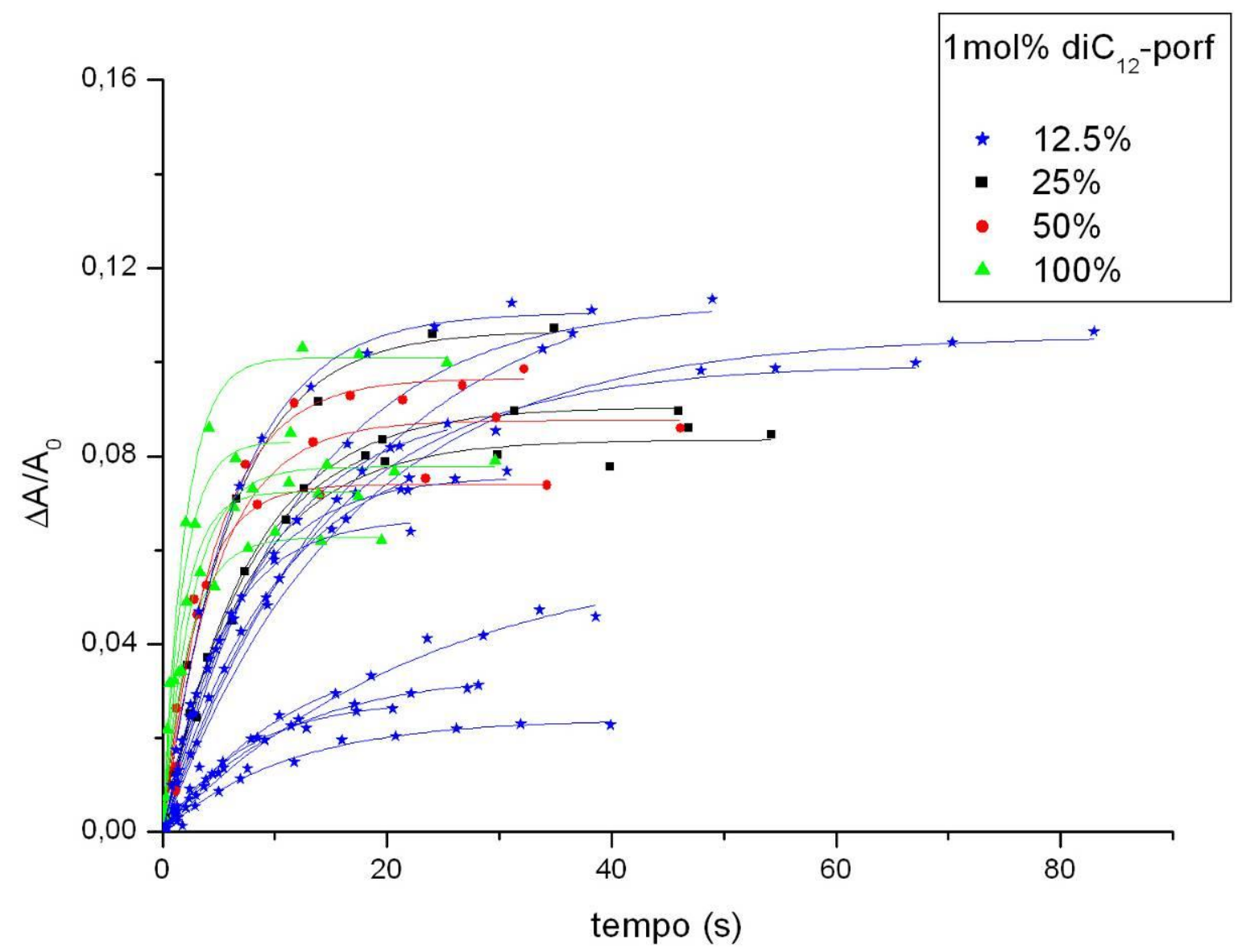

Figura 4.2: Gráfico do aumento de área de GUVs compostas por POPC sob irradiação em função do tempo na presença do campo elétrico, para a concentração da molécula fotoativa de $1 \mathrm{~mol} \%$ de $\mathrm{diC}_{12}$-porf e os diferentes filtros de intensidade de luz disponíveis. $\Delta \mathrm{A} / \mathrm{A}_{0}$ representa o aumento de área em relação a área inicial $A_{0}$ antes da irradiação. Cada ponto deste gráfico foi calculado através da equação 1 , da área reduzida de um prolato, que se encontra no capítulo 1. As linhas sólidas correspondem ao melhor ajuste aos dados experimentais utilizando a equação 2 do Capítulo 1.

Conforme podemos observar para a intensidade de luz de $12,5 \%$ da luz total, temos duas populações de GUVs que se comportam de maneira um pouco diferente. Embora ambas apresentem aumento de área, uma das populações expende mais tempo

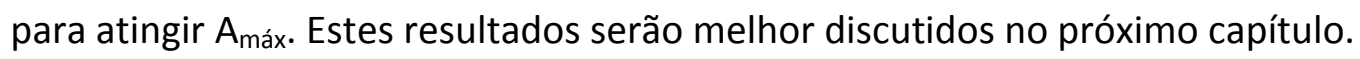

Além disso, a partir da figura 4.2 é possível observar que ao aumentarmos a intensidade de luz, o aumento de área ocorre num intervalo de tempo menor. Assim, para analisarmos de maneira quantitativa tal comportamento, de maneira similar a [20], ajustamos a equação 2 aos dados experimentais, resultando nos parâmetros $\Delta A_{\text {máx }} / A_{0}$ e $\tau$. 
A variação destes parâmetros em função da intensidade de luz se encontra nos gráficos das figuras 4.3 e 4.4 .

Através do gráfico da figura 4.3, observarmos que os aumentos de área máximos para todas as intensidades são praticamente constantes independendo da intensidade de luz utilizada. Já da figura 4.4 podemos ver que com o aumento da intensidade de luz ocorre um decréscimo do $\tau$, parâmetro intrinsecamente correlacionado com o tempo de fotoclareamento da molécula fotoativa, como visto em [20]. Assim, podemos concluir dos gráficos da figuras 4.3 e 4.4 que o aumento de área máximo independe do aumento da intensidade de luz, mas o $\tau$ é muito dependente.

Desta forma, pudemos concluir que o fotoclareamento da molécula acontece tão mais rápido quanto maior a intensidade de luz utilizada, o que era esperado pois aumenta a taxa de produção de ${ }^{1} \mathrm{O}_{2}$ com o tempo [20]. Por tal motivo, devido à rápida saturação para as intensidades de luz maiores escolhemos trabalhar com a menor intensidade de luz possível $(12,5 \%)$ para que pudéssemos estudar melhor o efeito do aumento de área num intervalo de tempo mensurável, como será visto no capítulo 5.

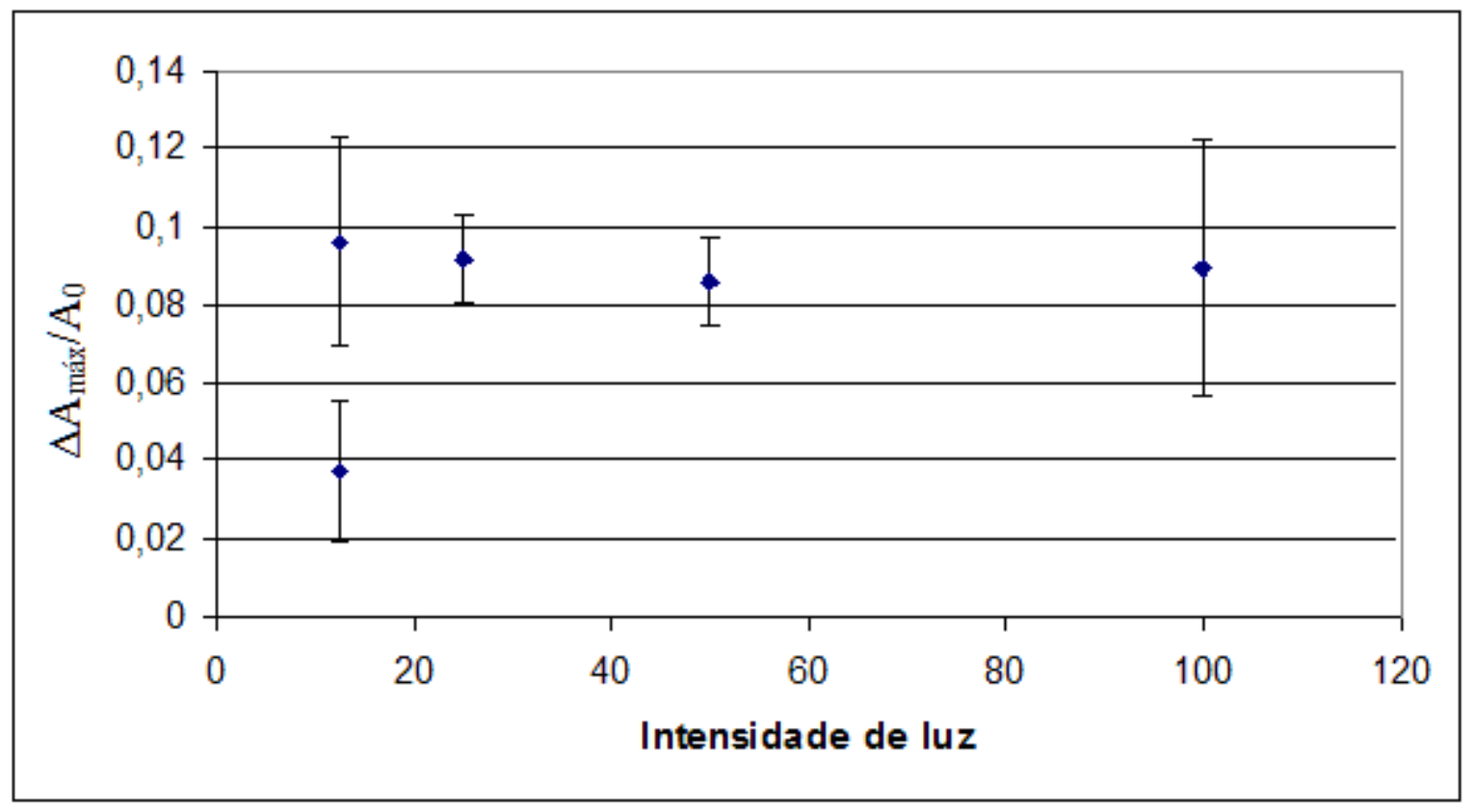

Figura 4.3: Média do parâmetro aumento de área máximo (obtido após o ajuste da equação 2) em função da intensidade de luz, para os dados de concentração de 1 mol\% de diC 12 -porf em GUVs de POPC. 


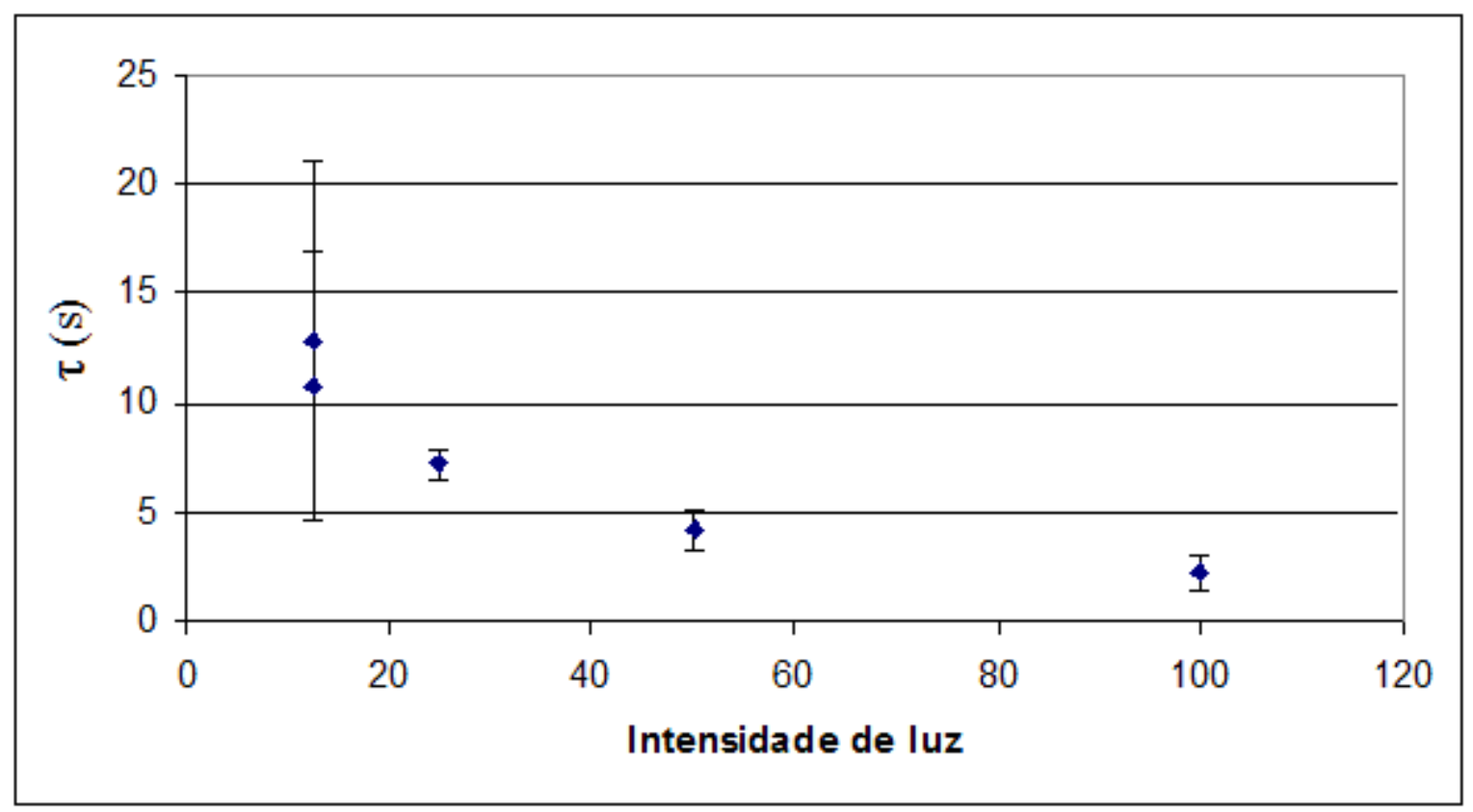

Figura 4.4: Média do parâmetro $\tau$ (obtido após o ajuste da equação 2) em função da intensidade de luz, para os dados de concentração de 1 mol\% de diC 12 -porf em GUVs de POPC.

\subsection{Estudos qualitativos das modificações morfológicas induzidas na membrana por foto-oxidação dos lipídeos}

Após estudar-se GUVs de várias composições de POPC:CL como descritos na seção 3.1, o próximo passo foi estudar as GUVs com a molécula fotoativa, variando-se também os meios onde essas vesículas eram crescidas.

Além dos estudos com membranas mistas compostas por POPC:CL, estudamos também membranas mistas de POPC:Col com a molécula fotoativa.

\subsubsection{Sistemas de POPC + dic 12 -porf em solução aquosa contendo sacarose e glicose}

Primeiramente, estudamos o efeito de irradiação em GUVs compostas somente por POPC +1 ou $3 \mathrm{~mol} \%$ dic $_{12}$-porf. Para estas GUVs compostas por POPC +1 ou 3 mol\% diC $_{12}$-porf, foi observado que a maioria das GUVs começa a flutuar após a irradiação, 
apresentando aumento de área e consequente formação de buds (pequenas vesículas ligadas à vesícula mãe por finos pescoços), como pode ser visto na figura 4.5.

Tal efeito é muito parecido com o observado em [20], o qual foi descrito no capítulo 1 (ver Anexo 1). Neste trabalho utilizavam-se somente vesículas de POPC e outra molécula fotossensível (PE-porf), também inserida na bicamada lipídica. Essa molécula fotoativa também possuía uma porfirina em sua estrutura, como está apresentado no capítulo 1.

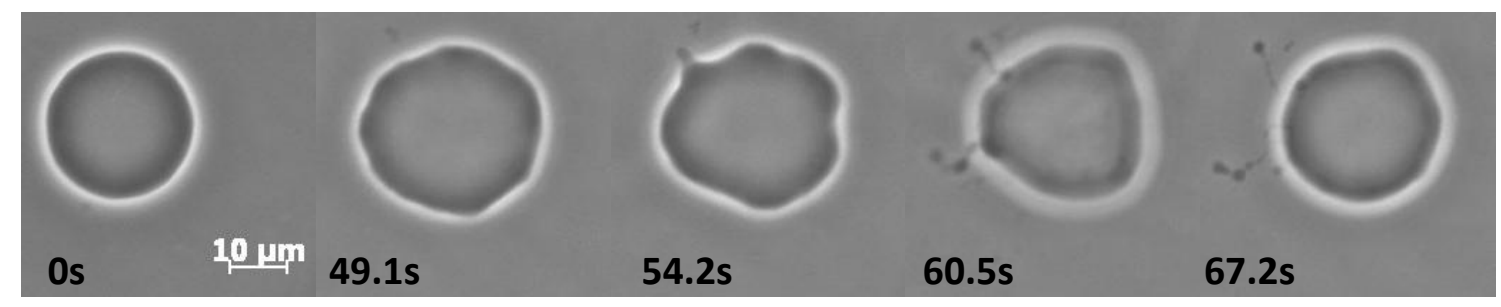

Figura 4.5: Efeito da irradiação de GUVs de POPC $+1 \mathrm{~mol} \%$ diC $_{12}$-porf. $\mathrm{Na}$ segunda imagem é possível observar que a vesícula começa a flutuar após a irradiação, ganha área e logo expele buds na seqüência. Imagem obtida no modo contraste de fase com a objetiva $63 x$.

\subsubsection{Sistemas de POPC:CL + diC $\underline{12}_{\text {-porf }}$}

- Sistemas de POPC:CL + dic $C_{12}$-porf em solução aquosa contendo sacarose e glicose:

O primeiro estudo foi feito apenas com glicose e sacarose. Para as GUVS compostas por POPC:CL:diC 12 -porf (80:20:1 ou 3) o efeito observado foi muito similar com POPC puro (figura 4.6). Sob irradiação, as GUVs sofrem alterações morfológicas mas não são destruídas.

Já para as vesículas de POPC:CL:diC ${ }_{12}$-porf (50:50:1 ou 3) o efeito é bem diferente do descrito no parágrafo anterior. Após a irradiação é possível observar dois diferentes cenários. São eles: i) às vezes não ocorria nada com a vesícula (em aproximadamente 50\% das vezes) e ii) às vezes ocorria formação de domínios (pontos pretos), podendo ser seguido pela formação de poros com vazamento da solução interna e destruição. Todos os cenários mencionados em (ii) encontram-se representados na figura 4.7. 
Uma das possíveis explicações para o que acontece quando a GUV aparentemente não reage ao estímulo da luz durante a irradiação seria: i) distribuição não homogênea do marcador entre as GUVs, ou seja, concentração menor da molécula fotoativa na membrana ou ii) a presença de CL oxidada na membrana causa um efeito diferente de membrana contendo apenas POPC oxidado. Voltaremos a este ponto na análise quantitativa dos dados no próximo capítulo. Já os efeitos dos domínios e sua formação serão melhor estudados nos próximos itens deste capítulo.

Vale lembrar que algumas GUVs de POPC:CL:diC ${ }_{12}$-porf (50:50:1 ou 3) já apresentavam domínios antes da irradiação, como visto no capítulo 3, e esses domínios aumentavam com a irradiação. Mas também observamos domínios que foram fotoinduzidos nesta composição lipídica e condição experimental.

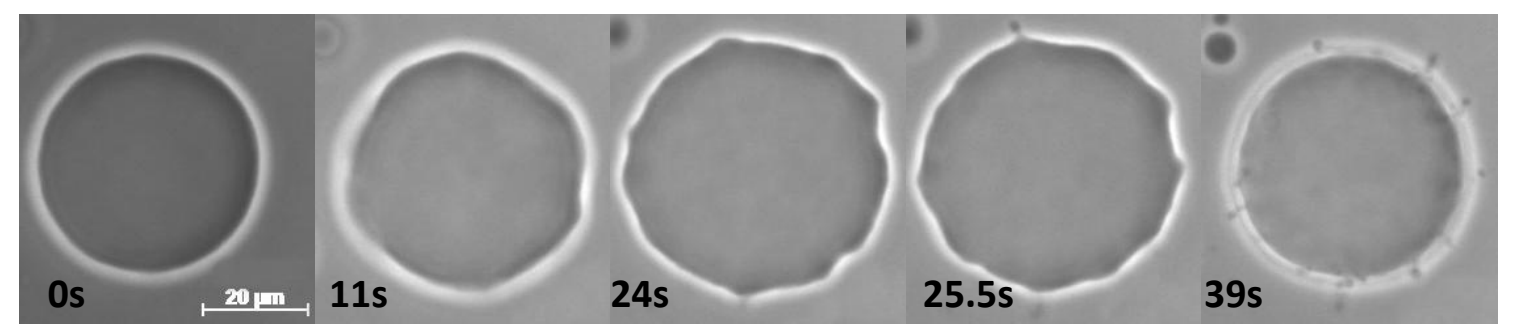

Figura 4.6: Vesícula de POPC:CL:diC ${ }_{12}$-porf(80:20:3) em solução aquosa de gli/sac: a primeira imagem é antes da irradiação e as seguintes durante a irradiação. A partir da terceira figura já é possível ver a formação de buds. Imagem obtida no modo contraste de fase com a objetiva 63x.

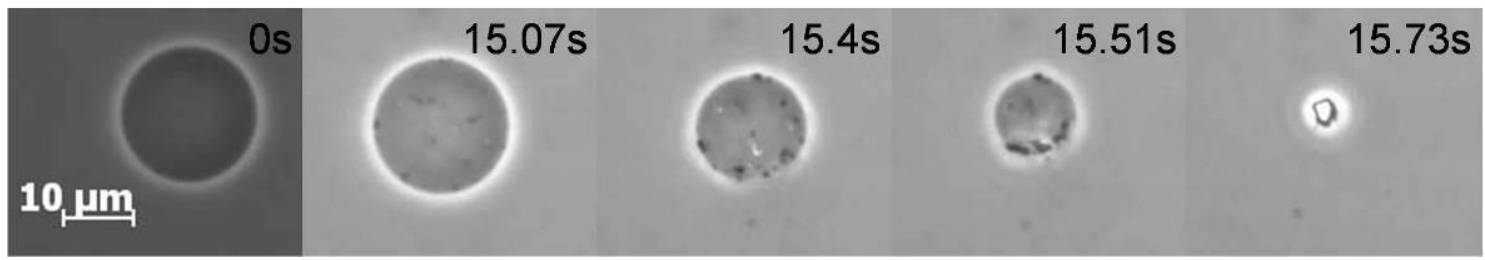

Figura 4.7: Vesícula de POPC:CL:diC 12 -porf(50:50:3)em solução aquosa de gli/sac: a primeira imagem é antes da irradiação e as seguintes durante a irradiação. Após 15.4 s é possível perceber que a vesícula faz um poro e diminui de volume, e a formação dos domínios (pontos pretas) é evidente. Após 15.73s, a mesma foi destruída. Imagem obtida no modo contraste de fase com a objetiva 63x. 
Como a CL é um lipídeo carregado, foi importante o estudo das vesículas compostas por esse fosfolipídeo em vários meios diferentes. Portanto, preparou-se GUVs de POPC +50 mol\% CL em meios contendo os seguintes aditivos: $\mathrm{NaCl}$, para regular a força iônica, tampão Hepes, para ajustar o pH da solução, e EDTA, um agente quelante que se liga a íons divalentes, como mencionado anteriormente.

- Sistemas de POPC:CL + di $C_{12}$-porf em solução aquosa contendo sacarose e glicose na presença de EDTA:

Investigamos as alterações induzidas por foto-oxidação em GUVs compostas por

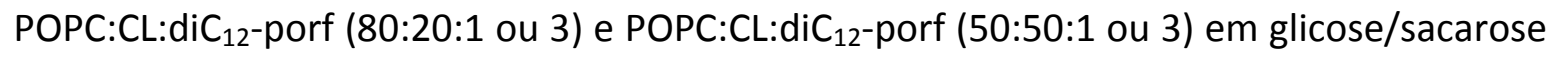
$+0,1 \mathrm{mM}$ EDTA. Os resultados evidenciaram que as vesículas irradiadas de POPC:CL:diC ${ }_{12}{ }^{-}$ porf (80:20:1 ou 3) apresentaram o mesmo comportamento das membranas formadas em glicose/sacarose sem nenhum aditivo (figura 4.6).

Já para as vesículas de POPC:CL: $\operatorname{diC}_{12}$-porf (50:50:1 ou 3) o efeito foi bem diferente de glicose/sacarose sem nenhum aditivo. Para esta configuração, não ocorreu destruição de membrana em nenhum caso, e a formação de domínios também foi suprimida. Durante a irradiação havia duas possibilidades: i) às vezes as GUVs flutuavam e ganhavam excesso de área (figura 4.8) e ii) às vezes nada ocorria e as vesículas permaneciam inalteradas.

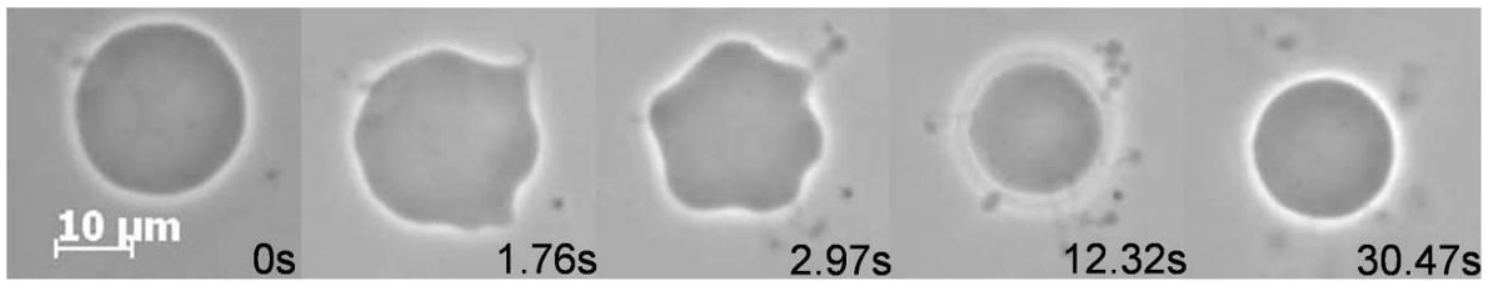

Figura 4.8: Vesícula de POPC:CL: diC $_{12}$-porf(50:50:3)em gli/sac + 0,1mM EDTA: a primeira imagem é antes da irradiação e as seguintes após esta. Na segunda, terceira e quarta imagens é possível ver a formação de buds. Imagem obtida no modo contraste de fase com a objetiva $63 x$. 
Assim sendo, os resultados mostraram que a presença de EDTA na solução suprime a formação dos domínios foto-induzidos e a destruição da membrana. Provavelmente, isso seja devido ao fato do EDTA agir como agente quelante, formando complexos muito estáveis com diversos íons metálicos de solução [32], como já havia sido comentado no capítulo 3.

- Sistemas de POPC:CL + diC $C_{12}$-porf em solução aquosa contendo sacarose na presença de EDTA e glicose na presença de Cálcio

Como comentado no capítulo 3, é possível que os íons $\mathrm{Ca}^{++}$presentes na água, mesmo em concentrações pequenas, devam complexar grupos fosfatos da CL induzindo formação de domínios na membrana. Por outro lado, observamos que a presença do EDTA, um possível quelante de $\mathrm{Ca}^{++}$, suprime a formação de domínios na membrana, como visto no capítulo 3, onde estudamos GUVs na ausência da molécula fotoativa.

Assim, para verificar a hipótese de que o efeito de formação ou supressão de domínios na membrana formada por $50 \%$ de CL seria devido a íons cálcio presentes em solução, crescemos GUVS com sacarose + 0,1mM EDTA na solução interna e colocamos no meio externo glicose $+0,1 \mathrm{mM} \mathrm{EDTA}+0,5 \mathrm{mM} \mathrm{CaCl}_{2}$.

Nessa nova configuração com Cálcio na solução externa, para as vesículas de POPC:CL:diC 12 -porf (80:20:1 ou 3) observou-se que, após a irradiação, as vesículas começavam a flutuar e ganhar excesso de área, mas logo em seguida aderiam ao vidro (grudavam) e as vezes chegavam até a estourar (ver figura 4.9).

Portanto, a presença de íons $\mathrm{Ca}^{++}$na solução interagindo com as GUVs faz com que as mesmas sejam atraídas pelo substrato do vidro, aderindo a este, o que leva as vesículas muitas vezes à destruição; efeito similar foi observado para GUVs diluídas em soluções de $\mathrm{CaCl}_{2}$ em [32].

Já as vesículas de POPC:CL:diC 12 -porf (50:50:1 ou 3) apresentaram novamente o mesmo efeito de formação de domínios e também destruição (ver figura 4.10), sendo que algumas também grudavam no vidro. 
Para aprofundarmos neste estudo, procuramos recobrir o vidro da cela de observação com albumina, buscando diminuir o efeito de adesão das GUVs no vidro, mediado por Cálcio, mas tal experimento não obteve sucesso.

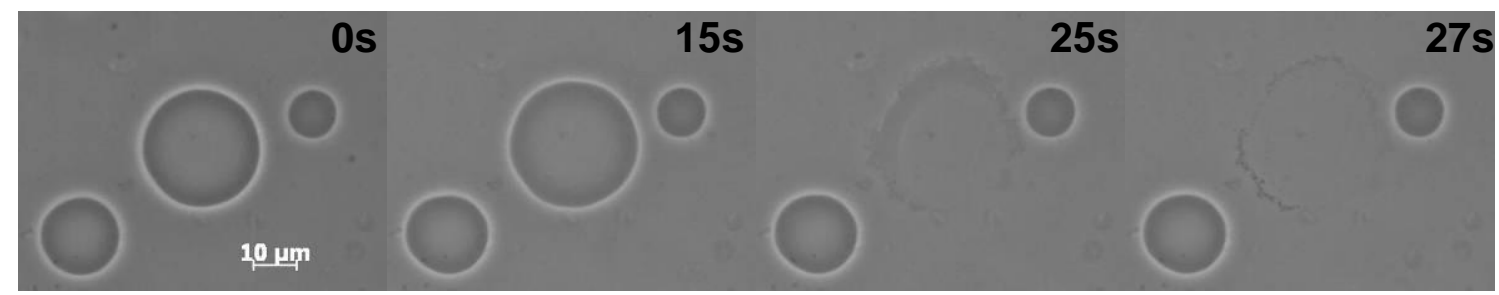

Figura 4.9: Vesícula de POPC:CL:diC 12 -porf(80:20:3) com sacarose + 0,1mM EDTA e glicose + 0,1mM EDTA + $0,5 \mathrm{mM} \mathrm{CaCl}$ : a primeira imagem é antes da irradiação e as seguintes durante a irradiação. Na segunda imagem a vesícula começa a ganhar área e adere ao vidro e na terceira imagem ela estoura. Imagem obtida no modo contraste de fase com a objetiva $63 x$.

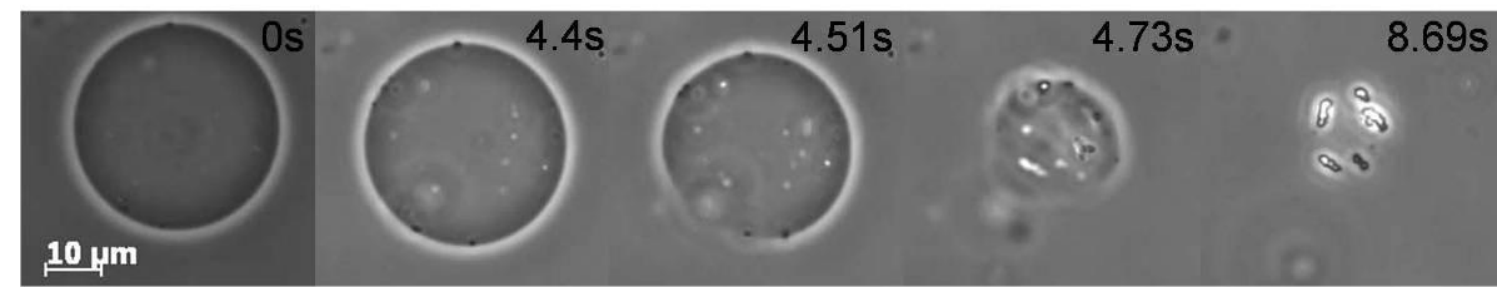

Figura 4.10: Vesícula de POPC:CL: diC $_{12}$-porf(50:50:3) com sacarose + 0,1mM EDTA e glicose + 0,1mM EDTA + $0,5 \mathrm{mM} \mathrm{CaCl}$ : a primeira imagem é antes da irradiação e as seguintes durante a irradiação. Na segunda imagem é possível ver a formação de domínios, na terceira a vesícula forma um poro e na última ocorre ruptura da membrana seguida de destruição. Imagem obtida no modo contraste de fase com a objetiva 63x.

Como a CL contém duas cargas negativas e a sua ligação ao cálcio é muito forte como é conhecido da literatura [5], é razoável supor que a presença de cálcio tenha um efeito aglutinador entre as moléculas de CL. Sua presença pode também induzir fases nãolamelares ou tendência à mudança de curvatura da membrana, que poderiam explicar o surgimento dos domínios na superfície das GUVs [5]. Assim, talvez sejam geradas linhas de tensão na membrana, as GUVs ficam mais frágeis e sujeitas à destruição pelo efeito da foto-oxidação dos lipídeos. 
Devido ao curto tempo para o desenvolvimento da dissertação e o objetivo do trabalho, optamos por realizar os experimentos com no máximo 50mol\% de CL e sempre utilizando EDTA para blindar o efeito das cargas ligadas provavelmente ao cálcio, presente na água, mesmo em concentrações pequenas $[32,39,40]$. A investigação da presença de domínios em GUVs compostas por POPC:CL e a resposta à foto-oxidação será objeto de um outro trabalho.

- Sistemas de POPC:CL + diC $C_{12}$-porf em solução aquosa contendo sacarose e glicose na presença de $\mathrm{NaCl}$ e tampão Hepes

Ainda a fim de se verificar qual o melhor meio para crescer as vesículas, estudou-se a influência de $\mathrm{NaCl}$ e tampão Hepes.

Para glicose/sacarose + 0,5mM NaCl as GUVS de POPC:CL:diC 12 -porf (80:20:1 ou 3) se comportaram como em glicose e sacarose (figura 4.6). Já as GUVs de POPC:CL:diC ${ }_{12}-$ porf (50:50:1 ou 3) apresentaram 3 possibilidades após a irradiação: ou não aconteceu nada com as vesículas, ou formaram domínios (figura 4.11), que as levavam algumas vezes à destruição ou, ainda, não formam e nem possuem domínios e ganharam excesso de área (figura 4.12).

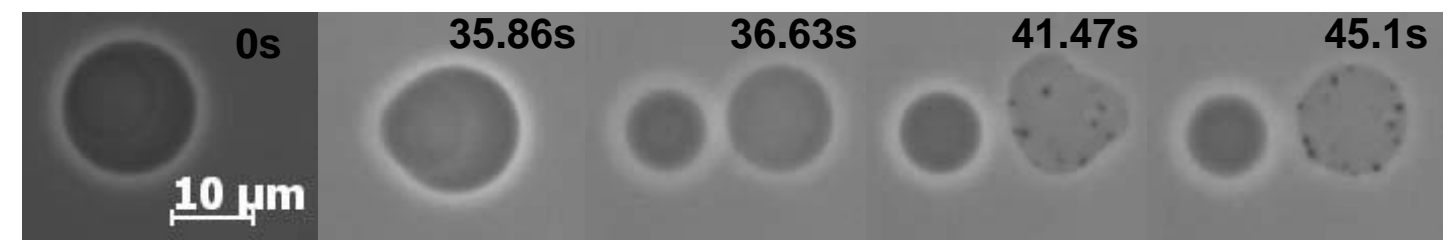

Figura 4.11: Vesícula de POPC:CL:diC ${ }_{12}$-porf(50:50:3) em solução aquosa de gli/sac + 0,5mM NaCl: a primeira imagem é antes da irradiação e as seguintes durante a irradiação. Na segunda imagem a vesícula abre um poro e expele a vesícula interna. Na terceira e quarta imagem é possível ver início da formação de domínios. Imagem obtida no modo contraste de fase com a objetiva 63x. 


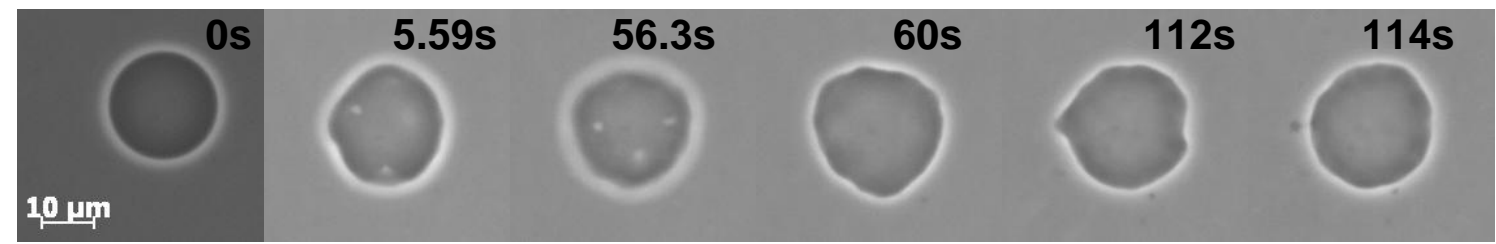

Figura 4.12: Vesícula de POPC:CL: diC $_{12}$-porf(50:50:3)em solução aquosa de gli/sac + 0,5mM NaCl: a primeira imagem é antes da irradiação e as seguintes durante a irradiação. Na quinta e sexta imagem é possível ver a formação de buds. Imagem obtida no modo contraste de fase com a objetiva 63x.

Com glicose/sacarose $+1 \mathrm{mM}$ de HEPES tanto as vesículas de POPC:CL:diC 12 $_{2}$-porf (80:20:1 ou 3) como as vesículas de POPC:CL:diC 12 -porf (50:50:1 ou 3) se comportaram como em glicose e sacarose (figuras 4.6 e 4.13 , respectivamente).

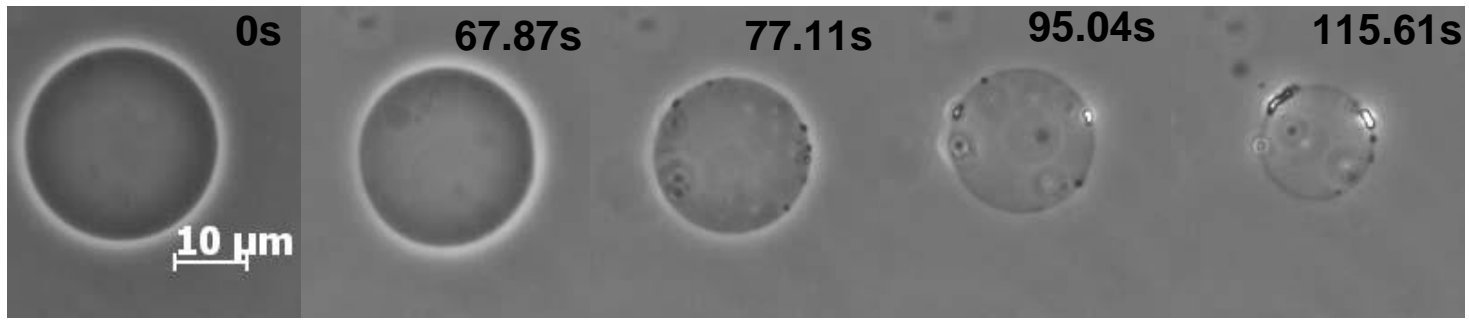

Figura 4.13: Vesícula de POPC:CL:diC 12 -porf(50:50:3) com sac/gli + 1mM HEPES: a primeira imagem é antes da irradiação e as seguintes durante a irradiação. Na segunda imagem é possível ver a formação de domínios e nas duas últimas sinais de destruição. Com o passar do tempo esta vesícula vai diminuindo de tamanho e perdendo o contraste por formação de poros. Imagem obtida no modo contraste de fase com a objetiva $63 x$.

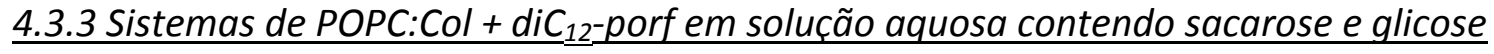

Além de irradiar vesículas com CL, irradiaram-se também vesículas com Col, para cinco tipos de composições: POPC:Col:diC 12 -porf (95:5: 1 ou 3), (90:10: 1 ou 3) e (75:25:1).

Para todas as composições mencionadas no parágrafo anterior os efeitos foram similares para as GUVs que continham somente POPC e molécula fotoativa na membrana, ou seja, após a irradiação as vesículas flutuavam, ganhavam área e dependendo do caso formavam buds ou não como pode ser visto na figura 4.14 . 


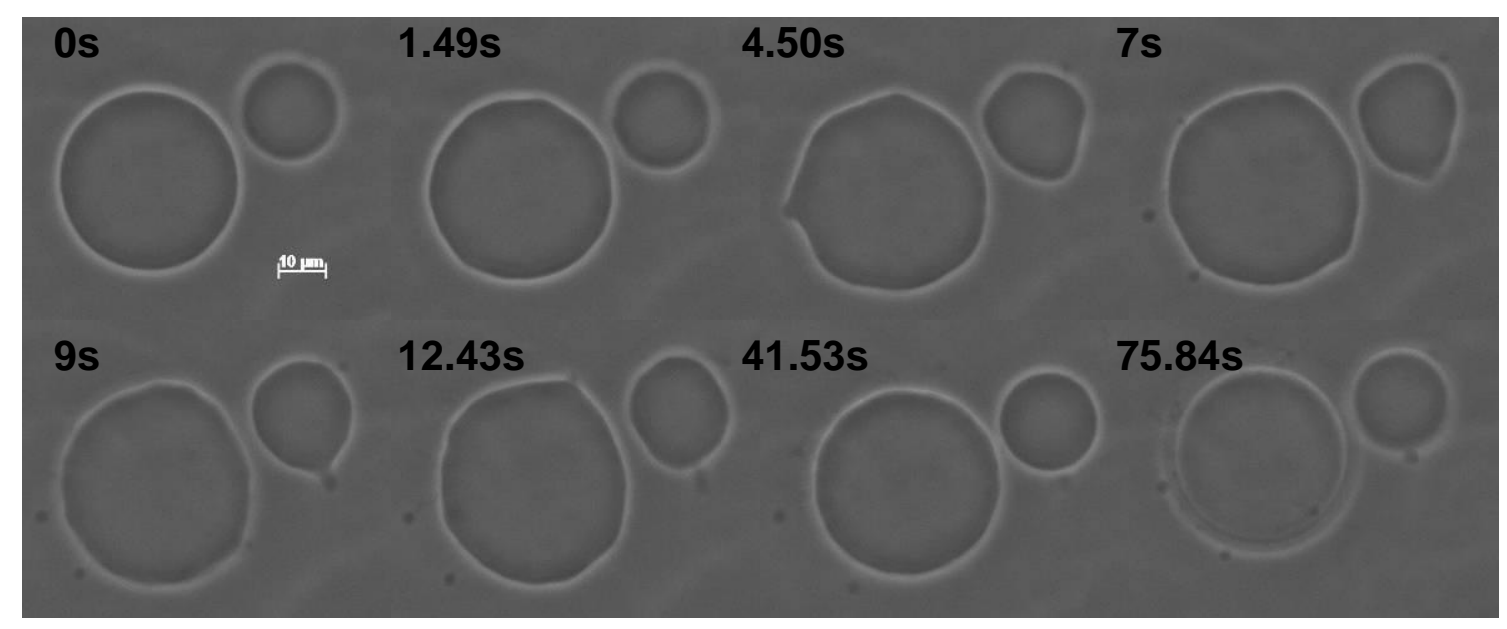

Figura 4.14: Vesículas de POPC:Col:diC 12 porf (95:5:1), após 4,5s de irradiação é possível observar que as duas vesículas começam a expelir um bud, que pode ser visto claramente nas imagens seguintes. Imagem obtida no modo contraste de fase com a objetiva $63 x$.

\subsection{Conclusões Parciais}

A partir dos estudos deste capítulo pudemos perceber que a molécula di $\mathrm{C}_{12}$-porf, assim como a PE-porf [20], incorporada em membrana, gera efeitos foto-oxidativos na mesma e sofre um fotoclareamento muito rápido (figura 4.1).

Também pudemos definir que existe uma correlação entre o aumento da intensidade de luz e o tempo de fotoclareamento da molécula, motivo pelo qual escolhemos fixar a menor intensidade de luz possível para todos os experimentos de forma que pudéssemos observar os fenômenos em um tempo mensurável.

Percebemos que as vesículas compostas somente por POPC $+\mathrm{diC}_{12}$-porf e POPC:Col + di $\mathrm{C}_{12}$-porf reagem ao estímulo da luz, passando a ter flutuações na membrana seguidas de um aumento de área, nunca ocorrendo destruição da membrana.

Já para $\mathrm{CL}$, um lipídeo carregado, pudemos perceber vários cenários diferentes dependendo da concentração desta. Para concentrações baixas de CL percebemos que o efeito é muito similar à GUVs formadas apenas por POPC e POPC:Col.

Para concentrações acima de $50 \mathrm{~mol} \%$ de $\mathrm{CL}$ percebemos, que em alguns casos, para glicose e sacarose sem nenhum aditivo, a membrana passa a formar domínios após a 
irradiação podendo ou não ser destruída. Assim, para investigar melhor esse sistema, estudamos estas vesículas em meios diferentes. Percebemos que ao crescer essas vesículas na presença de EDTA um agente quelante, as vesículas deixavam de ser destruídas e a formação de domínios era suprimida.

Entretanto ao adicionarmos $\mathrm{CaCl}_{2}$ na solução externa, percebemos que o efeito de formação dos domínios e destruição reaparecia, evidenciando que provavelmente íons $\mathrm{Ca}^{++}$presentes em solução, mesmo em pequenas concentrações, podem complexar com as cargas presentes na CL. Como conseqüência de tal complexação, membranas com alto teor de CL são passiveis de formar domínios lipídicos que, de alguma maneira, favorecem a destruição da membrana como resposta a foto-oxidação. 


\section{Capítulo 5: Foto-resposta de GUVs contendo a molécula fotoativa diC $_{12}$-porf: Análises Quantitativas e Discussão}

No capítulo anterior, mostramos que vesículas compostas por POPC e POPC:Col com a molécula fotoativa $\mathrm{diC}_{12}$-porf, ou membranas lipídicas contendo POPC:CL e a molécula fotoativa na presença do EDTA, ao serem irradiadas exibiam um aumento de área seguido ou não da emissão de buds. Com o objetivo de investigarmos como a presença de $\mathrm{CL}$ ou Col influencia tal aumento de área da membrana, optamos por estudar GUVs contendo até 50 mol\% de CL dispersas em solução na presença do EDTA e Col até 25 mol\% no sistema POPC:Col.

De maneira similar aos estudos apresentados no capítulo anterior, no qual definimos a intensidade de luz com que iríamos trabalhar e também como em [20], onde quantificamos o aumento de área de GUVs compostas por POPC e PE-porf, neste capítulo investigaremos em maior detalhe o aumento de área gerado em membranas mistas contendo diC $_{12}$-porf através da aplicação de um campo elétrico alternado, conforme protocolos descritos nos capítulos 1 e 2.

\subsection{Medidas de aumento de área com campo elétrico AC para GUVs compostas de POPC + diC $_{12}$-porf}

Iniciamos o nosso estudo de aumento de área em função do tempo de irradiação com GUVs compostas somente por POPC, mensurando os semi-eixos de um elipsóide prolato (figura 1.22) na presença de um campo elétrico. Como procedimento, interrompemos a irradiação sempre que a GUV começava a emitir buds ou grudava no eletrodo. Além disso, muitas vezes as GUVs atingiam o máximo de expansão de área e voltavam a ficar esféricas provavelmente devido à emissão de buds em planos que não tínhamos acesso. Neste caso, mensurávamos o máximo de expansão. 
Estudamos a foto-resposta de GUVs contendo as seguintes concentrações da molécula fotoativa: 0,$1 ; 0,2 ; 0,5 ; 1,2$ e 3 mol\% como ilustrado na figura 5.1. Vesículas contendo 0,1 mol\% de diC $_{12}$-porf na membrana não alongaram sob irradiação. Devido a esse fato, essa concentração não está representada nos gráficos. Provavelmente isto se deve a baixa concentração de molécula fotoativa na bicamada lipídica.

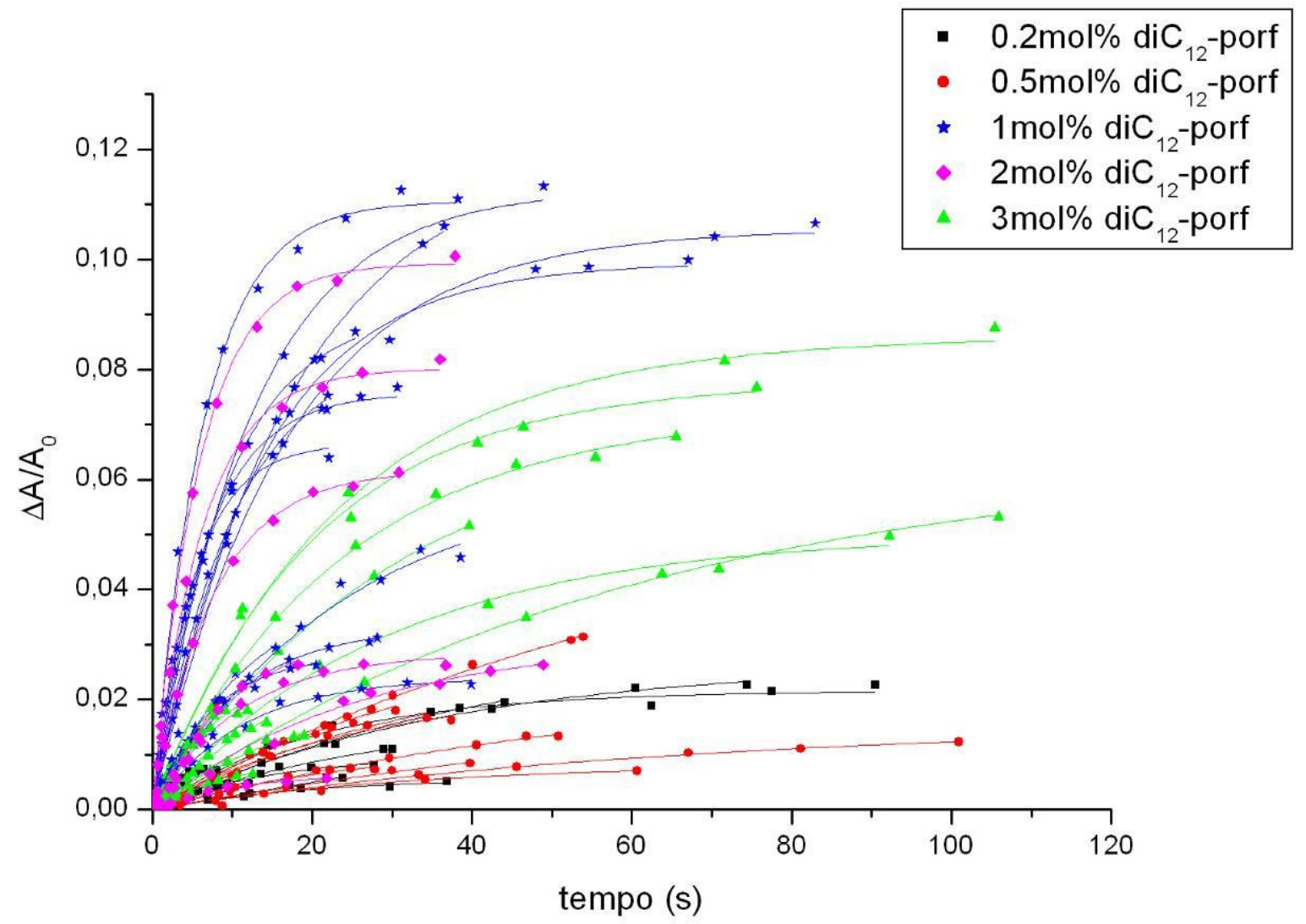

Figura 5.1: Aumento de área relativa em função do tempo para várias concentrações de diC ${ }_{12}$-porf. As linhas sólidas correspondem aos melhores ajustes utilizando a equação 2 aos dados experimentais.

Os resultados mostram, de maneira análoga ao que observamos anteriormente para membranas de POPC contendo até $10 \mathrm{~mol} \%$ de PE-porf [20], uma expansão de área relativa $\triangle A / A_{0}$ (onde $A_{0}$ corresponde a área inicial aparente da vesícula) que varia exponencialmente com o tempo, atingindo um valor máximo $A_{\text {máx }}$ em menos de dois minutos de irradiação. Além disso, o aumento de área é limitado e/ou modulado pelo fotoclareamento da molécula fotoativa com um tempo característico $\tau$ (equação 2). Se 
não houvesse o fotoclareamento da molécula fotossensibilizadora, a variação de aumento de área seria linear até que todos os lipídeos tivessem sido oxidados e no caso a vesícula fosse destruída. Mas, as GUVs se mantém integras durante a irradiação, não apresentando poros visíveis ou aumento de permeabilidade o que alteraria o contraste óptico das mesmas.

Conforme observamos na figura 5.1, GUVs contendo 1 e 2 mol\% de diC 12 -porf atingem o máximo de elongação em tempos menores, assim como apresentam uma taxa mais rápida de variação de área em função do tempo nos primeiros $10 \mathrm{~s}$, em comparação às concentrações menores de $\mathrm{diC}_{12}$-porf. Note que existem dois comportamentos diferentes de expansão de área tanto para $1 \mathrm{~mol} \%$ quanto para $2 \mathrm{~mol} \%$ de diC $_{12}$-porf incorporada na membrana. Além disso, parece que GUVs contendo 3 mol\% da molécula fotoativa apresentam uma foto-resposta intermediária entre 1 a 2 mol\% e 0,2 a 0,5 mol\%; estes pontos serão mais bem investigados a seguir.

Para uma melhor visualização dos dados apresentados na figura 5.1 resolvemos separar as populações de GUVs em 4 gráficos que estão representados na figura 5.2.

É possível notar da figura 5.2 que GUVs contendo 0,2 mol\% e 0,5 mol\% de $\mathrm{diC}_{12}$ porf respondem à irradiação de maneira similar dentro das variações observadas, apresentando pequeno aumento de área relativa com o tempo. Já para membranas

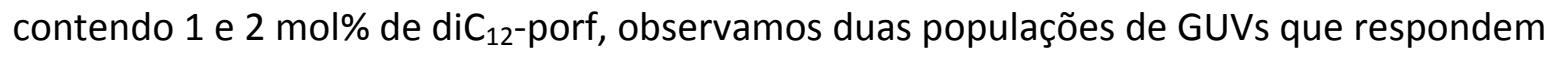
diferentemente à irradiação e apresentam aumentos de área maiores e menores. Muito provavelmente, uma distribuição não homogênea de moléculas fotoativas durante a formação das GUVs dá origem a membranas com composições ligeiramente diferentes das nominais.

O experimento foi repetido com GUVs de POPC contendo 1 mol\% de $\mathrm{diC}_{12}$-porf em dois dias distintos, com nova preparação da solução de POPC: diC $_{12}$-porf em clorofórmio. Os resultados evidenciaram que todas as vesículas tiveram aumento de área compatível com a primeira população que apresenta acréscimo de área da ordem de 10\% (figura 5.2). Note, entretanto, que a maioria das GUVs representativas das duas populações atinge $A_{\text {máx }}$ em menos de $20 \mathrm{~s}$ de irradiação, independentemente do valor de $A_{\text {máx} \text {. }}$ 
Por outro lado, o aumento de área para bicamadas lipídicas de POPC contendo 3 mol\% de diC $_{12}$-porf é menor do que para as duas primeiras populações tanto de $1 \mathrm{~mol} \%$ quanto de 2 mol\% de diC $_{12}$-porf.
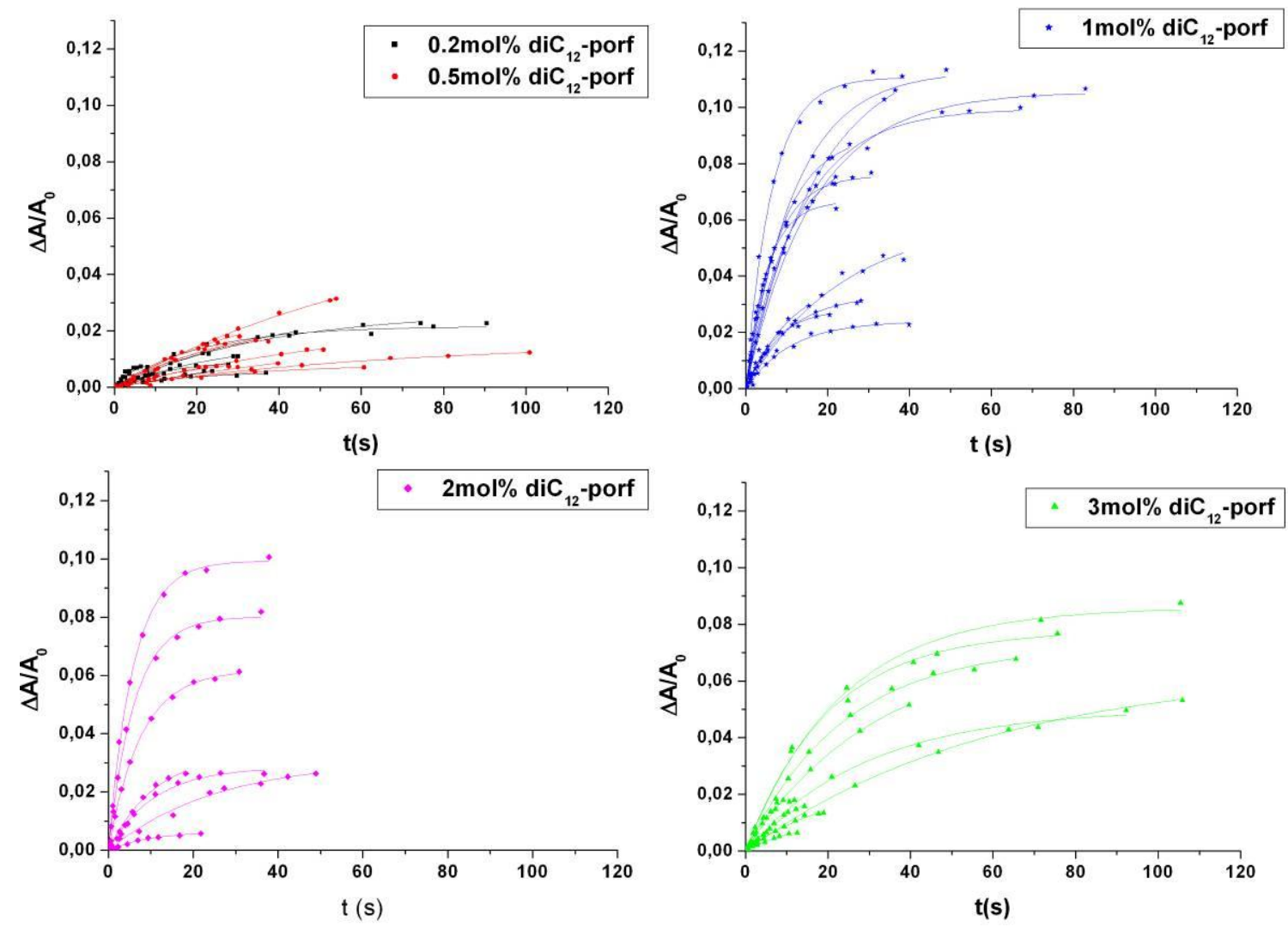

Figura 5.2: Aumento de área relativa em função do tempo para várias concentrações de $\operatorname{diC}_{12}$-porf. As linhas sólidas correspondem aos melhores ajustes utilizando equação 2 aos dados experimentais.

As linhas sólidas nas figuras 5.1 e 5.2 representam os melhores ajustes aos dados experimentais utilizando a equação 2. As figuras 5.3 e 5.4 apresentam os valores médios de $A_{\text {máx }}$ e $\tau$, com suas respectivas incertezas, em função da concentração da molécula fotoativa, respectivamente. Para 1 e 2 mol\% de diC $_{12}$-porf representamos os resultados para as duas populações de GUVs observadas.

A partir da figura 5.3 é possível observar que o área máxima atingida varia com a concentração de diC $_{12}$-porf, sendo máxima para a concentração de 1 mol \% de diC 12 $_{\text {-porf. }}$ 
Para membranas lipídicas contendo 2 mol\% e 3 mol\% de diC ${ }_{12}$-porf, o aumento de área relativa máximo é menor do que para $1 \mathrm{~mol} \%$.

Em termos dos valores de $\tau$ (figura 5.4), podemos observar valores maiores para concentrações de 0,2 mol\% e 0,5 mol\%, assim como para membranas contendo 3 mol\% da molécula fotoativa, diferentemente à constância nos valores de $\tau=2 \mathrm{~s}$ observada para PE-porf [20]. Ou seja, observamos nesta dissertação que membranas que responderam à irradiação de maneira mais moderada, com menor aumento de área, apresentam maior tempo característico de foto-branqueamento de $\mathrm{diC}_{12}$-porf. No caso de pequenas concentrações de $\mathrm{diC}_{12}$-porf, deve ocorrer uma menor geração de moléculas de oxigênio singlete via foto-oxidação em relação a $1 \mathrm{~mol} \%$ de molécula fotoativa, justificando o decréscimo da foto-degradação. Por outro lado, no caso de membranas contendo 3 mol $\%$ de $\mathrm{diC}_{12}$-porf, os resultados combinados de $A_{\text {máx }}$ e $\tau$ indicam que, provavelmente, a molécula fotoativa esteja formando dímeros ou oligômeros na membrana, diminuindo sua capacidade de produzir oxigênio singlete. Como consequência, ocorre um aumento no tempo de vida da molécula fotoativa. Tal hipótese poderia ser melhor explorada, mas não era o enfoque desta dissertação.

Ainda tentando entender como a concentração da molécula fotoativa influencia a resposta da membrana à irradiação, na figura 5.5 graficamos a taxa de variação de área no início do processo de irradiação. Isto corresponderia à variação linear esperada de área da membrana lipídica com o tempo de irradiação se a molécula fotossensibilizadora não fosse degradada.

Através da figura 5.5, percebemos então que o processo de geração de excesso de área por foto-oxidação é mais rápido para concentrações de 1 e 2 mol\% de diC $_{12}$-porf. Muito embora a resposta à foto-oxidação seja mais rápida para tais concentrações de $\mathrm{diC}_{12}$-porf presentes na membrana tanto em termos de aumento de área induzido como a fotodegradação das moléculas fotoativas, e o ideal seria trabalharmos em condições experimentais com fenômenos de observação ocorrendo num intervalo de tempo maior, optamos por continuar o trabalho investigando membranas mistas contendo $1 \mathrm{~mol} \%$ da molécula fotoativa. Isto porque acreditamos que quanto maior for o valor $A_{\text {máx }}$ atingido, 
mais confiável será a avaliação do efeito da CL ou colesterol na membrana de POPC + $\mathrm{diC}_{12}$-porf. Além disso, devido à reprodutibilidade das medidas, acreditamos que os resultados de variação de área máxima em torno de $10 \%$ apresentado por GUVs compostas por POPC na presença de 1 mol\% de diC $_{12}$-porf representam GUVs com distribuição mais homogênea da molécula fotoativa durante a formação das membranas. Assim, o valor nominal da concentração de diC $_{12}$-porf de 1 mol\% será utilizado para uma discussão quantitativa dos resultados abaixo e futuras comparações com efeitos de $\mathrm{CL}$ e colesterol na membrana.

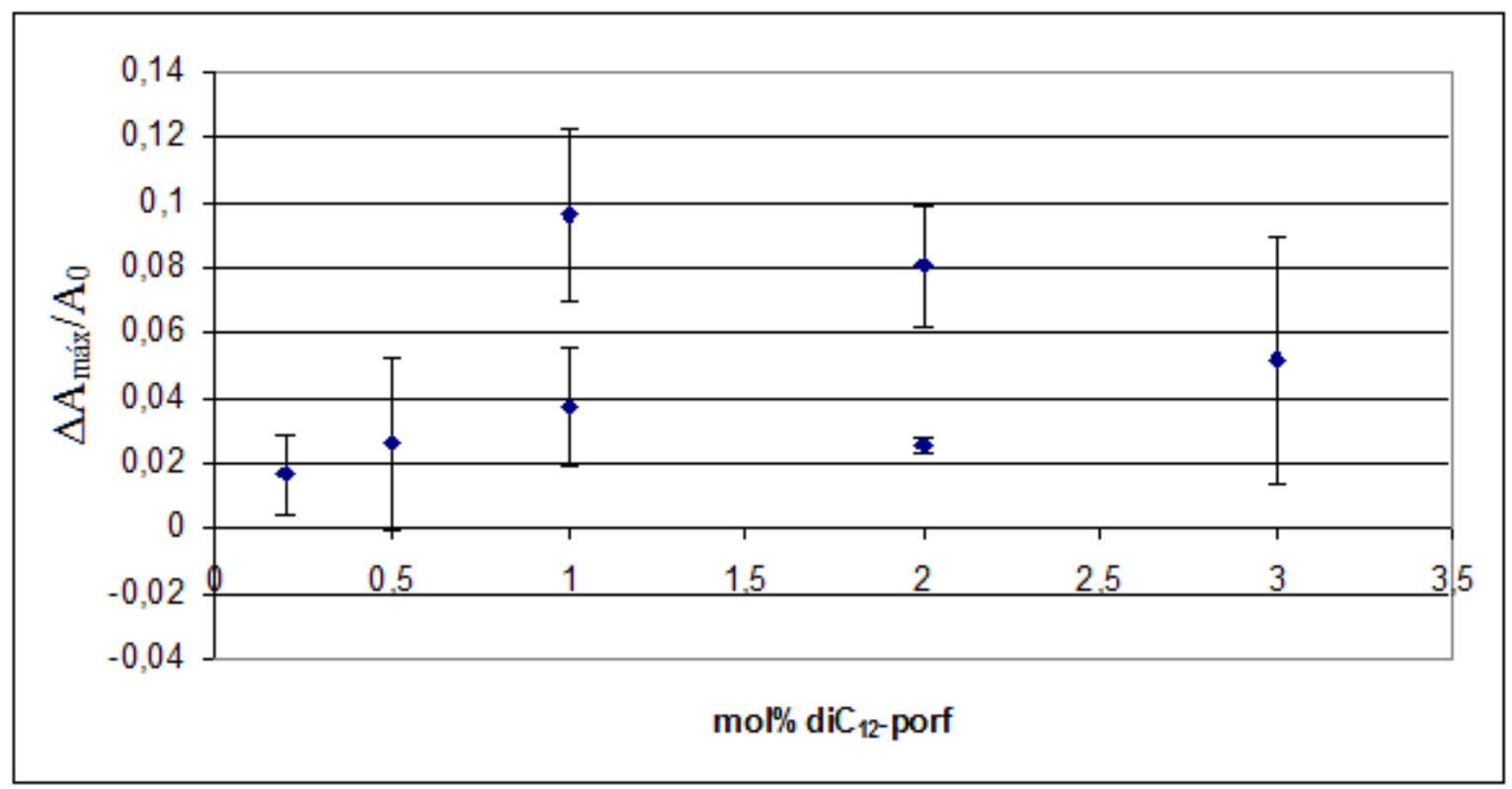

Figura 5.3: Valores médios do aumento máximo de área relativa obtido após o ajuste (figura 5.1 ou 5.2) em função da concentração da molécula fotoativa. Para as concentrações de 1 e 2 mol\% de diC ${ }_{12}$-porf existem duas populações de aumento de área distintos (ver figura 5.1 e 5.2). 


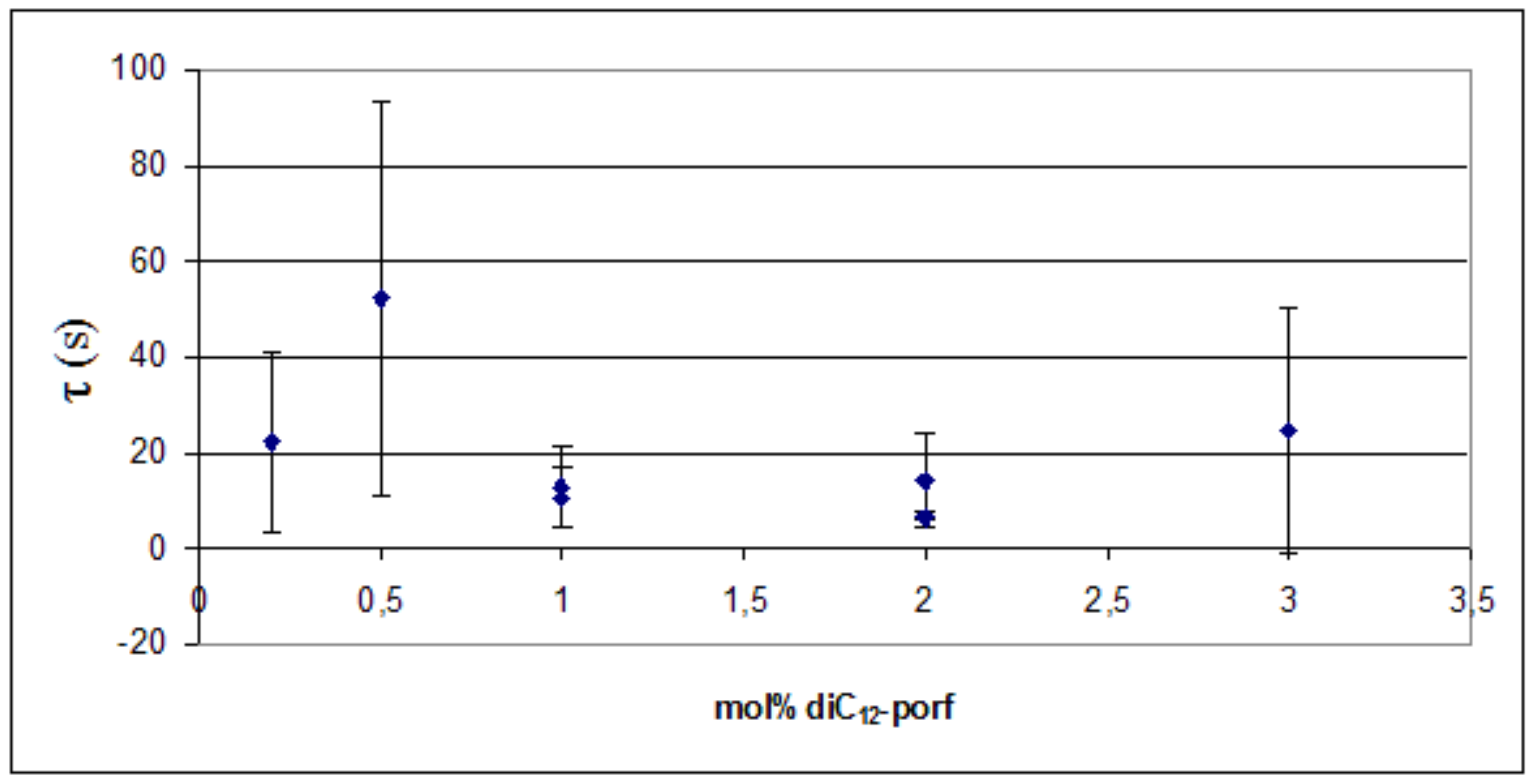

Figura 5.4: Valores médios do tempo característico $\tau$ obtido após os ajustes (figura 5.1 ou 5.2) em função da concentração da molécula fotoativa. Para as concentrações de 1 e 2 mol\% de diC ${ }_{12}$-porf existem duas populações de aumento de área distintos (ver figura 5.1 e 5.2).

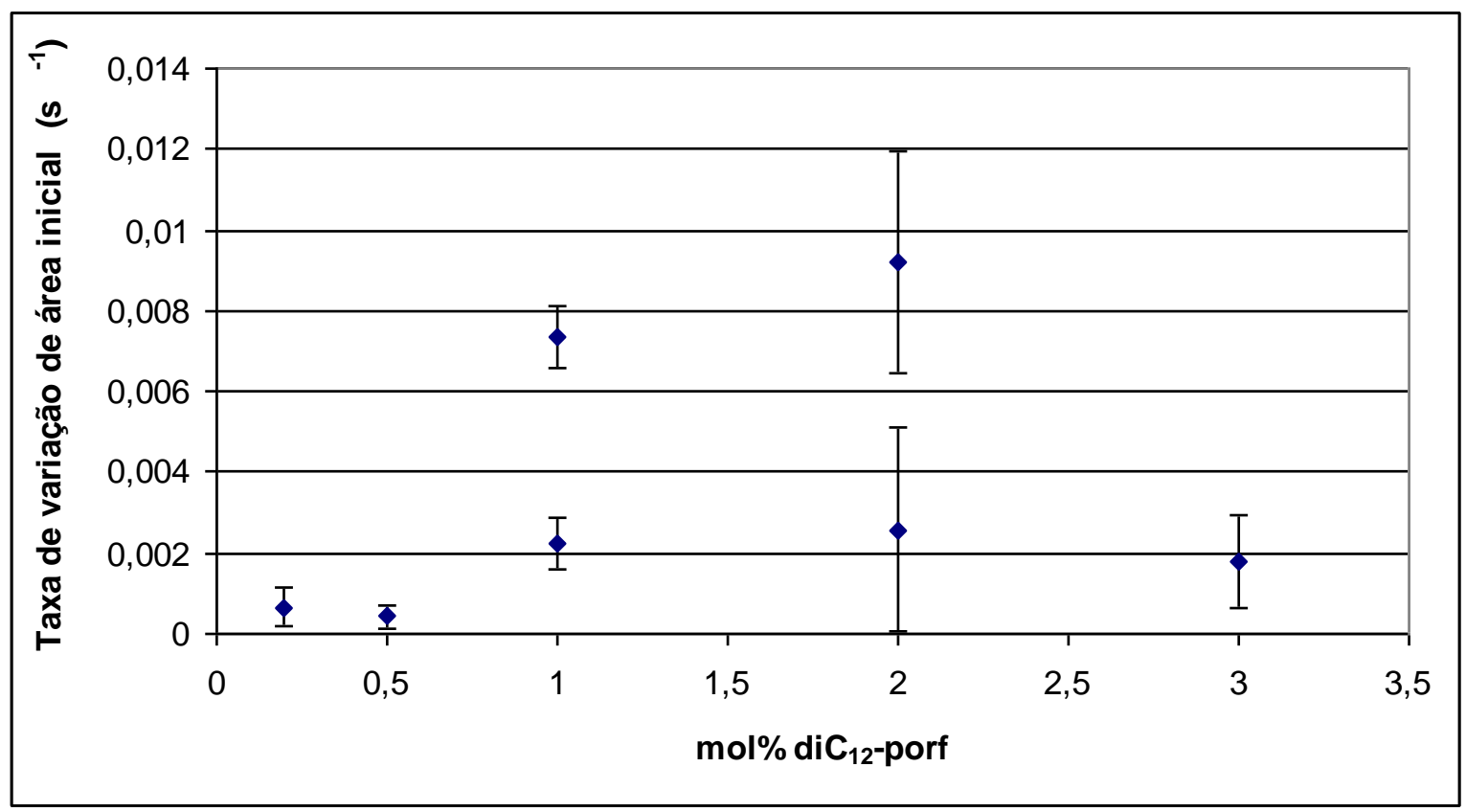

Figura 5.5: Taxa de variação de área inicial em função da concentração da molécula fotoativa. Para as concentrações de 1 e 2 mol\% de diC $_{12}$-porf existem duas populações de aumento de área distintos (ver figura 5.1 e 5.2). 
Vale a pena ressaltar que no trabalho anterior utilizando PE-porf em membranas de POPC [20] variações de área da ordem de 10 \% só foram observadas para concentrações de 10 mol\% de molécula fotoativa, ou seja, 10 vezes mais concentrado que no caso de $\mathrm{diC}_{12}$-porf. Portanto, parece num primeiro momento que $\mathrm{diC}_{12}$-porf é mais eficiente na geração de lipídeos oxidados durante a irradiação. Por outro lado, no trabalho anterior utilizamos uma densidade de potência de irradiação $P=5 \mathrm{~W} / \mathrm{cm}^{2}$ no comprimento de onda de irradiação $\lambda=400 \mathrm{~nm}$, enquanto nesta dissertação utilizamos $P$ $=0,3 \mathrm{~W} / \mathrm{cm}^{2}$ irradiando com mesmo $\lambda$. Calculando a taxa de produção de oxigênio singlete por molécula fotossensível, dada pela fórmula 4 [41],

$$
Q=\frac{\phi_{\Delta} \lambda P \sigma}{h c}(4)
$$

onde $\Phi_{\Delta}$ é rendimento quântico de produção de oxigênio singlete $=0,7$ [34], $\sigma$ é a seção de choque de absorbância de valor $1,7 \AA^{2}$ para a porfirina, $h$ é a constante de Planck e $c$ é a velocidade da luz, obtemos que, em nosso arranjo experimental, diC $\mathrm{C}_{12}$-porf gera 72 ${ }^{1} \mathrm{O}_{2} /$ s. No caso anterior, PE-porf gerava $900{ }^{1} \mathrm{O}_{2} / \mathrm{s}$. Tal diferença justifica o fato que PEporf apresentou tempo característico de foto-clareamento $\tau=2 \mathrm{~s}$, enquanto $\tau$ é da ordem de $10 \mathrm{~s}$ para $1 \mathrm{~mol} \%$ de diC $_{12}$-porf. Portanto, o uso de uma iluminação menos intensa protege a molécula fotoativa de foto-dano imediato. Como consequência, a peroxidação lipídica devido ao ataque de oxigênios singletes às duplas ligações das cadeias insaturadas de POPC permanece num intervalo de tempo maior (embora ainda em segundos). Novamente, associamos o aumento de área observado na membrana à formação de hidroperóxidos de POPC (figura 5.6). Uma vez que o grupo $\mathrm{OOH}$ é mais hidrofílico, ele deve migrar para a interface polar/apolar da membrana, tal que o hidroperóxido lipídico deve ocupar uma área maior por lipídeo [21]. 
<smiles>CCCCCCCC/C=C\CCCCCCCC(=O)OC[C@H](COP(=O)([O-])OCC[N+](C)(C)C)OC(=O)CCCCCCCCCCCCCC</smiles><smiles>COCCO</smiles>
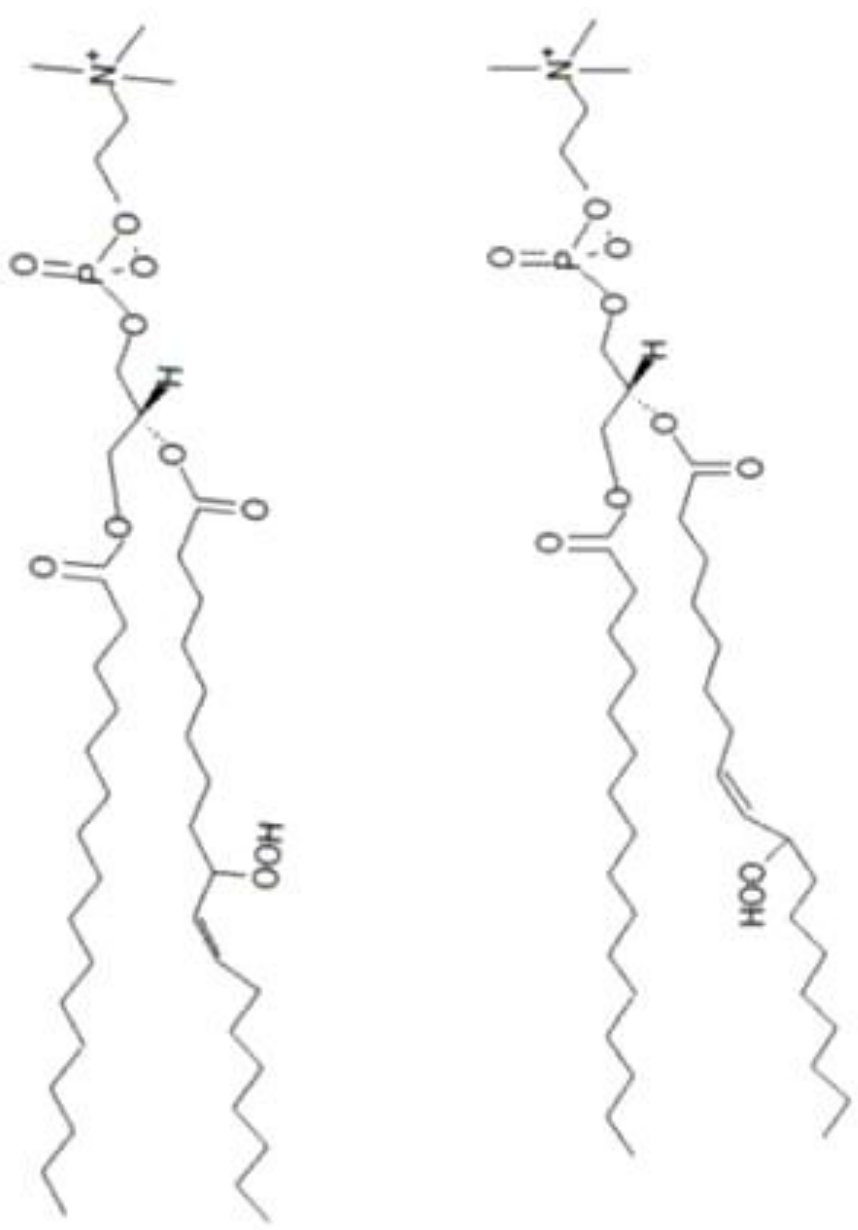

Figura 5.6: Esquema de peroxidação do POPC. Imagem cedida gentilmente pelo profo Mauricio S. Baptista. 
Considerando que o aumento de área relativo $\Delta A / A_{0}$ está diretamente relacionado a fração molar de moléculas de POPC que se transformam em hidroperóxidos, $\chi\llcorner\mathrm{LOH}$, nós podemos para quantificar a porcentagem de lipídeos hidroperoxidados (LOOH) que dão origem ao aumento máximo de área observado, fazer uso da equação 5 [20] dada por:

$$
\frac{\Delta A}{A_{0}}=\frac{X_{L O O H} \delta A}{\left(1-X_{p o r f}\right) A_{P C}+X_{p o r f} A_{p o r f}}
$$

onde $\chi_{\llcorner O O H}$ é a concentração de lipídeos peroxidados, $\delta A$ é o incremento de área devido à peroxidação de um lipídeo ( $\delta A=A_{L O O H}-A_{P C}$ e $\delta A / A_{P C}=0,15$ ), X porf é a concentração de $\mathrm{diC}_{12}$-porf, $\mathrm{APC}_{\mathrm{PC}}$ a área do POPC $\left(65 \AA^{2}\right)$ e $A_{\text {porf }}$ é da área a porfirina $\left(120 \AA^{2}\right)$.

Utilizando os valores acima e sabendo-se que 1 mol\% de diC $\mathrm{C}_{12}$-porf em membranas contendo 99 mol\% de POPC quando irradiadas, dá origem a um aumento máximo de área de cerca de $10 \%\left(\left(\Delta A / A_{0}\right)_{\text {máx }}=0,1\right)$, obtemos que tal aumento pode ser associado à peroxidação de $67 \%$ dos lipídeos. Este valor concorda com o valor anteriormente encontrado para a molécula de PE-porf (10 mol\%) de cerca de $60 \%$ de peroxidação lipídica quando a membrana atingia um excesso de área da ordem de $8 \%$ [20]. Vale a pena ressaltar que, muito embora a porcentagem de lipídeos hidroperoxidados na membrana seja alta, a mesma se mantém íntegra e não foi observada qualquer alteração na permeabilidade da mesma.

A concentração de lipídeos peroxidados $\chi_{\llcorner O O H}$, depende do tempo de irradiação e da eficiência do processo $n$. Na ausência de fotoclareamento, $\chi_{\llcorner\circ O H}$ deveria crescer linearmente com o tempo como:

$$
X_{\text {LOOH }}=n Q X_{\text {porf }} t(6)
$$

Contudo, na presença de fotoclareamento, a taxa de produção de $\chi_{\llcorner\circ o H}$ é dada por 


$$
X_{\text {LOOH }}=n Q X_{\text {porf }} \int_{0} d t^{\prime} e^{-t^{\prime} / \tau}
$$

onde $\tau$ está relacionado com o tempo de fotoclareamento. Assim resolvendo a integral da equação 7, e inserindo o resultado na equação 5, temos que

$$
\frac{\Delta A}{A_{0}} C_{\equiv}=n \tau \frac{\delta A}{A_{P C}} \frac{X_{p o r f} A_{P C}}{\left(1-X_{p o r f}\right) A_{P C}+X_{p o r f} A_{p o r f}}\left(1-e^{-t / \tau}\right)
$$

Levando em conta que $\chi_{\text {porf }}$ é um número muito menor comparado à fração molar de POPC ( $\left.\chi_{\text {porf }} \ll<1\right)$, a equação 8 , pode ser aproximada por

$$
\frac{\Delta A}{A_{0}} \boldsymbol{C}_{\equiv}=n Q \tau \frac{\delta A}{A_{P C}} X_{p o r f}\left(1-e^{-t / \tau}\right)
$$

Assim, comparando a equação 9 com a equação 2, temos que [20]

$$
\frac{\Delta A_{\max }}{A_{0}}=n Q \tau \frac{\delta A}{A_{P C}} X_{\text {porf }}(10) .
$$

De acordo com a equação $10, \Delta A_{\text {máx }} / A_{0}$ é uma função linear de $X_{\text {porf. }}$ Portanto, graficando estes valores para concentrações de diC ${ }_{12}$-porf até 1 mol\% (não graficamos acima deste valor pois, conforme discutido acima, parece que já existe dimerização da molécula fotoativa para concentrações maiores) observamos um comportamento linear (figura 5.7), cujo coeficiente angular é igual a 8.7. Portanto, levando em conta que $Q=72$ ${ }^{1} \mathrm{O}_{2} / \mathrm{s}, \delta \mathrm{A} / \mathrm{Apc}_{\mathrm{pc}}$ vale 0,15 e $\tau$ é da ordem de $10 \mathrm{~s}$, temos $\mathrm{n} \sim 1 / 12$. Isto significa que, em média, para cada 12 moléculas de oxigênio singlete interagindo com a membrana, uma interagirá quimicamente com a dupla ligação da cadeia acila de PC, dando origem a um hidroperóxido lipídico (POPC-OOH, figura 5.6). Portanto, neste caso encontramos que a eficiência do processo de foto-oxidação é alta utilizando diC ${ }_{12}$-porf como molécula 
fotoativa, com uma pequena taxa temporal de produção de oxigênio singlete por molécula fotossensibilizadora, em contraste com o valor relativamente baixo de $n=1 / 270$ encontrado para a molécula de PE-porf nas condições estudadas anteriormente [20].

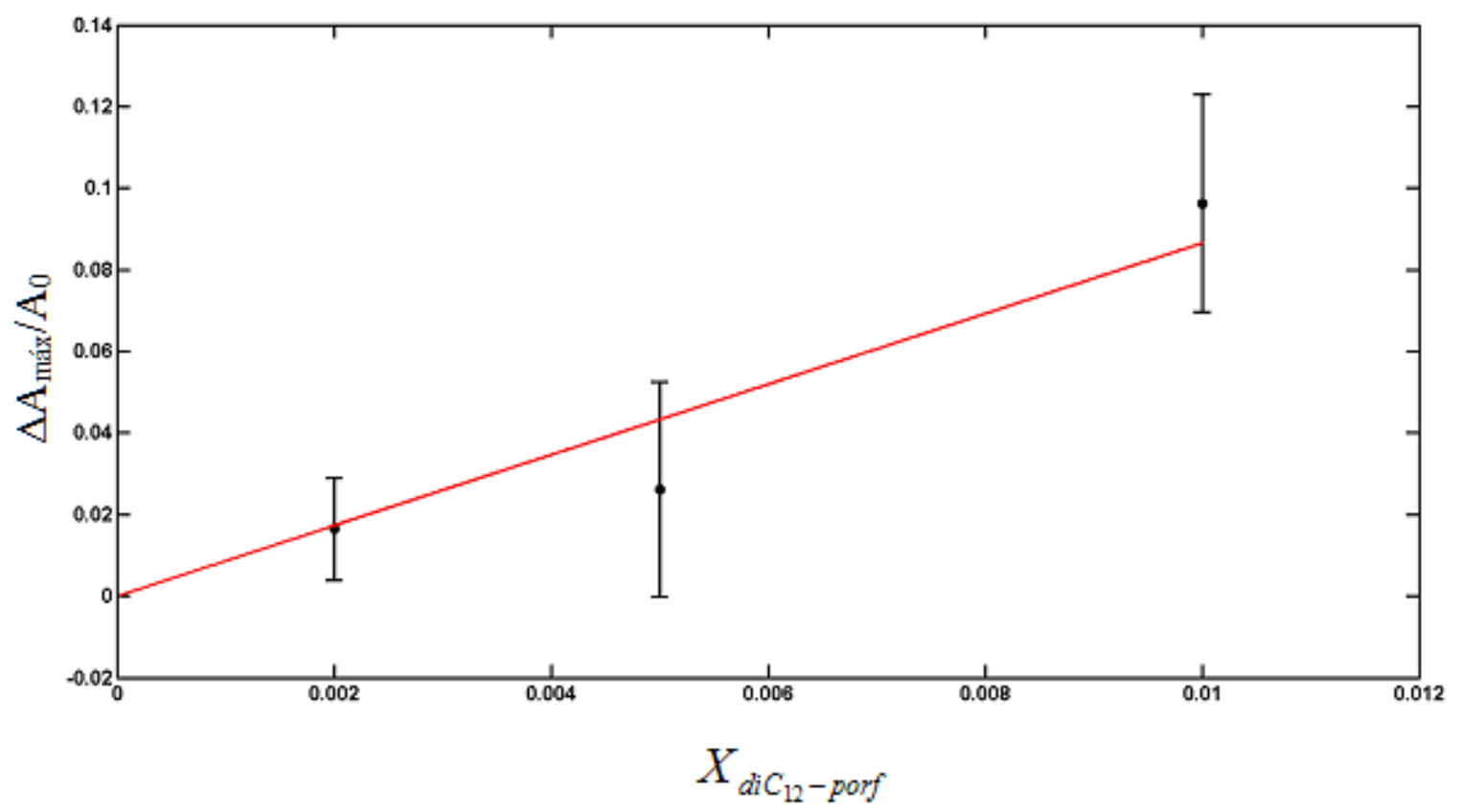

Figura 5.7: Área máxima em função da concentração de diC $_{12}$-porf.

\subsection{Medidas de aumento de área com campo AC para GUVs compostas de} POPC:Col + 1 mol\% de dic 12 -porf

Como mencionado no capítulo 4, estudaram-se também membranas compostas por POPC e pequena fração de colesterol. Os resultados do aumento de área da membrana estão representados na figura 5.8. Nesse gráfico fixamos a concentração da molécula fotoativa para $1 \mathrm{~mol} \%$, como mencionado na seção anterior, e variamos a concentração de colesterol. As linhas sólidas correspondem ao melhor ajuste usando a equação 2 aos dados experimentais. As figuras 5.9, 5.10 e 5.11 apresentam os valores médios encontrados para $A_{\text {máx, }} \tau$ e taxa de variação de área no início da irradiação, respectivamente. Note que, novamente, observamos duas populações de GUVs que apresentam comportamentos diferentes para os sistemas POPC:Col (90:10) e (75:25). 


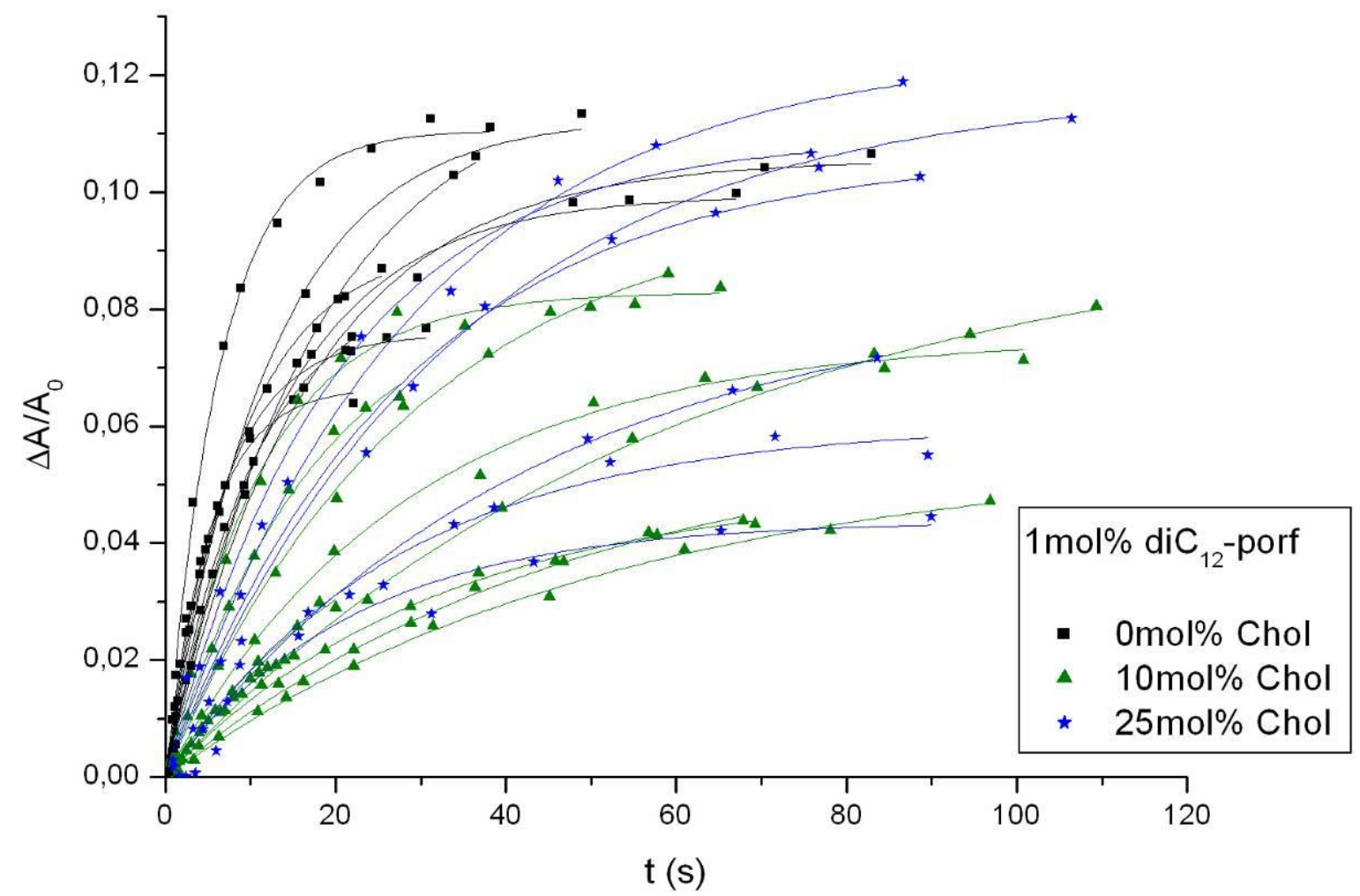

Figura 5.8: Aumento relativo de área da membrana em função do tempo e concentração de colesterol.

Nesse gráfico todas as curvas são para a concentração da molécula fotoativa de 1mol\%.

A figura 5.9 nos mostra que o aumento máximo de área é aproximadamente constante, independendo da concentração de Col. Entretanto, é possível notar a partir da figura 5.11 que a foto-oxidação lipídica que gera aumento de área é mais rápida no início da irradiação para membranas compostas somente por POPC do que a observada na presença de Col. Ao mesmo tempo, os valores de $\tau$ aumentam de 10 s para cerca de 30 s em membranas de POPC contendo Col (figura 5.10). Como conseqüência, após um tempo de irradiação membranas contendo POPC:Col atingem valores de $A_{\text {máx }}$ comparáveis a membranas contendo apenas POPC, irradiadas por um tempo menor, ou seja, a presença do Col aumenta o tempo de vida da molécula fotoativa em relação a membranas de POPC na ausência de Col. Isto provavelmente se deva ao fato de que a molécula de Col (figura 5.12) possui uma dupla ligação que está mais próxima ao centro de produção de oxigênio singlete do que a dupla ligação do POPC. 
Por outro lado, uma menor variação de aumento de área no início do processo de irradiação em membranas contendo colesterol (figura 5.11) reflete também que, muito possivelmente, o colesterol oxidado não contribui de maneira significativa para o aumento de área observado na membrana de POPC:Col. Para verificar tal hipótese, investigamos também como a irradiação afeta vesículas de DPPC:Col + $1 \mathrm{~mol} \%$ de dic $_{12}$-porf, e percebemos através deste estudo que nada ocorria com vesículas irradiadas, ou seja, nenhuma delas alongava, evidenciando nenhuma expansão de área. É bem conhecido que DPPC é um lipídeo saturado e membranas lipídicas contendo misturas de DPPC:Col (75:25) se encontram numa fase líquido-cristalina (líquido-ordenada) [42]. Portanto, este resultado revela que hidroperóxido de colesterol não causa mudanças na área da membrana como faz o hidroperóxido de POPC.

Assim, concluímos que o efeito de aumento de área em vesículas de POPC contendo até $25 \mathrm{~mol} \%$ de colesterol se deve principalmente à peroxidação do POPC (figura 5.6) e não do colesterol, embora o mesmo sofra oxidação (figura 5.12). Colesterol é uma molécula menor e não possui cadeias acilas flexíveis como uma molécula de POPC. Nossos resultados então demonstram que a mudança química promovida na molécula de colesterol pelo ataque de moléculas de ${ }^{2} \mathrm{O}_{1}$ (figura 5.12), que pode possibilitar um reposicionamento da molécula oxidada na membrana, é tal que este não induz um aumento de área significativo (ou observável) na mesma. De maneira análoga a membranas compostas por POPC e POPC-OOH, a presença de hidroperóxidos de colesterol na membrana não altera a permeabilidade da mesma, uma vez que não observamos variação de contraste das GUVs durante a irradiação devido a foto-oxidação dos lipídeos. 


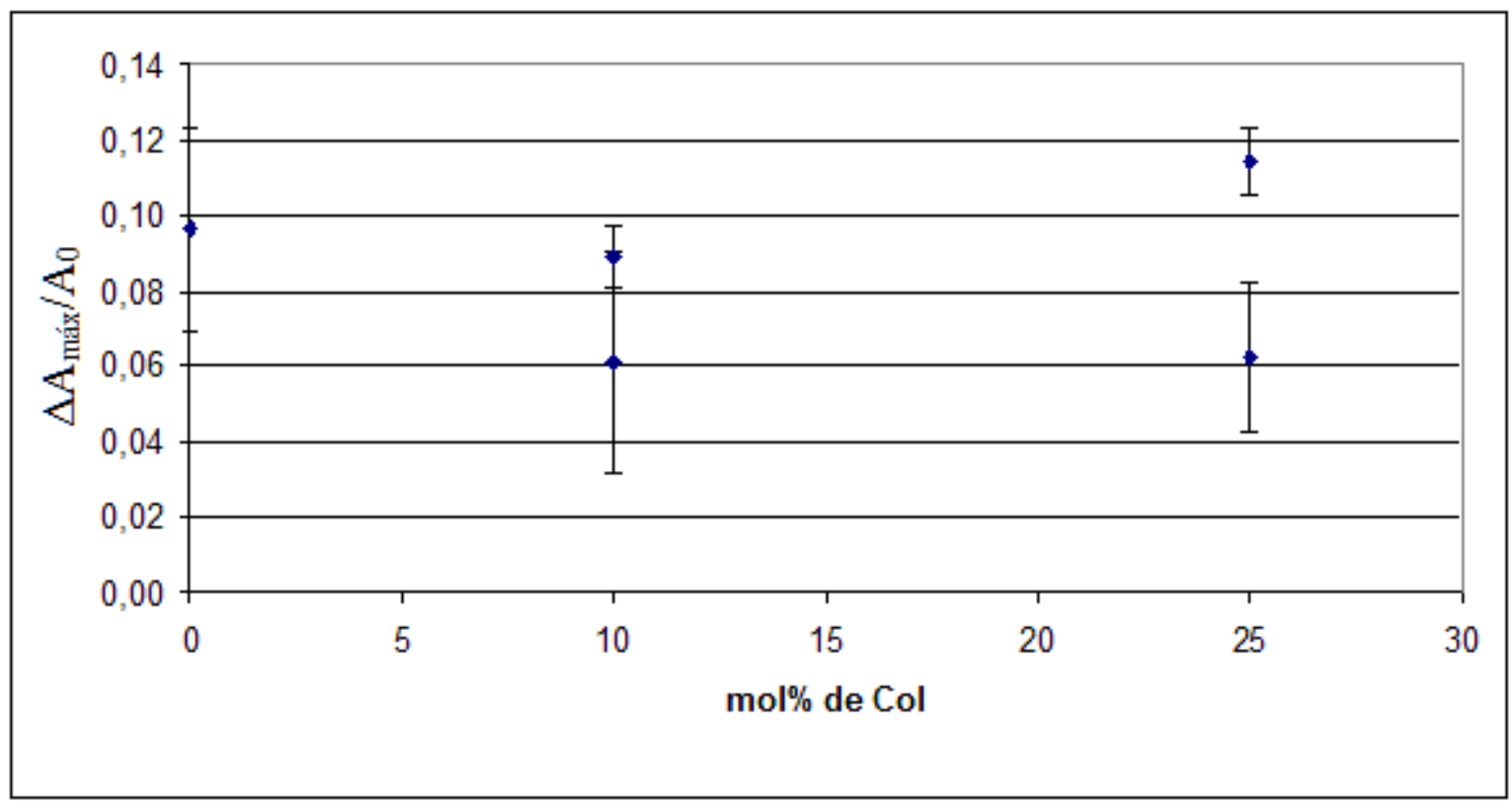

Figura 5.9: Valores médios do aumento máximo de área relativa obtido após o ajuste (figura 5.8) em função da concentração de Col, para a concentração de 1 mol\% de diC 12 $_{12}$-porf. As concentrações de 10 e 25 mol\% de Col apresentaram duas populações de aumento de área distintos (ver figura 5.8).

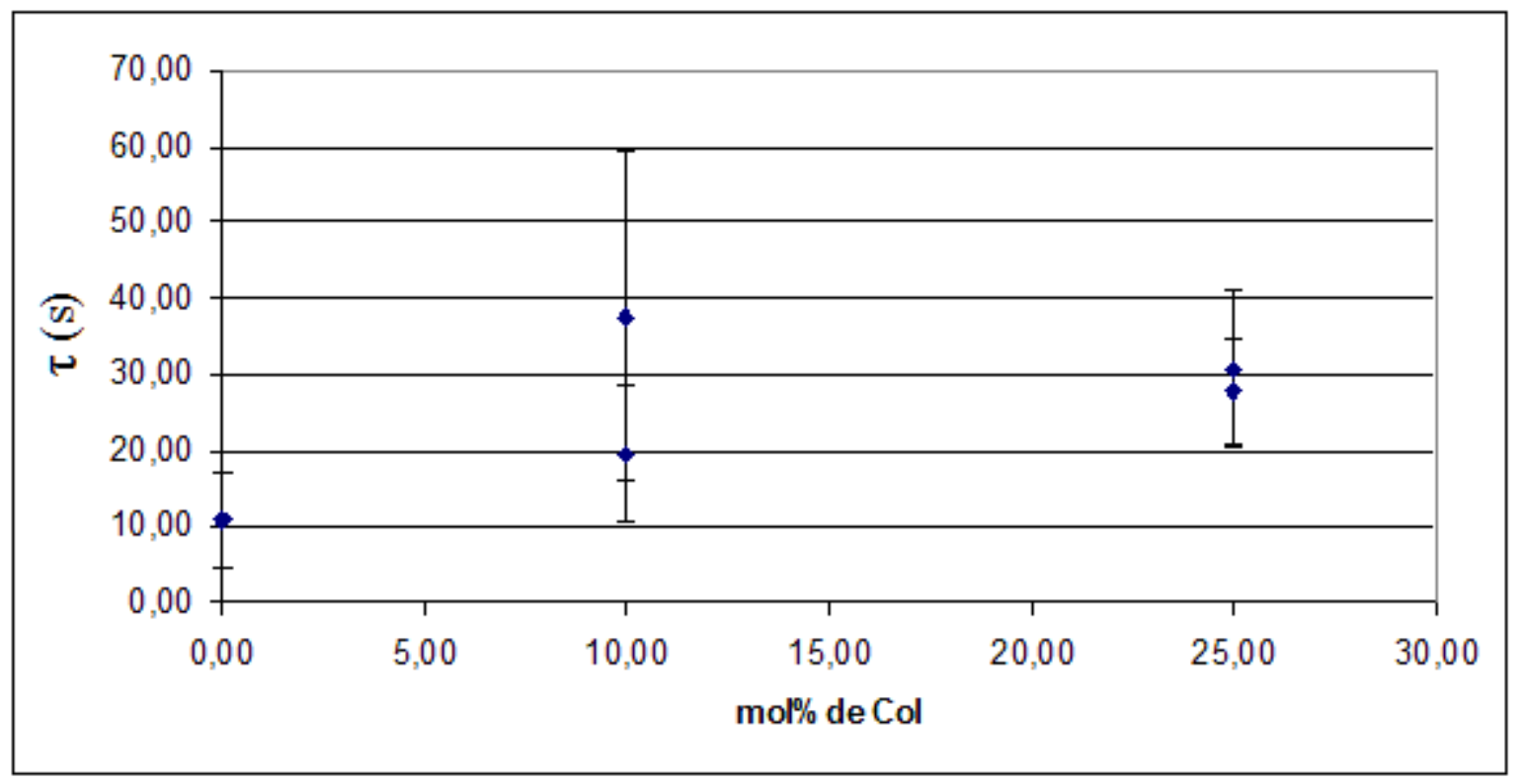

Figura 5.10: Valores médios do tempo característico $\tau$ obtido após o ajuste (figura 5.8) em função da concentração de Col, para a concentração de $1 \mathrm{~mol} \%$ de diC ${ }_{12}$-porf. As concentrações de 10 e 25 mol\% de Col apresentaram duas populações com tempos característicos distintos (ver figura 5.8). 


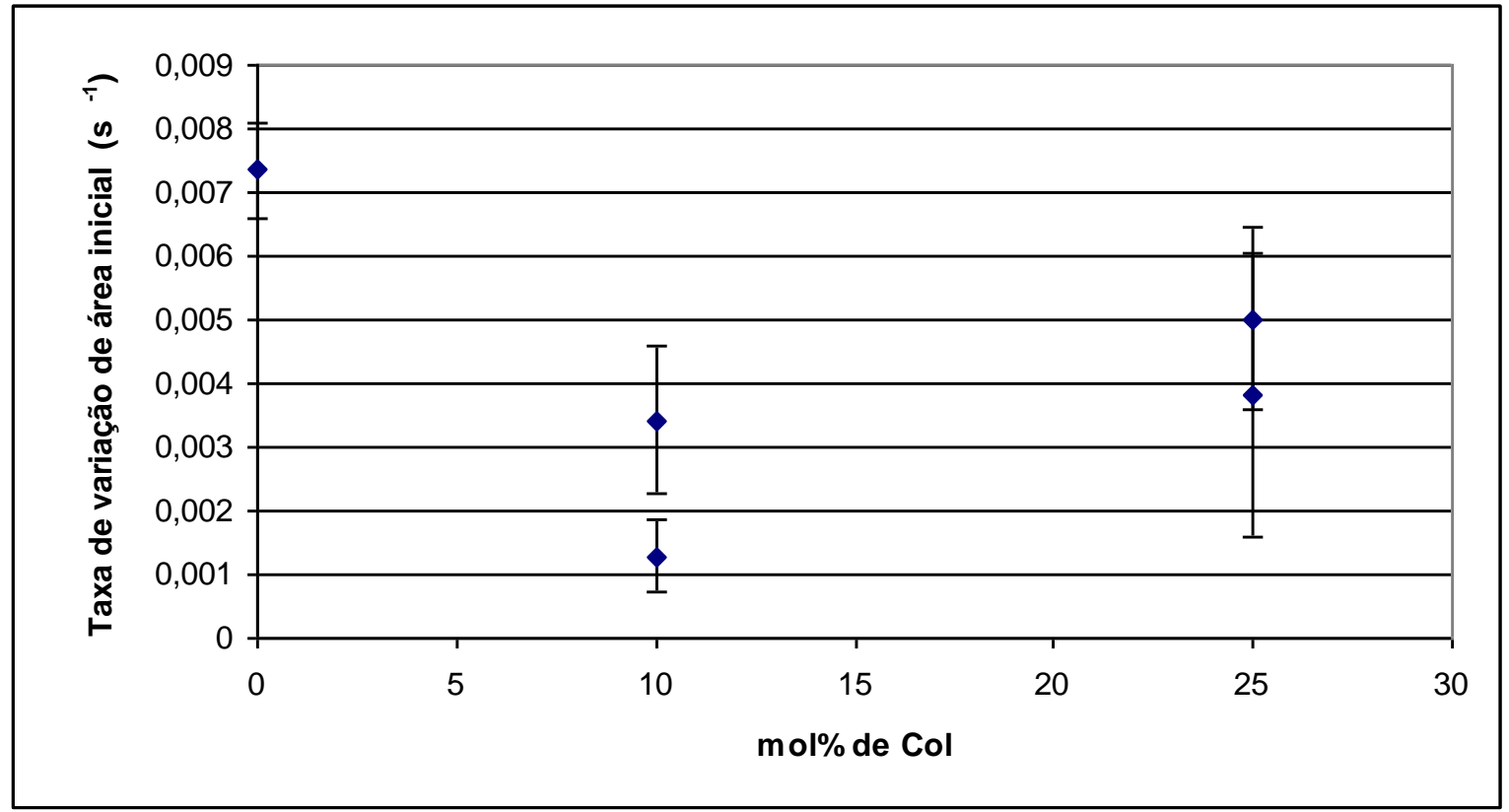

Figura 5.11: Taxa de variação relativa de área inicial em função da concentração de Col. As concentrações de 10 e $25 \mathrm{~mol} \%$ de Col apresentaram duas populações de aumento de área distintos (ver figura 5.8). 


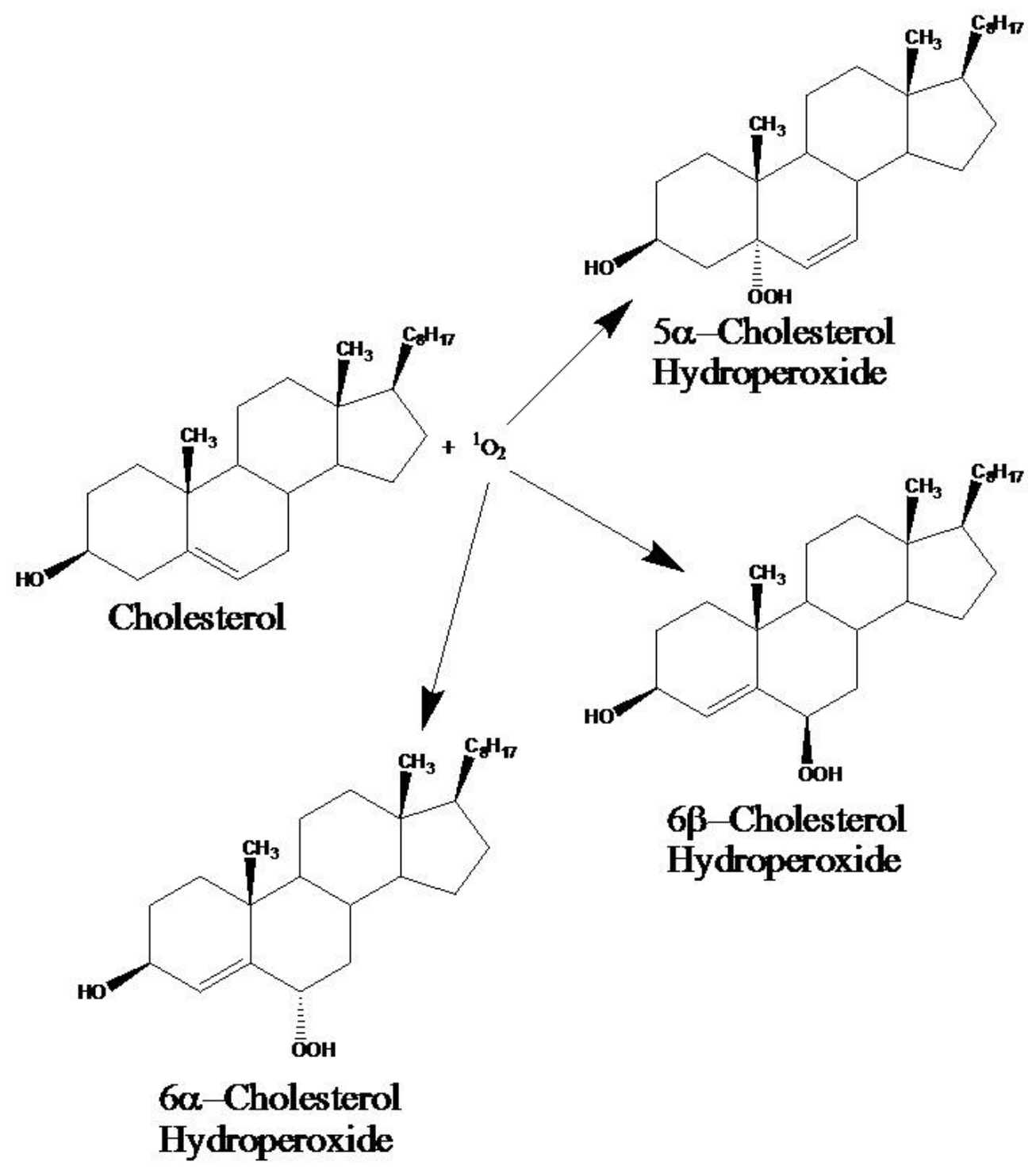

Figura 5.12: Esquema de peroxidação do colesterol. Imagem gentilmete cedida pelo porfo Mauricio S. Baptista.

5.3 Medidas de aumento de área com campo elétrico AC para GUVs compostas de POPC:CL +1 mol\% de dic 12 -porf

Como discutido no capítulo 4, nesta parte investigaremos membranas de POPC contendo até 50 mol\% de CL, dispersas em solução de EDTA, para evitarmos trabalhar com GUVs contendo domínios lipídicos visíveis, via um possível efeito quelante dos íons 
de cálcio presentes na solução aquosa. Além disso, conforme discutido na seção 5.1, investigaremos a resposta das membranas à foto-ativação de $1 \mathrm{~mol} \%$ de diC ${ }_{12}$-porf.

O gráfico da figura 5.13 mostra o aumento de área das membranas mistas em função do tempo de irradiação. Para podermos apreciar melhor o comportamento das GUVs, refizemos a figura com 5 gráficos, na qual em cada um dos cinco gráficos estamos apresentando sempre uma das cinco concentrações de $\mathrm{CL}$ comparando com 0 mol\% de CL, como está representado na figura 5.14.

A partir destes gráficos é possível perceber que a presença de $\mathrm{CL}$ altera a resposta das membranas à irradiação, sendo mais acentuada para as maiores concentrações de $\mathrm{CL}$ de 40 e 50 mol\%. As linhas sólidas representam os melhores ajustes da equação 2 aos dados experimentais, cujos parâmetros $A_{\text {máx }}$ e $\tau$ são apresentados nas figuras 5.15 e 5.16 , respectivamente.

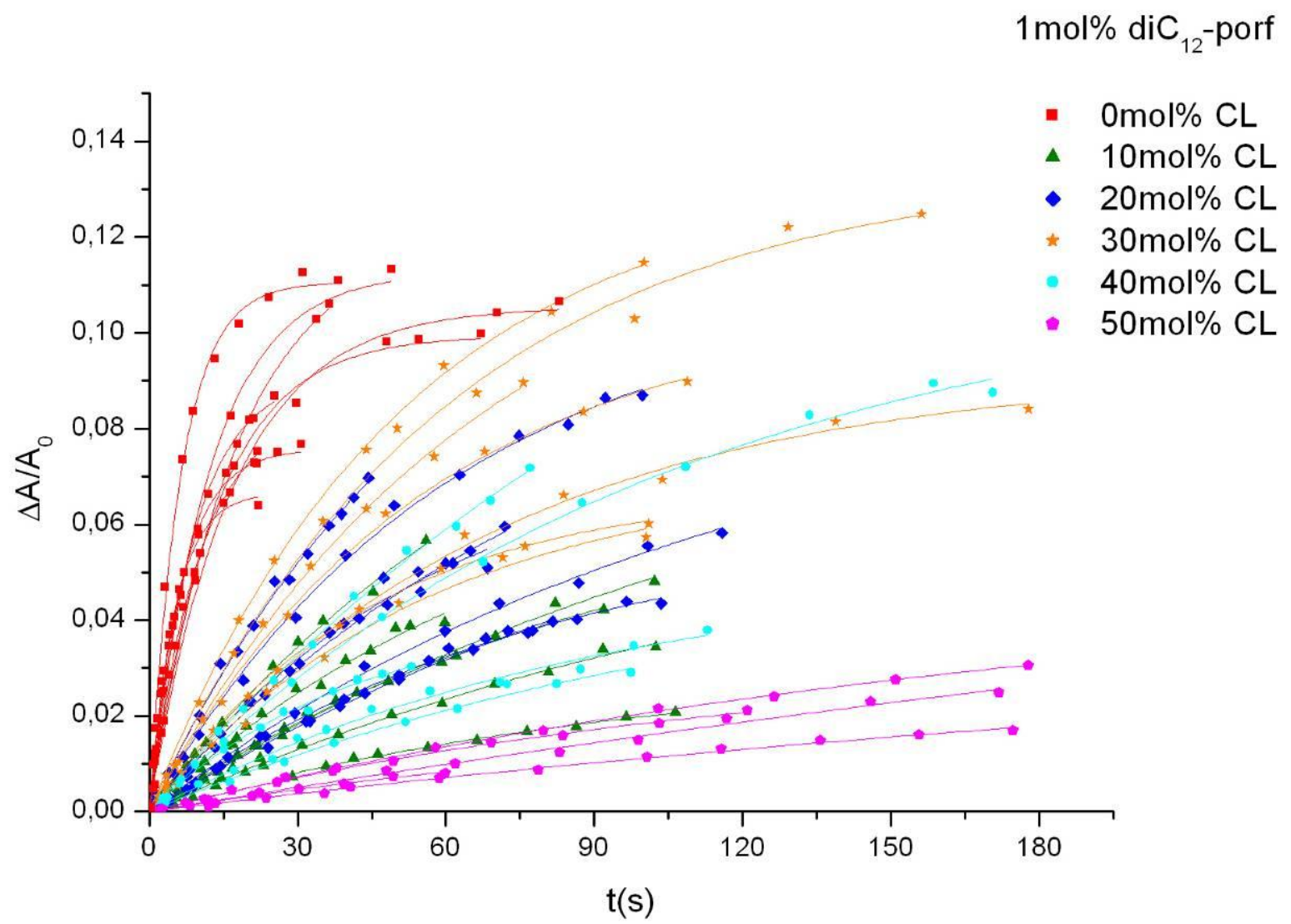

Figura 5.13: Aumento relativo de área da membrana em função do tempo e concentração de CL. Nesse gráfico toda as curvas são para a concentração da molécula fotoativa de $1 \mathrm{~mol} \%$. 

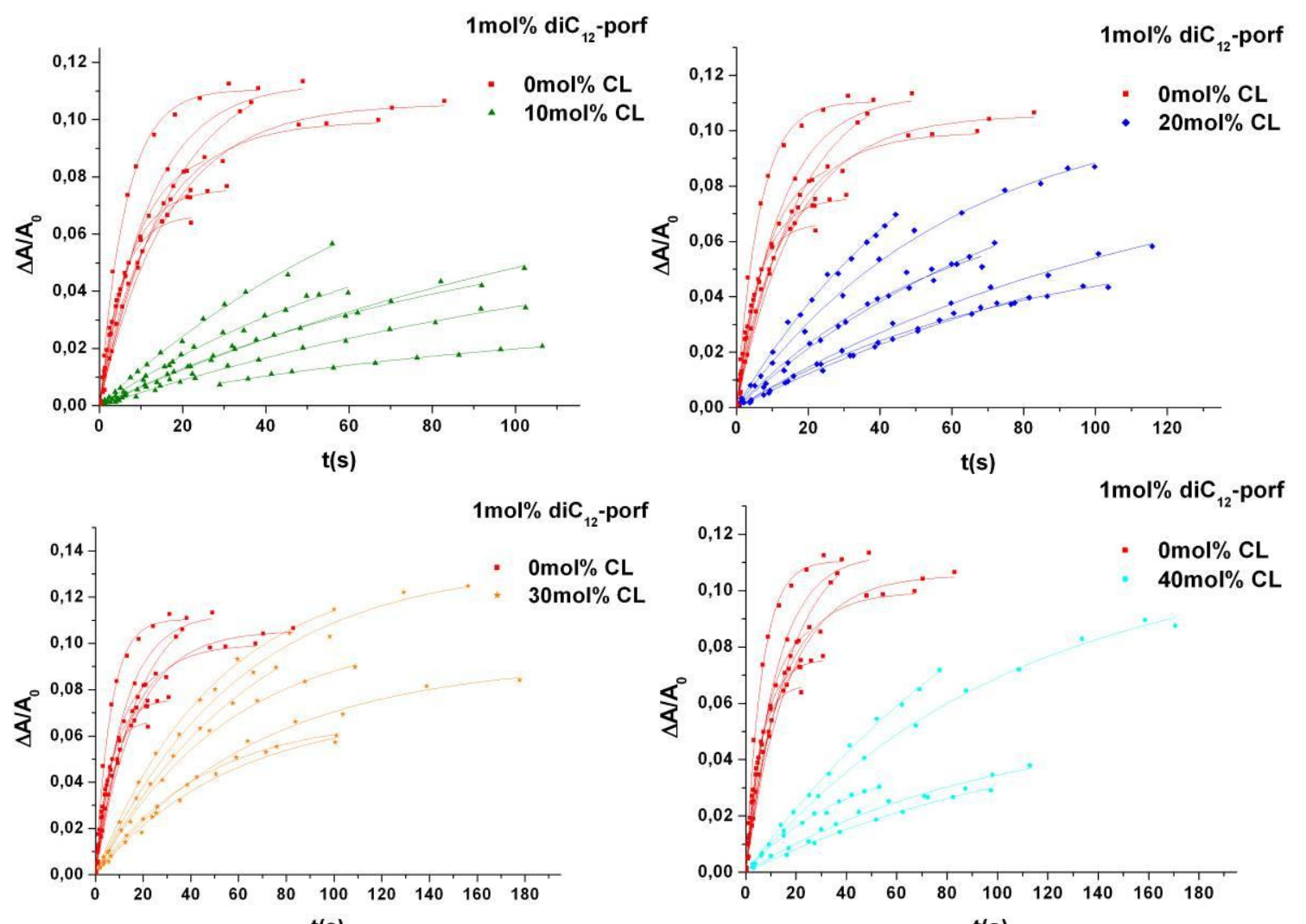

$t(s)$
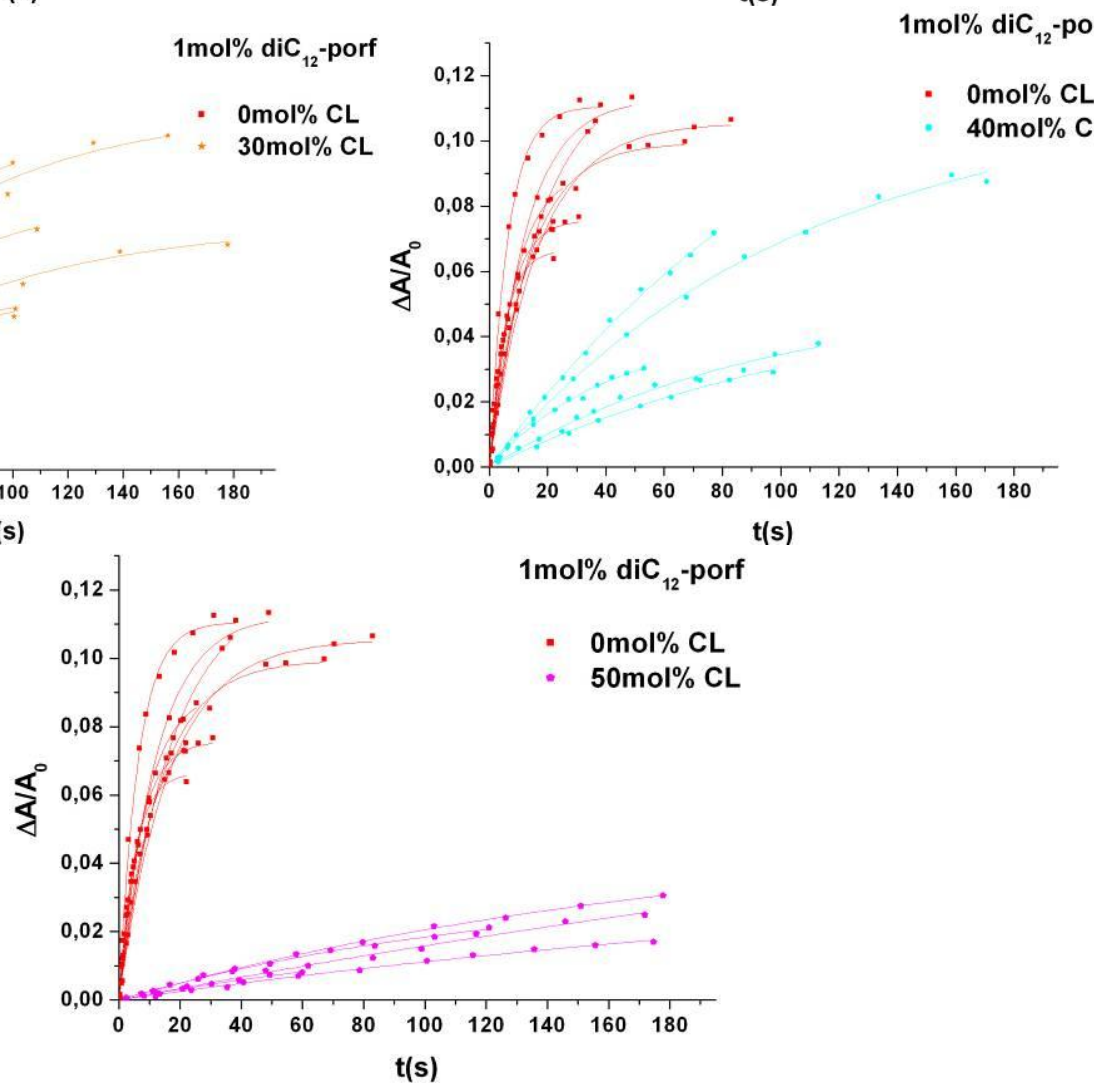

Figura 5.14: Aumento de área relativa em função do tempo para várias concentrações de $\mathrm{CL}$, em comparação com 0mol\% de CL. As linhas sólidas correspondem aos melhores ajustes utilizando equação 2 aos dados experimentais.

A partir da Figura 5.15 podemos observar que o aumento máximo de área da membrana é praticamente constante e da ordem de 10 \% para composições lipídicas contendo até 30 mol\% de $\mathrm{CL}$ em 70 mol\% de POPC. Por outro lado, para concentrações 
maiores de $\mathrm{CL}$, o aumento relativo de área máxima da membrana começa a decrescer sendo da ordem de 5\% para GUVs contendo POPC:CL (50:50).

Ao mesmo tempo, o tempo característico de foto-branqueamento da molécula diC $_{12}$-porf aumenta de $10 \mathrm{~s}$ na ausência de $C L$ para cerca de $100 \mathrm{~s}$ quando inserimos 10 a 40 mol\% de CL na membrana de POPC, e 250 s para GUVs mistas contendo 50 mol\% de CL (figura 5.16). Olhando a estrutura química da molécula de CL (figura 1.5 do capítulo 1), percebemos que a mesma oferece 4 novos sítios de peroxidação lipídica para o ataque de oxigênio singlete, concorrendo com a foto-oxidação do POPC e da própria molécula fotoativa, aumentando o tempo de vida da mesma.

Analisando a taxa de variação de área no início do processo de irradiação (figura 5.17), podemos notar uma diminuição acentuada da taxa de variação quando $\mathrm{CL}$ está presente na membrana em relação a GUVs compostas apenas por POPC. Ou seja, o processo de peroxidação de POPC e CL ocorre de tal maneira que o efeito combinado promove um aumento menor de variação de área da membrana com o tempo. No caso de membranas contendo até $30 \mathrm{~mol} \%$ de $\mathrm{CL}$, a formação de lipídeos oxidados leva a uma expansão de área de até 10 \% de maneira similar a GUVs formadas apenas por POPC, mas necessitam de um tempo maior de irradiação. Já para concentrações maiores de $\mathrm{CL}$, nossos resultados indicam que a presença desta molécula, embora foto-oxidada, não causa um aumento na membrana da mesma extensão como faz o hidroperóxido de POPC. 


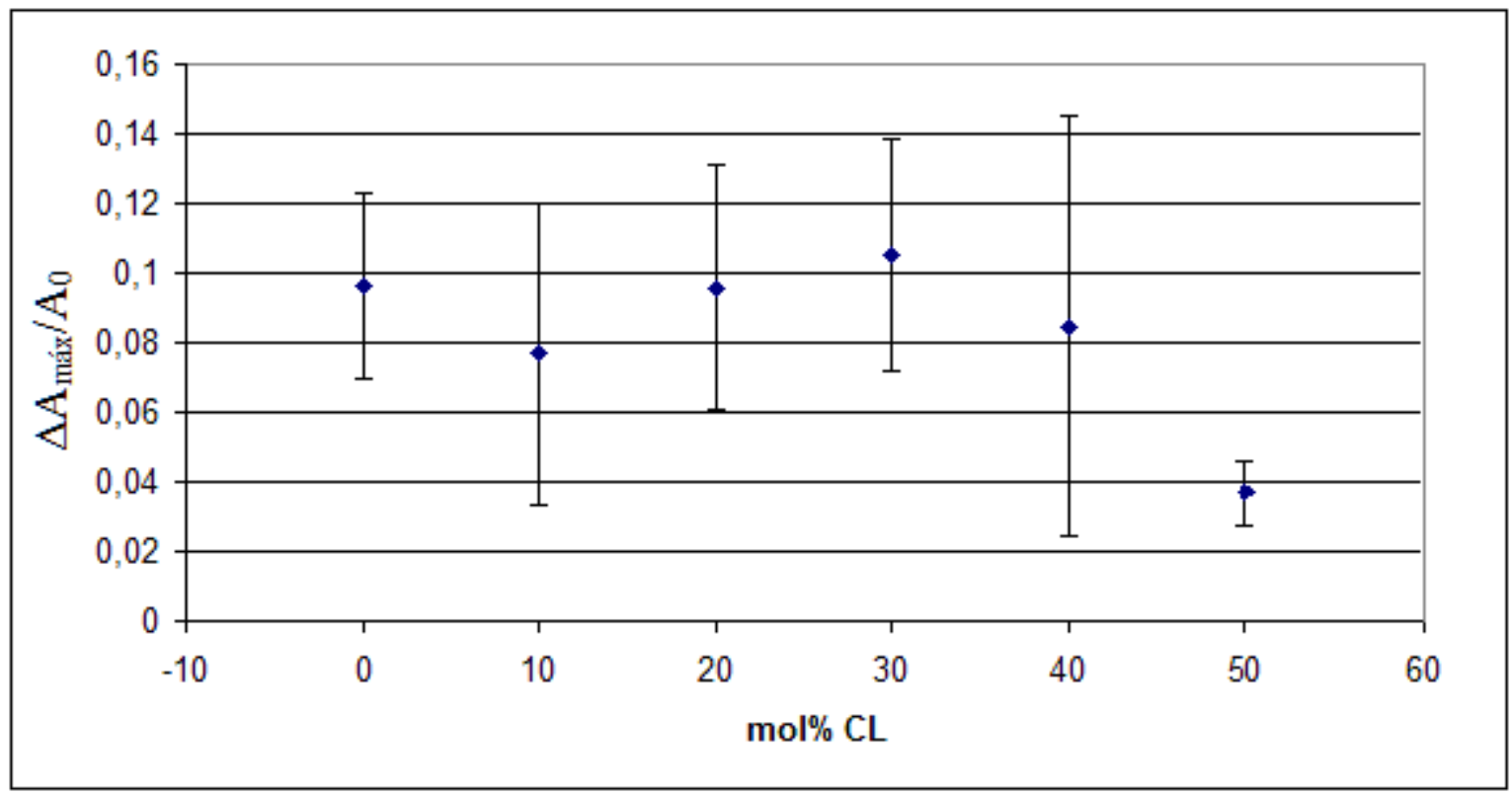

Figura 5.15: Valores médios do aumento máximo de área relativa obtido após o ajuste (figura 5.13 ou 5.14) em função da concentração de CL.

Resultados recentes [43] de isotermas de compressão de monocamadas lipídicas compostas por 100 \% de CL dispersas em solução de azul de metileno, sob irradiação, mostram um aumento de área de cerca de $1,5 \%$ a $30 \mathrm{mN} / \mathrm{m}$ (resultados não publicados da doutoranda de nosso grupo Thais F. Schmidt), ou seja, estes resultados evidenciam um aumento muito pequeno de expansão de área da CL quando foto-oxidada, que justificaria nossos resultados em bicamadas lipídicas. Entretanto, sabe-se que azul de metileno em solução aquosa apresenta uma carga positiva e interage muito fortemente com CL que possui duas cargas negativas, podendo se ligar formando dímeros e oligômeros na interface polar/apolar do lipídeo. A formação de dímeros e oligômeros de azul de metileno diminui a eficiência de geração de oxigênio singlete, o que pode, por sua vez, prejudicar a eficiência de foto-oxidação das moléculas de CL dispersas na monocamada. Portanto, um estudo da expansão de monocamadas de $\mathrm{CL}$ contendo diC $_{12}$-porf se faz necessário para quantificarmos a expansão de área induzida por foto-oxidação da cardiolipina e o efeito combinado da mesma com POPC-OOH na membrana lipídica. 


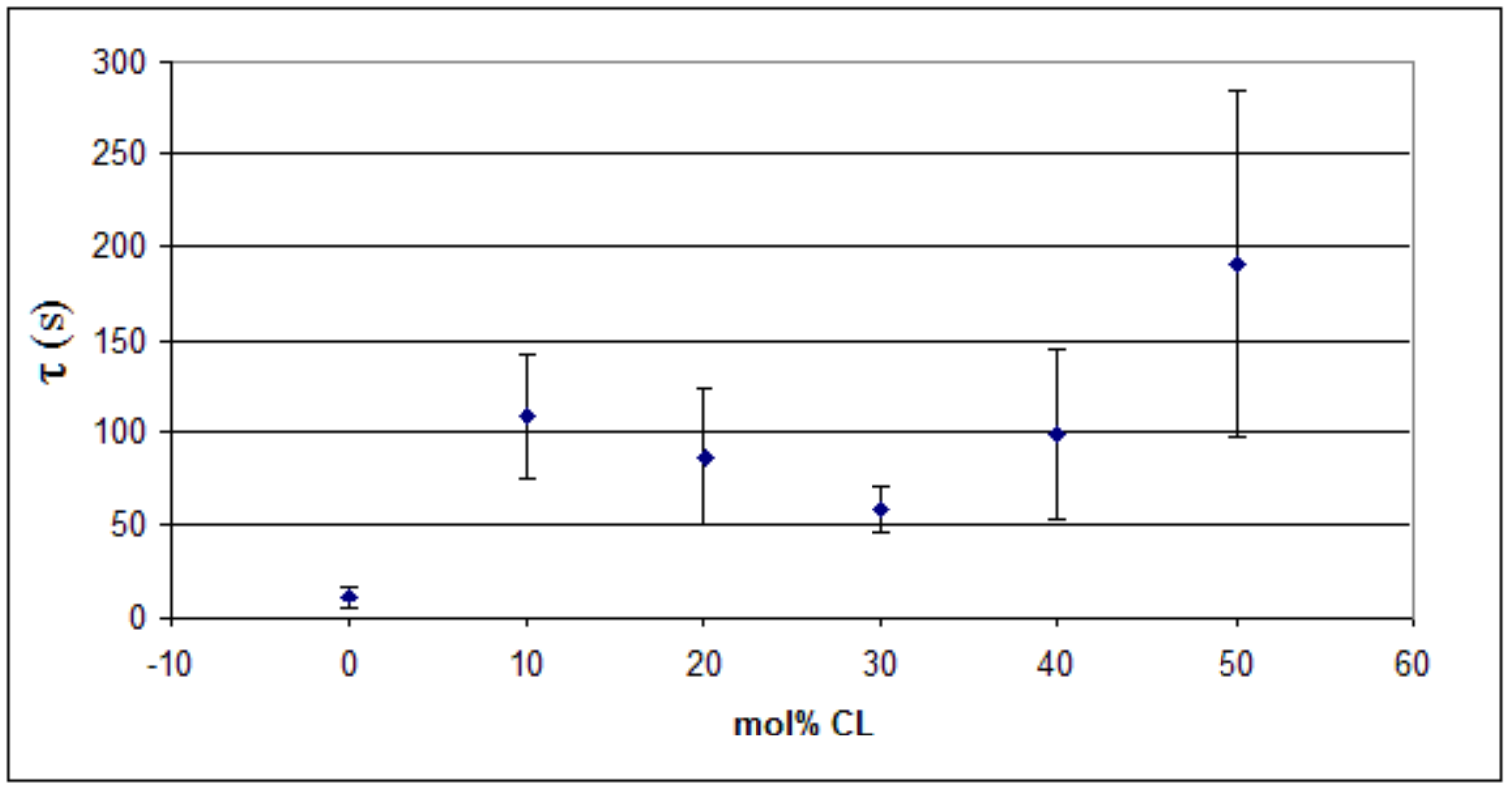

Figura 5.16: Valores médios do tempo característico t obtido após o ajuste (figura 5.13 ou 5.14) em função da concentração de $\mathrm{CL}$.

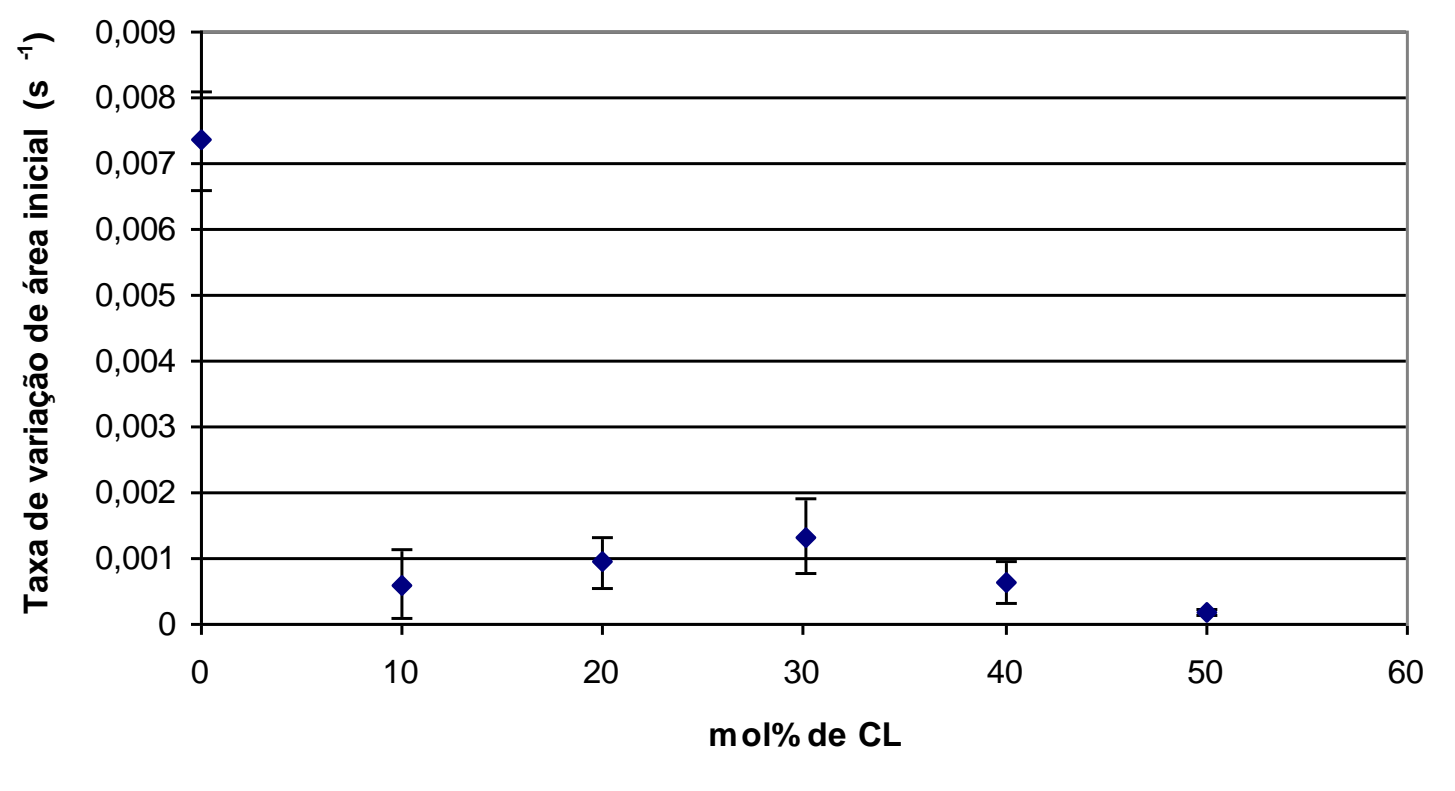

Figura 5.17: Taxa de variação de área inicial em função da concentração de CL. 


\section{Capítulo 6: Conclusões}

Neste trabalho utilizamos uma nova molécula fotossensibilizadora, sintetizada pelo Dr. Adjaci F. Uchoa do grupo do profo Mauricio S. Baptista (IQUSP). Tal molécula é formada por duas cadeias dodecil ligadas a uma porfirina, que chamamos de $\mathrm{diC}_{12}$-porf, e tem rendimento quântico de ${ }^{1} \mathrm{O}_{2}=0,7$ no máximo de absorção da porfirina $\lambda=400 \mathrm{~nm}$. Mostramos que a molécula fotoativa atua em membranas modelo, causando flutuações da membrana seguidas de aumento de área. Tal efeito é dependente da composição lipídica da membrana e do meio onde esta se encontra.

Primeiramente, evidenciamos que a presença de CL dificulta a formação das GUVs pelo método de eletroformação, com predomínio de GUVs pequenas e mal formadas para altas taxas de $\mathrm{CL}$ na membrana. Para concentrações igual ou maiores que $50 \mathrm{~mol} \%$ de $\mathrm{CL}$ observamos formação de domínios lipídicos na membrana. Tais domínios podem ser suprimidos pela presença de uma agente quelante de íons na solução, como o EDTA.

Sob irradiação, GUVs compostas por POPC, POPC:Col (até 25mol\%) e POPC:CL (concentrações menores que 50mol\%) dispersas em meio aquoso, respondem à fotooxidação, como discutido acima. Entretanto, para concentrações de CL igual a 50mol\% domínios lipídicos são foto-induzidos, a menos que EDTA seja adicionado à solução aquosa contendo açúcar. Por outro lado, a adição de $\mathrm{CaCl}_{2}$ induz a formação de domínios seguido de destruição da membrana durante a irradiação. Portanto, concluímos que íons $\mathrm{Ca}^{++}$ devem se complexar com as cargas negativas dos grupos fosfato da $\mathrm{CL}$, favorecendo a formação de domínios lipídicos. Resultados recentes da literatura [44] mostram que a presença de lipídeos oxidados favorece a difusão lateral dos lipídeos na membrana.

A análise quantitativa do aumento de área das GUVs com o tempo de irradiação nos deu suporte para concluir que:

(1) Para todas as membranas estudadas, o aumento de área segue um comportamento exponencial, onde o máximo de expansão da membrana é modulado pelo tempo de vida "útil" da molécula fotoativa. 
(2) No caso de GUVs compostas por POPC, observamos que o aumento máximo de área é proporcional ao aumento da concentração de diC $_{12}$-porf até $1 \mathrm{~mol} \%$. Concentrações maiores da molécula fotoativa provavelmente formam dímeros e/ou oligômeros na membrana diminuindo sua capacidade de geração de oxigênio singlete.

(3) A eficiência da foto-oxidação em GUVs compostas de POPC é tal que a cada 12 oxigênios singletes produzidos somente 1 reage com a dupla ligação da molécula de POPC.

(4) Para $1 \mathrm{~mol} \%$ de $\mathrm{diC}_{12}$-porf incorporado na membrana de POPC, a expansão máxima de área é da ordem de 10\%, indicando que cerca de $67 \%$ de hidroperóxidos de POPC são gerados. A membrana se mantém integra.

(5) Para 1 mol\% de diC $_{12}$-porf incorporado na membrana de POPC sob irradiação, o tempo de foto-clareamento de $\mathrm{diC}_{12}$-porf é da ordem de $\tau=10 \mathrm{~s}$.

(6) A presença de colesterol aumenta $\tau$ para 30s, devido ao fato de Col possuir sua dupla ligação mais próxima do centro de produção de oxigênio singlete. Ocorre uma diminuição da taxa de aumento de área da membrana com o tempo, provavelmente porque colesterol-oxidado não impacta em aumento de área da membrana como ocorre com POPC-oxidado.

(7) A presença de CL em membranas mistas de POPC tem efeito similar a de Col, com aumento de $\tau$ para 100 s para concentrações até $40 \mathrm{~mol} \%$ de CL e 200 s para concentrações de $50 \mathrm{~mol} \%$. Certamente, a presença de 4 caudas insaturadas de CL causam um efeito maior que o Col em proteger a foto-degradação da molécula fotoativa. Ao mesmo tempo, a foto-oxidação de POPC e CL levam a um aumento máximo de área similar até a composição de 40mol\% de CL em 60mol\% de POPC ( 10\%) embora o incremento de área seja bem mais lento quando a $C L$ está presente na membrana (a taxa de variação inicial de área diminui cerca de 7 vezes). Já para a composição da membrana de 50mol\% de CL em 50mol\% de POPC, ocorre uma diminuição de cerca de $50 \%$ no aumento máximo de área exibido pela membrana. 


\section{Referências Bibliográficas}

[1.] Stryer, L. Capítulo 11: Estrutura e Dinâmica de Membranas. Bioquímica. 4 ed. Estados Unidos. Editora Guanabara.1995. pgs. 245-272.

[2.] Disponível em: <http://biogeotc.wordpress.com/category/unidade-i-obtencao-demateria/> Acessado em: 13/10/11

[3.] Disponível em: <http://docentes.esalq.usp.br/luagallo/lipideos.html> Acessado em: $13 / 10 / 11$

[4.] Gennis, R. B. Chapter 2: The Structures and Properties of Membrane Lipids. Biomembranes: Molecular Structure and Function. Estados Unidos. Springer-Verlag. 1989. pgs $36-84$.

[5.] Schlamea, M.; Rua, D.; Greenberg, M. L., The biosynthesis and functional role of cardiolipin, Progress in Lipid Research, v. 39, p. 257-288, 2000.

[6.] Wang, C.; Youle, R. J., The Role of Mithocondria in Apoptosis, The Annual Review of Genetics, v.43, p.95-118, 2009.

[7.] Wright, M. M.; Howe, A. G.; Zaremberg, V., Cell membranes and apoptosis: role of cardiolipin, phosphatidylcholine, and anticancer lipid analogues, Biochem. Cell Biol., v. 82, p. 18-26, 2004.

[8.] Bröker, L. E.; Kruyt, F. A. E.; Giaccone, G., Cell Death Independent of Caspases: A Review, Clin Cancer Res, v. 11, no 9, 2005.

[9.] AVANTI POLAS LIPIDS. Disponível em: <http://www.avantilipids.com.br>. Acessado em: $13 / 10 / 11$

[10.] Disponível em: <http://rayolabordamonicabiologia.blogspot.com>. Acessado em: $11 / 10 / 11$.

[11.] Voet, D.; Voet, J. Lipids and Membranes. Biochemistry. 2 ed. Estados Unidos. Wiley. 1994. pgs. 277-330.

[12.] Omar, M. Estudos físico-químicos e estruturais de lipossomas compósitos de fosfatidilcolina e quitosana. Tese de doutorado - Universidade Federal do Rio Grande do Sul, Porto Alegre, 2008. 
[13.] Disponível em: <http://pt.wikipedia.org/wiki/Lipossoma>. Acesso em: 11/10/11

[14.] Santos, N. C.; Castanho, M. A. R. B., Lipossomas: A Bala Mágica acertou? Química Nova, v. 25., no 6B, p. 1181-1185. 2002.

[15.] Dougherty, T. J; et al., Photodynamic Therapy. Journal of the National Cancer Institute, v. 90, n. 12, p. 889-905, 1998.

[16.] Kübler, A. C., Photodynamic Therapy, Medical Laser Application, v. 20, p. 37-45, 2005.

[17.] Konan, Y. N.; Gurny, R.; Allémann, E., State of the art in the delivery of photosensitizers for photodynamic therapy, Journal of Photochemistry and Photobiology B: Biology, v.66, p. 89-106, 2002.

[18.] Ochsner, M., Photophysical and photobiological processes in the photodynamic therapy of tumours. Journal of Photochemistry and Photobiology B: Biology, v. 39, p. 1-18, 1997.

[19.] Caetano, W.; Haddad, P. S., Itri, R.; Severino, D.; Vieira, V. C; Baptista, M. S.; Schröder, A. P.; Marques, C. M., Photo-Induced Destruction of Giant Vesicles in Methylene Blue Solutions, Langmuir, v. 23, no 3, p. 1307-1314, 2006.

[20.] Riske, K. A.; Sudbrack, T. P.; Archilha, N. L.; Uchoa, A. F.; Schroder, A. P.; Marques, C. M.; Baptista, M. S.; Itri, R., Giant Vesicles under oxidative stress, Biophysical Journal, v. 97, p. 1362-1370, 2009.

[21.] Wong-ekkabut, J.; Xu, Z.; Triampo, W.; Tang, I-M; Tieleman, D. P.; et al., Effect of lipid peroxidation on the properties of lipid bilayers: a molecular dynamics study, Biophys. J., v. 93, p. 4225-4236, 2007.

[22.] Aranda, S.; Riske, K. A.; Lipowsky, R.; Dimova, R., Morphological Transitions of Vesicles Induced by Alternating Electric Fields, Biophysical Journal: Biophysical Letters, 2008.

[23.] Yamamoto, T.; Aranda-Espinoza, S.; Dimova, R.; Lipowsky, R., Stability of Spherical Vesicles in Electric Fields, Langmuir, v. 26, no14, p. 12390-12407, 2010. 
[24.] Perutková, S.; Frank, M.; Bohinc, K.; Bobojevic,G.; Zelko, J.; Rozman, B.; Kralj-Iglic, V.; Iglic, A., Interaction between equally charged membrane surfaces mediated by positively and negatively charged macro-ions, J. Membrane Biol., v. 236, p. 43-53, 2010.

[25.] Urbanija, J.; Babnik, B.; Frank, M.; Tomsic, N.; Rozman, B.; Kralj-Iglic, V.; Iglic, A., Attachment of $\beta 2$-glycoprotein I to negatively charged liposomes may prevent the release of daughter vesicles from the parent membrane., Eur. Biophys J., v. 37, p. 1085-1095, 2008.

[26.] Urbanija, J.; Tomsic, N.; Lokar, M.; Ambrozic, A.; Cucnik, S.; Rozman, B.; Kanduser, M.; Iglic, A.; Kralj-Iglic, V., Coalescence of phospholipid membranes as a possible origin of anticoagulant effect of serum proteins, Chem. Phys. Lipids, v. 150, p. 49-57, 2007.

[27.] Ambrozic, A.; Cucnik, S.; Tomsic, N.; Urbanija, J.; Lokar, M.; Babnik, B.; Rozman, B.; Iglic, A.; Kralj-Iglic, V., Interaction of giant phospholipid vesicles containing cardiolipin and cholesterol with $\beta 2$-glycoprotein-I and anti- $\beta 2$-glycoprotein-I antibodies, Autoimmunity Reviews, v. 6, p. 10-15, 2006.

[28.] Tomšiè, N.; Babnik, B.; Lombardo, D.; Mavcic, B.; Kandušer, M.; Iglic, A.; Kralj-Iglic, V., Shape and Size of Giant Unilamellar Phospolipid Vesicles Containing Cardiolipin, J. Chem. Inf. Model., v. 45, p. 1676-1679, 2005.

[29.] Pavlic, J. I.; Genova, J.; Zheliaskova, A.; Iglic, A.; Mitov, M. D., Electroformation of neutral and negatively charged phospolipid giant vesicles under physiological conditions, 2010.

[30.] Khalifat, N.; Puff, N.; Bonneau, S.; Fournier, J-B.;Angelova, M. I., Membrane Deformation under Local pH Gradient: Mimicking Mitochondrial Cristae Dynamics, Biophysical Journal, v. 95, p. 4924-4933, 2008.

[31.] Jalmar, O.; García-Sáez, A. J.; Berland, L.; Gonzalvez, F; Petit, P. X., Giant unilamellar vesicles (GUVs) as a new tool for analysis of caspase-8/Bid-FL complex binding to cardiolipin and its functional activity, Cell Death and Disease, v. 1, no e103, p. 1-9, 2010.

[32.] Vequi-Suplicy, C. C.; Riske, K. A.; Knorr, R. L.; Dimova, R., Vesicles with charged domains, Biochimica et Biophysica Acta, v. 1798, p. 1338-1346, 2010. 
[33.] Disponível em: <http://pt.wikipedia.org/wiki/Ficheiro:Edta_structure.png>. Acessado em: $11 / 10 / 11$

[34.] Comunicação oral Dr. Adjaci U. Fernandes.

[35.] Archilla, N. L. Interação entre um peptídeo antimicrobiano e vesículas de fosfolipídeos. 2008. Dissertação (Mestrado) - Instituto de Física da Universidade de São Paulo, São Paulo. 2008.

[36.] Angelova, M. I; Dimitrov, D. S., Liposome Electroformation, Faraday Discuss. Chem. Soc., v. 81, p. 303-311, 1986.

[37.] Walde, P.; Cosentino, K.; Engel, H.; Stano, P., Giant Vesicles: Preparations and Applications, Chem. BioChem., v. 11, p. $848-865,2010$.

[38.] Monte, L-R.; Ahyayauch, H.; Ibarguren, M.; Sot, J.; Alonso, A.; Bagatolli, L. A.; Goñi, F. M., Electroformation of Giant Unilamellar Vesicles from Native Membranes and Organic Lipid Mixtures for the study of lipid domains under physiological ionic-strength conditions. In: Weissig, V., Liposomes: Methods and Protocols, Volume 2: Biological Membrane Models, Methods in Molecular Biology, 2009.

[39.] Riske, K. A.; Döbereiner, H-G; Lamy-Freund, M. T., Comment on “Gel-Fluid Transition in Dilute versus Concentrated DMPG Aqueous Dispersions", Phys. Chem. B., v. 107, p. 5391-5392, 2003.

[40.] Riske, K. A.; Knorr, R. L.; Dimova, R., Bursting of charged multicomponent vesicles subjected to electric pulses, Soft Matter, v. 5, p. 1983-1986, 2009.

[41.] Busch, N. A.; Yarmush, M. L.; Toner, M., A theoretical formalism for aggregation of peroxidized lipids and plasma membrane stability during photolysis, Biophys. J., v. 75, p. 2956-2970, 1998.

[42.] MacMullen, T. P. W.; McElhaney, R. N., New aspects of the interaction of the cholesterol with dipalmitoylphosphatidylcholine bilayers as revealed by high-sensitivity differential scanning calorimetry, Biophys. Biochim. Acta, v. 1234, p. 90-98, 1995.

[43.] Comunicação oral Thais F. Schmidt. 
[44.] Beranova, L.; Cwiklik, L.; Jurkiewicz, P.; Hof, M.; Jungwirth, P., Oxidation changes physical properties of phospholipid bilayers: fluorescence spectroscopy and molecular simulations, Langmuir, v. 26, p. 6140-6144, 2010. 


\section{Trabalhos Publicados (Anexos)}




\title{
Giant Vesicles under Oxidative Stress Induced by a Membrane-Anchored Photosensitizer
}

\author{
Karin A. Riske, ${ }^{\dagger \star}$ Tatiane P. Sudbrack, ${ }^{\ddagger}$ Nathaly L. Archilha, ${ }^{\ddagger}$ Adjaci F. Uchoa, ${ }^{\S}$ André P. Schroder, ${ }^{\natural}$ \\ Carlos M. Marques, " Maurício S. Baptista, ${ }^{\S}$ and Rosangela Itri $^{\ddagger}$ \\ ${ }^{\dagger}$ Departamento de Biofísica, Universidade Federal de São Paulo, São Paulo, Brazil; ${ }^{\ddagger}$ Departamento de Física Aplicada, Instituto de Física, \\ §Departamento de Bioquímica, Instituto de Química, Universidade de São Paulo, São Paulo, Brazil; and IInstitut Charles Sadron, Université de \\ Strasbourg, Centre National de la Recherche Scientifique, Strasbourg, France
}

\begin{abstract}
We have synthesized the amphiphile photosensitizer PE-porph consisting of a porphyrin bound to a lipid headgroup. We studied by optical microscopy the response to light irradiation of giant unilamellar vesicles of mixtures of unsaturated phosphatidylcholine lipids and PE-porph. In this configuration, singlet oxygen is produced at the bilayer surface by the anchored porphyrin. Under irradiation, the PE-porph decorated giant unilamellar vesicles exhibit a rapid increase in surface area with concomitant morphological changes. We quantify the surface area increase of the bilayers as a function of time and photosensitizer molar fraction. We attribute this expansion to hydroperoxide formation by the reaction of the singlet oxygen with the unsaturated bonds. Considering data from numeric simulations of relative area increase per phospholipid oxidized (15\%), we measure the efficiency of the oxidative reactions. We conclude that for every 270 singlet oxygen molecules produced by the layer of anchored porphyrins, one eventually reacts to generate a hydroperoxide species. Remarkably, the integrity of the membrane is preserved in the full experimental range explored here, up to a hydroperoxide content of $60 \%$, inducing an $8 \%$ relative area expansion.
\end{abstract}

\section{INTRODUCTION}

It is well known that biological membranes contain a large amount of unsaturated lipids, which are susceptible to the attack of singlet oxygen and free radicals. These reactions generate lipid hydroperoxides and a large variety of unstable lipid species, which can lead to extensive free radical chain reactions. Oxidative stress can cause severe membrane damage and even cell death; although it is not yet clear to what extent the formation of lipid hydroperoxides is directly responsible for cell damaging. Peroxidation of lipids has been widely studied both in biological membrane extracts and in model lipid bilayers, and involves several reactions that depend both on membrane properties and on the oxidative agent (see (1) for a review). Oxidative reactions alter the chemical structure of unsaturated lipids, leading to changes in lipid bilayer properties, such as permeability, fluidity, and packing order (1-6). Though less emphasized, lipid peroxidation firstly causes an increase in area per lipid $(2,5)$. Molecular dynamics simulations have shown (5) that the hydroperoxide group has a tendency to reside close to the bilayer surface, due to its more hydrophilic character, resulting in an increase in area per lipid. Such area increase upon oxidation has been reported on lipid monolayers (7-9), but it has never been experimentally quantified in lipid bilayers.

Oxidative processes can be therapeutically used to kill tumor cells and heal several skin diseases. Photodynamic therapy (10) consists of directing a photosensitive molecule to a target tissue, e.g., tumors, followed by irradiation with

Submitted January 19, 2009, and accepted for publication June 18, 2009.

*Correspondence: kar@biofis.epm.br

Editor: Petra Schwille.

(C) 2009 by the Biophysical Society

0006-3495/09/09/1362/9 \$2.00 light. Photosensitive molecules, such as porphyrin derivatives or methylene blue, can easily transfer their energy to molecular oxygen thus generating singlet oxygen ${ }^{1} \mathrm{O}_{2}$ and/or free radicals. When irradiated, photosensitive molecules trigger oxidative reactions in the targeting tissue, causing oxidation of several biomolecules, which eventually lead to cell apoptosis/necrosis. Though final tissue death is a complex process that involves several intermediate steps, it is believed that damaging membranes is one of the first and key steps $(11,12)$. Some literature data also suggest that membrane proteins may be the main triggers of processes leading to cell death (13). Even so, the reaction efficiency between singlet oxygen and unsaturated lipids, as well as the relationship between the extent of lipid peroxidation and the corresponding changes in the physical properties of membranes, are not yet known.

The effects of oxidative stress on model lipid membranes can be addressed by optical observation of giant unilamellar vesicles (GUVs). GUVs have diameters of $\sim 10 \mu \mathrm{m}$, similar to cells, and allow for optical observation in real-time, which make them a handy tool to study different aspects of lipid bilayers $(14,15)$. Damage to membranes due to photoactivation of methylene blue present in the surrounding solution was previously studied by optical microscopy of GUVs made of dioleoyl phosphatidylcholine (16). GUVs immersed in a micromolar solution of methylene blue were destroyed upon few minutes of irradiation. The mechanism of membrane damage was attributed to lipid chain break with formation of short-chain amphiphiles (16).

In this work, we investigate photoinduced effects of a new porphyrin derivative incorporated in GUVs of palmitoyl 
oleoyl phosphatidylcholine (POPC). This new photosensitive molecule, PE-porph, was synthesized by us and consists of a porphyrin molecule chemically linked to the headgroup of two phosphatidylethanolamines (PE) (Fig. $1 A$ ). The key advantage of PE-porph is that it inserts into the bilayer, and therefore the photosensitive group is anchored on the bilayer. This localization ensures that the production of ${ }^{1} \mathrm{O}_{2}$ occurs close to its main target, the acyl chain double-bond of POPC.

We report here that irradiation of the anchored PE-porph induces morphological changes of GUVs, driven by an increase in surface area induced by lipid peroxidation. The increase in area is here quantified, taking advantage of the fact that lipid vesicles assume prolate shapes when subjected to an alternating current (AC) field (17). Since at constant field strength the magnitude of vesicle elongation depends on the excess area of the particular vesicle, we were able to monitor the membrane area increase as a function of the irradiation time for several different molar fractions of PE-porph. The comparison between the amount of singlet oxygen generated by PE-porph and the corresponding production of lipid hydroperoxides allowed us to estimate the efficiency of reaction between singlet oxygen and unsaturated lipids.

\section{MATERIALS AND METHODS}

\section{Materials}

The phospholipids 1-palmitoyl-2-oleoyl-sn-glycero-3-phosphocholine (POPC) and 1,2-dimyristoyl-sn-glycero-3-phosphoethanolamine (DMPE) were purchased from Avanti Polar Lipids (Alabaster, AL). The photosensitizer dimethyl 8,13-divinyl-3,7,12,17-tetramethyl-21H,23H-porphine-2,18-dipropyl-L- $\alpha$-dimyristoylphosphatidylethanolamine (PE-porph) was synthesized as described below.

\section{PE-porph synthesis}

PE-porph was obtained by the addition of dimyristoyl phosphatidylethanolamine (DMPE) to acyl chloride of protoporphyrin IX ( $\geq 95 \%$, purchased from Sigma-Aldrich, St. Louis, MO), both in previously dried dichloromethane. The solvent excess was removed by reduced pressure and PE-porph was purified by column chromatography, using silica gel 230:70 as stationary phase eluate with $\mathrm{CHCl}_{2} / \mathrm{MeOH} 20: 1$. The reaction occurred with a final yield of $71 \%$. The product formation was initially characterized in thin layer chromatography showing a single spot with radio frequency of 0.65 in $\mathrm{CHCl}_{2} / \mathrm{MeOH}$ 20:1. Ultraviolet visible (UV-VIS) spectroscopy and fluorescence spectra show the same features as the original chromophore, therefore the reaction occurred without changes in the porphyrin ring (Fig. $1 B$ ). The infrared spectrum shows a broad and intense band at $3400 \mathrm{~cm}^{-1}$, due to the axial $\mathrm{OH}$ deformation; two bands at 2922 and $2852 \mathrm{~cm}^{-1}$, characteristic of axial $\mathrm{CH}, \mathrm{CH}_{2}$, and $\mathrm{CH}_{3}$ deformations present in the alkyl chains of phosphatidylethanolamine; and an intense band at $1735 \mathrm{~cm}^{-1}$ due to the axial $\mathrm{C}=\mathrm{O}$ deformation, which is characteristic of amides derived from protoporphyrin IX. In the mass spectrum, the mass peak of the ion molecular $(1799 \mathrm{~m} / \mathrm{z})$ is within the detection limit. However, the pattern of fragmentation along with the data from infrared and UV-VIS spectroscopy allowed the unequivocal determination of the structure of PE-porph. Several signals with high mass prove the functionalization with the phospholipid molecule. The presence of peaks every 14 units are characteristic of molecules with high-molecular-weight alkyl chains. Furthermore, the peak at $569.3 \mathrm{~m} / \mathrm{z}$ can be associated to N/OC rupture of one of the amides and chain break at the second amide (Porphyrin- $\mathrm{NCH}_{2} \mathrm{CH}_{2} / \mathrm{OPO}_{3} \mathrm{R}$ ). Another peak at $1115.7 \mathrm{~m} / \mathrm{z}$ was attributed to the fragment $\mathrm{C}_{55} \mathrm{H}_{79} \mathrm{~N}_{6} \mathrm{O}_{10} \mathrm{P}$, resulting from oxygen-phosphorus break

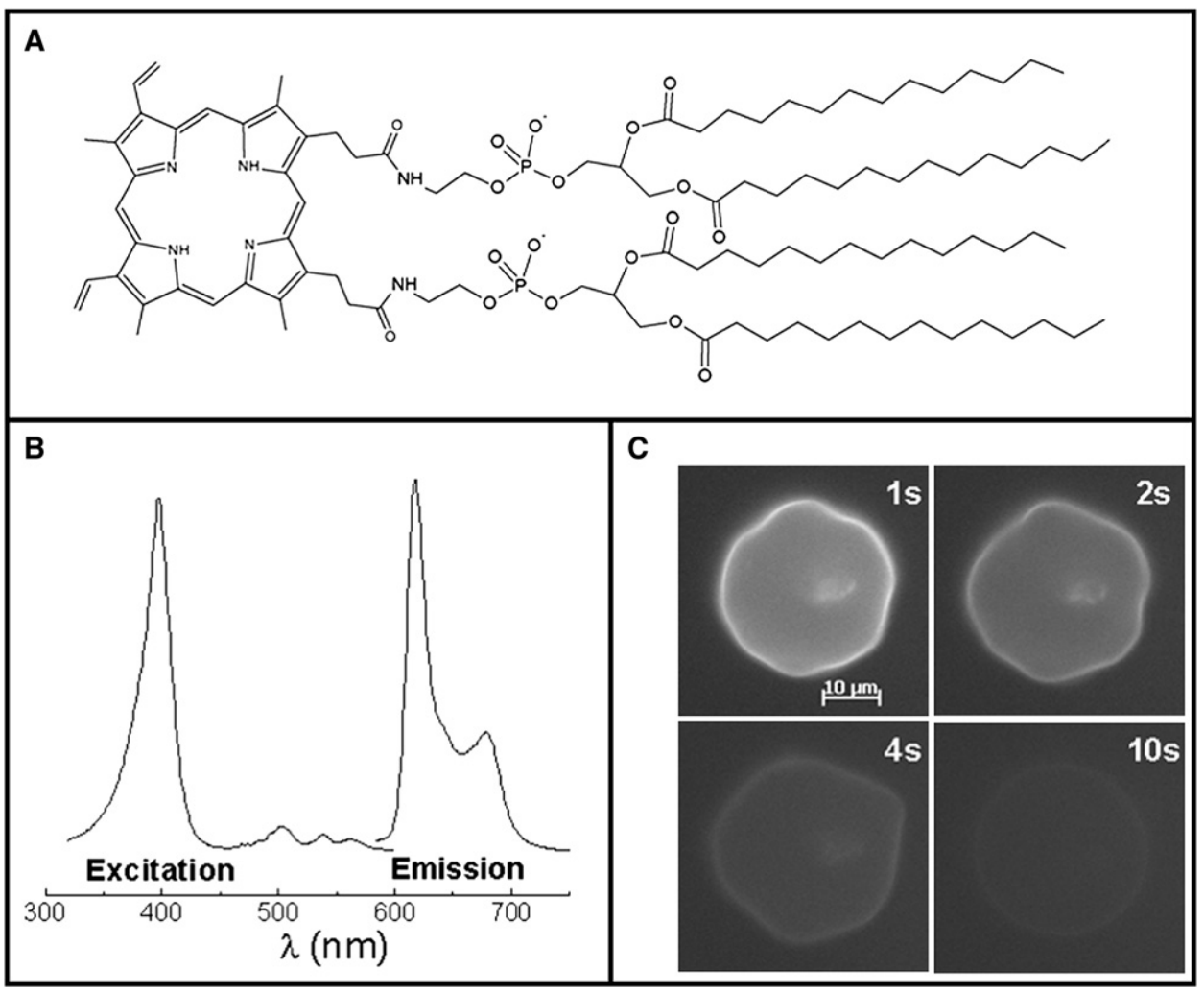

FIGURE 1 Characteristics of the photosensitive molecule PE-porph. (A) Chemical structure. $(B)$ Excitation and emission spectra of POPC GUVs with $X_{\text {porph }}=0.05$. (C) Fluorescence microscopy images of a POPC GUV containing $X_{\text {porph }}=0.03$ as a function of the irradiation time shown on the top of each snapshot. The scale bar represents $10 \mu \mathrm{m}$. 
(PpIX-NCH $\mathrm{NCH}_{2} \mathrm{O} / \mathrm{PO}_{3} \mathrm{R} 1$ ) of one of the PEs, and ester hydrolysis in one of the tails of the second PE group.

\section{Preparation of giant unilamellar vesicles}

Giant unilamellar vesicles of POPC containing different molar fractions of PE-porph $\left(X_{\text {porph }}=0.005-0.1\right.$, i.e., $\left.0.5-10 \mathrm{~mol} \%\right)$ were grown using the electroformation method (18). Briefly, $16 \mu \mathrm{L}$ of a $2 \mathrm{mg} / \mathrm{mL}$ lipid/PE-porph chloroform solution were spread on the surfaces of two conductive glasses (coated with Fluor Tin Oxide), which were then placed with their conductive sides facing each other and separated by a 2 -mm-thick Teflon frame. This electroswelling chamber was filled with $0.2 \mathrm{M}$ sucrose solution and connected to an alternating power generator at $1 \mathrm{~V}$ with a $10 \mathrm{~Hz}$ frequency for 1-2 $\mathrm{h}$. The vesicle solution was removed from the chamber and diluted $\sim 10$ times into a $0.2 \mathrm{M}$ glucose solution. This created a sugar asymmetry between the interior and the exterior of the vesicles. The osmolarities of the sucrose and glucose solutions were measured with a cryoscopic osmometer Osmomat 030 (Gonotec, Berlin, Germany) and carefully matched to avoid osmotic pressure effects. The vesicle solution was placed in an observation chamber. Due to the differences in density and refractive index between the sucrose and glucose solutions, the vesicles were stabilized by gravity at the bottom of the chamber and had better contrast when observed with phase contrast microscopy.

\section{Optical microscopy observation and irradiation}

Observation of giant vesicles was performed under an inverted microscope, Axiovert 200 (Carl Zeiss, Jena, Germany), equipped with a $\mathrm{Ph} 263 \times$ objective. Images were taken with an AxioCam HSm digital camera (Carl Zeiss). Irradiation of the samples was performed using the HBO $103 \mathrm{~W}$ Hg lamp of the microscope using a 400-nm excitation filter. The power density of the irradiation was $5 \mathrm{~W} / \mathrm{cm}^{2}$, measured with a Powermeter (Coherent, Santa Clara, CA). Some experiments were performed in the presence of an alternating electrical (AC) field of $10 \mathrm{~V}$ intensity and $1 \mathrm{MHz}$ frequency. In those cases, the vesicles contained a small amount of salt $(0.5 \mathrm{mM} \mathrm{NaCl})$ to ensure a higher conductivity inside, and thus to induce prolate deformation (17). For these measurements, the vesicle solution was placed in a special chamber purchased from Eppendorf (Hamburg, Germany), which consists of an 8-mm-thick Teflon frame confined between two glass plates through which observation was possible. A pair of parallel platinum electrode wires with $90 \mu \mathrm{m}$ in radius was fixed at the lower glass. The gap distance between the two wires was $0.5 \mathrm{~mm}$. The chamber was connected to a function generator.

\section{PE-porph incorporated in POPC dispersions: absorption and fluorescence spectra and singlet oxygen production}

Some control experiments were done with $X_{\text {porph }}=0.05$ in $0.1 \mathrm{mM}$ POPC dispersions (prepared by vortex, yielding multilamellar vesicles). Absorbance spectra were recorded on a UV-VIS 2400-PC spectrophotometer (Shimadzu, Kyoto, Japan). Fluorescence spectra were recorded in a Fluorog (Spex, Lisbon, Portugal) in right-angle mode interfaced to a PC, controlled by DM3000-F software. Absorbance at $400 \mathrm{~nm}$ and fluorescence emission at $640 \mathrm{~nm}$ (excitation at $400 \mathrm{~nm}$ ) were followed as a function of irradiation time with a conventional laser $(\lambda=532 \mathrm{~nm}, 5 \mathrm{~mW})$, and were found to decrease $\sim 15 \%$ after 25 min irradiation. The singlet oxygen ${ }^{1} \mathrm{O}_{2}$ production was determined by using a phosphorescence detection method. A pulsed Surelite III Nd:YAG laser (Continuum, West Newton, MA) was used as the excitation source operating at $532 \mathrm{~nm}(5 \mathrm{~ns}, 10 \mathrm{~Hz})$. The radiation emitted at $1270 \mathrm{~nm}$ was detected at right angle by a liquid nitrogen-cooled photomultiplier, model No. R5509 (Hamamatsu, Hamamatsu City, Japan) (19). The quantum yield of ${ }^{1} \mathrm{O}_{2}$ production, $\Phi_{\Delta}$, was calculated by measuring and comparing the emissions of sample (PE-porph) and standard (Hematoporphyrin IX), whose $\Phi_{\Delta}$ is 0.76 (20). Sample and standard solutions were prepared in methanol and absorptions were matched and amounted to 0.20 at $532 \mathrm{~nm}$.

\section{RESULTS}

\section{Characterization of the photosensitive molecule PE-porph}

The photosensitive molecule synthesized consists of a porphyrin molecule attached to two phosphatidylethanolamines, as schematically shown in Fig. $1 \mathrm{~A}$. The main spectral characteristics of PE-porph are quite similar to those observed for porphyrin incorporated in model membranes $(21,22)$, with the maximum absorption at $\sim 400 \mathrm{~nm}$ and the emission above $600 \mathrm{~nm}$ (see Fig. $1 B$ ). The quantum yield of singlet oxygen $\left({ }^{1} \mathrm{O}_{2}\right)$ production, $\Phi_{\Delta}$, was determined to be equal to 0.50 . Observation under the microscope in the fluorescence mode showed that the porphyrin is incorporated in the bilayer, as shown in Fig. $1 C$ for a GUV containing 3 mol \% of PE-porph. After some exposure to the excitation light, photobleaching of PE-porph occurred. Under our strongest illumination conditions, i.e., full power of the $\mathrm{Hg}$ lamp, photobleaching occurred typically within seconds, as can be seen in the sequence of fluorescence snapshots shown in Fig. $1 C$.

\section{Morphological changes of GUVs caused by irradiation of PE-porph}

Giant unilamellar vesicles (GUVs) of POPC containing $X_{\text {porph }}=0.005-0.1(0.5-10 \mathrm{~mol} \%$ PE-porph $)$ were irradiated and simultaneously observed under an optical microscope. Visible morphological shape changes occurred in the GUVs as soon as the irradiation started. Some examples are shown in Fig. 2 for vesicles with $X_{\text {porph }}=0.02$ and 0.05 . All vesicles showed an increase in their projected area. The increase in projected area was often accompanied by an increase in thermal fluctuations, especially when vesicles were initially spherical and tense; see the first snapshots in Fig. 2, $A$ and $B$. This is a clear indication that the area-tovolume ratio increased during illumination. At low PE-porph molar fraction (see Fig. $2 \mathrm{~A}$ ), the increase in excess area was moderate, resulting mainly in an increase of the apparent vesicle diameter. One can also discern a small increase in the shape roughness in the last snapshot of the figure. At higher PE-porph molar fractions, the increase in excess area and shape fluctuations appeared clearly (see Fig. 2 B). During the process, the vesicles generally became flatter, such that the focal plane of the vesicle equator was shifted to a lower level; see, for instance, the snapshot at $5 \mathrm{~s}$ in Fig. 2 A. In many cases, vesicles containing more than $X_{\text {porph }}=0.02$ expelled some buds, i.e., satellite vesicles still connected to the mother vesicle through thin necks; see snapshot at $43 \mathrm{~s}$ in Fig. $2 C$. The initial sugar asymmetry, seen by the presence of the phase contrast rings, was roughly maintained throughout the irradiation process, showing that no significant change in bilayer permeability has occurred, e.g., there was no opening of pores. We argue in the following that the morphological changes described above, i.e., the increase in projected area and in fluctuations, 

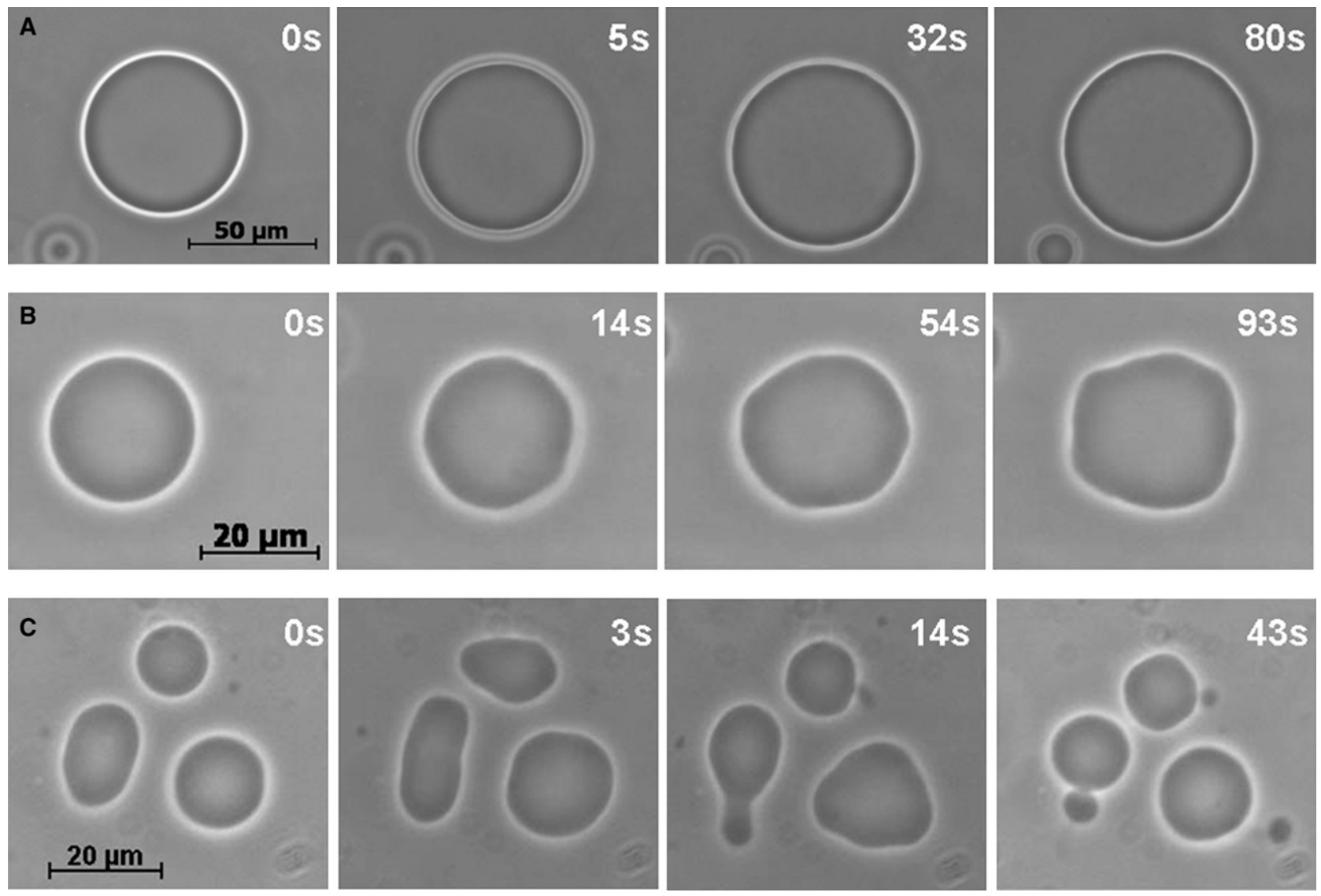

FIGURE 2 Effect of irradiation of POPC vesicles containing $X_{\text {porph }}=0.02(A)$ and $0.05(B$ and $C)$. The irradiation time is shown on the top of each snapshot.

expulsion of buds, are due to a mechanism of vesicle surface area increase at constant volume.

The shape of a vesicle at equilibrium is defined from the minimization of the bending elastic energy of the lipid bilayer at constant area and enclosed volume, depending basically on two parameters: the area-to-volume ratio and the effective differential area between the two monolayers (14). Thus, any increase in area at constant volume modifies the area-to-volume ratio, inducing a change in the vesicle shape. A cartoon showing a side view of the main morphological changes induced by irradiation of GUVs is shown in Fig. 3. After irradiation, spherical vesicles gained excess area and became oblates (Fig. 3 B). Further increase in area caused one (Fig. $3 C$ ) or many buds in a pearl chain (Fig. $3 D$ ) to be expelled, to release the excess area.

The morphological changes observed in our experiments occurred only during the first seconds of irradiation, after which the vesicles did not show any significant evolution. Furthermore, the shape changes appeared irreversible, and vesicles did not show any alteration after the irradiation was stopped. In a previous work (16), GUVs destruction was observed after several minutes of irradiation, depending on the concentration of another photosensitive molecule, methylene blue, dispersed in the aqueous solution. Although both photosensitizers have practically the same singlet oxygen production efficiency $\left(\Phi_{\Delta} \sim 0.5\right)$, photosensitization in the presence of methylene blue appears to be more destructive when compared to the same ${ }^{1} \mathrm{O}_{2}$ flux produced by PE-porph (16). This is explained by the fact that, contrary to methylene blue, porphyrins are photooxidized during exposure to light (see Fig. $1 C$ ). In fact, similar morphological changes associated with the increase in area were observed in the beginning of irradiation with methylene blue as described in Caetano et al. (16) and confirmed by us (results not shown), showing that increase in surface area is a trait of the initial steps of the oxidative damage, and is not caused by any specific effect of PE-porph. Another possible explanation for the differences in efficiency of GUV destruction between methylene blue and PE-porph may be the fact that methylene blue is also involved in dye-dye photosensitization processes, which may facilitate the progress of the peroxidation reactions $(23,24)$.

\section{Mechanisms of area increase}

We showed in the previous section that irradiation of PE-porph incorporated in the bilayer induces morphological changes in giant vesicles, driven by an increase in surface area. When pure vesicles (in the absence of PE-porph) were irradiated, no significant effects were observed, 


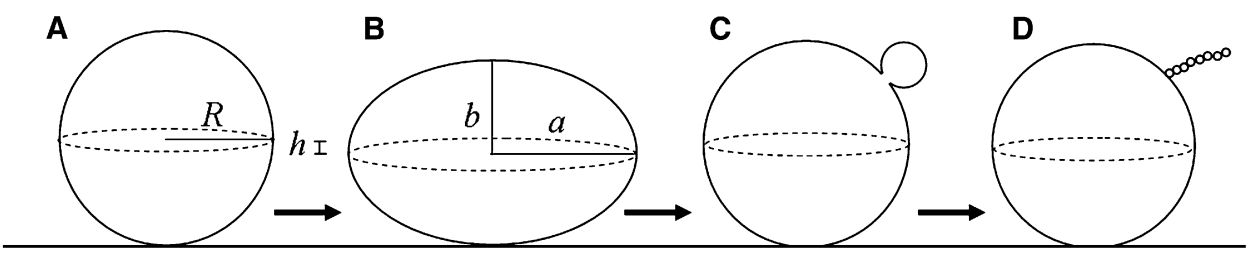

FIGURE 3 Schematic representation of the side view of the main morphological changes observed in vesicles as a result of irradiation of PE-porph: $(A)$ initially spherical vesicle, $(B)$ oblate vesicle, $(C)$ expelling of one bud, and (D) expelling of various buds (pearl chain). The line below represents the coverslip.

although in few cases a small increase in area occurred, caused probably by the strong UV illumination. This increase was smaller than the increase observed for the lowest molar fraction of PE-porph incorporated in this study $\left(X_{\text {porph }}=0.005\right)$. Photoinduced morphological changes occurred only when PE-porph was present in vesicles made of unsaturated lipids, like POPC. For example, irradiation of PE-porph incorporated in GUVs made of DMPC, a saturated lipid, did not induce any relevant shape changes of the vesicles (results not shown). Thus, the observed area increase is associated to general oxidative reactions of the lipid double-bonds. It is also worth mentioning that hardly any area increase was detected when GUVs containing conventional fluorescent probes were irradiated. A previous work reported some side effects of production of oxygen reactive species by such probes, widely used in fluorescence microscopy of GUVs (25). This oxidative side effect caused by irradiation of fluorescent probes is, however, minute compared to the extensive oxidative damage caused by porphyrin. This can be explained because the main relaxation from the excited state in these probes occurs via fluorescent emission and not by intersystem crossing to the triplet state, as is the case for photosensitive molecules.

To test whether ${ }^{1} \mathrm{O}_{2}$ production was linked to the area increase, we performed irradiation of GUVs with $X_{\text {porph }}=$ 0.05 in the presence of $1 \mathrm{mM}$ sodium azide $\left(\mathrm{NaN}_{3}\right)$, a known ${ }^{1} \mathrm{O}_{2}$ quencher. In that situation, almost no morphological changes were observed, as can be seen in the example shown in Fig. 4. We can thus conclude that the general reaction of ${ }^{1} \mathrm{O}_{2}$ with lipid double-bonds is the main agent that causes

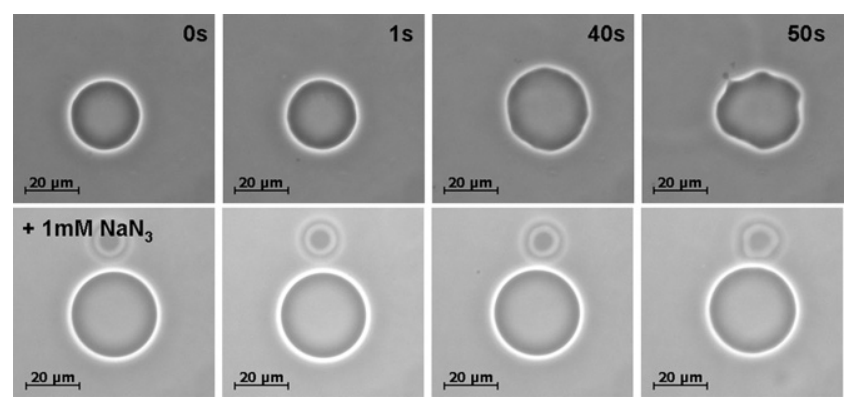

FIGURE 4 Effect of sodium azide $\left(\mathrm{NaN}_{3}\right)$ on GUVs made of POPC containing $X_{\text {porph }}=0.05$. The sequence shown on top was obtained in the absence of sodium azide, and clear morphological changes are observed as a result of irradiation. The sequence at the bottom was obtained in the presence of $1 \mathrm{mM} \mathrm{NaN}_{3}$, and almost no changes are detected. area increase. Lipid hydroperoxide is known to be the first stable product of this reaction (26), and it is thus reasonable to associate the observed area increase with the formation of hydroperoxides. This will be addressed later in Discussion.

\section{Area increase measurement}

Spherical vesicles changed initially into oblate-shaped vesicles as a result of irradiation; see cartoon in Fig. 3 B. Such deformation could, in principle, be used to roughly estimate the increase in surface area involved. However, because one of the semiaxes defining the oblate shape lies perpendicular to the focal plane, it cannot be directly assessed. Furthermore, deflated vesicles 1), might deform due to the contact with the coverslip; and 2), have some excess area hidden in fluctuations. Therefore, a different approach to estimate the area increase was used. It is known that in the presence of an AC field, lipid vesicles assume oblate or prolate shapes, with their symmetry axis lying parallel to the electric field, depending on the field frequency and conductivity ratio between the inner and outer solution (17). Thus, both semiaxes can be directly measured. In the case of oblate deformation, one of the long semiaxes lies perpendicular to the coverslip, thus susceptible to considerable deformations due to gravity. On the other hand, when the deformation is toward a prolate shape, one of the small semiaxes is perpendicular to the coverslip. Therefore, we chose to work with prolate shapes, because this implies less deformation due to the contact with the coverslip. For these experiments, vesicles containing $X_{\text {porph }}=0.005-0.1$ were grown with a small quantity of salt and then diluted into a salt-free solution, so that the conductivity of the inner solution was higher. Under these conditions, AC fields always induce prolate deformations, irrespective of the field frequency (17). The irradiation was then performed in the presence of an AC field, and the increase in excess area was assessed from the increase in the degree of deformation. For a given field strength/ frequency, the degree of deformation depends on the vesicle excess area. It is important to mention that the deformation induced by the weak AC field $(10 \mathrm{~V})$ is not enough to stretch the bilayer at the molecular level, as in the case of strong electric pulses (27) and pipette aspiration in the high tension regime (28). Instead, the deformation induced by the weak AC fields applied here acts only on the excess area, similar to experiments of aspiration with pipettes performed in the low tension regime (28). 


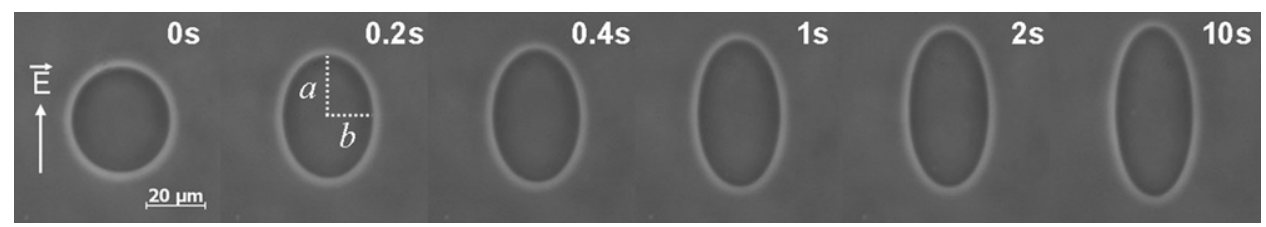

FIGURE 5 Irradiation of a GUV containing $X_{\text {porph }}=0.03$ in the presence of an $\mathrm{AC}$ field $(10 \mathrm{~V}, 1 \mathrm{MHz})$, which induces prolate deformation. The electric field direction is indicated on the left and the irradiation time on top of each snapshot. The scale bar represents $20 \mu \mathrm{m}$.

We chose vesicles that were initially almost spherical, i.e., had almost no excess area. Fig. 5 shows one example of irradiation of a GUV in the presence of an AC field. When the irradiation starts, the vesicle elongates as expected, assuming a prolate shape with its axis of symmetry lying parallel to the field, i.e., to the focal plane. From such sequence of images, the time evolution of both semiaxes was extracted. Each of these quantities shows a well-defined time variation: the largest semiaxis increases whereas the smallest semiaxis decreases with time.

Assuming that the vesicle shape is a prolate ellipsoid, both vesicle volume and surface area can be calculated. It should be noted that vesicles are not perfect prolates, as gravity and attractive interactions between the membrane and the substrate deform somewhat the vesicle. Within experimental error, the vesicle volume was roughly constant along the irradiation process (dispersion of $\pm 5 \%$, not shown), whereas the surface area clearly increased with irradiation time.

Fig. 6 shows typical curves of the increase in area as a function of irradiation time for three GUVs $\left(X_{\text {porph }}=\right.$ $0.01,0.05$, and 0.1 ), as computed from the semiaxes of the prolate deformation in the presence of an AC field. The

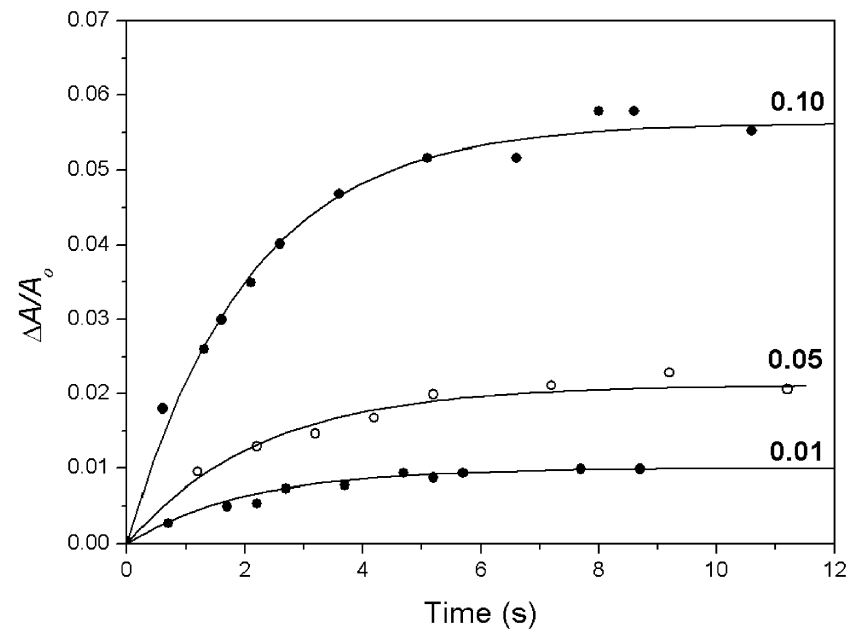

FIGURE 6 Relative area increase $\left(\Delta A / A_{\mathrm{o}}\right)$ as a function of irradiation time of POPC GUVs containing $X_{\text {porph }}=0.01,0.05$, and 0.10 , as indicated in the figure. The relative area increase was measured assuming prolate shape deformation of the GUVs in the presence of an AC field (see example in Fig. 5). The error in measuring the vesicle semiaxes is typically of the order of one pixel ( $\sim 1 \%$, since the typical vesicle diameter is $\sim 100$ pixels). This error was systematically smaller than the overall time evolution of the semiaxes lengths. The relative area increase was measured assuming that vesicles assume a prolate shape. We estimate the error of the relative area variation to be $<10 \%$. results show that the relative area expansion, $\Delta A / A_{\mathrm{o}}$ (where $A_{\mathrm{o}}$ is the initial vesicle apparent surface area), varies exponentially as a function of time, reaching a maximum value, $\Delta A_{\max } / A_{\mathrm{o}}$ after a few seconds of irradiation. According to this behavior, one can assume that the relative increase in area is modulated by the PE-porph photobleaching that increases exponentially with a characteristic time $\tau$, in such a way that

$$
\frac{\Delta A}{A_{\mathrm{o}}}=\frac{\Delta A_{\max }}{A_{\mathrm{o}}}\left(1-e^{-t / \tau}\right) .
$$

The lines in Fig. 6 correspond to the best fittings to the experimental data according to Eq. 1. Fig. 7, $A$ and $B$,

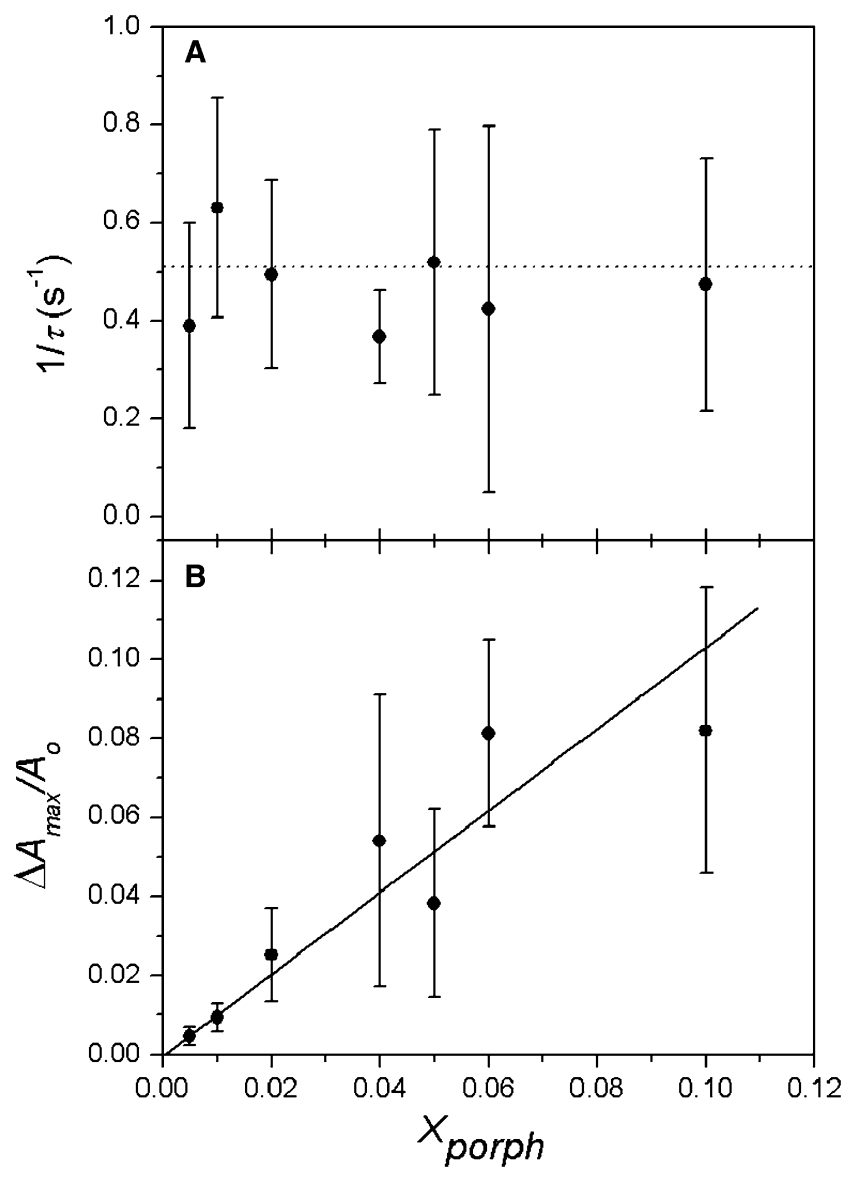

FIGURE 7 (A) Inverse of the characteristic time $(1 / \tau)$ and $(B)$ maximum relative area increase $\left(\Delta A_{\max } / A_{0}\right)$ obtained from the fits to the data using Eq. 1 as a function of the PE-porph molar fraction in the membrane $X_{\text {porph }}$. The error bars represent measurements performed on different GUVs. At least five vesicles were used for each value of $X_{\text {porph }}$. 
show the values of $1 / \tau$ and $\Delta A_{\max } / A_{0}$, respectively, obtained as a function of $X_{\text {porph }}$. As one can see, the characteristic time is practically constant $\left(1 / \tau=0.51 \pm 0.13 \mathrm{~s}^{-1}\right)$, whereas $\Delta A_{\text {max }} / A_{0}$ varies linearly with $X_{\text {porph }}$ up to $X_{\text {porph }}=0.10$. Furthermore, a photobleaching time of $\tau=2 \mathrm{~s}$ describes well the photobleaching observed under the conditions of our experiments (Fig. $1 C$ ).

\section{DISCUSSION}

Our results clearly show that irradiation of photosensitive molecules close to lipid membranes of unsaturated lipids cause an increase in the bilayer surface area, which drives morphological changes of closed objects such as vesicles. We also show that the area increase is mainly driven by the reaction between singlet oxygen ${ }^{1} \mathrm{O}_{2}$ and lipid doublebonds, which is known to primarily produce lipid hydroperoxides LOOH (21). The hydroperoxide group has a more hydrophilic character compared to the lipid acyl-chain milieu. It is accepted that this group migrates to the bilayer surface $(2,5,29)$, as schematically shown in Fig. 8 . The lipid with the hydroperoxide group occupies a larger area (5,7-9), which seems to be the origin of the overall increase in bilayer

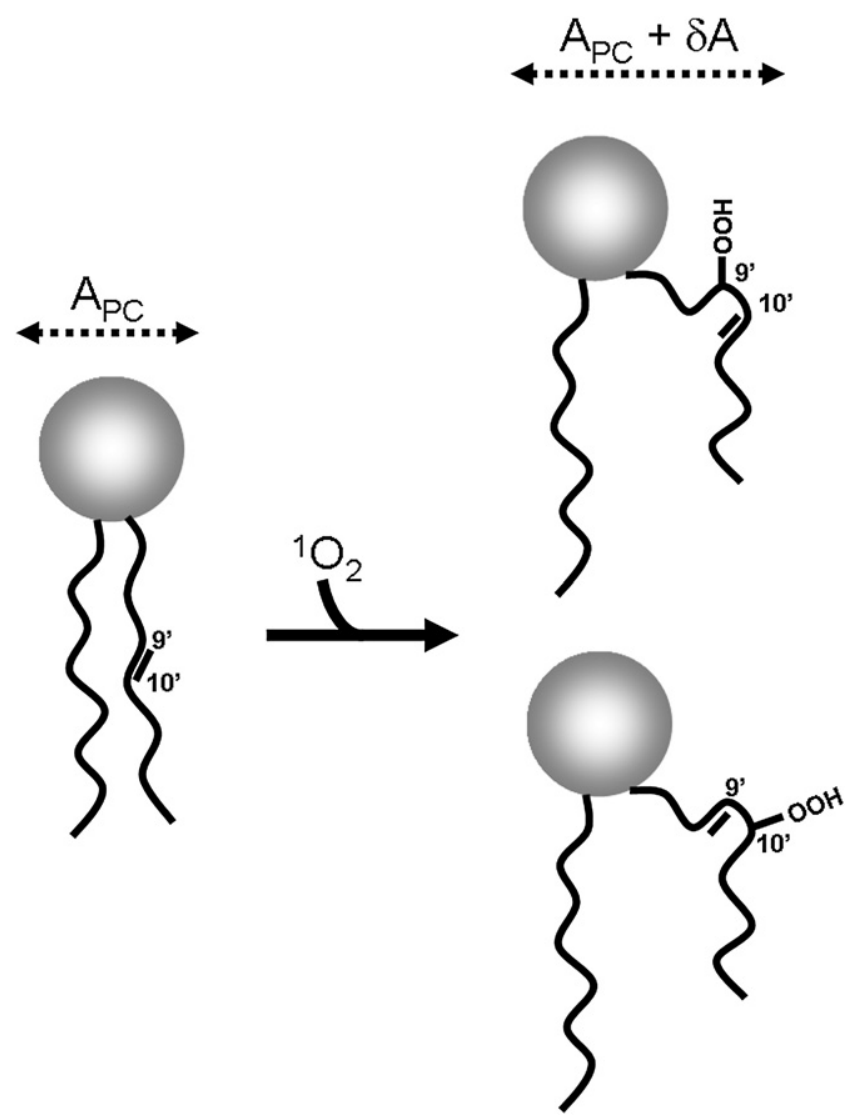

FIGURE 8 Schematic representation of the mechanism of area increase at the bilayer level. Singlet oxygen adds the more hydrophilic group -OOH at either $9^{\prime}$ or $10^{\prime}$ position, which migrates to the bilayer surface, imposing a kink to the acyl chain, with an accompanying increase in area $\delta A$ per lipid. surface area. If the oxidative reaction proceeds further, chain break can occur, producing an additional short-chain amphiphile, as observed previously after long time irradiation with methylene blue (16). However, since the reaction caused by irradiation of PE-porph is active only during the first seconds, due to photobleaching of the porphyrin group, we believe that the oxidative reaction is halted in its first step-namely, production of stable lipid hydroperoxides, which occupy a larger area per lipid, and induce the morphological changes observed in the GUVs.

There is no trivial way of directly quantifying the $\mathrm{LOOH}$ production in a single giant vesicle. Comparisons with $\mathrm{LOOH}$ production in small vesicles dispersion are not straightforward, as the experimental conditions are very different in both situations. In our setup, the irradiation is extremely intense and localized in the observation field, whereas in vesicle dispersions irradiation is not focused. However, we can assume that each $\mathrm{LOOH}$ produced adds a small increment $(\delta A)$ to the total bilayer area. In a recently published work, Wong-ekkabut et al. (5) estimated the amount of area increase caused by formation of lipid hydroperoxides, using molecular dynamics simulations. A linear increase in the average area per lipid was obtained from simulations with bilayers containing up to $50 \mathrm{~mol} \%$ of a lipid with a hydroperoxide group located at the ninth carbon of the acyl chain. Extrapolation of the data shown in Wong-ekkabut et al. (5) to $100 \mathrm{~mol} \% \mathrm{LOOH}$ shows that the area of one lipid may increase from 65 to $75 \AA^{2}$ with the formation of the hydroperoxide $\left(\delta A / A_{\mathrm{PC}} \sim 0.15\right)$. Using such an area increase per lipid, we can estimate the amount of hydroperoxides associated with the area increase experimentally observed in this work and subsequently determine a relation between the rate of ${ }^{1} \mathrm{O}_{2}$ production by PE-porph and the associated $\mathrm{LOOH}$ generation.

According to Busch et al. (30), the rate of ${ }^{1} \mathrm{O}_{2}$ production $Q$ per photosensitive molecule is given by

$$
Q=\frac{\Phi_{\Delta} \lambda P \sigma}{h c}
$$

where $\Phi_{\Delta}$ is the quantum yield of ${ }^{1} \mathrm{O}_{2}$ production of the photosensitive molecule, $\lambda$ is the wavelength of the irradiation light $(400 \mathrm{~nm}), P$ is the power density (see Materials and Methods), $\sigma$ is the cross section of absorbance, $h$ is the Planck's constant, and $c$ is the speed of light. For porphyrin, $\Phi_{\Delta}=0.5$ and $\sigma(400 \mathrm{~nm})=1.7 \AA^{2}$. Thus, in our setup, PE-porph generates $900{ }^{1} \mathrm{O}_{2} / \mathrm{s}$. Since PE-porph is anchored to the bilayer, we can assume that all ${ }^{1} \mathrm{O}_{2}$ produced will eventually hit the membrane. This is reasonable to assume, since the average diffusion range of ${ }^{1} \mathrm{O}_{2}$ in aqueous medium is around $100 \mathrm{~nm}(10)$.

By considering that the relative area increase, $\Delta A / A_{\mathrm{o}}$, is directly related to the molar fraction of POPC molecules that transform into hydroperoxides, $X_{\mathrm{LOOH}}$, we can write $\Delta A / A_{\mathrm{o}}$ as 


$$
\frac{\Delta A}{A_{\mathrm{o}}}=\frac{X_{\mathrm{LOOH}} \delta A}{\left(1-X_{\mathrm{porph}}\right) A_{\mathrm{PC}}+X_{\mathrm{porph}} A_{\mathrm{porph}}},
$$

where $A_{\mathrm{PC}}$ and $A_{\text {porph }}$ are the areas of POPC (65 $\left.\AA^{2}\right)$ and PEporph $\left(120 \AA^{2}\right)$, respectively, and $\delta A$ is the area increment due to peroxidation of one lipid $\left(\delta A=A_{\mathrm{LOOH}}-A_{\mathrm{PC}} ; \delta A /\right.$ $\left.A_{\mathrm{PC}}=0.15\right)(5) . X_{\mathrm{LOOH}}$ thus depends on the irradiation time and the efficiency $n$ of the reaction between singlet oxygen and the phospholipids. In the absence of photobleaching, $X_{\mathrm{LOOH}}$ should linearly increase with time as

$$
X_{\mathrm{LOOH}}(t)=n Q X_{\text {porph }} t .
$$

However, in the presence of photobleaching (see Fig. $1 C$ ), the production rate of $X_{\mathrm{LOOH}}$ reads

$$
X_{\mathrm{LOOH}}(t)=n Q X_{\mathrm{porph}} \int_{0}^{t} d t^{\prime} e^{-t^{\prime} / \tau},
$$

where $\tau$ is the photobleaching time. Solving Eq. 5 and inserting the result in Eq. 3, we obtain

$$
\frac{\Delta A}{A_{\mathrm{o}}}(t)=n Q \tau \frac{\delta A}{A_{\mathrm{PC}}} \frac{X_{\mathrm{porph}} A_{\mathrm{PC}}}{\left(1-X_{\mathrm{porph}}\right) A_{\mathrm{PC}}+X_{\mathrm{porph}} A_{\mathrm{porph}}}\left(1-e^{-t / \tau}\right) .
$$

Taking into account that $X_{\text {porph }}$ is a small number compared to the molar fraction of POPC $\left(X_{\text {porph }} \ll 1\right)$, Eq. 6 can be approximated by

$$
\frac{\Delta A}{A_{\mathrm{o}}}(t)=n Q \tau \frac{\delta A}{A_{\mathrm{PC}}} X_{\mathrm{porph}}\left(1-e^{-t / \tau}\right) .
$$

Comparing Eq. 7 to Eq. 1, one can obtain a relationship between $\Delta A_{\max } / A_{\mathrm{o}}$ and $X_{\mathrm{porph}}$ :

$$
\frac{\Delta A_{\max }}{A_{\mathrm{o}}}=n Q \tau \frac{\delta A}{A_{\mathrm{PC}}} X_{\mathrm{porph}} .
$$

According to Fig. $7 B, \Delta A_{\max } / A_{0}$ is described as a linear function of $X_{\text {porph }}$, with a slope close to 1 . Since we know $Q, \tau$, and the area increment $\delta A / A_{\mathrm{PC}}$, we can then calculate the efficiency $n$ of the lipid peroxidation process via singlet oxygen: $n=1 / 270$. This means that, on average, for each 270 singlet oxygen molecules reaching the membrane, one will interact chemically with the double-bound of the PC acyl chain and generate one lipid hydroperoxide. To our knowledge, this is the first time the efficiency of the reaction between phospholipids and singlet oxygen is evaluated in lipid bilayers. This relatively low value of $n \sim 0.0037$ is compatible with the low value of the total rate of suppression (chemical and physical) of ${ }^{1} \mathrm{O}_{2}$ by phospholipids $\left(k_{\mathrm{T}} \sim 5 \times\right.$ $10^{4} \mathrm{M}^{-1} \mathrm{~s}^{-1}$ ) (31) and the value of $n$ estimated for the oxidation of electron-rich olefin tetraphenylethylene by ${ }^{1} \mathrm{O}_{2}$ ( $n \sim 0.002)$ in methanol solutions (32).

It is also interesting to analyze the number of $\mathrm{LOOH}$ molecules that are produced. According to Fig. $7 B, \Delta A_{\max } / A_{\mathrm{o}}$ increases from 0.005 to 0.08 for $X_{\text {porph }}=0.005-0.1$. Using Eq. 3, we can associate this area increase with the peroxidation of $3-60 \%$ of the lipids. As we have already mentioned, the membrane remained intact under our experimental conditions, as can be seen by the permanence of the initial sugar asymmetry. Furthermore, no detectable change in vesicle volume was observed and no indication of macrodomain formation was detected. The bilayer surface seems to remain homogeneous. This result suggests that the membrane structure and plasticity may have a biological role in cell membranes in avoiding immediate rupture due to peroxidation, so that enzymatic defense has time to repair the phospholipids (33).

While studying the rupture of biological membranes of melanoma cells, Thorpe et al. (34) observed that the rupture initially occurred at single points in the plasma membrane. This effect was later modeled by Busch et al. (30) considering only the lipid part of the membrane and the effect of domain formation on the initial membrane rupture. Although some of the qualitative aspects of phenomena revealed by the numerical simulations of Busch et al. were also present in our experiments, i.e., the relationship between damage and ${ }^{1} \mathrm{O}_{2}$ generation, the quantitative aspects reported here are markedly different. In particular, Busch et al. tested efficiency values $n$ ranging from 0.2 to 0.03 , i.e., at least 10 times above the values calculated from our experimental data. Thus, we show in this study that a high fraction of LOOH groups can be formed in the membrane even in the low $n$ range. In addition, our results demonstrate that such high hydroperoxide content does not destroy the bilayer integrity, and does not lead to lipid domain formation or pore opening.

\section{CONCLUSIONS}

In this work we have studied a new photosensitive molecule, a porphyrin chemically linked to a lipid headgroup. When incorporated in lipid membranes, the photosensitive group resides at the bilayer surface. Thus, production of singlet oxygen occurs close to its main target, the double bonds of unsaturated lipids. This new photosensitizer allows for more controlled studies on the effect of lipid peroxidation.

We have studied the oxidative stress caused by the irradiation of this photosensitizer when incorporated in bilayers of unsaturated lipids forming GUVs, which can be observed with an optical microscope. Our results clearly show that lipid peroxidation causes an increase in bilayer area, which we measure as a function of the molar fraction of the photosensitive molecule incorporated and irradiation time. This is the first study to directly measure photoinduced area increase in lipid bilayers, which was previously observed experimentally only in monolayers (7-9). We associate the area increase with the production of hydroperoxides, which are known to occupy a larger area than normal unsaturated lipids, because of conformational changes imposed by migration of the more hydrophilic group to the bilayer surface $(2,5,29)$. Strikingly, 
peroxidation of as much as $60 \%$ of the lipids was still compatible with intact membranes. Using the rate of singlet oxygen production of the photosensitive molecule, we could estimate the efficiency of the oxidative process to be 0.0037 . We expect that our results will help in the development of improved models of membrane photoinduced damage, which may be of help in the fields of photodynamic therapy as well as of UV-A induced skin damage.

We are thankful to M. Teresa Lamy for allowing us to prepare our samples in her lab and to R. Dimova for some important suggestions on the area increase measurement. We acknowledge D. Severino for helping in some experiments.

This work was supported by Fundação de Amparo à Pesquisa do Estado de São Paulo (FAPESP) and by a FAPESP/Centre National de la Recherche Scientifique (CNRS) international agreement.

\section{REFERENCES}

1. Schnitzer, E., I. Pinchuk, and D. Lichtenberg. 2007. Peroxidation of liposomal lipids. Eur. Biophys. J. 36:499-515.

2. van Ginkel, G., J. H. Muller, F. Siemsen, A. A. van't Veld, L. J. Korstanje, et al. 1992. Impact of oxidized lipids and antioxidants, such as vitamin $\mathrm{E}$ and lazaroids, on the structure and dynamics of unsaturated membranes. J. Chem. Soc., Faraday Trans. 88:1901-1912.

3. Megli, F. M., and K. Sabatini. 2003. Respiration state IV-generated ROS destroy the mitochondrial bilayer packing order in vitro. An EPR study. FEBS Lett. 550:185-189.

4. Jacob, R. F., and R. P. Mason. 2005. Lipid peroxidation induces cholesterol domain formation in model membranes. J. Biol. Chem. 280:39380-39387.

5. Wong-ekkabut, J., Z. Xu, W. Triampo, I.-M. Tang, D. P. Tieleman, et al. 2007. Effect of lipid peroxidation on the properties of lipid bilayers: a molecular dynamics study. Biophys. J. 93:4225-4236.

6. Sotto-Arriaza, M. A., C. P. Sotomayor, and E. A. Lissi. 2008. Relationship between lipid peroxidation and rigidity in L- $\alpha$-phosphatidylcholine-DPPC vesicles. J. Colloid Interface Sci. 323:70-74.

7. Abousalham, A., F. Fotiadu, G. Buono, and R. Verger. 2000. Surface properties of unsaturated non-oxidized and oxidized free fatty acids spread as monomolecular films at an argon:water interface. Chem. Phys. Lipids. 104:93-99.

8. Abousalham, A., and R. Verger. 2006. Continuous measurement of the lipoxygenase-catalyzed oxidation of unsaturated lipids using the monomolecular film technique. Pharmacol. Res. 23:2469-2474.

9. Sabatini, K., J.-P. Mattila, F. M. Megli, and P. K. J. Kinnunen. 2006. Characterization of two oxidatively modified phospholipids in mixed monolayers with DPPC. Biophys. J. 90:4488-4499.

10. Ochsner, M. 1997. Photophysical and photobiological processes in the photodynamic therapy of tumors. J. Photochem. Photobiol. B Biol. 39:1-18.

11. Valenzeno, D. P. 1987. Photomodification of biological membranes with emphasis on singlet oxygen mechanisms. Photochem. Photobiol. 46:147-160.

12. Engelmann, F. M., I. Mayer, D. Gabrielli, K. Araki, H. E. Toma, et al. 2007. Interactions of cationic meso-porphyrins with biomembranes. $J$. Bioenerg. Biomembr. 39:175-185.

13. Tarr, M., A. Frolov, and D. P. Valenzeno. 2001. Photosensitizationinduced calcium overload in cardiac cells: direct link to membrane permeabilization and calcium influx. Photochem. Photobiol. 73:418-424.

14. Döbereiner, H.-G. 2000. Properties of giant vesicles. Curr. Opin. Colloid Interface Sci. 5:2560263.
15. Dimova, R., S. Aranda, N. Bezlyepkina, V. Nikolov, K. A. Riske, et al. 2006. A practical guide to giant vesicles. Probing the membrane nanoregime via optical microscopy. J. Phys. Condens. Matter. 18:S1151S1176.

16. Caetano, W., P. S. Haddad, R. Itri, D. Severino, V. C. Vieira, et al. 2007. Photo-induced destruction of giant vesicles in methylene blue solutions. Langmuir. 23:1307-1314.

17. Aranda, S., K. A. Riske, R. Lipowsky, and R. Dimova. 2008. Morphological transitions of vesicles induced by alternating electric fields. Biophys. J. 95:L19-L21.

18. Angelova, M. I., and D. S. Dimitrov. 1986. Liposome electroformation. Faraday Discuss. Chem. Soc. 81:303-311.

19. Uchoa, A. F., P. P. Knox, N. K. Seifullina, and M. S. Baptista. 2008. Singlet oxygen generation in the reaction centers of Rhodobacter sphaeroides. Eur. Biophys. J. 37:843-850.

20. Tanielian, C., and G. Heinrich. 1995. Effect of aggregation on the hematoporphyrin-sensitized production of singlet molecular oxygen. Photochem. Photobiol. 61:131-135.

21. Brault, D., C. Vever-Bizet, and T. L. Doan. 1986. Spectrofluorimetric study of porphyrin incorporation into membrane models-evidence for $\mathrm{pH}$ effects. Biochim. Biophys. Acta. 857:238-250.

22. van Steveninck, J., J. W. M. Lagerberg, P. Charlesworth, T. M. A. R. Dubbelman, and T. G. Truscott. 1994. Effects of the micro-environment on the photophysical properties of hematoporphyrin. Biochim. Biophys. Acta. 1201:23-28.

23. Severino, D., H. C. Junqueira, D. S. Gabrielli, M. Gugliotti, and M. S. Baptista. 2003. Influence of negatively charged interfaces on the ground and excited state properties of methylene blue. Photochem. Photobiol. 77:459-468.

24. Junqueira, H. C., D. Severino, L. G. Dias, M. Gugliotti, and M. S. Baptista. 2002. Modulation of the methylene blue photochemical properties based on the adsorption at aqueous micelle interfaces. Phys. Chem. Chem. Phys. 4:2320-2328.

25. Ayuyan, A. G., and F. S. Cohen. 2006. Lipid peroxides promote large rafts: effects of excitation of probes in fluorescence microscopy and electrochemical reactions during vesicle formation. Biophys. J. 91: 2172-2183.

26. Girotti, A. W. 2001. Photosensitized oxidation of membrane lipids: reaction pathways, cytotoxic effects, and cytoprotective mechanisms. J. Photochem. Photobiol. B Biol. 63:103-113.

27. Riske, K. A., and R. Dimova. 2005. Electro-deformation and -poration of giant vesicles viewed with high temporal resolution. Biophys. J. 88:1143-1155.

28. Evans, E., and W. Rawicz. 1990. Entropy-driven tension and bending elasticity in condensed-fluid membranes. Phys. Rev. Lett. 17:20942097.

29. Buettner, G. R. 1993. The pecking order of free radicals and antioxidants: lipid peroxidation, $\alpha$-tocopherol, and ascorbate. Arch. Biochem. Biophys. 300:535-543.

30. Busch, N. A., M. L. Yarmush, and M. Toner. 1998. A theoretical formalism for aggregation of peroxidized lipids and plasma membrane stability during photolysis. Biophys. J. 75:2956-2970.

31. Krasnovsky, Jr., A. A., and V. E. Kagan. 1979. Photosensitization and quenching of singlet oxygen by pigments and lipids of photoreceptor cells of the retina. FEBS Lett. 108:152-154.

32. Machado, A. E. H., M. L. Andrade, and D. J. Severino. 1995. Oxidation of an electron-rich olefin induced by singlet oxygen: mechanism for tetraphenylethylene. Photochem. Photobiol. A Chem. 91:179185.

33. Girotti, A. W. 1998. Lipid hydroperoxide generation, turnover, and effector action in biological systems. J. Lipid Res. 39:1529-1542.

34. Thorpe, W. P., M. Toner, R. M. Ezzell, R. G. Tompkins, and M. L. Yarmush. 1995. Dynamics of photoinduced cell plasma membrane injury. Biophys. J. 68:2198-2206. 


\title{
Observing the Solubilization of Lipid Bilayers by Detergents with Optical Microscopy of GUVs
}

\author{
Tatiane P. Sudbrack, ${ }^{\dagger}$ Nathaly L. Archilha, ${ }^{\dagger}$ Rosangela Itri, ${ }^{\dagger}$ and Karin A. Riske ${ }^{*, \dagger}$ \\ Institute of Physics, University of Sao Paulo, CP 66318, 05314-970, São Paulo, Brazil;Departamento de \\ Biofísica, Universidade Federal de São Paulo, R. Botucatu, 862, 04023-062, São Paulo, Brazil
}

Received: September 10, 2010; Revised Manuscript Received: November 22, 2010

\begin{abstract}
The solubilization of lipid bilayers by detergents was studied with optical microscopy of giant unilamellar vesicles (GUVs) composed of palmitoyl oleoyl phoshatidylcholine (POPC). A solution of the detergents Triton X-100 (TX-100) and sodium dodecyl sulfate (SDS) was injected with a micropipette close to single GUVs. The solubilization process was observed with phase contrast and fluorescence microscopy and found to be dependent on the detergent nature. In the presence of TX-100, GUVs initially showed an increase in their surface area, due to insertion of TX-100 with rapid equilibration between the two leaflets of the bilayer. Then, above a solubility threshold, several holes opened, rendering the bilayer a lace fabric appearance, and the bilayer gradually vanished. On the other hand, injection of SDS caused initially an increase in the membrane spontaneous curvature, which is mainly associated with incorporation of SDS in the outer layer only. This created a stress in the membrane, which caused either opening of transient macropores with substantial decrease in vesicle size or complete vesicle bursting. In another experimental setup, the extent of solubilization/destruction of a collection of GUVs was measured as a function of either TX-100 or SDS concentration.
\end{abstract}

\section{Introduction}

Detergents are widely used as solubilizing agents of biological membranes, especially for isolation, purification, and reconstitution of membrane proteins (for a review, see e.g. ref 1). Some examples of detergents commonly employed in biochemical applications are Triton X-100 (TX-100), octaethylene glycol dodecyl ether $\left(\mathrm{C}_{12} \mathrm{E}_{8}\right)$, sodium deoxycholate, and sodium dodecyl sulfate (SDS). Because of their amphiphilic character, detergents are incorporated in lipid bilayers at low concentrations but are able to solubilize the membrane at higher concentrations. Therefore, the interaction between detergents and model lipid bilayers has been widely investigated with several experimental approaches so as to gain knowledge on the mechanism of membrane solubilization. ${ }^{2-7}$ The most accepted model of membrane solubilization describes the process in three steps, in respect to the relative molar concentrations of bound detergent to lipid molecule. ${ }^{8-10}$ Briefly, detergents are incorporated into the bilayer structure up to a saturation point. Then, detergentrich bilayers coexist with mixed micelles. Finally, above the solubility limit, no bilayer structure remains and only mixed micelles and detergent monomers coexist in solution. Both the saturation and the solubility thresholds depend on the detergent critical micelle concentration, CMC, and on the membrane/ aqueous medium partition coefficient $K .{ }^{9}$ Some authors have shown that other intermediate states can be identified during the solubilization process of biological ${ }^{11}$ and model membranes. ${ }^{12,13}$ The partition coefficients and other thermodynamic parameters describing the partitioning of several detergents in lipid bilayers can be obtained with isothermal titration calorimetry and are important to help the understanding of the thermodynamics of detergent/lipid interaction. ${ }^{5,14-21}$

\footnotetext{
* To whom correspondence should be addressed. E-mail: kariske@ unifesp.br; Phone +55-11-5576-4530; Fax +55-11-5571-5780.

${ }^{\dagger}$ University of Sao Paulo.

* Universidade Federal de São Paulo.
}

A key parameter on the interaction of detergents with lipid bilayers is the rate of detergent flip-flop across the bilayer. ${ }^{4}$ Phospholipids generally exhibit a very slow flip-flop rate, so asymmetries between the external and internal leaflets are generally maintained within the course of a typical experiment. On the other hand, the flip-flop rate of detergents is highly dependent on the detergent nature and on the experimental conditions. For instance, the incorporation of SDS into one monolayer was determined to be almost instantaneous (below 1s), whereas significant flip-flop of SDS to the other monolayer was only detected after $10 \mathrm{~min}$ and became substantial after $1 \mathrm{~h}^{22}$ This slow flip-flop rate is consistent with the charged character of the SDS headgroup. Furthermore, the partition of ionic surfactants in the bilayer is also regulated by electrostatic interactions, which can either enhance or reduce the incorporation, depending on the surface charge of the bilayer. ${ }^{18} \mathrm{On}$ the other hand, the nonionic detergent $\mathrm{C}_{12} \mathrm{E}_{8}$ was found to quickly equilibrate between the two leaflets of the bilayer, with a flipflop half-time of $350 \mathrm{~ms}^{23}$ Although the flip-flop rate of TX100 was not directly measured yet, it has been assumed in the literature to be similar to that of $\mathrm{C}_{12} \mathrm{E}_{8}$, because of the nonionic character of the TX-100 headgroup. For example, there is a valid indication from ITC experiments that the flip-flop rate of TX100 and other nonionic detergents is a fast process within the time scale of one injection $(\sim 1 \mathrm{~min}){ }^{16,17,20}$

The shape transformations of lipid vesicles induced by detergents have attracted the attention of several groups. ${ }^{2,3,24}$ More recently, the observation of giant unilamellar vesicles (GUVs, $\sim 10 \mu \mathrm{m}$ ) with optical microscopy has revealed interesting aspects of detergent-induced shape changes. Nomura and co-workers ${ }^{25}$ have shown that depending on the combination of different detergents and bilayer compositions distinct topological transformations of lipid vesicles were observed, such as intermittent quakes, release of encapsulated liposomes, opening up, inside-out inversion and bursting. ${ }^{25}$ The interaction of a cationic surfactant with GUVs revealed shape transforma- 
tions prior to membrane destabilization, although adhesion of vesicles to the coverslip could be influencing vesicle morphology in that case. ${ }^{26}$ Incorporation of a bola-ampliphile into giant multilamellar vesicles induced cup-shaped deformations followed by extrusion of inner vesicles. ${ }^{27}$ Other works showed that the detergent $\mathrm{C}_{12} \mathrm{E}_{8}$ could speed up the shape transformations of GUVs. ${ }^{28,29}$ Moreover, optical microscopy of GUVs was also used to investigate the interaction of detergents with membranes of raft like composition, containing sphingomyelin and cholesterol. $^{30,31}$

In the present work, we use optical and fluorescence microscopy of GUVs composed of POPC (palmitoyl oleoyl phosphatidylcholine) to study the solubilization process of lipid bilayers by two detergents, namely TX-100 and SDS, at room temperature. Because of the differences in the hydrophobic contribution and the polar headgroups interaction of these detergents, their CMCs and flip-flop rates are very different. TX-100 is known to form micelles above $0.23 \mathrm{mM},{ }^{17}$ while the CMC of SDS in pure water is around $8 \mathrm{mM}^{32}$ The initial morphological changes of lipid vesicles and the subsequent bilayer disintegration/solubilization reflect the distinct characteristics of the interaction of lipid bilayers with either TX-100 or SDS.

\section{Materials and Methods}

Materials. The phospholipid POPC (1-palmitoyl-2-oleoylsn-glycero-3-phosphocholine) was purchased from Avanti Polar Lipids (Birmingham, AL) and was used without further purification. SDS (sodium dodecyl sulfate) and Triton X-100 were from Sigma-Aldrich (Missouri, USA). DiIC 18 (1,19dioctadecyl-3,3,39,39-tetramethylindocarbocyanine perchlorate) was purchased from Molecular Probes (Eugene, OR).

Determination of the CMCs of SDS and TX-100. The critical micelle concentration (CMC) of SDS and TX-100 in $0.2 \mathrm{M}$ glucose (the condition used throughout this work) was determined by means of isothermal titration calorimetry (ITC). The ITC measurements were performed in a MicroCal VP-ITC (Northampton, MA) at $25^{\circ} \mathrm{C}$. Concentrated samples of detergent (3.5 mM TX-100 or $140 \mathrm{mM} \mathrm{SDS}$, prepared in $0.2 \mathrm{M}$ glucose) were loaded in the titration syringe and the sample cell $(1.46$ $\mathrm{mL}$ ) was filled with $0.2 \mathrm{M}$ glucose. The detergent solution was titrated into the sample cell in aliquots of $5 \mu \mathrm{L}$. The top panel of Figure 1 shows the heat flow obtained from injections of TX-100 (left) and SDS (right). The heat of each injection, $Q_{\text {, }}$, was calculated from the integral of the corresponding peak after subtraction of a baseline using the software provided by MicroCal, and is shown in the middle panel of Figure 1. Each injection corresponds to a 280 -fold dilution of the micellar solution. In the first injections, the final detergent concentration in the sample cell was below the CMC; the micelles injected dissolved into monomers, a process that leads to a release or uptake of heat, depending on the detergent. As the final detergent concentration in the sample cell approached the CMC the process of demicellization came to a halt. Eventually, at concentrations well above the $\mathrm{CMC}$, only the heat of micelle dilution was detected. The CMC was determined from the inflection point of $Q_{\mathrm{i}}$ as a function of the concentration of detergent in the sample cell. This could be better determined from the first derivative of $Q_{\mathrm{i}}$ with respect to the detergent concentration, as shown in the bottom part of Figure 1. Under our experimental condition $\left(0.2 \mathrm{M}\right.$ glucose, $\left.25^{\circ} \mathrm{C}\right)$, the CMCs obtained were $0.27 \mathrm{mM}$ TX-100 and $8 \mathrm{mM}$ SDS, in good agreement with previously published data. ${ }^{17,32}$ Our results show that the process of demicellization is endothermic for SDS and

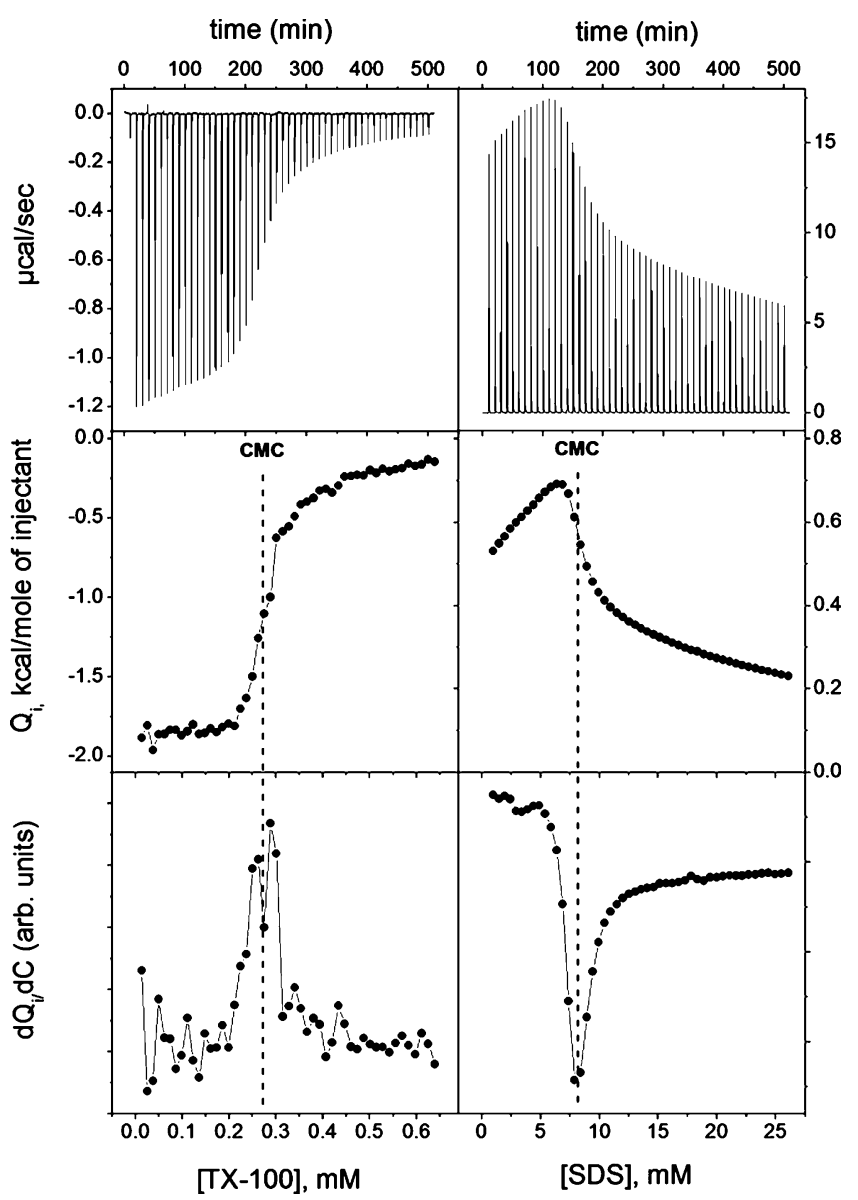

Figure 1. Determination of the CMC of TX-100 and SDS in $0.2 \mathrm{M}$ glucose using isothermal titration calorimetry (ITC). Top: Heat flow vs time for $5 \mu \mathrm{L}$ injections of $3.5 \mathrm{mM}$ TX-100 (left) and $140 \mathrm{mM}$ SDS (right) into the sample cell $(1.46 \mathrm{~mL})$. Middle: Integrated heat per injection, $Q_{\mathrm{i}}$, normalized with respect to the number of moles of injectant. Bottom: First derivative of the integrated heat with respect to the concentration of detergent. The dashed lines indicate the CMC values, which were taken as the inflection point of $Q_{\mathrm{i}}$ as a function of the detergent concentration. The temperature was $25^{\circ} \mathrm{C}$.

exothermic for TX-100, as reported elsewhere. ${ }^{17,18,33}$ The fact that the heat of demicellization $\left(\Delta H_{\text {demic }}\right)$ of SDS is not constant below the $\mathrm{CMC}$ is characteristic of SDS at $25^{\circ} \mathrm{C} .{ }^{33}$ It was shown previously that $\Delta H_{\text {demic }}$ of SDS increases linearly with temperature, being negative at 15 and $20^{\circ} \mathrm{C}$ and becoming positive above $25{ }^{\circ} \mathrm{C}$. It is also interesting to call the attention to the fact that the transition range between dissolution and dilution of micelles is quite broad for SDS, and is not even finished at the end of the experiment at $25 \mathrm{mM}$ SDS. It should be mentioned that the stability of micelles will be different in the presence of lipid bilayers.

Preparation and Observation of Giant Unilamellar Vesicles (GUVs). Giant unilamellar vesicles made of POPC were grown using the electroformation method. ${ }^{34}$ Briefly, $16 \mu \mathrm{L}$ of a $2 \mathrm{mg}$ / $\mathrm{mL}$ lipid chloroform solution was spread on the surfaces of two conductive glasses (coated with fluorine tin oxide), which were left under vacuum for $\sim 2 \mathrm{~h}$ to remove all traces of the organic solvent. The glasses were placed with their conductive sides facing each other and separated by a $2 \mathrm{~mm}$ thick Teflon frame to form a chamber which was filled with $0.2 \mathrm{M}$ sucrose solution. The glass plates were connected to a function generator and an alternating current of $1 \mathrm{~V}$ with a $10 \mathrm{~Hz}$ frequency was applied for about $2 \mathrm{~h}$. Before observation, the vesicle solution was diluted $\sim 10$ times into a $0.2 \mathrm{M}$ glucose solution to create a 
sugar asymmetry between the inside and the outside of the vesicles. The osmolarities of the sucrose and glucose solutions were measured with a cryoscopic osmometer Osmomat Gonotec 030 (Berlin, Germany) and carefully matched to avoid osmotic pressure effects. Because of the differences in density and refractive index between the sucrose and glucose solutions, the vesicles were stabilized by gravity at the bottom of the observation chamber and had better contrast when observed with phase contrast microscopy.

GUVs were observed with an inverted microscope Zeiss Axiovert 200 (Jena, Germany) equipped with a Zeiss AxioCam HSm digital camera (Jena, Germany). Two different experimental setups were used. In the first one, a $0.2 \mathrm{M}$ glucose solution containing $0.1-15 \mathrm{mM}$ TX-100 or $10-54 \mathrm{mM}$ SDS was injected with a glass micropipette of about $15 \mu \mathrm{m}$ diameter placed at about $50 \mu \mathrm{m}$ from a chosen GUV. The micropipettes were prepared using a vertical puller PC-10 from Narishige (Tokyo, Japan) and were controlled with a micromanipulator MP-225 from Sutter Instruments (Novato, CA). The injection flux was adjusted manually with a micrometer knob pressing a $10 \mu \mathrm{L}$ Hamilton syringe (Sutter Instruments, Novato, CA). In this setup, the vesicles were observed with a $63 \times \mathrm{Ph} 2$ objective, either with phase contrast or in fluorescent mode (illumination with a mercury lamp HBO 103W and a set of filters with excitation at $540-552 \mathrm{~nm}$ and emission band at $575-640 \mathrm{~nm}$ ). In the other experimental setup, $100 \mu \mathrm{L}$ of a solution of GUVs prepared in $0.2 \mathrm{M}$ sucrose were diluted in $700 \mu \mathrm{L}$ of a $0.2 \mathrm{M}$ glucose solution containing increasing concentrations of TX100 or SDS. This yielded a lipid concentration around $1 \mu \mathrm{M}$. The solution was then immediately placed in the observation chamber and followed under phase contrast with a $10 \times \mathrm{Ph} 1$ objective. A representative observation field $\left(750 \times 1000 \mu \mathrm{m}^{2}\right)$ was chosen and recorded for $10 \mathrm{~min}$. The number of GUVs deposited on the coverslip surface as a function of time for each detergent concentration was used as a means to quantify the relative number of intact GUVs in the presence of both detergents. The GUVs were counted manually and only vesicles bigger than $\sim 10 \mu \mathrm{m}$ were chosen. All experiments were performed at room temperature.

\section{Results and Discussion}

Optical and fluorescence microscopy of giant unilamellar vesicles made of POPC in the presence of the detergents TX100 and SDS were used to study the solubilization processes of lipid bilayers. A solution of detergent at different concentrations loaded in a micropipette was injected close to individual GUVs. The actual concentration of detergents close to the GUVs was somewhat lower because of rapid dilution after injection. Nonetheless, typical vesicle responses were obtained for different concentration ranges of both detergents employed. In another setup, the GUVs were diluted in well determined concentrations of detergent, and the relative number of the remaining intact GUVs was measured as a function of the detergent concentration. The results obtained for each detergent will be presented consecutively, followed by a discussion on the mechanism of bilayer solubilization by both detergents.

Triton X-100 (TX-100). Figure 2 shows the effect of injecting $0.1 \mathrm{mM}$ TX-100 (below the CMC) close to one vesicle, which was initially spherical and tense (first snapshot). The micropipette with a steady flow was brought close to the vesicle (indicated by an upward arrow in Figure 2). As a result, visible shape fluctuations were observed after few seconds (see snapshots at 27 and $35 \mathrm{~s}$ ), indicating that the vesicle acquired excess area. After that, the micropipette was removed (indicated

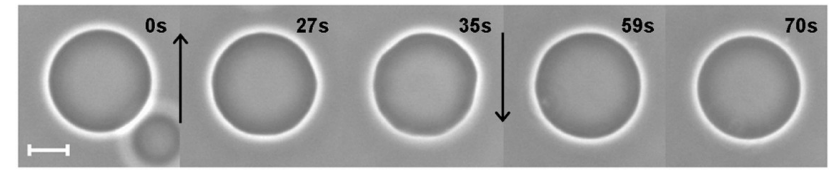

Figure 2. Sequence of snapshots obtained with phase contrast of a

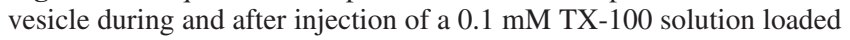
in a micropipette. The micropipette was brought close to the vesicle from the right side $(0 \mathrm{~s})$ and was removed after $40 \mathrm{~s}$, indicated by upward and downward arrows, respectively. The scale bar represents $10 \mu \mathrm{m}$.
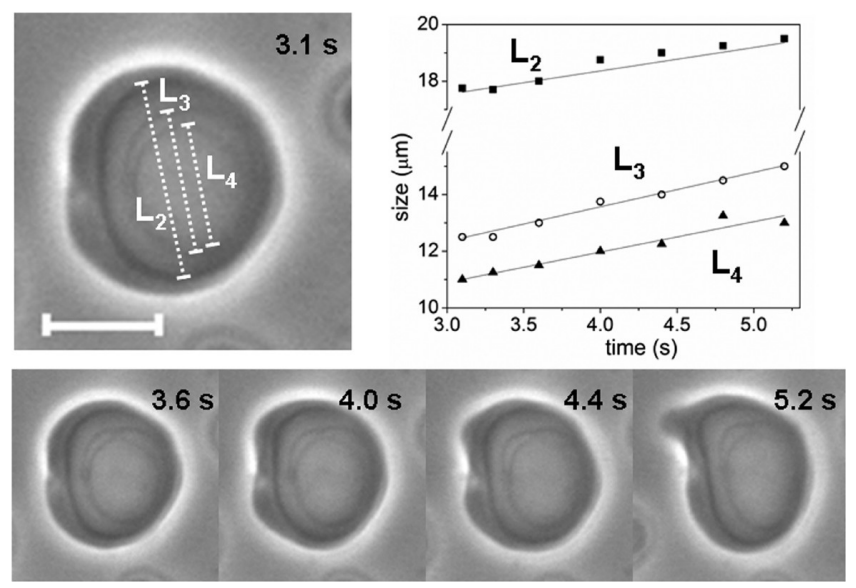

Figure 3. Sequence of snapshots obtained with phase contrast of an oligolamellar vesicle in the beginning of injection of a $1 \mathrm{mM} \mathrm{TX}-100$ solution loaded in a micropipette. The time on top is relative to the moment when the micropipette was brought close to the vesicle. The scale bar represents $10 \mu \mathrm{m}$. In the first snapshot, the dimensions which were chosen as an indication of the increase in the size of the vesicles are indicated as lamellae L2, L3, L4. The graph on top shows the time evolution of the size of the inner vesicles.

by a downward arrow), the detergent diffused away, and the vesicle returned to its initial spherical shape within $30 \mathrm{~s}$ (59 and $70 \mathrm{~s}$ ). Note that the vesicle optical contrast due to the sucrose/glucose asymmetry was maintained throughout the whole process, implying that no significant changes in bilayer permeability occurred at this stage. Increase in vesicle area was detected for all observed GUVs (more than 50). If the micropipette was removed, at least part of the increase in area was always reversed. Figure S1 of the Supporting Information shows another vesicle during and after injection of a low concentration of TX-100.

In one particular preparation of vesicles, we unexpectedly got mainly oligolamellar vesicles. This offered the possibility of evaluating the effect of TX-100 on inner (entrapped) vesicles, and therefore estimating how easily TX-100 can cross bilayers. Figure 3 shows the beginning of injection of TX-100 on such a vesicle, which had at least 4 lamellae. The sequence clearly shows that the area of all lamellae increase at similar rates, even the innermost ones. We measured one of the dimensions of the inner vesicles during the first seconds of injection, and found out that the size of all vesicles increased basically at the same rate within the time resolution of our experiment $(\sim 0.5 \mathrm{~s})$. These results are shown in the graph of Figure 3.

If the micropipette was loaded with a concentration higher than $\sim 0.4 \mathrm{mM}$ TX-100 (thus not far from the CMC of TX100, part A of Figure 1), vesicle solubilization was observed after the increase in area. Figure 4 shows two different sequences obtained during injection of $1 \mathrm{mM} \mathrm{TX}-100$. The first sequence (part A of Figure 4) shows the effect of injecting TX-100 on two GUVs, both initially spherical. As the micropipette is 


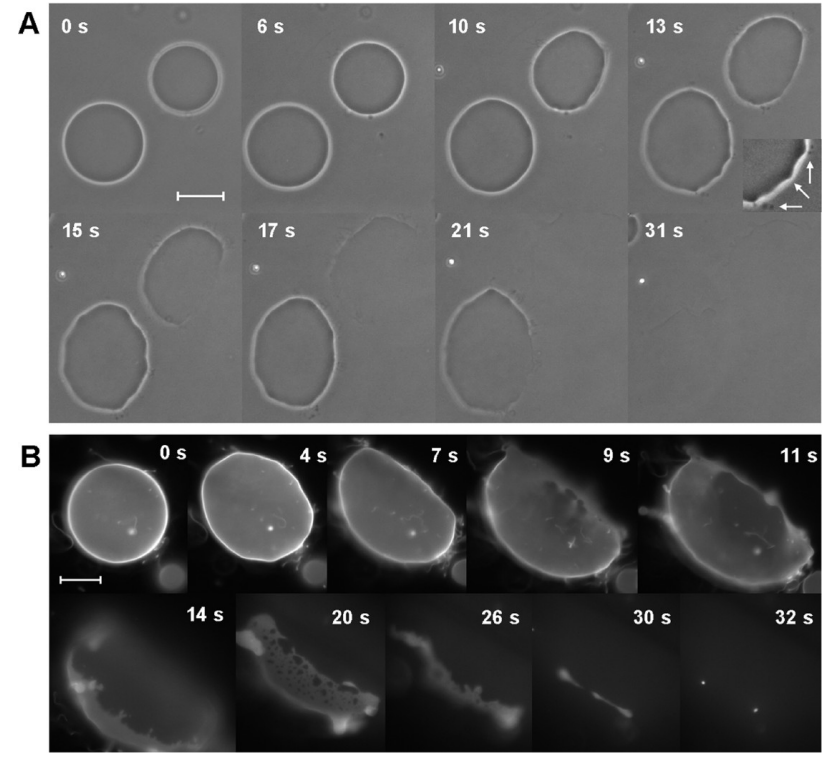

Figure 4. Sequence of snapshots showing the effect of injection of a $1 \mathrm{mM}$ TX-100 solution loaded in a micropipette. The time on top of each snapshot refers to the moment when the micropipette was brought close to the vesicle from the right side. A) Images obtained with phase contrast. The insert at $13 \mathrm{~s}$ shows a detail of the buds expelled (indicated with arrows). The contrast of this image was enhanced. B) Images obtained with fluorescence microscopy. The bilayer contains $1 \mathrm{~mol} \%$ DiIC $_{18}$. The scale bar on the first snapshot of each series represents 20 $\mu \mathrm{m}$.

brought close to the vesicles, distinguishable shape fluctuations and significant increase in area are observed on both vesicles $(6-13 \mathrm{~s})$. Note that the vesicle shapes adopted are not equilibrium shapes because the increase in area is faster than the time scale for shape transitions (few seconds). Also, the concentration of detergent is not homogeneous around the vesicle because the injection comes from the right side. Nonetheless, the increase in surface area caused by the presence of TX-100 is evident. The snapshots at $10-17 \mathrm{~s}$ show that several buds are expelled from the vesicle side facing the micropipette because of the rapid increase in area and/or to some transient increase in spontaneous curvature (protrusions coming out of the membrane and insert at $13 \mathrm{~s}$ ). Up to this point, the vesicle contrast is maintained. The next snapshots $(15-31 \mathrm{~s}$ for the vesicle on top and $21-31 \mathrm{~s}$ for the vesicle at the bottom) show the process of vesicle solubilization; pores seem to open initially on the vesicle side facing the micropipette, the optical contrast due to the original sugar asymmetry decreases and the bilayer vanishes, indicating that the lipids are being removed from the bilayer and incorporated into submicroscopic aggregates, most probably micelle-like structures.

To facilitate the visualization of the final solubilization process, injection of TX-100 was also followed by making use of fluorescence microscopy. In that case, the vesicles were prepared with the bilayer probe $\mathrm{DiIC}_{18}$. One example is shown in part B of Figure 4. The vesicle is also initially spherical and injection of TX-100 initially causes increase in bilayer area and possibly a small increase in spontaneous curvature. After $9 \mathrm{~s}$ several holes open on the side facing the micropipette and the bilayer becomes perforated like a lace fabric. The lace pattern starts to develop from the bilayer edges, which gradually vanish as the lipids are removed from the bilayer and most probably transferred into submicroscopic micelle-like structures. This dynamic perforation continues until the whole bilayer disappears and only a background fluorescence coming from the micelle- like structures is observed. Figure S2 of the Supporting Information shows several snapshots obtained with fluorescence microscopy of perforated bilayers resembling a lace fabric during the solubilization process of various vesicles.

From the optical microscopy observations, we conclude that the presence of TX-100 caused a clear increase in vesicle area, which could be partially reversed if the injection was stopped at concentrations below the onset of solubilization (not far from the CMC of TX-100, Figure 1), at around $0.4 \mathrm{mM}$ TX-100 in the micropipette. Moreover, even entrapped vesicles showed a marked increase in area, revealing that TX-100 can easily and rapidly cross the bilayer. Above the onset of solubilization, at $\sim 0.4$ mM TX-100, vesicle solubilization followed as a dynamic perforation until complete disappearance of the bilayer structure. It should be remarked, however, that because of rapid dilution after injection, the actual concentration of detergent close to the bilayer surface was smaller than the one loaded in the micropipette. Furthermore, the effects caused by high concentration of TX-100 were first observed in the vesicle side facing the micropipette, showing that the detergent concentration was not homogeneous around the vesicle. Vesicle burst was never observed after injection of TX-100.

In another experimental setup, GUVs were diluted in a glucose solution containing increasing concentrations of TX100 and the solution was rapidly placed under the microscope and observed with a low magnification objective to record a larger area with several vesicles. In the absence of TX-100, the GUVs slowly deposit on the coverslip surface because of gravity. On the other hand, if this experiment is repeated in the presence of TX-100 in the outer medium, the number of GUVs counted on the coverslip surface reflects the number of intact vesicles only, which preserved the original sugar asymmetry (nonperforated/solubilized). It should be noted that any change in vesicle size, shape, and permeability will affect the deposition rate and therefore alter the number of intact vesicles reaching the coverslip surface. A complete description of this experimental setup can be found elsewhere. ${ }^{35}$ To illustrate, part A of Figure 5 shows some snapshots obtained 10 min after dilution of GUVs in a solution containing increasing concentrations of TX-100. In the presence of $0.03 \mathrm{mM}$ TX-100, no significant change in the number of GUVs deposited on the coverslip is observed. On the other hand, the number of intact GUVs decreases as the concentration of TX-100 is further increased, until hardly any GUVs are observed in the presence of 0.18 $\mathrm{mM}$ TX-100. The number of intact GUVs was counted as a function of time (up to $10 \mathrm{~min}$ ) for increasing concentration of TX-100 (not shown). The relative number of GUVs that remained intact in the presence of the detergent, $X_{\mathrm{GUV}}$, was thus calculated as $1-X$, where $X$ is the ratio between the number of GUVs in the presence and in the absence of TX100 for each time. Inspection of the data shows that $X_{\mathrm{GUVs}}$ depends mainly on the concentration of TX-100 and not much on time, at least up to $10 \mathrm{~min}$. As a representative example, part B of Figure 5 shows $X_{\mathrm{GUV}}$ as a function of TX-100 concentration after $10 \mathrm{~min}$ of incubation. As one can see, as the concentration of TX-100 increases, $X_{\mathrm{GUVs}}$ decreases and reaches zero at $0.18 \mathrm{mM}$, that is, below the CMC of TX-100, when hardly any intact GUVs are observed. The large error bars, especially at low detergent concentrations, could reflect the fact that vesicles change morphology at low detergent concentration, resulting in a different deposition rate due to gravity. The relation of $X_{\mathrm{GUVs}}$ with the extent of vesicle solubilization will be discussed in a following section. 
A
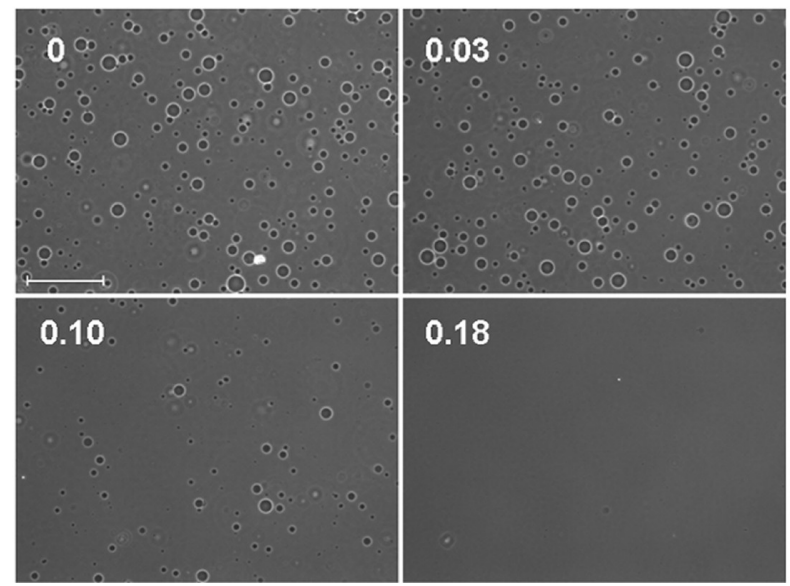

B

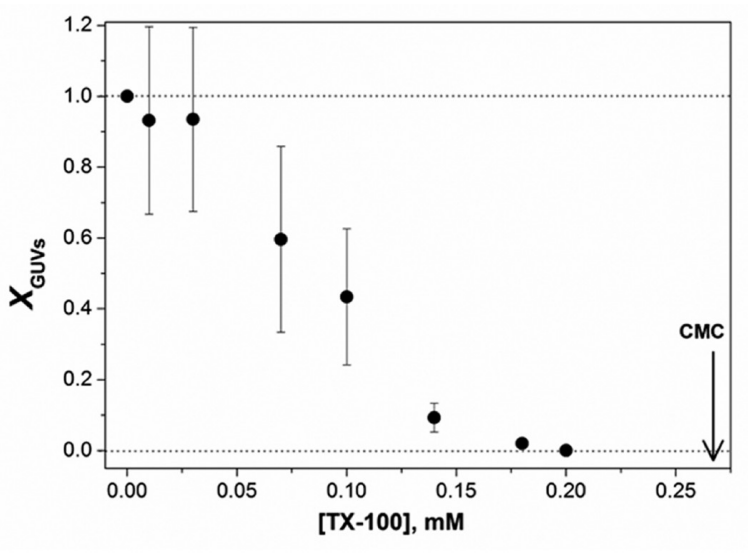

Figure 5. A) Snapshots obtained $10 \mathrm{~min}$ after dilution of GUVs into $0.2 \mathrm{mM}$ glucose containing different concentrations of TX-100 (indicated in $\mathrm{mM}$ on top of each snapshot). A low magnification objective $(10 \times)$ was used. The scale bar represents $200 \mu \mathrm{m}$. B) Relative number of intact GUVs deposited on the coverslip surface after $10 \mathrm{~min}\left(X_{\mathrm{GUVs}}\right)$ as a function of TX-100. The error bars refer to the uncertainty associated with the values extracted from at least two different experiments. The CMC of TX-100 $(0.27 \mathrm{mM})$ is indicated with an arrow (Figure 1).

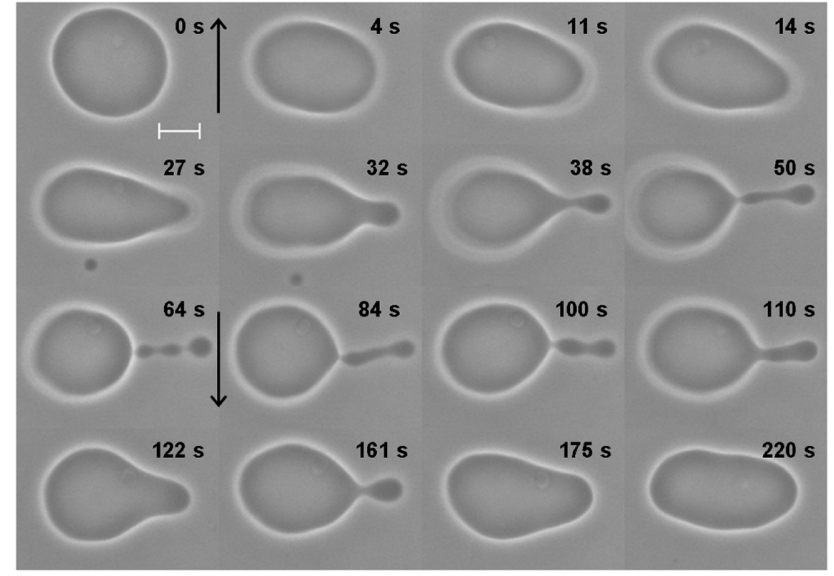

Figure 6. Sequence of snapshots obtained with phase contrast of a vesicle during and after injection of a $10 \mathrm{mM}$ SDS solution loaded in a micropipette. The micropipette was brought close to the vesicle from the right side $(0 \mathrm{~s})$ and was removed after $70 \mathrm{~s}$, indicated by upward and downward arrows, respectively. The scale bar represents $10 \mu \mathrm{m}$.

Sodium Dodecyl Sulfate (SDS). The effect of injecting SDS close to GUVs was quite different from that observed during injection of TX-100. For SDS concentrations up to $20 \mathrm{mM}$ SDS, injections induced only a change in vesicle shape, which could be partially reversed if the injection was terminated. Figure 6 shows one such example (injection of $10 \mathrm{mM} \mathrm{SDS}$ ). We chose a vesicle that started with excess area, visualized by its floppy appearance because it allowed for shape transformations due to changes in spontaneous curvature (spherical vesicles cannot be deformed due to changes in spontaneous curvature only). Judging by the large shape fluctuations observed, this vesicle seemed to be originally oblate (note that only the cross-section of a vesicle is observed with phase contrast). Once the micropipette is brought close to the vesicle (indicated with an upward arrow), the oblate vesicle first becomes prolate (4 s), then adopts a pearlike shape (11-27 s), and finally undergoes sequential budding transitions (38-64 s). This sequence of shape transitions are driven by an increase in membrane spontaneous curvature.$^{36}$ Once the injection stops (downward arrow), the vesicle spontaneous curvature is slowly reversed, although not completely (the vesicle finishes with a prolate shape at $220 \mathrm{~s}$ ). It is reasonable to assume that the concentration of detergent around this vesicle is roughly homogeneous during slow injection of a low detergent concentration because the shapes adopted by this vesicle corresponds roughly to equilibrium shapes in the shape phase diagram. ${ }^{36}$ No changes in vesicle contrast occurred during the whole injection process, showing that the bilayer permeability was not affected significantly.

Another example of changes in spontaneous curvature induced by injection of SDS on a nonspherical vesicle is shown in the Figure S3 of the Supporting Information. There, injection of $20 \mathrm{mM}$ SDS induced an even higher increase in spontaneous curvature: several buds as in a pearl chain are released and later reabsorbed by the mother vesicle after the end of injection. All nonspherical vesicles with excess area adopted shapes with higher spontaneous curvatures as a consequence of injection of SDS. Spherical vesicles were not altered by injection of up to $20 \mathrm{mM}$ SDS.

Above $30 \mathrm{mM}$ SDS, all vesicles eventually burst. In some cases, especially in the range $30-40 \mathrm{mM}$ SDS, transient macropores opened and a vesicle structure was still preserved afterward, although with a significant decrease in size; eventually the remaining vesicle also burst. Figure 7 illustrates two examples of injection of 30 and $40 \mathrm{mM}$ SDS on GUVs, showing one event of bursting and one of opening of transient macropores. The vesicles chosen in both examples were initially spherical and therefore could not be deformed due to changes in spontaneous curvature. It is important to state that injection of SDS never created excess area in initially spherical vesicles, as seen with injection of TX-100 (Figure 2). The vesicle shown in panel A bursts within $10 \mathrm{~ms}$. The vesicle quickly disintegrates into small bilayer fragments, which are still visible under optical microscopy. It is thus difficult to resolve when the bilayer fragments are finally solubilized into micellar structures because of the low optical resolution. Panel B shows one example of sequential opening of macropores. A large macropore opens suddenly $(0.176 \mathrm{~s})$, seen by the efflux of the darker sucrose solution, and reseals within few seconds (5.408s). After some time, a new macropore opens (14.784-14.832 s). After each opening/closing of a macropore, the vesicle size decreases significantly, due to loss of volume and/or area. Finally, the vesicle bursts (16.288 s) and only bilayer fragments are left (16.320 s).

From our observations we conclude that the incorporation of SDS into the lipid vesicles promotes initially changes in vesicle shape, driven by an increase in membrane spontaneous 
A

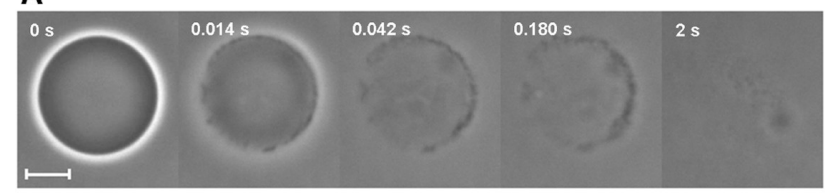

B

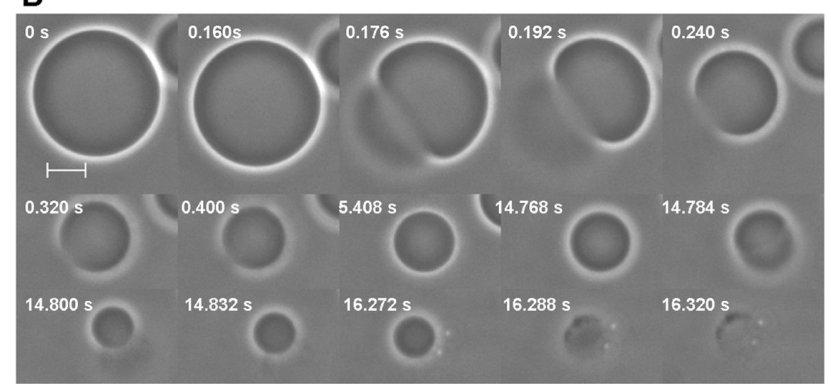

Figure 7. Two sequences of snapshots obtained with phase contrast of two vesicles during injection of a A) 30 and B) $40 \mathrm{mM}$ SDS solution loaded in a micropipette. The time marked on top are related to the moment preceding vesicle bursting/poration, which occurred seconds after the beginning of injection. These sequences were obtained at our highest recording speed, $60 \mathrm{fps}$. The scale bars represent $10 \mu \mathrm{m}$.

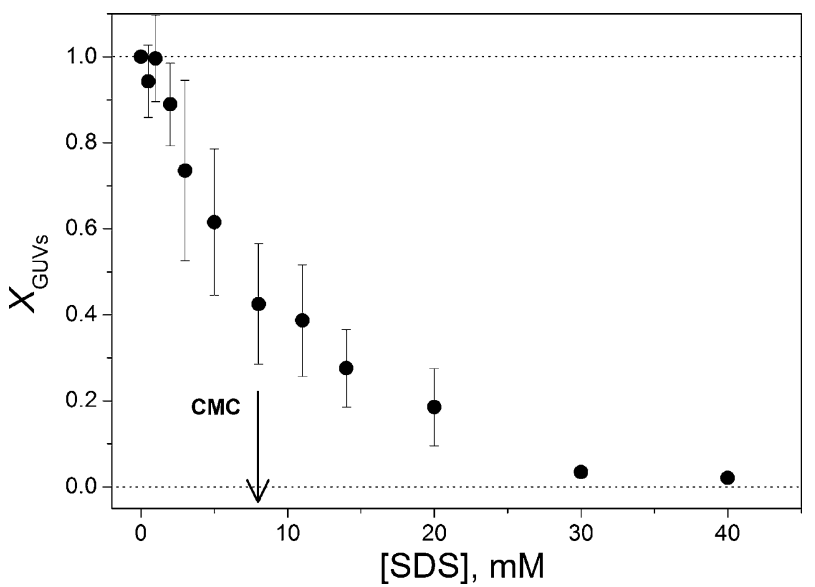

Figure 8. Results extracted from dilution experiments of GUVs into different concentrations of SDS. The relative number of intact GUVs after $10 \mathrm{~min}, X_{\mathrm{GUV}}$, is plotted as a function of SDS concentration. The error bars refer to the uncertainty associated with the values extracted from at least two different experiments. The CMC of SDS $(8 \mathrm{mM})$ is indicated with an arrow.

curvature. Increase in bilayer area was not observed. Then large transient macropores open or the entire vesicle bursts. The final process of solubilization of the remaining bilayer fragments into micelle-like structures cannot be followed with optical microscopy.

Experiments with the dilution protocol were also performed with SDS in the same way as described for TX-100 (Figure 5). The decrease in the number of GUVs as the SDS concentration increases is related to the extent of GUV bursting. The fraction of intact GUVs deposited on the coverslip surface after $10 \mathrm{~min}$, $X_{\mathrm{GUV}}$, is shown as a function of SDS concentration in Figure 8. At low concentrations of $\operatorname{SDS}(0.5-1 \mathrm{mM}), X_{\mathrm{GUVs}} \sim 1$ showing that no significant vesicle burst is induced. Between 2 and $20 \mathrm{mM}$ SDS, $X_{\mathrm{GUVs}}$ decreases. Complete vesicle destruction $\left(X_{\mathrm{GUVs}} \sim 0\right)$ is achieved only above $30 \mathrm{mM}$ SDS, well above the CMC of SDS $(8 \mathrm{mM})$. Figure 8 shows that the errors obtained from different dilutions were significantly smaller than those observed with TX-100, probably because GUVs are not much altered before bursting, and thus the deposition rate is not so much detergent dependent. These results also show that the intermediate regime between no effect and complete vesicle disruption is broader for SDS than for TX-100, coinciding with the broad transition range observed in the ITC measurements (Figure 1). It should be noted that $X_{\mathrm{GUVs}}$ is not necessarily related to the actual solubilization of bilayers, a process which should follow vesicle destabilization.

Mechanism of Bilayer Solubilization. Observation of giant vesicles in the presence of the detergents TX-100 and SDS revealed that the mechanism of bilayer solubilization depends on the amphiphile employed. TX-100 causes initially an increase in vesicle surface area followed by a dynamic bilayer perforation with subsequent complete solubilization. On the other hand, SDS induces initially an increase in bilayer spontaneous curvature until a macropore opens, which can either reseal after significant decrease in size or open continuously (vesicle burst); eventually all vesicles burst and the bilayer fragments are probably solubilized later on. Although the steps involved in the solubilization process showed to be different for the two detergents, the complete solubilization/destruction of lipid vesicles occurs in a concentration range not far from the CMC of each detergent.

According to the three-stage model of bilayer solubilization by detergents, ${ }^{9}$ the key parameter describing this process is the effective ratio $R_{\mathrm{b}}$ between the molar concentrations of bound detergent $\left(C_{\text {det, }}\right)$ and total lipid $\left(C_{\text {lip }}\right)$ :

$$
R_{\mathrm{b}}=C_{\mathrm{det}, \mathrm{b}} / C_{\text {lip }}
$$

Initially, detergents are incorporated in bilayers up to a saturation point, reached at $R_{\text {sat. }}$ Then, detergent-rich bilayers coexist with mixed micelles up to a solubility threshold at $R_{\text {sol }}$, after which mixed micelles coexist with detergent monomers in solution. Among the models describing the partitioning of nonionic detergents, such as TX-100, between water and lipid bilayers, the best one defines a simple linear relation between the ratio $R_{\mathrm{b}}$ and the concentration of free detergent in solution $\left(C_{\text {det, }}\right)^{5,10}$ such that:

$$
R_{\mathrm{b}}=K C_{\mathrm{det}, \mathrm{f}}
$$

where $K$ is the partition coefficient of the detergent between the aqueous and bilayer phases.

The data obtained with the dilution protocol shows the relative number of intact GUVs, $X_{\mathrm{GUV}}$, as a function of TX-100 concentration (part B of Figure 5). Although $X_{\mathrm{GUVs}}$ cannot be directly associated with the equilibrium between vesicles and micelles, this result can be interpreted in the light of the threestage model as follows. Below $R_{\text {sat }}, \mathrm{TX}-100$ is incorporated in the bilayer causing changes in vesicle morphology due to increase in area. Although no significant change in membrane permeability was observed within few minutes at this stage (see Figure 2), an increase in permeability is to be expected for longer time incubation with TX-100 even at subsolubilizing concentrations. ${ }^{7,11}$ The relative number of GUVs should not change $\left(X_{\mathrm{GUVs}}\right.$ $\sim 1$ ) in this region. However, due to changes in the deposition rate of deflated (intact) vesicles or to decrease in sugar asymmetry due to partial leakage, $X_{\mathrm{GUV}}$ decreases as the concentration of TX-100 increases. Also, if vesicle size decreases, a decrease in $X_{\mathrm{GUVs}}$ is to be expected. At the onset of bilayer solubilization, at $R_{\text {sat }}$, the bilayers become highly perforated and are no longer able to sustain the sugar asymmetry. Therefore, even if perforated vesicles could still remain between $R_{\text {sat }}$ and $R_{\text {sol }}$, these vesicles do not deposit on the coverslip surface and therefore $X_{\mathrm{GUVs}} \sim 0$. Thus, we conclude that the saturation limit $R_{\text {sat }}$ is reached at around $0.18 \mathrm{mM}$ TX-100 
(Figure 5). With our protocol, we are not able to detect the solubility threshold $R_{\text {sol }}$. If the partition coefficient $K$ of TX100 in POPC bilayers is known, then eq 2 gives $R_{\mathrm{b}}$ for a specific $C_{\text {det,f }}$. Since the lipid concentration in GUV preparations is very low, $\sim 1 \mu \mathrm{M}, C_{\text {det,b }}$ is very small compared to the total concentration of TX-100. Therefore, we can assume that $C_{\mathrm{det}, \mathrm{f}}$ is similar to the total concentration of TX-100. The partition coefficient $K$ of TX-100 in POPC vesicles was calculated previously with ITC, and found to be $3000 \mathrm{M}^{-1}{ }^{17}$. Consequently, we extract from our data that $R_{\text {sat }} \approx 0.54$, in very good agreement with values previously obtained with other methods $\left(R_{\text {sat }} \sim 0.4-0.8^{3,19,37,38}\right)$. As expected, TX-100 can be classified as a strong detergent, solubilizing lipid bilayers at a ratio $R_{\text {sat }}<$ $K \mathrm{CMC}=0.8 .{ }^{17} \mathrm{In}$ principle, observation of GUVs during injection of TX-100 (as in Figure 4) could be used to estimate the maximum area increase caused by TX-100 incorporation in an intact bilayer (before the onset of perforation). The maximum area increase should correspond to the excess area brought by insertion of one TX-100 molecule for every $\sim 2$ lipid molecules. However, because we only have access to the cross section of the focal plane of the vesicles and several buds are expelled (snapshots at 13s for the upper vesicle and 17s for the lower vesicle in Figure 2), quantification of vesicle surface area becomes unfeasible.

The solubilization of bilayers by SDS should also follow the three-stage model and be dictated by the ratio $R_{\mathrm{b}}$. However, the determination of $R_{\mathrm{b}}$ is not as straightforward as for the nonionic detergent TX-100, because incorporation of SDS in the bilayer is hindered by electrostatic repulsion as $R_{\mathrm{b}}$ increases. This means that in eq $2 K$ has the meaning of an apparent partition coefficient, which decreases with $R_{\mathrm{b}}$. If $C_{\mathrm{det}, \mathrm{f}}$ in eq 2 is replaced by the concentration of free SDS at the bilayer surface, which depends on the surface potential, then $K$ represents the intrinsic partition coefficient and is independent of $R_{\mathrm{b}}$. Tan and co-workers ${ }^{18}$ attempted to calculate the intrinsic partition coefficient for SDS in POPC membranes and described the whole thermodynamics of insertion of SDS into lipid bilayers, but at high ionic strength. Because our results were obtained with pure water, a direct comparison cannot be easily done. Furthermore, our results with GUVs show that SDS caused vesicle bursting. After vesicle burst, bilayers fragments were still visible, although in the limit of our optical resolution. Therefore, it is not clear whether the threshold for macropore opening or vesicle burst coincides with the onset of bilayer solubilization.

On the other hand, it is interesting to notice that the decrease of $X_{\mathrm{GUVs}}$ with the concentration of SDS is well correlated with the decrease of the heat of demicellization, $Q_{\mathrm{i}}$, measured with ITC (Figure 1). This could indicate that the destruction of GUVs caused by SDS could be simply related to the process of micelle formation, which for SDS happens in a wide concentration range.

Injection of TX-100 and SDS caused at first changes in vesicle morphology, due to insertion of detergents in the bilayer (below $R_{\text {sat }}$ ). We can rationalize the different vesicle shape changes induced by TX-100 (Figure 2 and Figure S1 of the Supporting Information) and SDS (Figure 6 and Figure S3 of the Supporting Information) as follows. In our setup, the detergents are injected in the external medium and are thus initially incorporated in the outer monolayer only. That causes an increase in monolayer area, according to the geometry of the detergent molecule inserted (both hydrophobic and hydrophilic portions). The flipflop rate of the detergent molecules regulates the migration of the inserted molecules to the inner leaflet. As a consequence, the alterations on vesicle shape, which happen within a few seconds, are quite distinct depending on the detergent flip-flop rate.

The nonionic detergent TX-100 has a fairly long hydrophilic portion, comprising 9-10 ethylene glycol units. However, this hydrophilic part can easily cross the bilayer, and therefore the flip-flop rate of TX-100 can be considered to be almost instantaneous as compared to the experiment time scale (seconds to minutes). ${ }^{20,23}$ In fact, injection of TX-100 on oligolamellar vesicles (Figure 3 ) showed that all lamellae sense the presence of TX-100 instantaneously within the time resolution of our experiment $(\sim 0.5 \mathrm{~s})$. Therefore, this is a clear indication that the flip-flop rate of TX-100 in POPC bilayers is faster than $0.5 \mathrm{~s}$. Consequently, the fast flip-flop rate ensures a rapid equilibration of TX-100 between both leaflets, and the initial effect caused by TX-100 is a significant increase in bilayer area, as clearly detected in the GUVs. A slightly higher concentration in the external monolayer at fast insertion rates could occur, since buds are expelled as the area is rapidly increased (part A of Figure 4 ). Above $R_{\text {sat }}$, the bilayer structure is destabilized and several pores open at the same time as lipids get solubilized into submicroscopic micelle-like structures. During the coexistence of bilayers and micelles, the detergent-rich membrane resembles a lace fabric. The solubility threshold, $R_{\text {sol }}$, is reached when all lipids are incorporated into micellar structures and no bilayers are observed with optical microscopy. The sequence of events depicting the mechanism of bilayer solubilization induced by TX-100 is summarized in a cartoon in part A of Figure 9.

Recently, the effects of detergents, including TX-100 and SDS, on membranes at subsolubilizing concentrations were studied with several techniques. It has been shown that, even below $R_{\text {sat }}$, TX-100 induces complete leakage of entrapped vesicle volume and significant increase in phospholipid flipflop rate. ${ }^{7}$ It should be noted that these results were obtained after incubation of vesicles with TX-100 for at least $30 \mathrm{~min}$. On the other hand, observation of individual GUVs in the presence of TX-100 shows that detergent flip-flop must occur almost instantaneously (less than $0.5 \mathrm{~s}$ ), whereas contrast loss due to increased permeability with accompanying significant phospholipid flip-flop do not happen in the time course of one experiment (minutes). On the other hand, an increase in bilayer permeability at longer incubation times could explain the decrease of intact vesicles reaching the coverslip surface $\left(X_{\mathrm{GUVs}}\right)$ in the dilution protocol for $R_{\mathrm{b}}<R_{\text {sat }}$ (Figure 5).

The anionic detergent SDS exhibits a slow flip-flop rate at room temperature (minutes to hours), due to its charged headgroup. ${ }^{22}$ So, we can here assume that no significant flipflop of SDS occurs during our experiment time scale. In fact, injection of SDS never induced increase in vesicle surface area, which would be evident especially when injection occurred on spherical vesicles. Therefore, the SDS molecules must insert in the external monolayer only. The asymmetric incorporation of SDS molecules imposes a strain on the bilayer, which curves outward to accommodate the area difference between both monolayers (increase in spontaneous curvature). It should be mentioned that detergent-induced lipid flip-flop, which could wipe out this area difference, was also not observed in the time course of our experiments. Also, no significant decrease in contrast occurred at this stage, showing that the permeability of the membrane was not significantly altered. Above a certain strain threshold, the bilayer disrupts through the opening of a large macropore, which can either reseal or open continuously (burst). Generally, vesicle burst was observed more frequently as the concentration of SDS was increased. In some cases, 


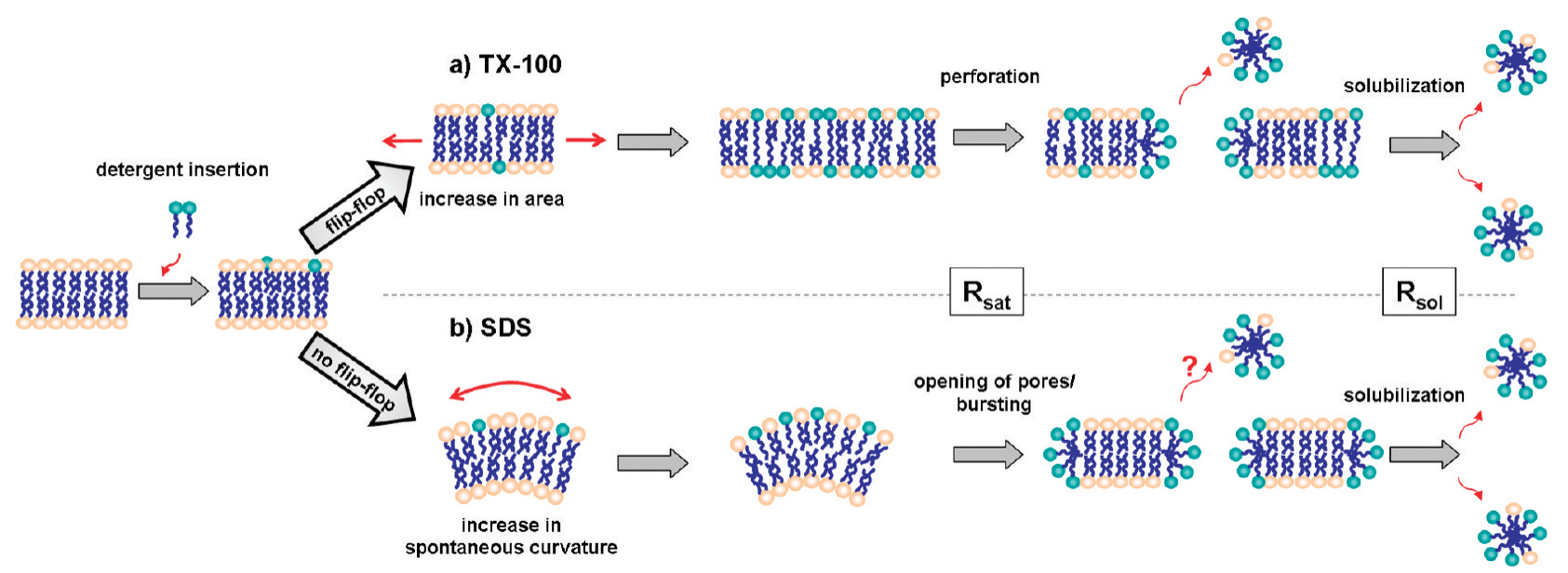

Figure 9. Cartoon representing the mechanisms of solubilization of lipid bilayers induced by the detergents a) TX-100 and b) SDS. The key feature is the flip-flop rate of the detergent. $R_{\text {sat }}$ and $R_{\text {sol }}$ represent respectively the saturation and solubilization thresholds of the ratio between bound detergent and total lipids.

opening of transient macropores was enough to relieve the strain on the bilayer by allowing the SDS molecules to redistribute on both sides of the membrane. After the opening and resealing of a transient macropore the size of the vesicle decreased considerably. Eventually, all vesicles burst and only bilayer fragments remain. The complete solubilization of these bilayer pieces was difficult to follow with optical microscopy, and therefore it is not possible to determine the onset of the solubilization process. The sequence of events described for the mechanism of bilayer destruction by SDS is depicted in part B of Figure 9.

\section{Conclusions}

Optical microscopy of GUVs can be used to follow the dynamics of several processes of biological relevance involving lipid bilayers. Here, we observed the process of membrane solubilization by detergents, a routine that is widely used to solubilize biological membranes or extract and purify membrane proteins. We clearly show that the ability of detergents to equilibrate between two leaflets of the bilayer is governing the morphological changes of the vesicles during the first stage of solubilization. Our experiments indicate that the flip-flop rate of TX-100 in POPC bilayers is faster than $0.5 \mathrm{~s}$. Therefore, TX-100 rapidly equilibrates between both monolayers and initially causes an increase in bilayer area. Above the onset of solubilization, the bilayer is solubilized in a dynamic perforation process. The relative number of intact GUVs in the presence of increasing concentrations of TX-100 allowed us to determine the onset of bilayer solubilization, which corresponds to the saturation limit of detergent insertion. With our setup, we showed that bilayers of POPC can accommodate up to 0.54 TX-100 molecules per lipid, in very good agreement with previously reported data and consistent with the classification of TX-100 as a strong detergent. On the other hand, SDS is only incorporated in the external monolayer during the course of the experiment due to its slow flip-flop rate. Consequently, the bilayer curves outward to accommodate the asymmetrical area increase and the initial shape changes of GUVs are related to an increase in the membrane spontaneous curvature. Then, a transient macropore opens to relieve the stress or the whole vesicle bursts. Final solubilization of the remaining bilayer fragments into micelle-like structures should happen later on.

Acknowledgment. We are thankful to M. T. Lamy for allowing us to prepare our samples in her lab and to J. Aboulafia and V. L. A. Nouailhetas for the use of the micropipette puller. This work was supported by FAPESP. K.A.R. acknowledges the infrastructure provided by the Department of Applied Physics (IF-USP) and the financial support of inctFCx. T.P.S. and N.L.A. thank FAPESP fellowships and R.I. thanks CNPq for a research fellowship.

Supporting Information Available: Figures of other examples of increase in vesicle area and bilayer perforation caused by injection of TX-100 and increase in spontaneous curvature due to injection of SDS. This material is available free of charge via the Internet at http://pubs.acs.org.

\section{References and Notes}

(1) Jones, M. N. Int. J. Pharm. 1999, 177, 137-159. 204.

(2) Alonso, A.; Villena, A.; Goñi, F. M. FEBS Lett. 1981, 123, 0200-

(3) De la Maza, A.; Parra, J. L. Biochem. J. 1994, 303, 907-914.

(4) Kragh-Hansen, U.; le Maire, M.; Møller, J. V. Biophys. J. 1998, $75,2932-2946$. 85 .

(5) Heerklotz, H.; Seelig, J. Biochim. Biophys. Acta 2000, 1508, 69-

(6) Goñi, F. M.; Alonso, A. Biochim. Biophys. Acta 2000, 1508, 5168.

(7) Ahyayauch, H.; Bennouna, M.; Alonso, A.; Goñi, F. M. Langmuir 2010, 26, 7307-7313.

(8) Lichtenberg, D.; Robson, R. J.; Dennis, E. A. Biochim. Biophys. Acta 1983, 737, 285-304.

(9) Lichtenberg, D. Biochim. Biophys. Acta 1985, 821, 470-478.

(10) Schurtenberger, P.; Mazer, N.; Kanzig, W. J. Phys. Chem. 1985, $89,1042-1049$.

(11) Preté, P. S. C.; Domingues, C. C.; Meirelles, N. C.; Malheiros, S. V.P.; Goñi, F. M.; de Paula, E.; Schreier, S. Biochim. Biophys. Acta 2010, . doi:10.1016/j.bbamem.2010.10.016.

(12) Lasch, J. Biochim. Biophys. Acta 1995, 1241, 269-292.

(13) Le Maire, M.; Champeil, P.; Møller, J. V. Biochim. Biophys. Acta 2000, 1508, 86-111.

(14) Wenk, M. R.; Seelig, J. Biophys. J. 1997, 73, 2565-2574.

(15) Wenk, M. R.; Seelig, J. J. Phys. Chem. B 1997, 101, 5224-5231.

(16) Heerklotz, H.; Binder, H.; Epand, R. M. Biophys. J. 1999, 76, 26062613.

(17) Heerklotz, H.; Seelig, J. Biophys. J. 2000, 78, 2435-2440.

(18) Tan, A.; Ziegler, A.; Steinbauer, B.; Seelig, J. Biophys. J. 2002, $83,1547-1556$.

(19) Heerklotz, H. Biophys. J. 2002, 83, 2693-2701.

(20) Heerklotz, H.; Szadkowska, H.; Andersin, T.; Seelig, J. J Mol. Biol. 2003, 329, 793-799.

(21) Arnulphi, C.; Sot, J.; Garcí-Pacios, M.; Arrondo, J. L.; Alonso, A.; Goñi, F. M. Biophys. J. 2007, 93, 3504-3514.

(22) Cócera, M.; López, O.; Estelrich, J.; Parra, J. L.; de la Maza, A. Langmuir 1999, 15, 6609-6612.

(23) Le Maire, M.; Møller, J. V.; Champeils, P. Biochemistry 1987, 26, $4803-4810$. 
21 .

(24) Edwards, K.; Almgren, M. J. Colloid Interface Sci. 1991, 147, 1-

(25) Nomura, F.; Nagata, M.; Inaba, T.; Hiramatsu, H.; Hotani, H.; Takiguchi, K. Proc. Natl. Acad. Sci. U.S.A. 2001, 98, 2340-2345.

(26) Arrigler, V.; Kogej, K.; Majhenc, J.; Svetina, S. Langmuir 2005,

21, 7653-7661.

(27) Toyota, T.; Tsuha, H.; Yamada, K.; Takakura, K.; Yasuda, K.; Sugawara, T. Langmuir 2006, 22, 1976-1981.

(28) Babnik, B.; Miklavčič, D.; Kandušer, M.; Hägerstrand, H.; KraljIglič, V.; Iglič, A. Chem. Phys. Lipid 2003, 125, 123-138.

(29) Mavčič, B.; Babnik, B.; Iglič, A.; Kandušer, M.; Slivnik, T.; KraljIglič, V. Bioelectrochem. 2004, 63, 183-187.

(30) Tamba, Y.; Tanaka, T.; Yahagi, T.; Yamashita, Y.; Yamazaki, M. Biochim. Biophys. Acta 2004, 1667, 1-6.

(31) Staneva, G.; Seigneuret, M.; Koumanov, K.; Trugnan, G.; Angelova, M. I. Chem. Phys. Lipids 2005, 136, 55-66.
(32) Paula, S.; Süs, W.; Tuchtenhagen, J.; Blume, A. J. Phys. Chem. 1995, 99, 11742-11751.

(33) Chatterjee, A.; Moulik, S. P.; Sanyal, S. K.; Mishra, B. K.; Puri, P. M. J. Phys. Chem. B 2001, 105, 12823-12831.

(34) Angelova, M. I.; Dimitrov, D. S. Faraday Discuss. Chem. Soc. 1986, 81, 303-311.

(35) Domingues, T. M.; Riske, K. A.; Miranda, A. Langmuir 2010, 26, 11077-11084.

(36) Döbereiner, H.-G. Curr. Opin. Colloid Interface Sci. 2000, 5, 2560263.

(37) Paternostre, M.-T.; Roux, M.; Rigaud, J.-L. Biochemistry 1988, 27, 2668-2677.

(38) Partearroyo, M. A.; Alonso, A.; Goñi, F. M.; Tribout, M.; Paredes, S. J. Colloid Interface Sci. 1996, 178, 156-159.

JP108653E 


\title{
The membranotropic activity of $\mathrm{N}$-terminal peptides from the pore-forming proteins sticholysin I and II is modulated by hydrophobic and electrostatic interactions as well as lipid composition
}

\author{
Uris Ros $^{l}$, Lohans Pedrera ${ }^{l}$, Daylín Díaz ${ }^{1}$, Juan C de Karam ${ }^{l}$, Tatiane P Sudbrack ${ }^{2}$,

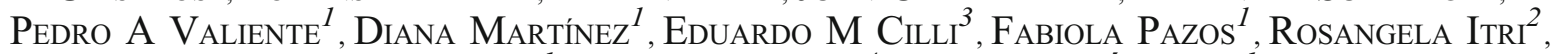 \\ Maria E Lanio ${ }^{1}$, Shirley Schreier ${ }^{4}$ and Carlos Álvarez ${ }^{1}, *$ \\ ${ }^{1}$ Center for Protein Studies, Biology Faculty, University of Havana, Havana, Cuba \\ ${ }^{2}$ Department of Applied Physics, Institute of Physics, University of São Paulo, São Paulo, Brazil \\ ${ }^{3}$ Department of Biochemistry, Institute of Chemistry, São Paulo State University, Araraquara, São Paulo, Brazil \\ ${ }^{4}$ Department of Biochemistry, Institute of Chemistry, University of São Paulo, São Paulo, Brazil \\ *Corresponding author (Fax, +53-832-12321; Email, calvarez@fbio.uh.cu)
}

The sea anemone Stichodactyla helianthus produces two pore-forming proteins, sticholysins I and II (St I and St II). Despite their high identity (93\%), these toxins exhibit differences in hemolytic activity that can be related to those found in their N-terminal. To clarify the contribution of the N-terminal amino acid residues to the activity of the toxins, we synthesized peptides spanning residues 1-31 of St I ( $\left.\mathrm{StI}_{1-31}\right)$ or 1-30 of St II ( $\left.\mathrm{StII}_{1-30}\right)$ and demonstrated that $\mathrm{StII}_{1-30}$ promotes erythrocyte lysis to a higher extent than $\mathrm{StI}_{1-31}$. For a better understanding of the molecular mechanism underlying the peptide activity, here we studied their binding to lipid monolayers and pemeabilizing activity in liposomes. For this, we examined the effect on peptide membranotropic activity of including phospatidic acid and cholesterol in a lipid mixture of phosphatidylcholine and sphingomyelin. The results suggest the importance of continuity of the 1-10 hydrophobic sequence in $\mathrm{StII}_{1-30}$ for displaying higher binding and activity, in spite of both peptides' abilities to form pores in giant unilamellar vesicles. Thus, the different peptide membranotropic action is explained in terms of the differences in hydrophobic and electrostatic peptide properties as well as the enhancing role of membrane inhomogeneities.

[Ros U, Pedrera L, Díaz D, de Karam JC, Sudbrack TP, Valiente PA, Martínez D, Cilli EM, Pazos F, Itri R, Lanio ME, Schreier S and Álvarez C 2011 The membranotropic activity of N-terminal peptides from the pore-forming proteins sticholysin I and II is modulated by hydrophobic and electrostatic interactions as well as lipid composition. J. Biosci. 36 1-11] DOI 10.1007/s12038-011-9156-4

\section{Introduction}

The pore-forming proteins sticholysin I and sticholysin II (St I/II) produced by the sea anemone Stichodactyla helianthus (Lanio et al. 2001) are highly hemolytic toxins with $93 \%$ sequence identity. St I and II form hydrophilic pores both in natural and model lipid membranes of around $1 \mathrm{~nm}$ hydrodynamic radius (Tejuca et al. 2001). Despite the extensive work carried out aiming at clarifying how these water-soluble proteins bind, oligomerize and eventually disrupt target membranes, the role of each amino acid sequences or domains involved in the

Keywords. Actinoporin; hemolytic peptide; permeabilizing activity; pore-forming toxin; sticholysin

Abbreviations used: $\mu$, mean hydrophobic moment; $\pi$, surface pressure; CF, carboxyfluorescein; Chol, cholesterol; GUV, giant unilamellar vesicles; H, mean hydrophobicity; LUV, large unilamellar vesicle; MLV, multilamellar vesicles; PA, phosphatidic acid; PC, phosphatidyl choline; SM, sphingomyelin; St I and St II, sticholysins I and II 
mechanism of lysis it is barely known (Tejuca et al. 1996; Martínez et al. 2001; Álvarez et al. 2009). Sticholysins belong to the actinoporin family, a unique class of eukaryotic pore-forming toxins exclusively found in sea anemones (Kem 1988). Actinoporins are cysteine-less proteins with molecular weight around $20 \mathrm{kDa}$ and high affinity for sphingomyelin (SM)-containing membranes (Anderluh and Maček 2002).

The main difference in the primary sequence between sticholysins lies in their N-terminal, where all non-conservative substitutions and one conservative substitution are found (Huerta et al. 2001). Compared to St II, St I contains two additional anionic amino acid residues $\left(\mathrm{Glu}^{2}\right.$ and $\left.\mathrm{Asp}^{9}\right)$ instead of non-polar amino acid Ala, in positions 1 and 8 of St II. St I has an extra polar residue (Ser) at position 1, rendering St II's N-terminal 1-10 sequence more hydrophobic than its counterpart in St I. The most noteworthy functional difference between these toxins is that the lytic activity of St II is approximately 3- to 6-fold higher than that of St I in human red blood cells (Martínez et al. 2001). Since the N-terminal region of sticholysins is probably involved in pore formation (Álvarez et al. 2003; Mancheño et al. 2003; Casallanovo et al. 2006), their different hemolytic activity could be due, at least partly, to differences in this region.

To gain insight into the molecular mechanism of the differential activity of sticholysins, two peptides reproducing the N-terminal sequence of St I comprising residues 1-31 ( StI $\left._{1-31}\right)$ or the equivalent segment in St II (StII ${ }_{1-30}$ ) were synthesized (table 1). The fragments contain the amphipathic $\alpha$-helix (14-23 in St II and 1524 for St I) preceded by a more (St II) or less (St I) hydrophobic sequence described for sticholysins (Mancheño et al. 2003; Castrillo et al. 2009). St II peptide is cationic at $\mathrm{pH} 7$ (net charge +2 ) in contrast to $\mathrm{StI}_{1-31}$, which has no net charge. In a previous characterization of peptide activity, we demonstrated that $\mathrm{StII}_{1-30}$ is 3-fold more active than $\mathrm{StI}_{1-31}$, qualitatively reproducing the differential hemolytic activity of toxins, which suggests that the N-terminal plays a key role in protein function (Cilli et al. 2007).

Here, we compare peptide binding to lipid monolayers formed at the air-water interface and correlate them with their ability to permeabilize liposomes of different composition. To this end, interaction of peptides with membranes composed of phosphatidylcholine (PC) and SM, the anionic phospholipid phospatidic acid (PA) and cholesterol (Chol) were studied. Results obtained here were explained in terms of differences in the molecular mechanism of action modulated by dissimilarity in hydrophobic continuity of the sequence 1-10/11 and net charge between $\mathrm{StII}_{1-30}$ and $\mathrm{StI}_{1-31}$, respectively.

\section{Materials and methods}

\subsection{Chemicals and reagents}

All 9-fluorenylmethyloxycarbonyl amino acids and Rink-amide MBHAR resin were purchased from Advanced Chemtech (Louisville, KY, USA) and Novabiochem (San Diego, CA, USA). Egg phosphatidylcholine (PC), egg sphingomyelin (SM), 1-palmitoyl-2-oleoyl-snglycero-3-phosphate (PA) and cholesterol (Chol) were purchased from Avanti Polar Lipids (Alabaster, AL, USA), claimed to be $99 \%$ pure, and were used without further purification. Solvents and reagents were from Sigma-Aldrich Co (St Louis, MO, USA) and Fluka (Buch, Switzerland).

\subsection{Peptide synthesis}

The peptides, with amidated C-terminus, were synthesized manually according to the standard $\mathrm{N}_{\alpha}$-Fmoc protectinggroup strategy (Atherton and Sheppard 1988) as previously described (Casallanovo et al. 2006). The peptides' homogeneity was checked by analytical HPLC (Varian, Walnut

Table 1. Peptide sequences, net charge, average hydrophobicity $(\mathrm{H})$ and mean hydrophobic moment $(\mu)$

\begin{tabular}{|c|c|c|c|c|c|c|c|c|}
\hline \multirow[b]{2}{*}{ Peptide } & \multirow[b]{2}{*}{ Sequence } & \multirow{2}{*}{$\begin{array}{c}\text { Net Charge } \\
(\mathrm{pH} 7)\end{array}$} & \multicolumn{2}{|c|}{$\mathrm{H}$} & \multicolumn{2}{|c|}{$\mu$} & \multicolumn{2}{|c|}{ Predicted orientation } \\
\hline & & & $1-11^{*}$ & $14-24 *$ & $1-11^{*}$ & $14-24 *$ & $1-11^{*}$ & $14-24 *$ \\
\hline $\mathrm{StI}_{1-31}$ & SELAGTIIDGASLTFEVLDKVLGELGKVSRK-NH ${ }_{2}$ & 0 & 0.38 & 0.28 & 0.41 & 0.55 & Surface & Surface \\
\hline $\mathrm{StII}_{1-30}$ & $\underline{\text { ALAGTIIAGASLTFQVLDKVLEELGKVSRK-NH}}{ }_{2}$ & +2 & 0.64 & 0.16 & 0.16 & 0.66 & Transmembrane & Surface \\
\hline
\end{tabular}

The differences between sticholysins's peptides are underlined. All peptide C-terminal are amidated.

*The sequences include the hydrophobic stretch 1-11 and the amphiphilic $\alpha$-helix 14-24 according to the 3D structure of St II (Mancheño et al. 2003) or 1-11 and 15-25 according to 3D structure of StI (Castrillo et al. 2009). H and $\mu$ were calculated according to the Eisenberg procedure (Eisenberg et al. 1984). This method uses an optimized 11-residue window and an angular frequency between consecutive residues fixed at $100^{\circ}$ (program MOMENT Transmembrane Helix Prediction, http://www.doe-mbi.ucla.edu/services). 
Creek, CA, USA), using UV detection at $220 \mathrm{~nm}$. The identity of the peptides was confirmed by electrospray mass spectrometry on a ZMD model apparatus (Micromass, Manchester, UK) and amino acid analysis (Shimadzu, Tokyo, Japan).

\subsection{Surface pressure measurements on lipid monolayers}

Surface pressure measurements were carried out with a $\mu$ Through-S system (Kibron, Helsinki, Finland) at $25^{\circ} \mathrm{C}$ under constant stirring employing plates of ca. $3.14 \mathrm{~cm}^{2}$. The aqueous phase consisted of $300 \mu \mathrm{L}$ of Tris-buffered saline (TBS: $145 \mathrm{mM} \mathrm{NaCl}, 10 \mathrm{mM}$ Tris- $\mathrm{HCl}, \mathrm{pH}$ 7). The lipidic mixture pre-dissolved in chloroform:methanol (2:1, $\mathrm{v}: \mathrm{v})$ was gently spread over the surface, and the desired initial surface pressure $\left(\pi_{0}\right)$ was attained by changing the amount of lipid applied to the air-water interface. The peptides were injected into the sub-phase to achieve $0.1 \mu \mathrm{M}$ peptide final concentration, at which peptides have no effect on surface tension of the air-water interface. The increment in surface pressure $(\Delta \pi)$ was recorded as a function of the elapsed time until a stable signal was obtained.

\subsection{Leakage studies from carboxyfluorescein containing- $L U V$}

Large unilamellar vesicles (LUV) were prepared by extruding a solution of multilamellar vesicles (MLV) in the presence of $80 \mathrm{mM}$ carboxyfluorescein (CF) (pH 7 adjusted by adding $\mathrm{NaOH}$ ), and subjected to six cycles of freezing and thawing. A two-syringe LiposoFast Basic unit extruder (Avestin Inc., Ontario, Canada) was used, equipped with two stacked $100 \mathrm{~nm}$ polycarbonate filters (Nuclepore, Maidstone, UK). To remove untrapped fluorophore, vesicles were filtered through a mini-column (Pierce, Rockford, USA) loaded with Sephadex G-50-medium pre-equilibrated with TBS. LUV permeabilization was determined using a FLUOstar OPTIMA microplate reader (BMG Labtech, Offenburg, Germany) by measuring the fluorescence $\left(\lambda_{\mathrm{exc}}=490 \mathrm{~nm}\right.$ and $\lambda_{\mathrm{em}}=520 \mathrm{~nm}$ ) of released CF. Black plastic 96-well microplates (SPL-Life Sciences, Seoul, South Korea) were pretreated with $0.1 \mathrm{mg} / \mathrm{mL}$ Prionex (Pentapharm, Basel, Switzerland), which strongly reduces unspecific binding of protein and vesicles to plastic (Dalla Serra et al. 1999). Each well was filled with the elution buffer plus $10 \mu \mathrm{M}$ of LUV. Finally, peptide was added, in a total volume of $200 \mu \mathrm{L}$, at the final concentration reported in the text. After mixing vesicles and peptides, the release of $\mathrm{CF}$ produced an increase in fluorescence $(f)$, due to the dequenching of the dye into the external medium, which was resolved in time. Spontaneous leakage of dye was negligible under these conditions. Maximum release was always obtained by adding $1 \mathrm{mM}$ Tx100 (final concentration) and provided the fluores- cence value $f_{\max }$. The fraction of fluorophore release $(F)$ was calculated as follows:

$$
F=\left(f t-f_{o}\right) /\left(f_{\max }-f_{o}\right)
$$

where $f o$ and $f t$ represent the value of fluorescence before or at time $t$ after peptide addition, respectively.

Phospholipid concentration was mesuared by determining inorganic phosphate according to Rouser et al. (1970).

\subsection{Optical microscopy of giant unilamellar vesicles}

Giant unilamellar vesicles (GUV) were grown using the electroformation method (Angelova and Dimitrov 1986). Briefly, $16 \mu \mathrm{L}$ of a $2 \mathrm{mg} / \mathrm{mL}$ lipid in chloroform solution were spread on the surfaces of two conductive glasses coated with Fluor Tin Oxide, which were then placed with their conductive sides facing each other and separated by a $2 \mathrm{~mm}$ thick Teflon frame. This electroswelling chamber was filled with $0.2 \mathrm{M}$ sucrose solution and connected to an alternating current of $1 \mathrm{~V}$ with a $10 \mathrm{~Hz}$ frequency for $2 \mathrm{~h}$. The vesicle suspension was removed from the chamber and diluted $\sim 10$ times into a $0.2 \mathrm{M}$ glucose solution containing $10-80 \mathrm{nM}$ of peptide. The osmolarities of the sucrose and glucose solutions were previously measured with a Gonotec 030 cryoscopic osmometer (Osmomat, Berlin, Germany) and carefully matched to avoid osmotic pressure effects. Then, vesicles were immediately placed in the observation chamber. Due to the differences in density and refractive index between sucrose and glucose solutions, the vesicles were stabilized by gravity at the bottom of the observation chamber and visualized with a $63 \mathrm{x} \mathrm{Ph} 2$ objective in phase contrast mode of an inverted microscope Zeiss Axiovert 200 (Zeiss, Jena Germany) equipped with a Zeiss AxioCam digital camera (Zeiss, Jena, Germany).

\section{Results}

\subsection{Hydrophobic and amphipatic properties of StI $_{1-31}$ and $\mathrm{StII}_{1-30}$}

A distinctive feature of $\mathrm{StII}_{1-30}$ when compared with $\mathrm{StI}_{1-31}$ is the higher mean hydropathy index of its first $10 \mathrm{~N}$-terminal residues (figure 1A). In addition, sequences comprising residues $14-31\left(\mathrm{StI}_{1-31}\right)$ and $13-30\left(\mathrm{StII}_{1-30}\right)$ are characterized by a high mean hydrophobic moment ( $\mu$ ) (figure 1B), as indicator of the amphiphilicity of an $\alpha$-helix (Eisenberg et al. 1984). Both properties, the presence of a highly hydrophobic sequence followed by an amphipatic $\alpha$-helix, are representative characteristics of membrane spanning pore-forming peptides. While the hydrophobic stretch may help to partition into membrane hydrophobic core, the 


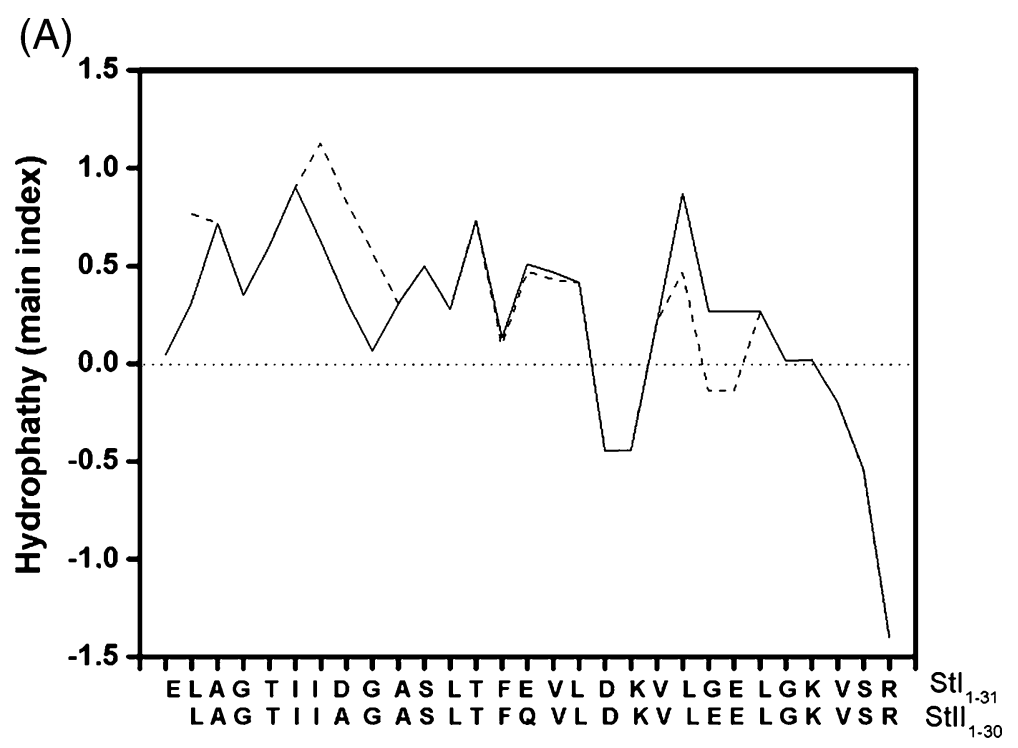

Amino acid sequences
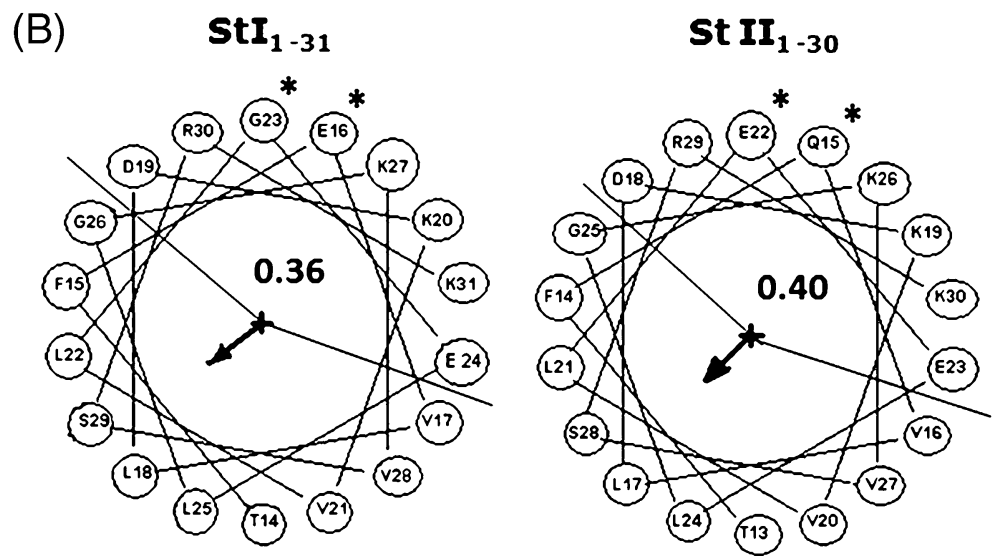

Figure 1. $\mathrm{StI}_{1-31}$ and $\mathrm{StII}_{1-30}$ hydrophathy profiles and wheel projections of their amphiphilic segments. (A) Hydrophathy profile $\mathrm{StI}_{1-31}(-)$ and $\mathrm{StII}_{1-30}(--)$. Calculations were based on the hydropathy values reported by Eisenberg (Eisenberg et al. 1984). (B) Wheel projections with their corresponding $\mu$ of the most amphiphilic segment of $\operatorname{StI}_{1-31}(14-31)$ and StII $_{1-30}$ (13-30). Differences between StI ${ }_{1-31}$ and StII - $_{1}$ ${ }_{30}$ sequences are labeled with asterisks. The $\mu$ is indicated by an arrow that points towards the hydrophobic face of the helix (Eisenberg et al. 1984).

amphipatic helix would contribute to form the hydrophilic pore (Yeaman and Yount 2003).

The Hydrophobic Moment Plot is often used to identify putative transmembrane $\alpha$-helices of integral membrane proteins, based on the relation between their $\mu$ and the corresponding mean hydrophobicity $(H)$. The resulting plot classifies the peptides according to their propensity to be a putative transmembrane peptide or a surface seeking one (Eisenberg et al. 1984). Table 1 shows $H$ and $\mu$ calculated for $1-11$ and the 14-24/15-25 sequences from $\mathrm{StII}_{1-30} / \mathrm{StI}_{1-31}$, respectively. The major difference between these peptides is given by the higher $\mathrm{H}$ and lower $\mu$ of the 1-11 amino acid segment of StII $_{1-30}$ in contrast to $\mathrm{StI}_{1-31}$. In fact, taking into account these parameters, this sequence is predicted as a transmembrane segment in $\mathrm{StII}_{1-30}$, while in $\mathrm{StI}_{1-31}$ the equivalent stretch is predicted as a surface seeking one. Regarding the segment that includes the $\alpha$-helix of sticholysins, it was predicted as a surface seeking for both peptides due to their higher $\mu$ and lower $\mathrm{H}$.

\subsection{Binding to lipid monolayers}

The increase in surface pressure by the association of peptides to previously formed lipid monolayers at the airwater interface can be employed to characterize their ability to interact with organized lipids. To this end, the studied lipid monolayers were composed of PC:SM (50:50), 
PC:SM:PA (50:45:5), PC:SM:Chol (20:45:35) and PC:SM:PA: Chol (30:45:5:20). PC:SM was selected as a starting mixture since this binary composition has proved to be adequate for binding of sticholysins to lipid membranes (Tejuca et al. 1996). Chol is a more apolar structure than the other lipids studied and was incorporated into a mixture of PC and SM due to its abundance and regulatory properties in membranes (Sackmann 1995); in fact, Chol and SM tend to form microdomains in membranes (Simons and Vaz 2004). Finally, inclusion of the anionic phospolipid PA allowed studying the influence of electrostatic interactions on peptide binding. This phospholipid is present only in small amount in the outer layer of the citoplasmatic membrane (Op dem Kamp 1979; Langner and Kubica 1999), thus including $5 \mathrm{~mole} \%$ into the lipid mixture could be mimicking the cell composition of mammalian cells.

The increase in surface pressure $(\Delta \pi)$ due to peptide interaction was evaluated at several initial pressures $\left(\pi_{0}\right)$ of the lipid monolayer. Figure 2 shows $\Delta \pi$ at equilibrium upon $\mathrm{StI}_{1-31}$ (figure 2A) or $\mathrm{StII}_{1-30}$ (figure 2B) addition as a function of $\pi_{0}$ for monolayers of different compositions. A suitable parameter for the characterization of peptide-lipid interaction is the critical pressure $\left(\pi_{\mathrm{c}}\right)$, obtained by extrapolating to zero the $\Delta \pi$ at equilibrium as a function of $\pi_{0}$ (insets, figures $2 \mathrm{~A}$ and $\mathrm{B}$ ). This parameter corresponds to the minimum pressure that must be applied to avoid incorporation of the peptide into a monolayer and is directly correlated with its affinity for the monolayer (Brockman 1999).

In zwitterionic PC:SM (50:50) monolayers (figure 2) $\pi_{\mathrm{c}}$ for $\mathrm{StII}_{1-30}$ was higher than that for $\mathrm{StI}_{1-31}$. In fact $\pi_{\mathrm{c}}$ for StII $_{1-30}$ is close to $35 \mathrm{mN} \mathrm{m}^{-1}$, which corresponds to the lateral pressure of a typical biological membrane (Brockman 1999). Even though such surface pressure is only an average value that can undergo large fluctuations depending on its compressibility (Phillips et al. 1975), it has been proposed that when $\pi_{\mathrm{c}}$ is higher than this critical limit, the peptide not only associates to the monolayer but also penetrates it (Caaveiro et al. 2001).

The inclusion of PA in the PC:SM mixture, promoted an increase in $\pi_{\mathrm{c}}$ for StII $_{1-30}$ but no change was observed for $\mathrm{StI}_{1-31}$. In PC:SM monolayers, the difference between both peptides in terms of $\pi_{\mathrm{c}}$ is around $4.77 \mathrm{mN} \mathrm{m}^{-1}$, being even higher in PC:SM:PA $\left(7.71 \mathrm{mN} \mathrm{m}^{-1}\right)$. The fact that PAenhanced binding differences by promoting a larger interaction of $\mathrm{StII}_{1-30}$ to this negatively charged monolayer points out a possible role of peptides' charge on their binding to membranes. In order to further understand the involvement of the two negatively charged residues $\left(\mathrm{Glu}^{2}\right.$ and $\mathrm{Asp}^{9}$ ) of $\mathrm{StI}_{1-31}$, not present in $\mathrm{StII}_{1-30}$ (table 1) for binding, we also synthesized a shorter peptide, $\mathrm{StI}_{12-31}$, which lacks these two anionic residues and assessed its interaction with PC:SM:PA monolayer. This shorter peptide is characterized by a positive charge of +2 at $\mathrm{pH}$
7 , keeping the charged residues situated in the amphiphilic portion of $\mathrm{StI}_{1-31}$ (table 1). When $\mathrm{StI}_{1-31}$ was devoid of the first N-terminal 11 amino acids, the truncated peptide, i.e. $\mathrm{StI}_{12-31}$, yielded a higher $\pi_{\mathrm{c}}$ in the negatively charged monolayer $\left(\pi_{\mathrm{c}}=30.10 \mathrm{mN} \mathrm{m}{ }^{-1}\right)$. These results clearly indicate that the first sequence of St I carrying the two extra anionic residues $\left(\mathrm{Glu}^{2}\right.$ and $\left.\mathrm{Asp}^{9}\right)$ somehow hinders binding to the negatively charged membrane.

Incorporation of Chol into the starting lipid ensemble (PC:SM) did not modify binding of $\mathrm{StI}_{1-31}$ when compared to the monolayer devoid of this sterol (figure 2A), in contrast with StII $_{1-30}$, which showed an increase in the affinity for the Chol-containing monolayer (figure 2B). Similar to the increase promoted by PA, Chol enhanced the difference of $\pi_{\mathrm{c}}$ between both peptides from $4.77 \mathrm{mN} \mathrm{m}^{-1}$ in $\mathrm{PC}: \mathrm{SM}$ monolayer to $7.1 \mathrm{mN} \mathrm{m}^{-1}$ in PC:SM:Chol monolayer. To clarify if the preferential binding of $\mathrm{StII}_{1-30}$ to this monolayer - in which the hydrophobic properties were enhanced due to Chol - was related to the presence of the higher hydrophobic segment 1-10, a shorter peptide $\mathrm{StII}_{11-30}$ was also synthesized. This peptide lacks the first 10 amino acids of StII $_{1-30}$ but keeps peptide charge $(+2$ at $\mathrm{pH} 7)$ since it shares the same ionizable groups. The deletion of 1-10 sequence of $\mathrm{StII}_{1-30}$ elicited a decrease in the affinity for the monolayer evidenced in a lower $\pi_{\mathrm{c}}$ value of $\mathrm{StII}_{11-30}$ (31.89 $\mathrm{mN} \mathrm{m}{ }^{-1}$ ) compared to $\mathrm{StII}_{1-30}$ (figure 2B). Altogether the results point out that affinity of $\mathrm{StI}_{1-31}$ or $\mathrm{StII}_{1-30}$ for a lipid monolayer is mainly influenced by the first ten or eleven amino acid residues of their $\mathrm{N}$-terminal sequence.

In addition we studied binding of $\mathrm{StI}_{1-31}$ and $\mathrm{StII}_{1-30}$ to more complex monolayers of PC:SM:PA:Chol in an attempt to approach the lipid heterogeneity of erythrocyte membrane, a classical model target for studying the actinoporins' activity (Martínez et al. 2001) and their peptides (Cilli et al. 2007). It is remarkable that both peptides attain $\pi_{\mathrm{c}}$ values higher than $35 \mathrm{mN} \mathrm{m}^{-1}$ (figure $2 \mathrm{~A}$ and $\mathrm{B}$ ), indicating that they probably penetrate this lipid monolayer (Caaveiro et al. 2001). In summary, this was the only monolayer to which $\mathrm{StI}_{1-31}$ showed a relevant interaction. In fact, the differences in terms of $\pi_{\mathrm{c}}$ between peptides diminished to $5.84 \mathrm{mN} \mathrm{m}^{-1}$, as compared to monolayers containing either PA $(7.71 \mathrm{mN}$ $\mathrm{m}^{-1}$ ) or Chol $\left(7.10 \mathrm{mN} \mathrm{m}^{-1}\right)$, being higher than that found for PC:SM monolayer $\left(4.77 \mathrm{mN} \mathrm{m}^{-1}\right)$ (inset, figures $2 \mathrm{~A}$ and $\mathrm{B})$.

\subsection{Vesicles permeabilization by peptides}

Since the functional activity of peptides in terms of hemolysis (Cilli et al. 2007) and size of the pore formed by StII $_{1-30}$ (Casallanovo et al. 2006) have been previously characterized, in this study we examined whether $\mathrm{StI}_{1-31}$ and $\mathrm{StII}_{1-30}$ were able to permeabilize LUV of the same lipid compositions used in monolayer studies. Under the experimental 

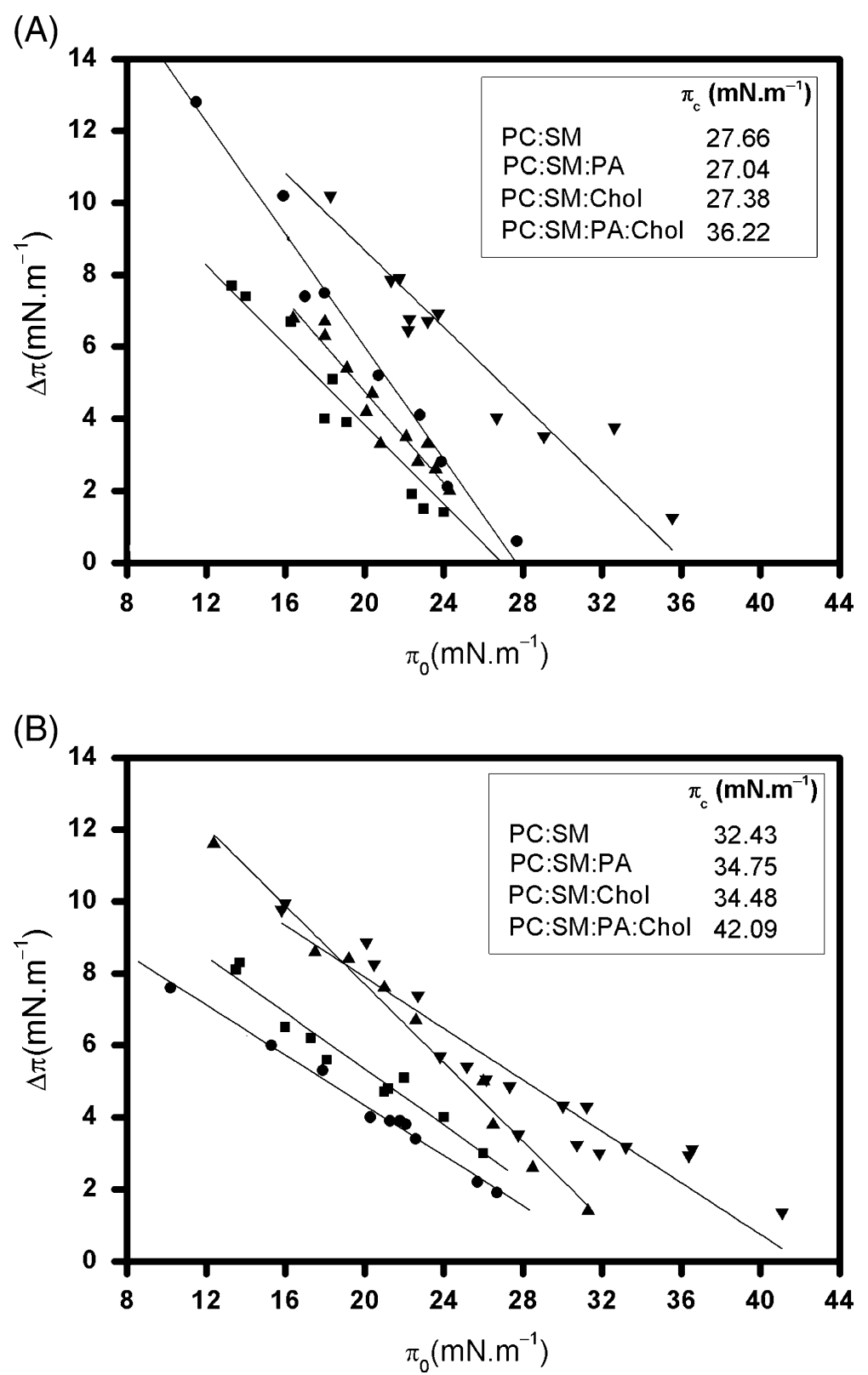

Figure 2. Critical pressure induced by peptides on monolayers of different lipid composition. (A) StI $1_{1-31}$ and (B) StII $1-30$. Critical pressure $\left(\pi_{\mathrm{c}}\right)$ : Pressure that must be applied to avoid incorporation of the peptide into the monolayer, directly correlated with the affinity of the peptides for the lipids. $\Delta \pi$ is the pressure increase in the lipidic monolayer due to peptide binding. Lines represent the best linear fit of the $\Delta \pi$ as a function of the initial monolayer pressure $\left(\pi_{\mathrm{o}}\right)$. Peptide concentration: $0.1 \mu \mathrm{M}$. Buffer solution TBS pH 7 . T $25^{\circ} \mathrm{C}$. Lipid

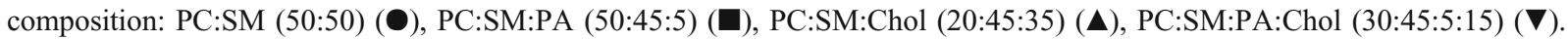

conditions employed herein, the phase behaviour of monolayer and liposomes has been reported to be the same (Veatch and Keller 2002).

Figure $3 \mathrm{~A}$ exemplifies the time course of the $\mathrm{CF}$ release upon $\mathrm{StII}_{1-30}$ addition to PC:SM LUV. This result evidences that both the initial rate as well as the extent of the process are time and dose dependent. The final extent of the fluorophore release elicited by the peptide $(F)$ was plotted as a function of peptide concentration. In LUV, StII $1-30$ promoted the release of the dye from the vesicles to a larger extent than $\mathrm{StI}_{1-31}$ and its effect was dependent on peptide concentration (figures 3B-D). Similar to lipid binding, permeabilization activity is driven by interplay between peptide and membrane properties. The inclusion of PA enhanced $\mathrm{StII}_{1-30}$ activity while that of $\mathrm{StI}_{1-31}$ experienced a drastic fall remaining non-detectable. However, inclusion of 


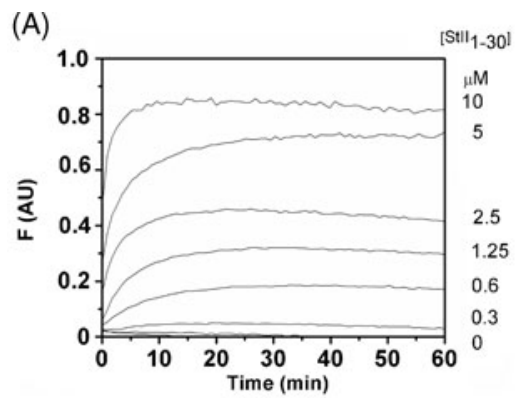

(B)

(C)
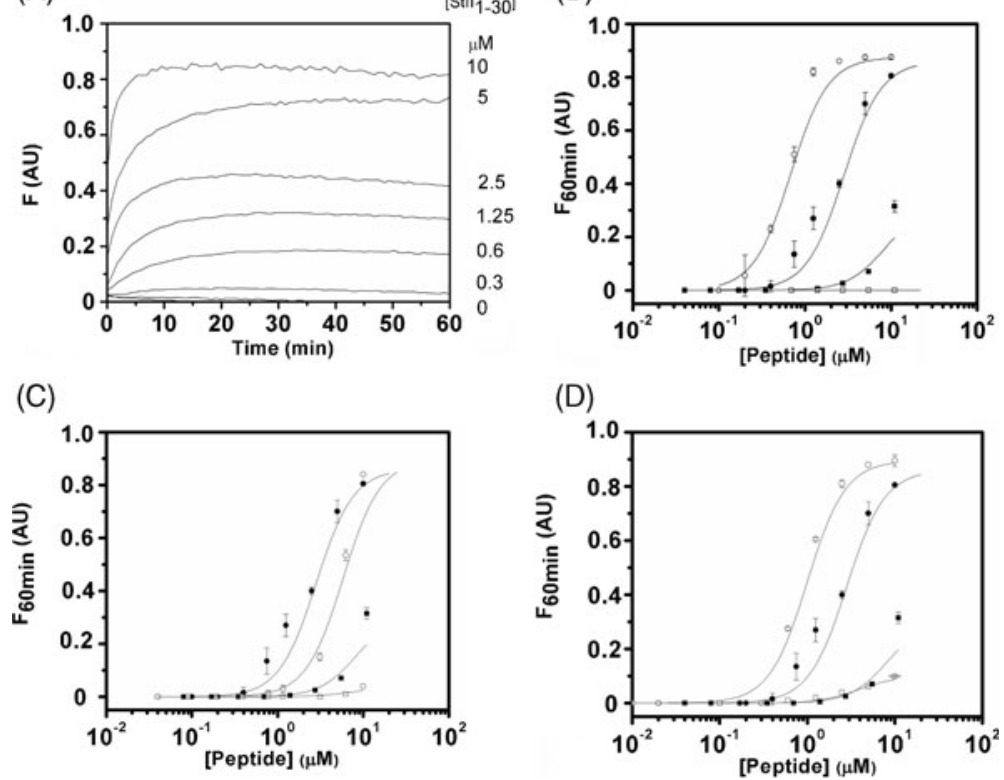

Figure 3. Release of carboxyfluorescein from LUV promoted by peptides. (A) Time course of PC:SM (50:50) LUV permeabilization as

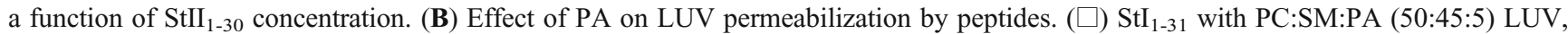

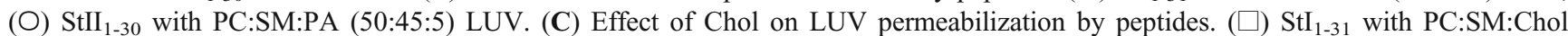

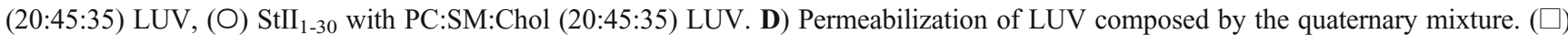
StI $_{1-31}$ with PC:SM:PA:Chol (30:45:5:20) LUV, (O) StII ${ }_{1-30}$ with PC:SM:PA:Chol (30:45:5:20) LUV. For B, C and D (ם) StI $1-31$ with PC:SM (50:50) LUV, (-) StII $1-30$ with PC:SM (50:50) LUV. F: fraction of fluorophore release. Curves in B, C and D were fitted to a Hill function $\left(F_{60 \min }=F_{\max } \text { [peptide] }\right]^{n} / \mathrm{C}_{50}{ }^{n}+$ [peptide] $\left.^{n}\right)$ using Origin 8.0, Microcal Inc. (USA). Experiments were done in triplicate $\left(R^{2}>0.99\right.$ and $\chi_{\text {red }}^{2}<10^{-4}$ ). Lipid concentration: $10 \mu \mathrm{M}$. Buffer solution TBS pH 7. T $25^{\circ} \mathrm{C}$.

Chol into the lipid mixture dropped the permeabilizing activity of $\mathrm{StII}_{1-30}$ and practically rendered $\mathrm{StI}_{1-31}$ unable to permeabilize LUV (figure 3C). In the complex lipid mixture PC:SM:PA:Chol, StII ${ }_{1-30}$ also showed a higher activity than StI $_{1-31}$ (figure 3D).

In order to compare the relative activity of $\mathrm{StII}_{1-30}$ in presence of LUV of different compositions, permeabilization parameters were determined by fitting the experimental data to a Hill sigmoid model as showed in figures $3 \mathrm{~B}, \mathrm{C}$ and D. $F_{\max }$ is the maximum dye release achieved at high peptide concentrations, while $C_{50}$ is the concentration necessary to promote the release of $50 \%$ of CF entrapped and $n$ is the power dependence of $F$ on toxin dose, the socalled cooperativity number (table 2). According to $F_{\max }$, both peptides achieved their maximum activity in PC:SM liposomes promoting the permeabilization of c.a. $90 \%$ of vesicle ensemble in the assay. The fact that not all the vesicles were apparently permeabilized might be due to the fact that Triton X-100 affects the fluorescence of CF either directly (Chen and Knutson 1988) or indirectly, diminishing light scattering by disruption of membrane integrity. In addition, $n$ was higher than 1 for all lipid compositions, indicating the necessity of a minimum number of peptide molecules for $\mathrm{StII}_{1-30}$ permeabilization activity as described for actinoporins (Belmonte et al. 1993; Tejuca et al. 1996). Even though $F_{\max }$ and $n$ did not considerably differ among liposomal compositions, $C_{50}$ reflected the different StII $_{1-30}$ activity for all the lipid mixtures analysed. Liposomes containing PA (PC:SM:PA and PC:SM:PA:Chol) became around 3-fold more susceptible to permeabilization than PC: SM vesicles, in contrast to PC:SM:Chol in which the inclusion of Chol caused a drop of twice of the activity in PC:SM.

\subsection{Visualization of peptides effect on $G U V$}

With an aim to visualize the effect of both peptides on vesicles, GUV were diluted into peptide-containing glucose solution and immediately placed in the observation chamber. Changes in GUV features were followed over time by video microscopy. Figure 4 shows how the presence of 10 $\mathrm{nM}$ of StII $_{1-30}$ in the outer GUV solution impacted on PC: SM:PA:Chol lipid membrane that exhibited initially optical contrast due to sucrose/glucose asymmetry (snapshot A). Such a contrast gradually diminished with time, reflecting changes in the bilayer permeability as a result of the inner 
Table 2. Parameters derived from LUV permeabilization induced by the peptides

\begin{tabular}{llll}
\hline & & \multicolumn{2}{c}{ StII $_{1-30}$} \\
\cline { 2 - 4 } LUV composition & \multicolumn{1}{c}{$F_{\max }$} & $C_{50}(\mu \mathrm{M})$ & \\
\hline PC:SM (50:50) & $0.91 \pm 0.04$ & $2.4 \pm 0.3$ & $1.5 \pm 0.2$ \\
PC:SM:PA (50:45:5) & $0.88 \pm 0.02$ & $0.6 \pm 0$ & $2.7 \pm 0.4$ \\
PC:SM:Chol (20:45:35) & $0.91 \pm 0.01$ & $5.5 \pm 0.1$ & $2.9 \pm 0.1$ \\
PC:SM:PA:Chol (30:45:5:20) & $0.89 \pm 0.02$ & $0.9 \pm 0.1$ & $2.4 \pm 0.3$ \\
\hline
\end{tabular}

$F_{\text {max }}$ : maximum fluorescence attained at high peptide concentration, $C_{50}$ : peptide concentration necessary to achieve $50 \%$ of $F_{\text {max }}$, $n$ : cooperativity number derived from the power dependence of the fraction of fluorophore release $(F)$ on toxin concentration. When $n$ results higher than 1 indicates cooperativity, i.e. suggests oligomerization even though cannot provide the true molecularity of the assembly for permeabilization.

All parameters were calculated by fitting dose-dependence curves of permeabilization induced by peptides (figures 3B, C and D) to a Hill

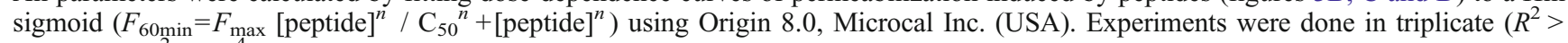
0.99 and $\left.\chi_{\text {red }}^{2}<10^{-4}\right)$.

and outer solutions exchange. The complete loss of membrane contrast was observed (snapshots B and C) within a time interval of $2 \mathrm{~min}$ of GUV visualization, without any change in the membrane integrity in terms of lipid bilayer solubilization and/or macropores opening. In fact, the increase in membrane permeability must be due to the formation of pores that are smaller than the microscope resolution of few microns. It is noteworthy that the GUV remained unchangeable up to $10 \mathrm{~min}$ of further continuous observation (snapshot none shown), implying that $\mathrm{StII}_{1-30}$ promoted stable sub-micron pore formation in the lipid membrane. Similar observations were also recorded for $\mathrm{StI}_{1-31}$ in contact with GUV of PC:SM:PA:Chol. Despite this similarity, 8-fold more molecules of $\mathrm{StI}_{1-31}$ were required in comparison to $\mathrm{StII}_{1-30}$ for visualizing the equivalent effect, which qualitatively correlated with binding to lipid monolayer and permeabilizing activity in LUV.

\section{Discussion}

St I and St II are characterized by a few amino acid substitutions spread throughout the primary sequence, exhibiting all the non-conservative changes in their N-terminal (Huerta et al. 2001). The presence of hydrophobic $(\approx$ residues $1-10)$ and highly amphipathic ( $\approx$ residues $14-35)$ sequences in both St's N-terminal supports the assumption that this region is probably involved in pore formation (Anderluh and Maček 2002; Malovrh et al. 2003; Mancheño et al. 2003; Casallanovo et al. 2006; Álvarez et al. 2009; Castrillo et al. 2009). Both toxins exert their hemolytic action in human red blood cells in the nanomolar concentration range, but St II is about 5- to 6-fold more active than St I (Martínez et al. 2001). We have previously demonstrated by CD spectroscopy studies and theoretical predictions that the synthetic peptide $\mathrm{StII}_{1-30}$ can mimic folding and functional properties of St II's N-terminus (Casallanovo et al. 2006). In that work we emphasized the contribution of St II's N-terminal region, in particular, the hydrophobic amino acid sequence $1-10$ to pore formation. On the other hand, differences in activity observed between sticholysins were found to be correlated with the activity of $\mathrm{StI}_{1-31}$ and $\mathrm{StII}_{1-30}$ (Cilli et al. 2007). In addition, both peptides show a high propensity to acquire $\alpha$-helical structure in trifluoroethanol, a well-known inducer of secondary structure (Buck 1998) and in liposomes, somehow reproducing the presence of an $\mathrm{N}$ terminal $\alpha$-helix of sticholysins (Mancheño et al. 2003; Castrillo et al. 2009).

In this work the relative influence of the hydrophobic and electrostatic interactions on peptides binding to lipid monolayers and permeabilizating activity in vesicles were analysed given that an adequate balance between the net charge and hydrophobicity is essential for membranotropic peptides to display their activity (Blondelle et al. 1999; Tossi et al. 2000; Yeaman and Yount 2003). To this end, experiments modulating membrane properties such as surface charge by including the anionic PA or membrane hydrophobicity and lipid organization by Chol addition to the basal PC:SM lipid mixture were performed.

A distinctive feature of $\mathrm{StII}_{1-30}$ is the higher net positive charge $(+2$ at $\mathrm{pH} 7$ ) (table 1) and larger mean hydropathy index of its first $10 \mathrm{~N}$-terminal residues when compared to $\mathrm{StI}_{1-31}$ (table 1 and figure 1). In contrast, $\mathrm{StI}_{1-31}$ has no net charge at $\mathrm{pH} 7$ on account of two additional acidic aminoacids $\left(\mathrm{Glu}^{2}\right.$ and $\left.\mathrm{Asp}^{9}\right)$ in the hydrophobic segment 1-10 (table 1), which leads to a decrease in the hydrophobicity of this sequence. These attributes of peptide sequences may determine their different penetration upon binding to membranes as predicted (table 1). In fact, the lower $\pi_{\mathrm{c}}$ showed by $\mathrm{StI}_{1-31}$ (figure $2 \mathrm{~A}$ ) when compared to $\mathrm{StII}_{1-30}$ in lipid monolayers (figure 2B) could reflect a less deep insertion into the membrane of the former peptide. 

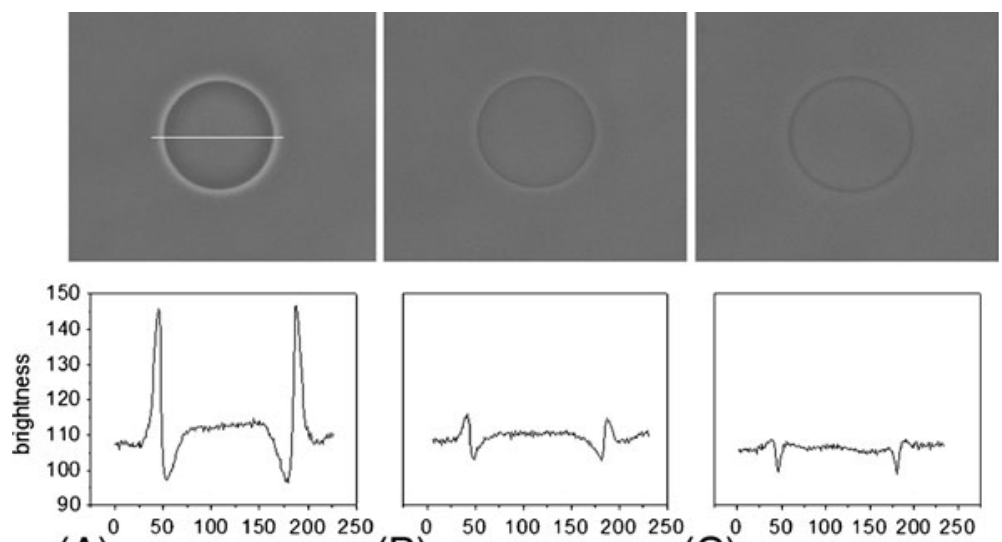

(B)

pixels

${ }^{250}(\mathrm{C})$

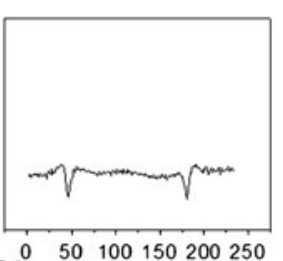

(A)

Figure 4. Visualization of the effect elicited by StII ${ }_{1-30}$ on GUV. Upper row: GUV snapshots immediately placed in contact with StII ${ }_{1-30}$ (A). GUV after $2 \mathrm{~min}(\mathbf{B})$ or $4 \mathrm{~min}(\mathbf{C})$ of visualization. Lower row: Line profile of the phase contrast. The solid line (in upper A) indicates the transversal section selected for the profiles. GUV composition PC:SM:PA:Chol (30:45:5:20). Internal solution 0.2 M sucrose, external solution $0.2 \mathrm{M}$ glucose containing $10 \mathrm{nM}$ of $\mathrm{StII}_{1-30} . \mathrm{T} \sim 25^{\circ} \mathrm{C}$. $\mathrm{StI}_{1-31}$ peptide impacted on membrane properties in a similar way, leading to a gradual loss of inner-outer medium contrast of the membrane with time, as shown as example in the figure for StII $I_{1-30}$. Despite this similarity, 8-fold more molecules of $\mathrm{StI}_{1-31}$ were required in comparison to $\mathrm{StII}_{1-30}$ for visualizing the equivalent effect. After contrast loss, GUV remained unchangeable up to 1 hour on further continuous observation.

StII $_{1-30}$ shows not only a higher affinity for monolayers (insets figure $2 \mathrm{~A}$ and $\mathrm{B}$ ) but a larger vesicle permeabilization of membranes (figures 3 and 4) than its counterpart $\mathrm{StI}_{1-31}$, in agreement with the previously informed relative hemolytic activity of these peptides (Cilli et al. 2007). In response to the peptides' net electric charge (table 1), modification of the surface membrane charge prompted different binding and permeabilizing activity of $\mathrm{StII}_{1-30}$ and $\mathrm{StI}_{1-31}$ (figures 2 and 3, respectively). The negatively charged membrane surface moderately increased the ability of the cationic $\mathrm{StII}_{1-30}$ for binding to monolayers (figure 2B) and significantly enhanced its permeabilizing activity (figure 3 and table 2), suggesting the contribution of the electrostatic forces in vesicles permeabilization by this peptide. Conversely, the negatively charged surface membrane did not modify the low binding ability of the neutral $\mathrm{StI}_{1-31}$ to zwitterionic membranes (figure 2) probably due to the presence of two anionic amino acidic residues $\left(\mathrm{Glu}^{2}\right.$ and $\left.\mathrm{Asp}^{9}\right)$. These results clearly indicate the leader condition of the first 1-10 sequence for peptide binding and the essentiality of a hydrophobic continuum for a larger membrane perturbation. In spite of the fact that a lower affinity for $\mathrm{StI}_{1-31}$ was not apparent for lipid monolayers (figure 2A), its activity decreased when PA was included in vesicles (figure $3 \mathrm{~B}$ and table 2), suggesting that $\mathrm{Ser}^{1}$, $\mathrm{Glu}^{2}$ and $\mathrm{Asp}^{9}$ may somehow impair membrane penetration or peptide oligomerization in this membrane model system.

Together with PC and SM, Chol is one of the most important lipids in eukaryotic cells, ranging up to $50 \mathrm{~mole} \%$ in red blood cells (Sackmann 1995). There is evidence that high Chol concentration (> $35 \mathrm{~mole} \%$ ) in conjunction with sphyngolipids is vital to the formation of highly ordered lipid domains in membranes. As for St II and equinatoxin II another actinoporin isolated from the Mediterranean Sea anemone Actinia equina, the presence of lipidic microdomains seems to provide a particularly favorable arrangement of lipids for the association and activity of these toxins with membranes (Barlič et al. 2004; Martínez et al. 2007). It has been also demonstrated that lateral heterogeneity of membrane favours the action of lytic peptides (Pokorny and Almeida 2005).

Taking into account the relevance of lipid microdomains for actinoporins and several membranotropic peptides, here we evaluated the effect of including Chol on peptides activity by comparing their action in PC:SM and PC:SM: Chol systems. Inclusion of Chol in a PC:SM monolayer promotes a moderate increase in binding of $\mathrm{StII}_{1-30}$ (figure 2B) probably favoured by its 1-10 hydrophobic amino acid sequence. As expected for the lower hydrophobicity of the first 1-11 amino acid sequence of $\mathrm{StI}_{1-31}$ (table 1), inclusion of Chol did not modify peptide binding to the lipid monolayer (figure 2A). Interestingly, inclusion of this lipid in liposomes containing PC:SM noticeably impairs the ability of both peptides for pore formation (figure $3 \mathrm{C}$ and table 2). A plausible explanation for the apparent contradiction as for $\mathrm{StII}_{1-30}$ might be that membranes containing PC:SM:Chol do not favour the competent penetration and/or oligomerization of peptide for pore formation.

Moreover, here it was demonstrated the enhancing role of membrane lateral heterogeneity in peptide binding and activity. The notorious increase observed in binding for 
both peptides to quaternary lipid monolayers supports this hypothesis (figures $2 \mathrm{~A}$ and $\mathrm{B}$ ). Nonetheless, $\mathrm{StII}_{1-30}$ remained more active than $\mathrm{StI}_{1-31}$ in both monolayers and LUV. Additionally, it can not be disregarded that probable coexisting phase domains might be enriched in PA (VequiSuplicy et al. 2010), leading to locally enhanced membrane surface negative charge and hence $\mathrm{StII}_{1-30}$ activity.

Studies with GUV have proven to be a useful tool for following the mechanism of action of several bioactive molecules on lipid membranes. In our case, the effect of the peptides upon membrane causes a membrane optical contrast loss due to changes in its permeability. A detergent-like mechanism cannot be invoked to explain the phase contrast loss (Sudbrack et al. 2011) since both peptides seem to form relatively stable pores into GUV albeit at different concentrations (figure 4). Furthermore, as for $\mathrm{StII}_{1-30}$, we had previously demonstrated its ability to form pores of around $1 \mathrm{~nm}$ of radius in erythrocytes (Casallanovo et al. 2006). It is worth mentioning that observations with GUV represent the first experimental evidence that $\mathrm{StII}_{1-30}$ as well as $\mathrm{StI}_{1-31}$ cause membrane injury by stable pore formation in liposomes.

In summary, the results showed in the current work demonstrates the relative contribution of hydrophobic and electrostatic forces as well as lipid heterogeneity to the differential activity of $\mathrm{StI}_{1-31}$ and $\mathrm{StII}_{1-30}$. Replacement of $\mathrm{Ala}^{1}$ and $\mathrm{Ala}^{8}$ in $\mathrm{StII}_{1-30}$ by $\mathrm{Glu}^{2}$ and $\mathrm{Asp}^{9}$ and an extra Ser ${ }^{1}$ turns $\mathrm{StI}_{1-31}$ 's 1-10 sequence less hydrophobic than $\mathrm{StII}_{1-30}$, characterized by an uninterrupted hydrophobic segment. These features could be correlated with the higher activity of StII ${ }_{1-30}$ by facilitating peptide partition and a deeper insertion of its N-terminus into membrane. The membranotropic action of $\mathrm{StII}_{1-30}$ and $\mathrm{StI}_{1-31}$ can be explained in terms of the balance of hydrophobic and electrostatic properties. Additionally, membrane heterogeneity plays an important role in binding and pore formation. Overall, this study suggests that the different activity of sticholysins could be due to a different penetration of their N-termini into the lipid bilayer governed by the balance of hydrophobic and hydrophilic properties.

\section{Acknowledgements}

The authors thank Ms Frieda Aina Amapindi for her careful revision of the manuscript. This work was partly supported by CAPES-MES and CNPq-MES (Brazil-Cuba) collaboration projects. EMC, RI and SS are CNPq research fellows. UR is a grantee from IFS (4616), Sweden; TPS is a recipient from FAPESP fellowship.

\section{References}

Álvarez C, Casallanovo F, Shida CS, Nogueira LV, Martínez D, Tejuca M, Pazos IF, Lanio ME, et al. 2003 Binding of sea anemone pore-forming toxins sticholysins I and II to interfacesModulation of conformation and activity, and lipid-protein interaction. Chem. Phys. Lipids 122 97-105

Álvarez C, Mancheño JM, Martínez D, Tejuca M, Pazos F and Lanio ME 2009 Sticholysins, two pore-forming toxins produced by the Caribbean Sea anemone Stichodactyla helianthus: Their interaction with membranes. Toxicon 3457 1-14

Anderluh G and Maček P 2002 Cytolitic peptide and protein toxins from sea anemones (Anthozoa: Actinaria). Toxicon 40 111-124

Angelova M and Dimitrov D 1986 Liposome electroformation. Faraday Disc. Chem. Soc. $81303-311$

Atherton E and Sheppard RC 1988 Solid Phase peptide synthesis: A practical approach (Oxford University Press)

Barlič A, Gutiérrez-Aguirre I, Caaveiro JM, Cruz A, Ruiz-Argüello MB, Pérez-Gil J and González-Mañas JM 2004 Lipid phase coexistence favors membrane insertion of Equinatoxin-II, a pore-forming toxin from Actinia equina. J. Biol. Chem. 279 34209-34216

Belmonte G, Pederzolli C, Maček P and Menestrina G 1993 Pore formation by the sea anemone cytolysin equinatoxin II in red blood cells and model lipid membranes. J. Membr. Biol. 131 11-22

Blondelle SE, Lohner K and Aguilar MI 1999 Lipid-induced conformation and lipid binding properties of cytolytic and antimicrobial peptides: determination and biological specifity. Biochim. Biophys. Acta 1462 89-108

Brockman H 1999 Lipid monolayers: why use half a membrane to characterize protein-membrane interactions? Curr. Opin. Struct. Biol. 9 438-443

Buck M 1998 Trifluoroethanol and colleagues: cosolvents come of age. Recent studies with peptides and proteins. Q. Rev. Biophys. 31 297-355

Caaveiro JM, Echabe I, Gutierrez-Aguirre I, Nieva JL, Arrondo JL R and Gonzales-Mañas JM 2001 Differential interaction of equinatoxin II with model membranes in response to lipid composition. Biophys. J. 80 1343-1353

Casallanovo F, de Oliveira FJF, de Souza FC, Ros U, Martínez Y, Pentón D, Tejuca M, Martínez D, Pazos F, Pretinhes TA, Spisni A, Cilli EM, Lanio ME, Álvarez C and Schreier S 2006 Model peptides mimic structure and function of the N-terminus of the pore-forming toxin Sticholysin II. Biopolymers 84 169-180

Castrillo I, Alegre-Cebollada JG, Martínez del Pozo A, Gavilanes J, Santoro J and Bruix M 2009 1H, 13C, and 15N NMR assignments of the actinoporin Sticholysin I. Biomol NMR Assign. 3 5-7

Chen RF and Knutson JR 1988 Mechanism of fluorescence concentration quenching of carboxyfluorescein in liposomes: energy transfer to non-fluorescent dimers. Anal. Biochem.172 61-77

Cilli EM, Pigossi FT, Crusca E, Ros U, Martínez D, Lanio ME, Álvarez C and Schreier S 2007 Correlation between differences in amino-terminal sequences and different hemolytic activity of sticholysins. Toxicon 50 1201-1204

Dalla Serra M, Fagiuoli G, Nordera P, Bernhart I, Della Volpe C, Di Giorgio D, Ballio A and Menestrina G 1999 The interaction of lipodepsipeptide toxins from Pseudomonas syringae $p v$. syringae with biological and model membranes: a comparison of syringotoxin, syringomycin and syringopeptins. Mol. PlantMicrobe Interact. 12 391- 400 
Eisenberg D, Weiss RM and Terwilliger TC 1984 The hydrophobic moment detects periodicity in protein hydrophobicity Proc. Natl. Acad. Sci. USA 81 140-144

Huerta V, Morera V, Guanche Y, Chinea G, González LJ, Betancourt L, Martínez D, Álvarez C, et al. 2001 Primary structure of two cytolysin isoforms from Stichodactyla helianthus differing in their hemolytic activity. Toxicon 39 1253-1256

Kem WR 1988 Sea anemone Toxins: structure and action. The biology of the nematocyst (New York: Academic Press)

Langner M and Kubica K 1999 The electrostatics of lipid surfaces. Chem. Phys. Lipids 101 3-35

Lanio ME, Morera V, Álvarez C, Tejuca M, Gómez T, Pazos F, Besada V, Martínez M, Huerta V, Padrón G and Chávez MA 2001 Purification and characterization of two hemolysins from Stichodactyla helianthus. Toxicon 39 187-194

Malovrh P, Barlič A, Podlesek Z, Maček P, Menestrina G and Anderluh G 2003 A novel mechanism of pore formation: Membrane penetration by the N-terminal amphipathic region of Equinatoxin. J. Biol. Chem. 278 22678-22685

Mancheño JM, Martin-Benito J, Martínez-Ripoll M, Gavilanes JG and Hermoso JA 2003 Sticholysin II actinoporins revel insights into the mechanism of membrane pore formation. Structure $\mathbf{1 1}$ $1319-1328$

Martínez D, Otero A, Álvarez C, Pazos F, Tejuca, M, Lanio ME, Gutiérrez-Aguirre I, Barlič A, et al. 2007 Effect of sphingomyelin and cholesterol in the interaction of St II with lipidic interfaces. Toxicon 49 68-81

Martínez D, Soto C, Casallanovo F, Pazos F, Álvarez C, Lanio ME, Casallanovo F, Schreier S, et al. 2001 Properties of St I y St II, two isotoxins isolated from Stichodactyla helianthus: A comparison. Toxicon 39 1547-1560

Op den Kamp JAF 1979 Lipid asymmetry in membranes. Annu. Rev. Biochem. 48 47-71
Phillips MC, Graham DE and Hauser H 1975 Lateral compressibility and penetration into phospholipid monolayers and bilayer membranes. Nature (London) 254 154-156

Pokorny A and Almeida PFF 2005 Permeabilization of raftcontaining lipid vesicles by lysin: a mechanism for cell sensitivity to cytotoxic peptides. Biochemistry 44 9538-9544.

Rouser G, Fkeischer S and Yamamoto A 1970 Two dimensional thin layer chromatographic separation of polar lipids and determination of phospholipids by phosphorus analysis of spots. Lipids $5494-496$

Sackmann E 1995 Biological membranes architecture and function; in Handbook of biological physics (eds) R Lipowsky and E Sackmann (Amsterdam: Elsevier) pp 1-62

Simons K and Vaz WL 2004 Model systems, lipid rafts, and cell membranes. Annu. Rev. Biophys. Biomol. Struct. 33 269-295

Sudbrack TP, Archilla NL, Itri R and Riske KA 2011 Observing the solubilization of lipid bilayers by detergents with optical microscopy of GUVs. J. Phys. Chem. B 115 269-277

Tejuca M, Dalla Serra M, Ferreras M, Lanio ME and Menestrina G 1996 Mechanism of membrane permeabilization by sticholysin I, a cytolysin isolated from the venom of the sea anemone Stichodactyla helianthus. Biochemistry 35 14947-14957

Tejuca M, Dalla Serra M, Potrich C, Álvarez C and Menestrina G 2001 Sizing the radius of the pore formed in erytrocytes and lipid vesicles by the toxin sticholysin I from the sea anemone Stichodactyla helianthus. J. Membr. Biol. 183 125-135

Tossi A, Sandri L and Giangaspero A 2000 Amphipathic, alphahelical antimicrobial peptides. Biopolymers $47465-477$

Veatch SL and Keller SL 2002 Organization in lipid membranes containing cholesterol. Phys. Rev. Lett. 89268101

Vequi-Suplicy CC, Riske KA, Knorr RL and Dimova R 2010 Vesicles with charged domains. Biochim. Biophys. Acta 1798 1338-1347

Yeaman MR and Yount NY 2003 Mechanisms of antimicrobial peptide action and resistance. Pharmacol. Rev. 55 27-55

MS received 07 June 2011; accepted 17 August 2011

ePublication:

Corresponding editor: Амiт СНАTTOPADHYAY 